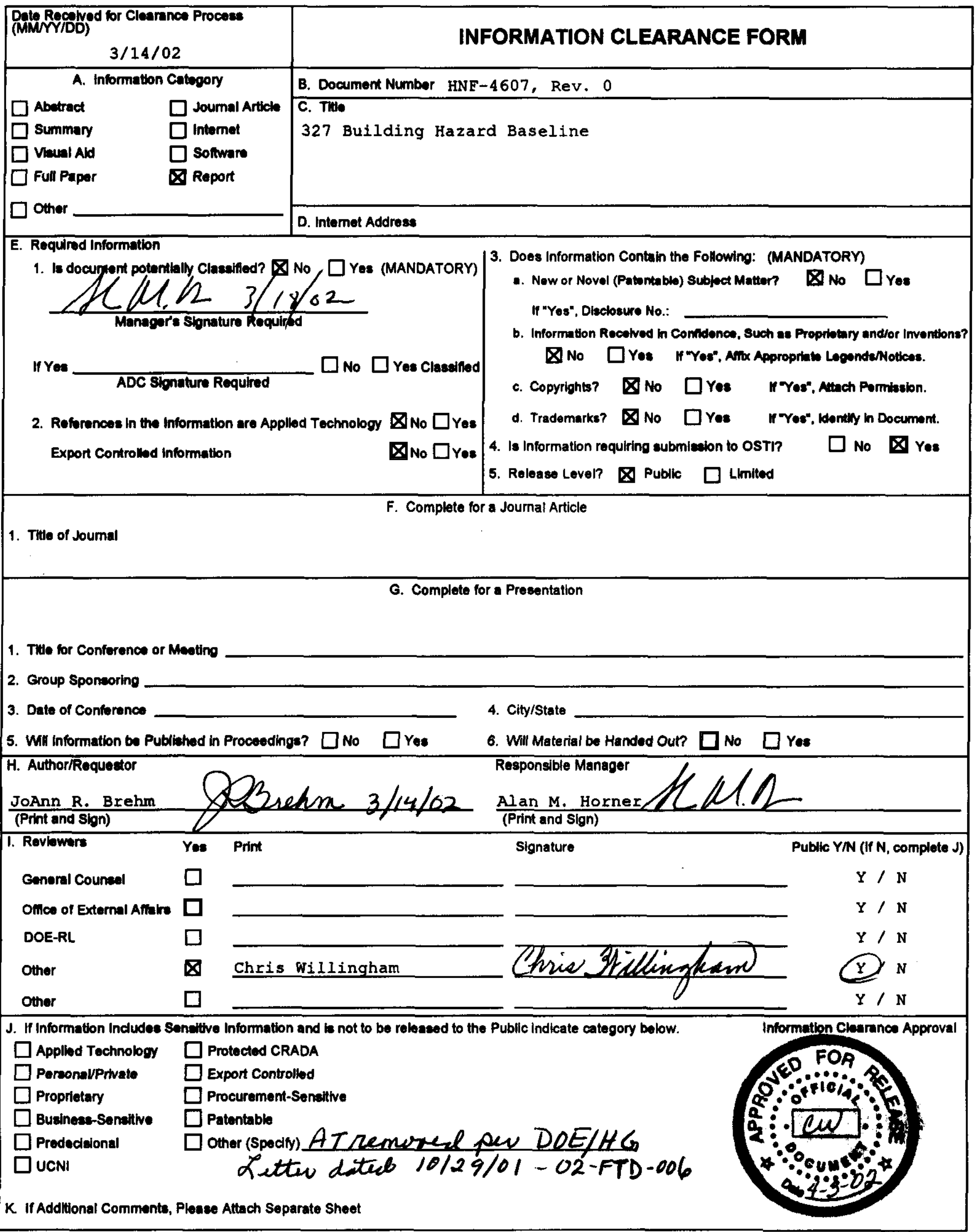




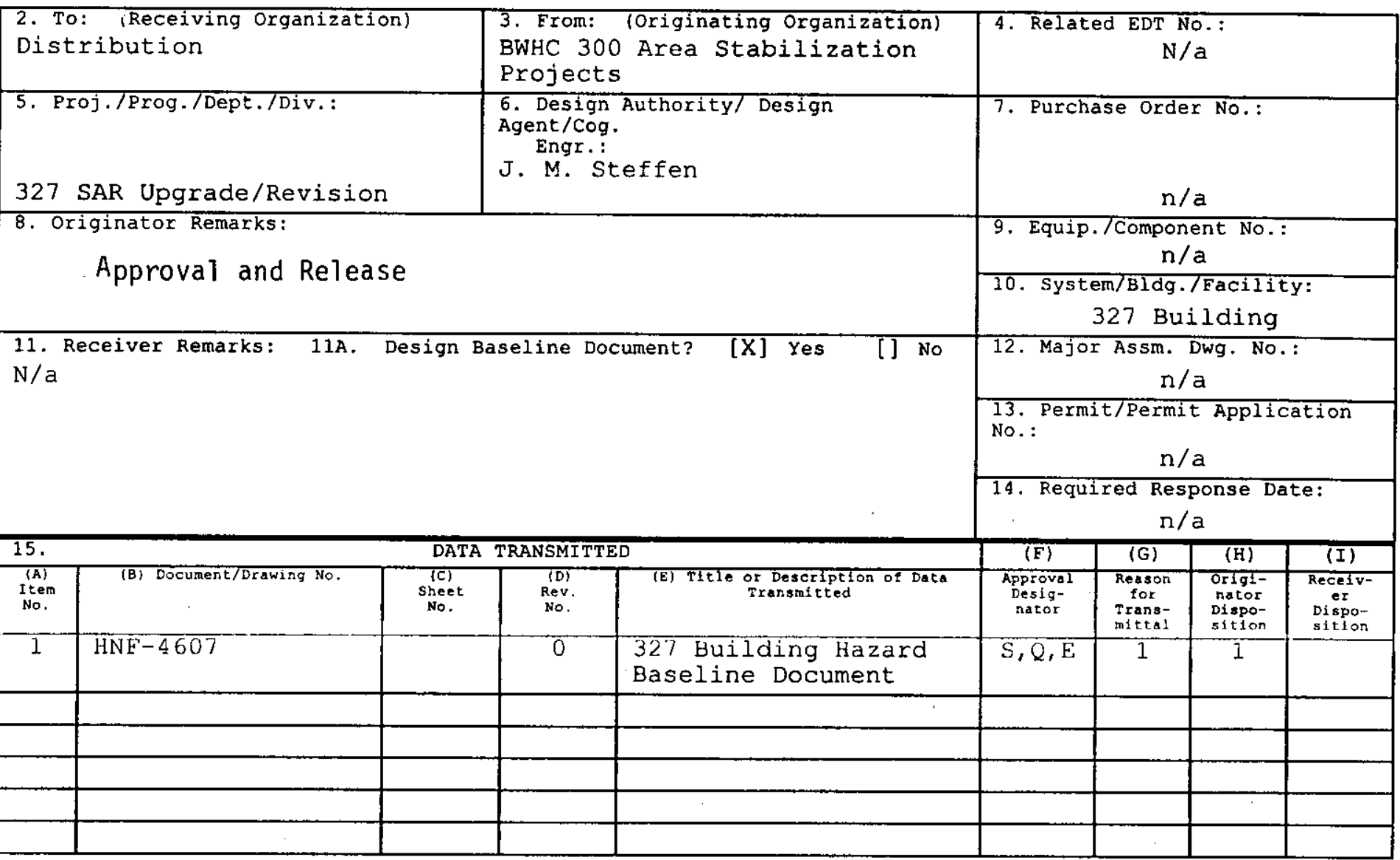

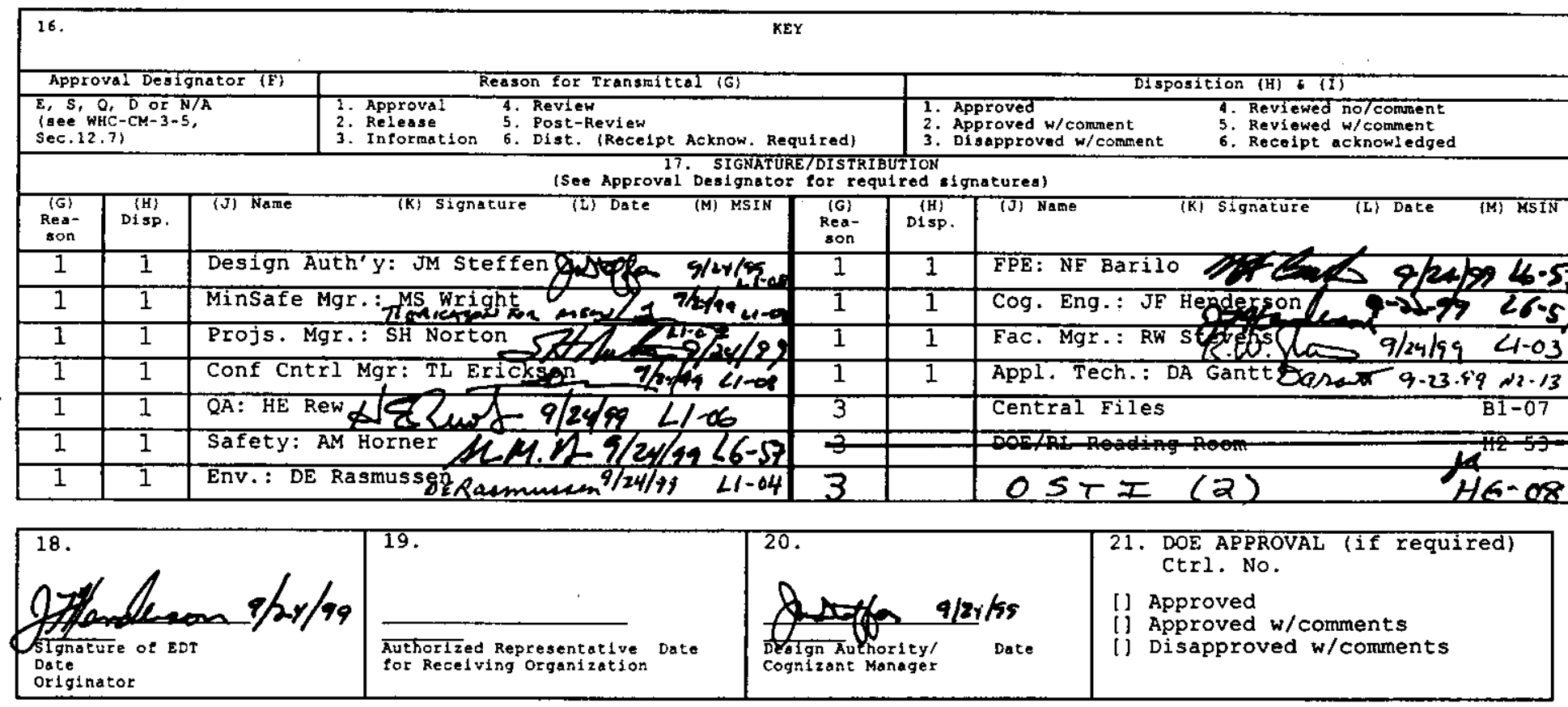

BD-7400-172-2 (05/96) GEF097 


\title{
327 BUILDING HAZARD BASELINE DOCUMENT
}

\author{
J. M. Steffen
}

B\&W Hanford Company

Richland, Washington 99352

U.S. Department of Energy Contract DE-AC06-96RL13200

EDT/ECN: 623109

UC: 2000

Org Code: 19500

Charge Code: HN990011 (CACN 101162, COA BB20)

B\&R Code: EX3120020

Total Pages: $210 \mathrm{ga}$

Type of LIMITED USE Information: APPLIED TECHNOLOGY

APPROVED FOR
PUBLIC RELEASE

Key Words: 327 Building Hazard Analysis, Preliminary Hazard Analysis, Hazard Baseline, Hazard Identification, Hazard Checklist, Stabilization/Deactivation

Abstract: This document identifies the hazards in the 327 Building at the time that a facility walk through was performed during FY99, presents a PHA of stabilization and deactivation activities, and provides a basis for the hazard evaluation and accident analysis that will be developed in the 327 Building Basis for Interim Operation (B10).

Activities addressed in this hazard baseline document include:

- Stabilization and deactivation activities in preparation for eventual decomissioning of the 327 Building and the rout ine hand ing, processing, and shipment of waste to support these activities.

o

324/327 Building Minimum Safe Project engineering and maintenance activities to maintain the building and systems viable - especially the Safety SSCs - to allow stabilization, deactivation, and waste handing activities with a minimum of risk to workers, the public, and the enviroment.

Printed in the United States of America. To obtain copies of this document, contact: WHC/BCS Document Control Services, P.0. Box 1970, Mailstop H6-08, Richland WA 99352, Phone (509) 372-2420; Fax (509) 376-4989.
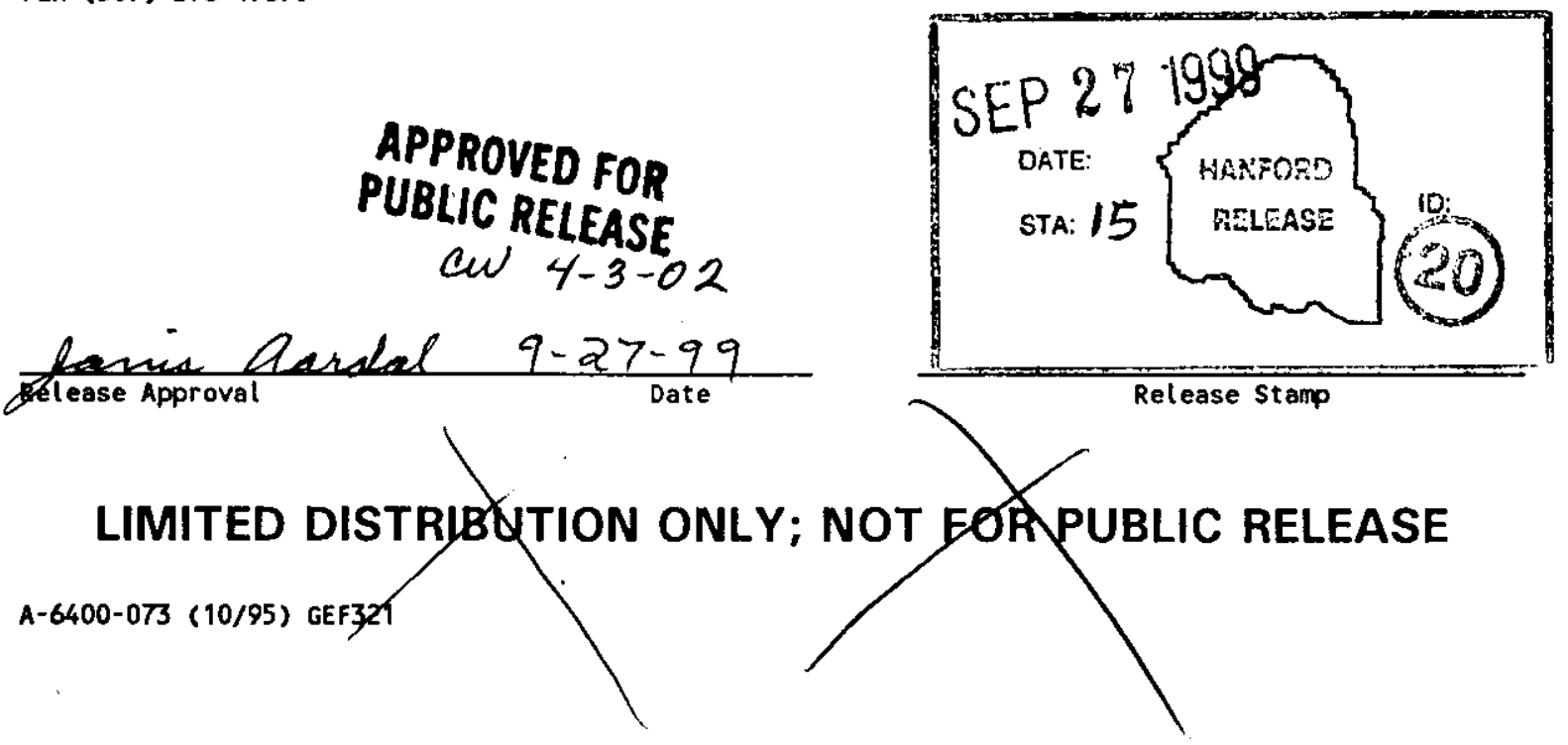


\section{RESTRICTIVE LEGAL NOTICES}

\section{This Notice shall not be separated from the attached document.}

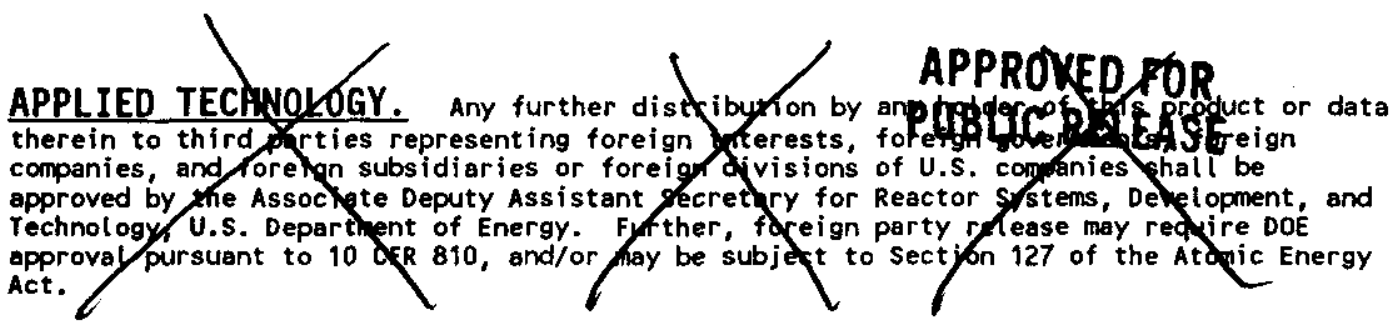

LEGAL DISCLAIMER. This report was prepared as an account of work sponsored by an agency of the United States Government. Neither the United States Government nor any agency thereof, not any of their employees, nor any of their contractors, subcontractors or their employees, makes any warranty, express or implied, or assumes any legal liability or responsibility for the accuracy, completeness, or any third party's use or the results of such use of any information, apparatus, product, or process disclosed, or represents that its use would not infringe privately owned rights. Reference herein to any specific commercial product, process, or service by trade name, trademark, manufacturer, or otherwise, does not necessarily constitute or imply its endorsement, recommendation, or favoring by the United States Government or any agency thereof or its contractors or subcontractors. The views and opinions of authors expressed herein do not necessarily state or reflect those of the United States Government or any agency thereof.

PATENT STATUS. This document copy, since it is transmitted in advance of patent clearance, to made available in confidence solely for use in performance of work under contract with the-U.S. Department of Energy. This document is gat to be published nor its contents otherwise draceminated or used for purposes other itron specified above before patent approval for such nalease or use has been secupd, upon request, from the Patent Counsel, U.S. Department of Emogy Field officen Richland, WA.

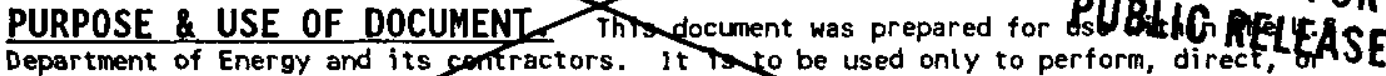

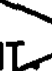
APPROVED FOR integrate work under U.S. Department of Energy contracts. This document is not approved for public release untit reviewed.

This report has been reproduced from the best available copy. Avajable in paper copy and microfiche Printed in the United States of America. Available to tha U.S. Department of Energy ond its contractors from:

U.S. Department of Energy

Office of Scientific and Technical Information (OSTI)

P.O. Box 62

Oak Ridge, TN 37831

Telephone: (615) 576-8401

DISTRIBUTION LIMITATION: Distribution authorized to the Department of Energy and DOE Contractors only; other requests shall be approved by the cognizant DOE Departmental Element. 


\section{Building}

\section{Hazard Baseline Document}

Prepared for the U.S. Department of Energy

Hanford Management and Integration Contractor for the U.S. Department of Energy under Contract OE-AC06-96RL13200
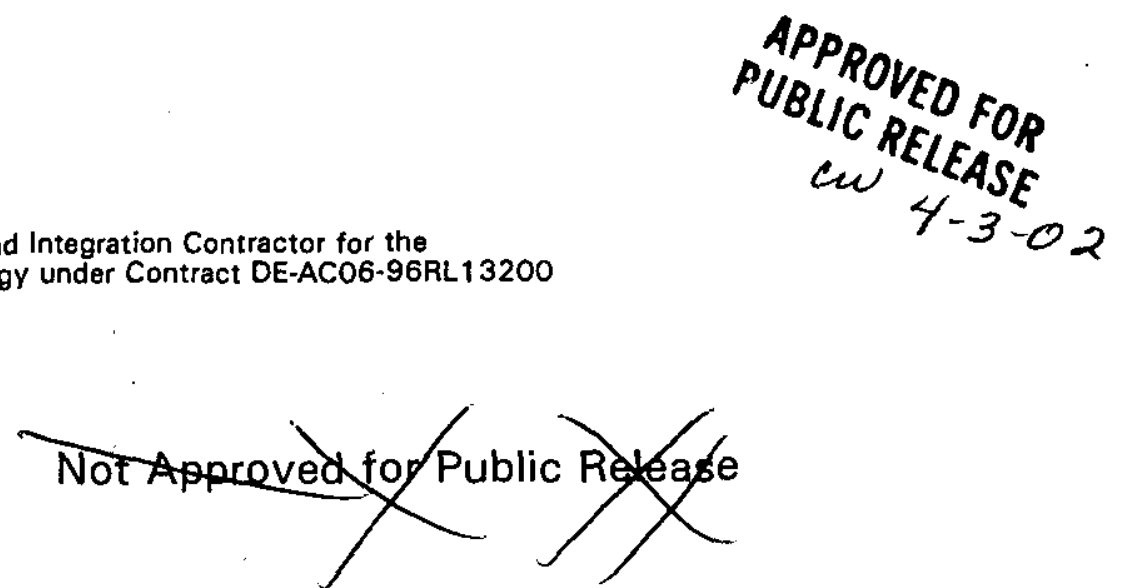
TABLE OF CONTENTS

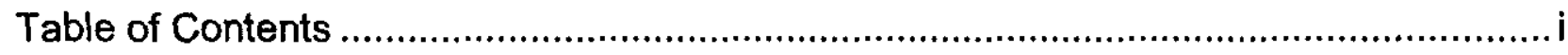

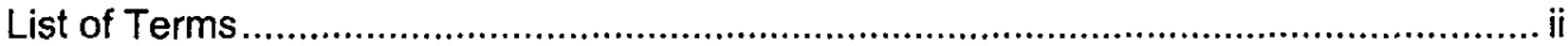

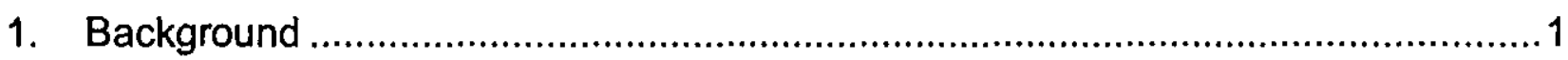

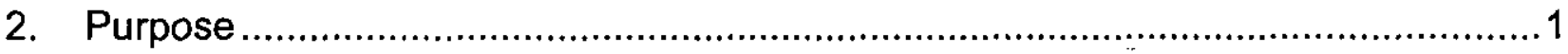

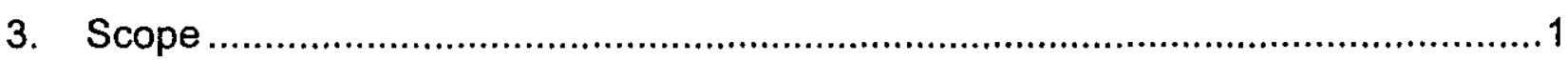

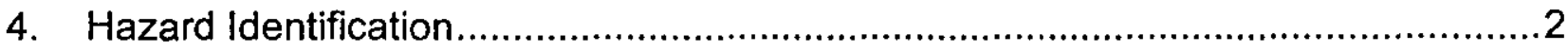

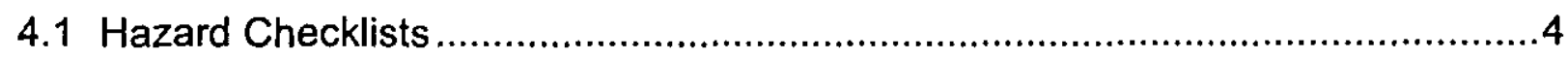

4.2 Preliminary Hazard Analysis ............................................................................

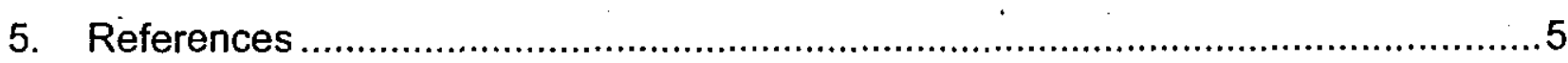

Appendix A. Hazard Checklists

Appendix B. Preliminary Hazard Analysis 


\section{LIST OF TERMS}

AOG

BWHC

D\&D

DOE

EDL

$\mathrm{FDH}$

HEPA

HLV

HVAC

LEL

LLV

NDA

NWVP

OSR

PHA

PHMC

POG

REC

RLWS

RPS

SAR

SEL

SER

SMF

SNM

TPA

VV

WBS
Auxiliary Off-Gas

B\&W Hanford Company

Decontamination and Decommissioning

U.S. Department of Energy

Engineering Development Laboratory

Fluor Daniel Hanford, Inc.

High Efficiency Particulate Air

High Level Vault

Heating Ventilation and Air Conditioning

Large Equipment Laboratory

Low Level Vault

Non-Destructive Analysis

Nuclear Waste Vitrification Program

Operational Safety Requirement

Preliminary Hazards Analysis

Project Hanford Management Contractor

Process Off-Gas

Radiochemical Engineering Complex

Radioactive Liquid Waste System

Retention Process Sewer

Safety Analysis Report

Small Equipment Laboratory

Safety Evaluation Report

Shielded Material Facility

Special Nuclear Material

Tri-Party Agreement

Vessel Ventilation

Work Breakdown Structure 


\section{BACKGROUND}

The 327 Building, Post-Irradiation Testing Laboratory, is a Category 2-nonreactor nuclear facility currently operated by B\&W Hanford Company (BWHC) for Fluor Daniel Hanford, Inc (FDH). Operating since 1953, the 327 Building was designed to provide shielded, ventilated, and specially equipped laboratories for physical and metallurgical examination and testing of irradiated fuels, concentrated fission products, and structural materials in support of operational efforts being carried out at Hanford. The primary operating area on the main floor includes a canyon area and connecting bays where auxiliary operations are performed. The canyon area contains shielded cells and the cell operating stations and consoles. A transfer and storage area is located at one end of the building. Two bridge cranes are used to transfer casks containing radioactive structural materials or fuel from the receiving area to the cells or between the cells.

\section{PURPOSE}

The purpose of this document is to document the hazard baseline for the 327 Building. The hazard baseline was developed using two techniques; walking down the facility and completing checklists and preparing a Preliminary Hazards Analysis (PHA).

This hazard baseline document identifies the hazards in the 327 Building at the time of the facility walk through, presents a PHA of stabilization and deactivation activities, and provides a basis for the hazard evaluation and accident analysis that will be developed in the 327 Building Basis for Interim Operation (BIO).

\section{SCOPE}

Activities addressed in this hazard baseline document include:

- Stabilization and deactivation activities in preparation for eventual decommissioning of the 327 Building and the routine handling, processing, and shipment of waste to support these activities.

- 324/327 Building Minimum Safe Project engineering and maintenance activities to maintain the building and systems viable-especially the Safety SSCs-to allow stabilization, deactivation, and waste handling activities with a minimum risk to workers, the public, and the environment.

Stabilization and deactivation activities will remove and/or reduce human health and environmental hazards associated with the 327 Building, and will place the facility in the lowest radiological classification possible. These activities concentrate on removing, reducing, and 
stabilizing the industrial, radiological, and chemical hazards remaining in the building at the time of transition from its operational mission. Following stabilization and deactivation, the 327 Building will be placed in surveillance and maintenance mode pending re-use or final Decontamination and Decommissioning (D\&D) when the facility is tumed over to the Environmental Restoration and Management Contractor.

\section{HAZARD IDENTIFICATION}

Safety Analysis consists of a hazards analysis and an accident analysis. Safety analysis requirements for existing Hanford site facilities are established by HNF-PRO-430, Safety Analysis Program; HNF-PRO-700, Safety Analysis and Technical Safety Requirements; and HNF-PRO-701, Safety Analysis Process - Existing Facility. In accordance with these requirements, guidance for the preparation of this safety analysis was taken from DOE-STD-3011-94, Guidance for Preparation of DOE 5480.22 (TSR) and DOE 5480.23 (SAR) Implementation Plans and from HNF-PRO-704, Hazard and Accident Analysis Process. DOE-STD-3011-94 and HNF-PRO-704 both specify the application of the graded approach to the safety analysis effort. The safety analysis must be comprehensive enough to demonstrate the following:

- the facility hazards are understood and all of the major hazards have been evaluated, and

- dominant accident scenarios with the potential for significant consequences inside or outside the facility have been identified, and features (both engineered and administrative) are established to prevent or mitigate the consequences of the identified accidents.

The hazards analysis is required to:

- be based on the inventory enveloping radioactive and hazardous materials that may be stored, used, or formed within the 327 Building; and

- identify the energy sources that may contribute to an uncontrolled release of radioactive or other hazardous material.

The potential hazards associated with the 327 Building were identified by:

- reviewing historical safety documentation;

- reviewing facility operating procedures;

- reviewing the proposed stabilization and deactivation activities;

- discussions with building personnel and subject matter experts; and

- performing and documenting a physical walkthrough of the building.

The existing safety documentation reviewed included the following:

- HNF-SD-SPJ-SAR-002, Rev. 1B, 327 Building Safety Analysis Report, (BWHC 1998a), 
- HNF-SD-HT-FHA-003, 327 Facility Fire Hazard Analysis (Hughes 1997).

The 327 Building is a Hazard Category 2 facility and has transitioned from process operations to stabilization and deactivation activities. Based on this information, the use of hazard checklists and a preliminary hazards analysis (PHA) technique to evaluate the major hazards are appropriate to systematically identify the hazards baseline for the 327 Building.

Table 1 provides an overview of the stabilization/deactivation activities addressed during the hazard identification process.

Table 1. Stabilization and Deactivation Activities Evaluated

\begin{tabular}{|c|c|c|}
\hline Table Reforence & 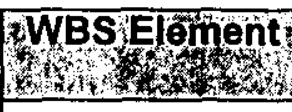 & 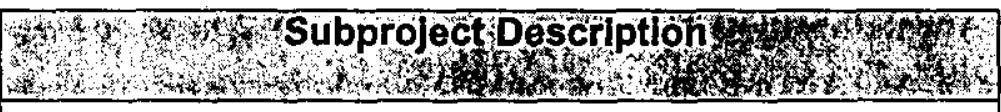 \\
\hline B-1 & 1K7M04 OA 01 & 327 Facility Operational Surveillance \\
\hline B-2 & $1 \mathrm{~K} 7 \mathrm{M} 050 \mathrm{~A} 01$ & 327 Facility Maintenance/Calibrations \\
\hline B-3 & 1K7M05 OA 02 & 327 Facility Corrective Maintenance \\
\hline B-4 & 1K7FOA OB 03 & 327 Facility Waste Bucket Retrieval and Packaging \\
\hline B-5 & 1K7FOA OE 03 & $\begin{array}{l}327 \text { Facility Legacy Material, Metallurgical Sample Retrieval and } \\
\text { Packaging }\end{array}$ \\
\hline B-6 & 1K7R01 OA 03 & $\begin{array}{l}327 \text { Facility Radioactive Liquid Waste System, Construction and } \\
\text { Acceptance Testing }\end{array}$ \\
\hline B-7 & $1 K 7 Z 010 A 01$ & 327 Facility Radiological Basement \\
\hline B-8 & 1K7M04 OA 01 & 327 Facility Cells \\
\hline B-9 & $1 \mathrm{~K} 7 \mathrm{ZO} 20 \mathrm{CO} 01$ & 327 Facility Canyon Cells, B-Cell \\
\hline B-10 & $1 \mathrm{~K} 7 Z 02$ OE 01 & 327 Facility Canyon Cells, C-Cell \\
\hline B-11 & $1 \mathrm{~K} 7 \mathrm{Z02} 0 \mathrm{G} 01$ & 327 Facility Canyon Cells, D-Cell \\
\hline B-12 & $1 \mathrm{~K} 7 \mathrm{Z02} 0 \mathrm{~J} 01$ & 327 Facility Canyon Cells, E-Cell \\
\hline B-13 & $1 \mathrm{~K} 7 \mathrm{ZO} 2 \mathrm{OL} 01$ & 327 Facility Canyon Ceils, F-Cell \\
\hline B-14 & $1 \mathrm{~K} 7 \mathrm{Z} 02$ ON 01 & 327 Facility Canyon Cells, G-Cell \\
\hline B-15 & $1 \mathrm{~K} 7 \mathrm{Z} 02 \mathrm{OP} 01$ & 327 Facility Canyon Ceils, $\mathrm{H}-\mathrm{Ce}$ ll \\
\hline B-16 & 1K7Z02 OR 01 & 327 Facility Canyon Cells, I-Cell \\
\hline B-17 & $1 \mathrm{~K} 72020 T 01$ & $\begin{array}{l}327 \text { Facility Canyon Cells, Special Environmental Radiometallurgy } \\
\text { Facility (SERF) Ceil }\end{array}$ \\
\hline B-18 & $1 \mathrm{~K} 7 \mathrm{Z} 02$ OV 01 & 327 Facility Decontamination Chamber/Transfer and Storage Basins \\
\hline B-19 & $1 \mathrm{~K} 7 \mathrm{ZO} 20 \mathrm{~V} 03$ & 327 Facility Spent lon Exchange Column Removal \\
\hline B-20 & $1 \mathrm{~K} 7 Z 020 \times 01$ & 327 Facility Dry Storage \\
\hline B-21 & $1 \mathrm{~K} 7 \mathrm{Z} 03$ OE 01 & 327 Facility Canyon Support Areas \\
\hline B-22 & 1K7Z03 0G 01 & $\begin{array}{l}327 \text { Facility Special Environmențal Radiometallurgy Facility Support } \\
\text { Area and Room } 19\end{array}$ \\
\hline B-23 & $1 \mathrm{~K} 72030 \mathrm{~J} 01$ & 327 Facility Non-Radiological Support Rooms \\
\hline B-24 & $1 \mathrm{~K} 7 \mathrm{ZO3}$ OL 01 & 327 Facility Exterior and Yard \\
\hline $8-25$ & $1 \mathrm{~K} 7 \mathrm{Z03}$ OP 01 & 327 Facility Stand-Alone Mothballed Equipment \\
\hline B-26 & $1 \mathrm{~K} 7 \mathrm{Z03}$ OR 01 & 327 Facility Building Roof and Equipment \\
\hline B-27 & 1K7Z03 0T 01 & 327 Facility Waste Compactor/Truck Load/Canyon Gallery \\
\hline
\end{tabular}




\begin{tabular}{|c|c|l|}
\hline B-28 & 1 K7Z04 OA 03 & 327 Facility Process Sewer \\
\hline B-29 & 1 K7Z04 OA 05 & $\begin{array}{l}327 \text { Facility Retention Process Sewer/Radioactive Liquid Waste } \\
\text { System }\end{array}$ \\
\hline B-30 & 1 K7Z04 OC 01 & $\begin{array}{l}327 \text { Facility Heating, Ventilation, and Air Conditioning (HVAC), Cell } \\
\text { Exhaust }\end{array}$ \\
\hline B-31 & 1 K7Z04 OC 03 & $\begin{array}{l}\text { 327 Facility Heating, Ventilation, and Air Conditioning (HVAC), } \\
\text { Canyon Exhaust }\end{array}$ \\
\hline
\end{tabular}

\subsection{HAZARD CHECKLISTS}

A walkthrough of the facility was conducted to ensure that the significant quantities of radioactive or hazardous materials and energy sources associated with the facility design, processes, and stabilization/deactivation activities were identified. A Hazardous Material/Energy Source Checklist (HNF-PRO-704, Table 2) was used to document observations for specific locations within the building during the walkthrough.

The checklist provides a list of hazard categories (e.g., electrical, flammable materials, and ionizing radiation sources) to assist in the identification process, each of which contains several specific sub-elements. Hazards on the checklists existing within the individual location were noted on the checklists, including the quantity, chemical and physical form (as applicable), and process or storage condition. In addition, the existence of any additional hazards not appearing on the checklists was noted. Discussions with building personnel and subject matter experts were held during the walkthrough and also subsequent to its completion in order to confirm locations and quantities of hazards.

Hazards were then evaluated to identify the potential scenarios that could lead to significant releases of radioactive or hazardous materials and to rank these scenarios based on potential consequences and frequency. Based on the rankings, bounding accidents for each type of postulated scenario will be further developed in the 327 Building BIO.

Completed checklists are provided in Appendix A.

\subsection{PRELIMINARY HAZARD ANALYSIS}

A PHA technique was used to systematically review and document the hazards associated with stabilization and deactivation activities. The PHA form was used for the analysis of the hazards associated with the 327 Building. A brief description of the content of each column on the PHA form follows.

- Equipment/Area - lists the specific type(s) of equipment involved in the postulated accident and/or the area of the facility involved. 
- Activity - provides a brief description of the action taking place when the postulated accident might occur.

- Hazard - lists the intrinsic hazard (radioactivity, toxic material, etc.) present or potentially present in the process or facility being analyzed.

- Accident - refers to an abnormal event or sequence of events that, combined with the intrinsic hazard could potentially result in adverse consequences to a facility worker and/or person at a distance from the facility.

- Cause - list an abnormal event or combination of event that might initiate the accident.

- Consequence - describes the postulated unmitigated consequences of the accident.

- Consequence Rank - contains a rating of the accident consequence severity. Unmitigated consequences of accidents resolving airborne releases of radioactive material were ranked. Because the low hazardous chemical inventories, the airborne release consequences of hazardous chemical were ranked low. Accidents involving exposures to facility workers were ranked using engineering judgement. Accidents involving worker injury due to standard industrial hazards were ranked IND.

- Frequency Rank - contains an estimate of the accident frequency. Abbreviations used are A for anticipated (frequency greater than $10^{-2} / \mathrm{yr}$ ); $\mathrm{U}$ for unlikely (frequency between $10^{-2} / \mathrm{yr}$ and $10^{-4} / \mathrm{yr}$ ); and EU for extremely unlikely (frequency less than $10^{-6} / \mathrm{yr}$ ).

- Engineered Control - lists the engineered design features that might act to mitigate or prevent the consequences of the hazardous conditions.

- Administrative Control - lists the administrative controls (e.g., procedure) that might act to mitigate or prevent the consequences of the hazardous conditions.

- Comments - notes special conditions that might apply to the postulated accident or items for further resolution as deactivation planning progresses.

Completed PHA forms for each activity identified in Table 1 are provided in Appendix B.

\section{REFERENCES}

AIChE 1992, Guidelines for Hazard Evaluation Procedures, Second Edition, Center for Chemical Process Safety, American Institute of Chemical Engineers, New York, New York.

BWHC 1997, 324/327 Facilities Stabilization Projects Administration Manual, HNF-IP-1264, Section 2.7, Unreviewed Safety Questions, B\&W Hanford Company, Richland, Washington.

BWHC 1998a, 327 Building Safety Analysis Report, HNF-SD-SPJ-SAR-002, Rev 1B, B\&W Hanford Company, Richland, Washington. 
BWHC 1998b, Operational Safety Requirements for the 327 Building, HNF-SD-SPJ-OSR-002, Rev 2, B\&W Hanford Company, Richland, Washington.

BWHC 1999, 324/327 Building Stabilization/Deactivation Project Project Management Plan, HNF-IP-1289, Rev 2, B\&W Hanford Company, Richland, Washington.

DOE-STD-3011-94, Guidance for Preparation of DOE 5480.22 (TSR) and DOE 5480.23 (SAR) Implementation Plans, U.S. Department of Energy, Washington, D.C.

HNF-PRO-430, Rev. 1, Safety Analysis Program, Fluor Daniel Hanford Inc., Richland, Washington

HNF-PRO-700, Rev. 1, Safety Analysis and Technical Safety Requirements, Fluor Daniel Hanford Inc., Richland, Washington

HNF-PRO-701, Safety Analysis Process - Existing Facility, Fluor Daniel Hanford Inc., Richland, Washington

HNF-PRO-704, Hazards and Accident Analysis Process, Fluor Daniel Hanford Inc., Richland, Washington.

Hughes 1997, 327 Facility Fire Hazard Analysis, HNF-SD-HT-FHA-003, Hughes and Associates Inc., Baltimore, Maryland. 


\section{Appendix A}

\section{Hazard Checklists}




\begin{tabular}{|c|c|}
\hline 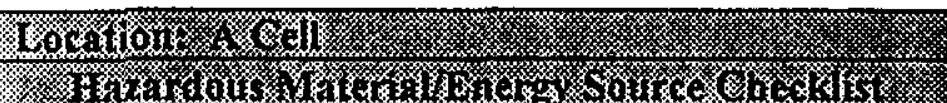 & 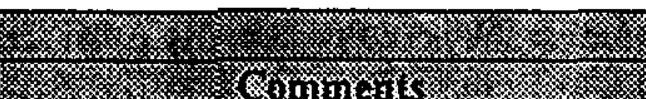 \\
\hline $\begin{array}{l}\text { Electrical } \\
\text { Electrical Equipment - Power tools, waste compactor }\end{array}$ & \\
\hline $\begin{array}{l}\text { Thermal } \\
\text { Electrical equipment } \\
\text { Welding }-480 \mathrm{~V} \text { Heli-arc welder for sleeves } \\
\text { Power tools }\end{array}$ & . \\
\hline $\begin{array}{l}\text { Friction } \\
\text { Power tools, waste compactor, crimper }\end{array}$ & \\
\hline $\begin{array}{l}\text { Corrosives } \\
\text { Decon Solution }\end{array}$ & \\
\hline $\begin{array}{l}\text { Kinetic-Linear } \\
\text { Crane loads }\end{array}$ & \\
\hline $\begin{array}{l}\text { Mass, Gravity, Height } \\
\text { Human Effort } \\
\text { Crane }\end{array}$ & \\
\hline $\begin{array}{l}\text { Explosives/Pyrophorics } \\
\text { Hydrogen }\end{array}$ & $\begin{array}{l}\text { Low generation rate of hydrogen from } \\
\text { hydrolysis. }\end{array}$ \\
\hline $\begin{array}{l}\text { Nuclear Criticality } \\
\text { Hot cell }\end{array}$ & \\
\hline $\begin{array}{l}\text { Flammable Materials } \\
\text { Isopropyl Alcohol } \\
\text { Epoxy Fixative } \\
\text { Rags } \\
\text { Legacy waste cans may contain combustible/flammable materials }\end{array}$ & $\begin{array}{l}\text { Up to } 500 \mathrm{~mL} \text { of Isopropyl Alcohol routinely } \\
\text { allowed in the cells. The introduction of } \\
\text { other chemicals requires approval. The } \\
\text { leaded glass windows do not contain oil. }\end{array}$ \\
\hline $\begin{array}{l}\text { lonizing Radiation Sources } \\
\text { Fissile material } \\
\text { Radioactive Material }-25 \text { to } 35 \text { legacy waste cans visible }\end{array}$ & \\
\hline Other & $\begin{array}{l}\text { A Cell is currently used for compacting } \\
\text { legacy waste cans, packaging (including in- } \\
\text { cell welding), and loading } 55 \text { gallon waste } \\
\text { drums. }\end{array}$ \\
\hline
\end{tabular}




\begin{tabular}{|c|c|}
\hline 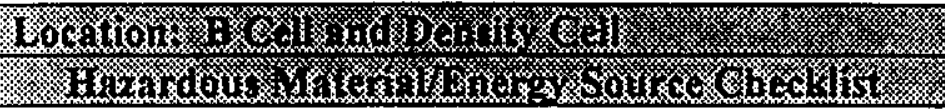 & 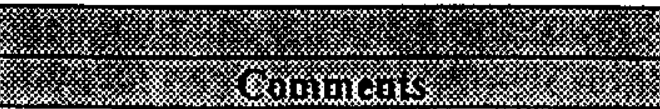 \\
\hline $\begin{array}{l}\text { Electrical } \\
\text { Electrical Equipment } \\
\text { Power Tools }\end{array}$ & (2) \\
\hline $\begin{array}{l}\text { Thermal } \\
\text { Electrical equipment } \\
\text { Power tools }\end{array}$ & \\
\hline Friction & \\
\hline$\frac{\text { Corrosives }}{\text { Decon Solution }}$ & \\
\hline $\begin{array}{l}\text { Kinetic-Linear } \\
\text { Crane loads }\end{array}$ & \\
\hline $\begin{array}{l}\text { Mass, Gravity, Height } \\
\text { Human Effort } \\
\text { Crane }\end{array}$ & \\
\hline $\begin{array}{l}\text { Explosives/Pyrophorics } \\
\text { Hydrogen }\end{array}$ & $\begin{array}{l}\text { Low generation rate of hydrogen from } \\
\text { hydrolysis. }\end{array}$ \\
\hline $\begin{array}{l}\text { Nuclear Criticality } \\
\text { Hot cell }\end{array}$ & \\
\hline $\begin{array}{l}\text { Flammable Materials } \\
\text { Isopropyl Alcohol } \\
\text { Epoxy Fixative } \\
\text { Rags } \\
\text { Legacy waste cans may contain combustible/flammable materials }\end{array}$ & $\begin{array}{l}\text { Up to } 500 \mathrm{~mL} \text { of Isopropyl Alcohol routinely } \\
\text { allowed in the cells. The introduction of } \\
\text { other chemicals requires approval. }\end{array}$ \\
\hline $\begin{array}{l}\text { Ionizing Radiation Sources } \\
\text { Fissile material - historical metallurgical samples } \\
\text { Radioactive Material }\end{array}$ & $\begin{array}{l}\text { There are fuel cards located on the side of the } \\
\text { cell that indicate the curie content of the } \\
\text { samples. Scott Johnston keeps track of the } \\
\text { total curie content of the cells. } \\
\text { There was a portable metal radwaste storage } \\
\text { bin located next to the cell. }\end{array}$ \\
\hline $\begin{array}{l}\text { Other } \\
\text { There is a potential for breaking and segregating the mounted } \\
\text { metallurgical samples in this cell. The epoxy from the samples } \\
\text { will be packaged in waste buckets. The samples will be packaged } \\
\text { in } 1 \text { in. tubes. These tubes will be loaded in to the SERF Cask for } \\
\text { shipment to the } 324 \text { Building. } \\
\text { The Density Cell (approximately } 3 \mathrm{ft} \times 3 \mathrm{ft} \times 5 \mathrm{ft} \text { ) is attached to } \\
\text { the side of B Cell. }\end{array}$ & \\
\hline
\end{tabular}




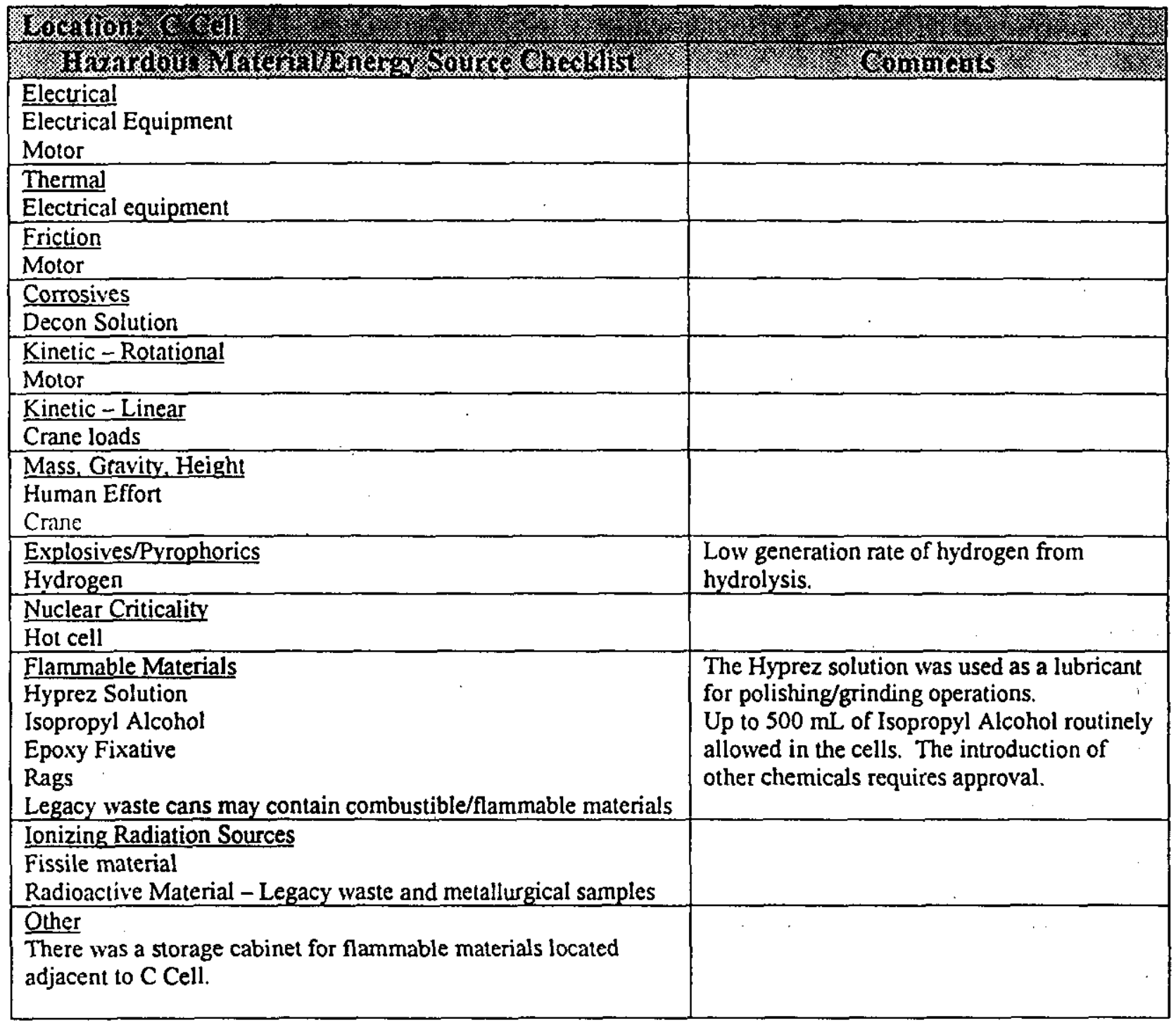




\begin{tabular}{|c|c|}
\hline 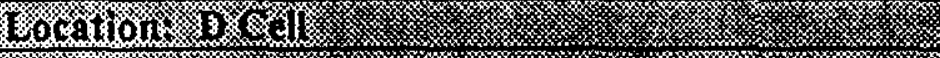 & 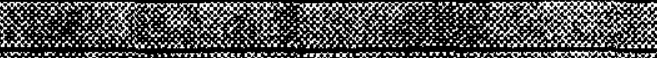 \\
\hline ․ & 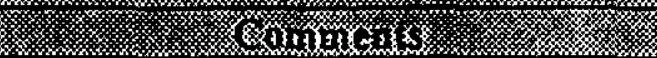 \\
\hline$\frac{\text { Electrical }}{\text { Electrical Equipment }}$ & \\
\hline $\begin{array}{l}\text { Thermal } \\
\text { Electrical equipment } \\
\text { RF heating equipment } \\
\text { Welding } \\
\text { Power tools }\end{array}$ & \\
\hline $\begin{array}{l}\text { Friction } \\
\text { Motors } \\
\text { Power Tools } \\
\end{array}$ & \\
\hline$\frac{\text { Corrosives }}{\text { Decon Solution }}$ & \\
\hline$\frac{\text { Kinetic - Rotational }}{\text { Motors }}$ & \\
\hline$\frac{\text { Kinetic-Linear }}{\text { Crane loads }}$ & . \\
\hline $\begin{array}{l}\text { Mass, Gravity, Height } \\
\text { Human Effort } \\
\text { Crane }\end{array}$ & \\
\hline $\begin{array}{l}\text { Pressure - Volume } \\
\text { Gas pressurization capability }\end{array}$ & 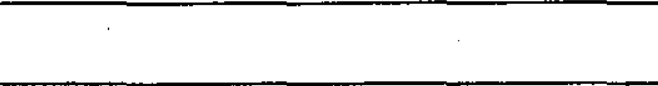 \\
\hline $\begin{array}{l}\text { Explosives/Pyrophorics } \\
\text { Hydrogen }\end{array}$ & $\begin{array}{l}\text { Low generation rate of hydrogen from } \\
\text { hydrolysis. }\end{array}$ \\
\hline $\begin{array}{l}\text { Nuclear Criticality } \\
\text { Hot cell }\end{array}$ & \\
\hline $\begin{array}{l}\text { Flammable Materials } \\
\text { Isopropyl Alcohol } \\
\text { Epoxy Fixative } \\
\text { Rags } \\
\text { Legacy waste cans may contain combustible/flammable materials }\end{array}$ & $\begin{array}{l}\text { Up to } 500 \mathrm{~mL} \text { of Isopropyl Alcohol routinely } \\
\text { allowed in the cells. The introduction of } \\
\text { other chemicals requires approval. }\end{array}$ \\
\hline $\begin{array}{l}\text { Ionizing Radiation Sources } \\
\text { Fissile material } \\
\text { Radioactive Material }\end{array}$ & $\therefore$ \\
\hline Other & \\
\hline
\end{tabular}




\begin{tabular}{|c|c|}
\hline 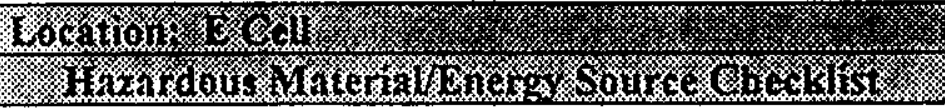 & 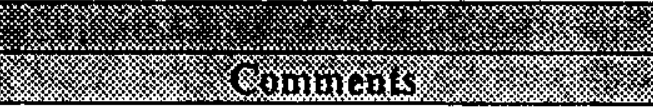 \\
\hline $\begin{array}{l}\text { Electrical } \\
\text { Electrical Equipment } \\
\text { Motor }\end{array}$ & \\
\hline $\begin{array}{l}\text { Thermal } \\
\text { Electrical equipment }\end{array}$ & \\
\hline$\frac{\text { Friction }}{\text { Motor }}$ & \\
\hline 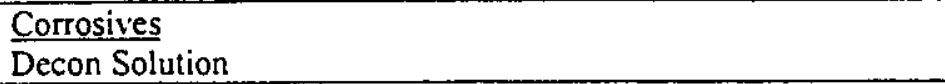 & \\
\hline$\frac{\text { Kinetic-Rotational }}{\text { Motor }}$ & \\
\hline $\begin{array}{l}\text { Kinetic-Linear } \\
\text { Crane loads }\end{array}$ & \\
\hline $\begin{array}{l}\text { Mass, Gravity, Height } \\
\text { Human Effort } \\
\text { Crane }\end{array}$ & \\
\hline $\begin{array}{l}\text { Explosives/Pyrophorics } \\
\text { Hydrogen }\end{array}$ & $\begin{array}{l}\text { Low generation rate of hydrogen from } \\
\text { hydrolysis. }\end{array}$ \\
\hline $\begin{array}{l}\text { Nuclear Criticality } \\
\text { Hot cell }\end{array}$ & \\
\hline $\begin{array}{l}\text { Flammable Materials } \\
\text { Hyprez Solution } \\
\text { Isopropyl Alcohol } \\
\text { Epoxy Fixative } \\
\text { Rags } \\
\text { Legacy waste cans may contain combustible/flammable materials }\end{array}$ & $\begin{array}{l}\text { The Hyprez solution was used as a lubricant } \\
\text { for polishing/grinding operations. } \\
\text { Up to } 500 \mathrm{~mL} \text { of Isopropyl Alcohol routinely } \\
\text { allowed in the cells. The introduction of } \\
\text { other chemicals requires approval. }\end{array}$ \\
\hline $\begin{array}{l}\text { Ionizing Radiation Sources } \\
\text { Fissile material } \\
\text { Radioactive Material - Legacy waste and metallurgical samples }\end{array}$ & $\begin{array}{l}\text { 78.1g U-235, 20.2g Pu, 643.7 Ci FP, } \\
3,643.5 \mathrm{~g} \text { Enriched } \mathrm{U}(<20 \%) \text { per } \mathrm{HNF}-3480 \\
\text { Rev. } 0\end{array}$ \\
\hline$\frac{\text { Other }}{\text { E Cell performed the same function as } C \text { Cell. }}$ & \\
\hline
\end{tabular}




\begin{tabular}{|c|c|}
\hline 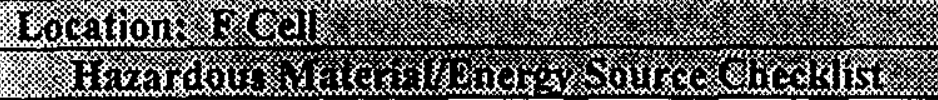 & 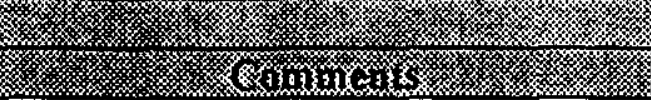 \\
\hline $\begin{array}{l}\text { Electrical } \\
\text { Electrical Equipment } \\
\text { Motors - Lathe } \\
\text { Power Tools } \\
\text { Wiring }\end{array}$ & \\
\hline $\begin{array}{l}\text { Thermal } \\
\text { Electrical equipment } \\
\text { Power tools }\end{array}$ & \\
\hline $\begin{array}{l}\text { Friction } \\
\text { Motors } \\
\text { Power Tools } \\
\end{array}$ & \\
\hline Corrosives & \\
\hline $\begin{array}{l}\text { Kinetic - Rotational } \\
\text { Motors }\end{array}$ & \\
\hline $\begin{array}{l}\text { Kinetic-Linear } \\
\text { Crane loads } \\
\end{array}$ & \\
\hline $\begin{array}{l}\text { Mass, Gravity, Height } \\
\text { Human Effort } \\
\text { Crane }\end{array}$ & $i$ \\
\hline $\begin{array}{l}\text { Explosives/Pyrophorics } \\
\text { Hydrogen }\end{array}$ & $\begin{array}{l}\text { Low generation rate of hydrogen from } \\
\text { hydrolysis. } \\
\text { The spill of a sodium/potassium alloy and } \\
\text { kerosene into the drain line resulted in a fire } \\
\text { in the mid } 70 \text { 's. The alloy reacted with the } \\
\text { water and displaced the kerosene from the } \\
\text { drain into the cell. The } 2 \text { gallon inventory of } \\
\text { kerosene and glycol burned and pressurized } \\
\text { the cell expelling plugs thereby spreading } \\
\text { contamination in the canyon. }\end{array}$ \\
\hline $\begin{array}{l}\text { Nuclear Criticality } \\
\text { Hot cell }\end{array}$ & $\therefore$ \\
\hline $\begin{array}{l}\text { Flammable Materials } \\
\text { Isopropyl Alcohol } \\
\text { Epoxy Fixative } \\
\text { Rags } \\
\text { Legacy waste cans may contain combustible/flammable materials }\end{array}$ & $\begin{array}{l}\text { Up to } 500 \mathrm{~mL} \text { of Isopropyl Alcohol routinely } \\
\text { allowed in the cells. The introduction of } \\
\text { other chemicals requires approval. }\end{array}$ \\
\hline $\begin{array}{l}\text { Ionizing Radiation Sources } \\
\text { Fissile material } \\
\text { Radioactive Material }\end{array}$ & $\begin{array}{l}14.5 \mathrm{~g} \mathrm{u}-235,0.3 \mathrm{~g} \mathrm{Pu}, 139.4 \mathrm{~g} \mathrm{FP} \\
249.4 \mathrm{~g} \text { enriched } \mathrm{U}(<20 \%) \text { per HNF-3480 } \\
\text { Rev. } 0\end{array}$ \\
\hline Other & \\
\hline
\end{tabular}




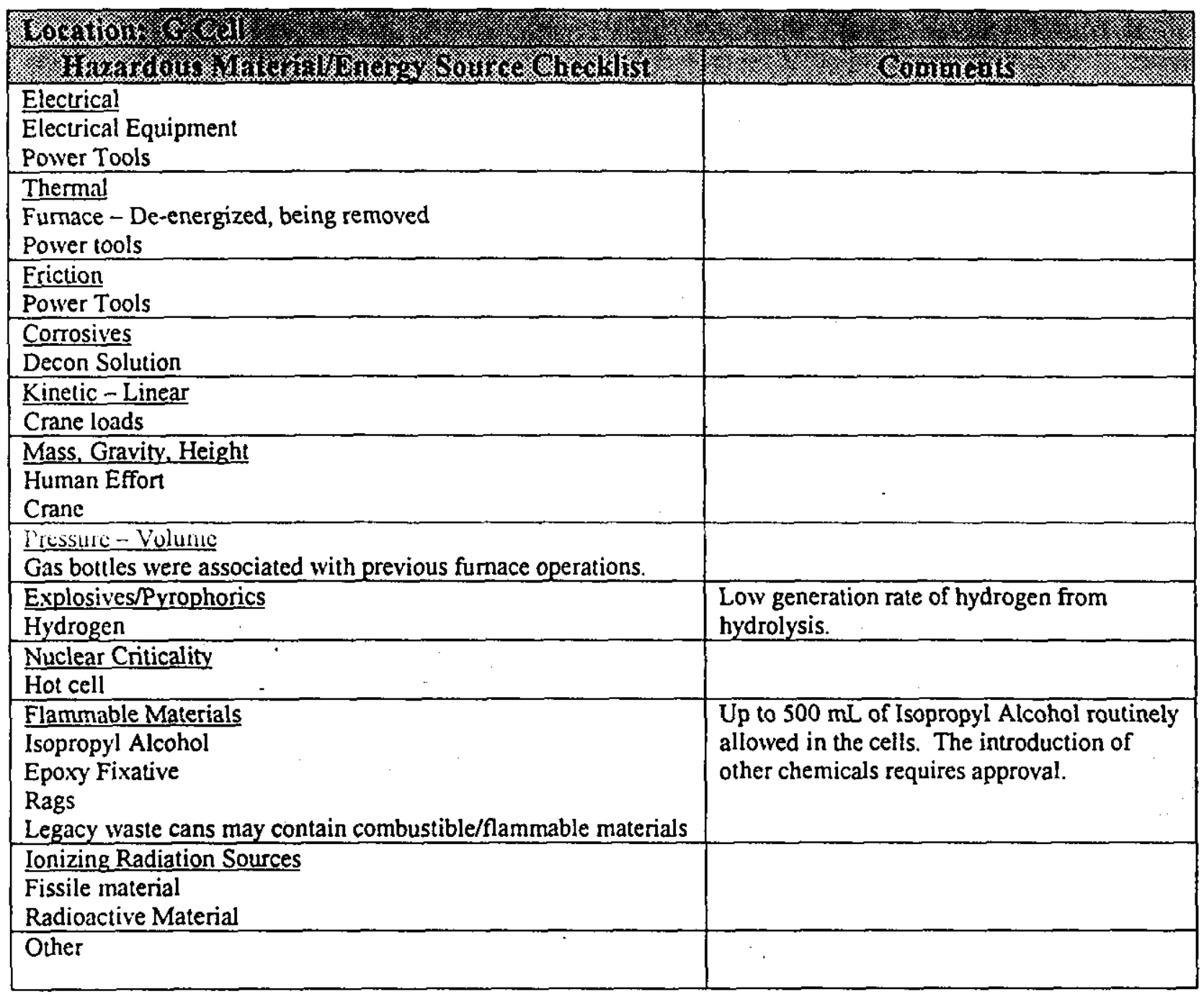




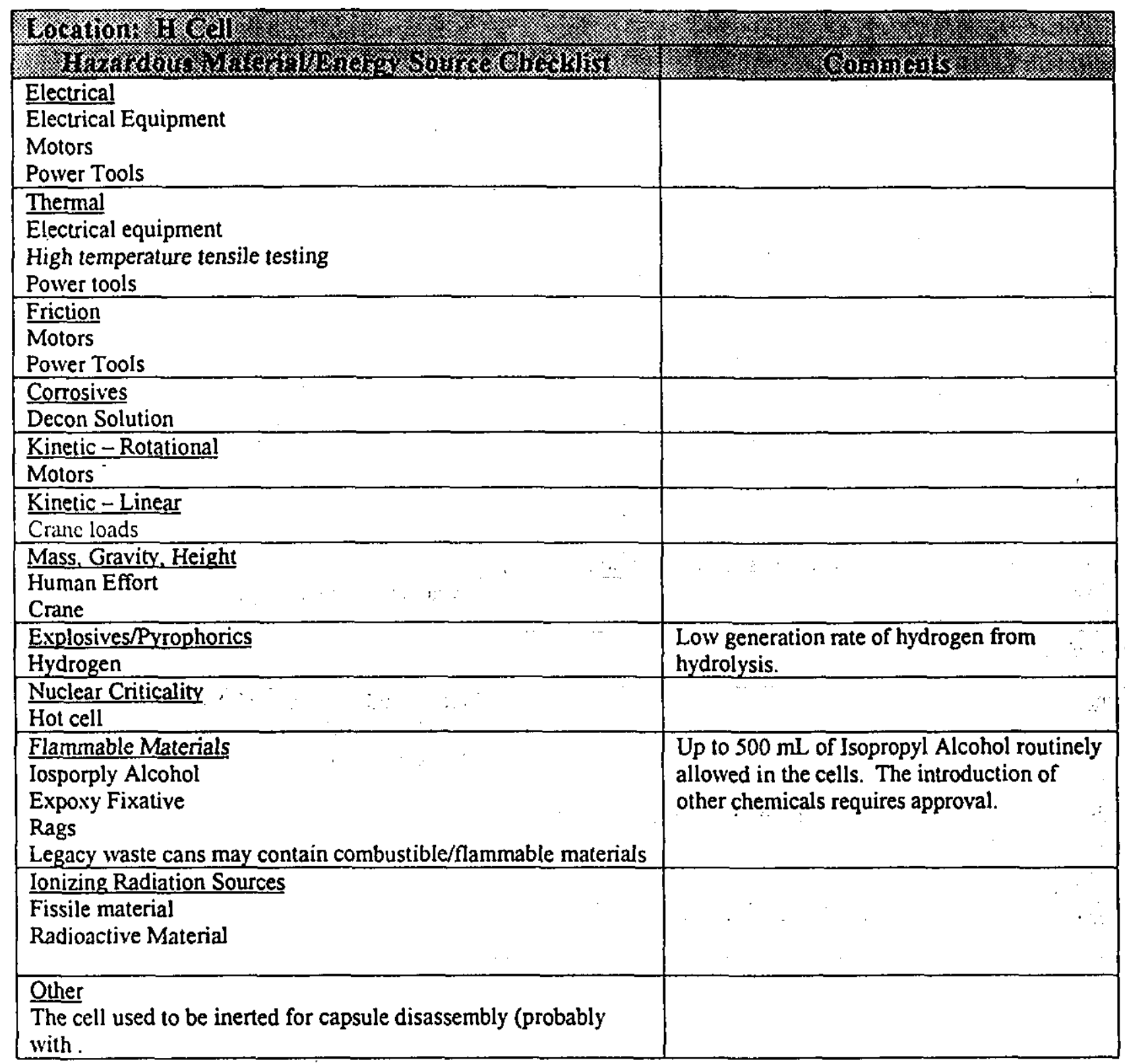




\begin{tabular}{|c|c|}
\hline Y Sou a Hou & ( \\
\hline 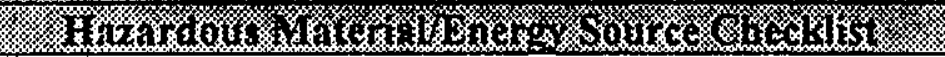 & . \\
\hline $\begin{array}{l}\text { Electrical } \\
\text { Electrical Equipment - Corrosion testing equipment } \\
\text { Motors }\end{array}$ & \\
\hline $\begin{array}{l}\text { Thermal } \\
\text { Electrical equipment }\end{array}$ & \\
\hline$\frac{\text { Friction }}{\text { Motors }}$ & \\
\hline $\begin{array}{l}\text { Corrosives } \\
\text { Acids - Unknown } \\
\text { Caustics - Unknown } \\
\text { Decon Solution }\end{array}$ & \\
\hline$\frac{\text { Kinetic - Rotational }}{\text { Motors }}$ & \\
\hline $\begin{array}{l}\text { Kinetic-Linear } \\
\text { Crane loads }\end{array}$ & \\
\hline $\begin{array}{l}\text { Mass, Gravity, Height } \\
\text { Human Effort } \\
\text { Crane }\end{array}$ & \\
\hline $\begin{array}{ll}\text { Explosives/Pyrophorics } & \\
\text { Hydrogen } & \\
\text { Gases, others }\end{array}$ & $\begin{array}{l}\text { Low generation rate of hydrogen from } \\
\text { hydrolysis. }\end{array}$ \\
\hline $\begin{array}{l}\text { Nuclear Criticality } \\
\text { Hot cell }\end{array}$ & \\
\hline $\begin{array}{l}\text { Flammable Materials } \\
\text { Isopropyl Alcohol } \\
\text { Epoxy Fixative } \\
\text { Rags } \\
\text { Legacy waste cans may contain combustible/flammable materials }\end{array}$ & $\begin{array}{l}\text { Up to } 500 \mathrm{~mL} \text { of Isopropyl Alcohol routinely } \\
\text { allowed in the cells. The introduction of } \\
\text { other chemicals requires approval. }\end{array}$ \\
\hline $\begin{array}{l}\text { Hazardous Materials } \\
\text { Corrosives - Unknown }\end{array}$ & \\
\hline $\begin{array}{l}\text { Ionizing Radiation Sources } \\
\text { Fissile material } \\
\text { Radioactive Material }\end{array}$ & $\begin{array}{l}\text { 20.2g U-235, 17.2g Pu, 849.5 Ci FP, } \\
332.9 \mathrm{~g} \text { Enriched U (<20\%) per HNF-3480 } \\
\text { Rev. } 0 \\
\text { Three Low-Level Waste Drums were stored } \\
\text { outside the cell. }\end{array}$ \\
\hline $\begin{array}{l}\text { Other } \\
\text { The Evaporation Cell is attached to I Cell. }\end{array}$ & $\begin{array}{l}\text { The cell has been inactive for some time. } \\
\text { Personnel indicated that it was essentially } \\
\text { left "as is" by the last operator. The cell } \\
\text { therefore has unknowns associated with it. }\end{array}$ \\
\hline
\end{tabular}




\begin{tabular}{|c|c|}
\hline 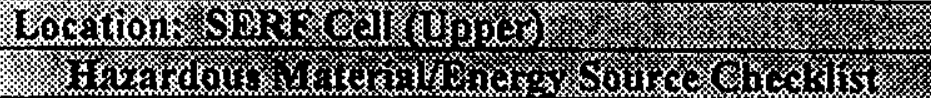 & 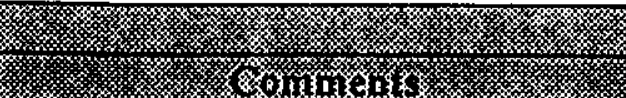 \\
\hline $\begin{array}{l}\text { Electrical } \\
\text { Electrical Equipment } \\
\text { Motors } \\
\text { Power Tools }\end{array}$ & \\
\hline $\begin{array}{l}\text { Thermal } \\
\text { Electrical equipment } \\
\text { Power tools }\end{array}$ & \\
\hline $\begin{array}{l}\text { Friction } \\
\text { Motors } \\
\text { Power Tools } \\
\end{array}$ & \\
\hline$\frac{\text { Corrosives }}{\text { Decon Solution }}$ & \\
\hline$\frac{\text { Kinetic-Rotational }}{\text { Motors }}$ & , \\
\hline $\begin{array}{l}\text { Kinetic-Linear } \\
\text { Crane loads (1 Ton Crane) }\end{array}$ & \\
\hline $\begin{array}{l}\text { Mass, Gravity, Height } \\
\text { Human Effort } \\
\text { Crane }\end{array}$ & \\
\hline $\begin{array}{l}\text { Pressure - Volume } \\
\text { Gas bottles }\end{array}$ & $\begin{array}{l}\text { There were several gas cylinders staged } \\
\text { next to the SERF Cell. }\end{array}$ \\
\hline $\begin{array}{l}\text { Explosives/Pyrophorics } \\
\text { Hydrogen }\end{array}$ & $\begin{array}{l}\text { Low generation rate of hydrogen from } \\
\text { hydrolysis. }\end{array}$ \\
\hline $\begin{array}{l}\text { Nuclear Criticality } \\
\text { Hot cell }\end{array}$ & \\
\hline $\begin{array}{l}\text { Flammable Materials } \\
\text { Isopropyl Alcohol } \\
\text { Hyprez } \\
\text { Epoxy Fixative } \\
\text { Rags } \\
\text { Legacy waste cans may contain combustible/flammable materials }\end{array}$ & $\begin{array}{l}\text { Up to } 500 \mathrm{~mL} \text { of Isopropyl Alcohol } \\
\text { routinely allowed in the cells. The } \\
\text { introduction of other chemicals requires } \\
\text { approval. } \\
\text { A storage container for Isopropyl Alcohol } \\
\text { and two storage containers for Hyprez } \\
\text { soution were attached to piping next to the } \\
\text { SERF Cell. }\end{array}$ \\
\hline $\begin{array}{l}\text { Hazardous Materials } \\
\text { A nitrogen atmosphere is maintained in the SERF Cell. }\end{array}$ & \\
\hline $\begin{array}{l}\text { Ionizing Radiation Sources } \\
\text { Fissile material } \\
\text { Radioactive Material }\end{array}$ & $\begin{array}{l}\text { 77.1g U-235, 23.7g Pu, 2,980.6 Ci FP, } \\
144.0 \mathrm{~g} \text { Enriched U (<20\%) }\end{array}$ \\
\hline $\begin{array}{l}\text { Other } \\
\text { SERF extends below grade to a lowver storage area. }\end{array}$ & $\begin{array}{l}\text { An oxygen monitor is interlocked with the } \\
\text { electrical supply. }\end{array}$ \\
\hline
\end{tabular}




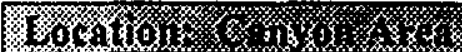

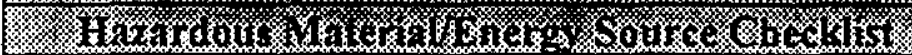

Electrical

Electrical Equipment

High Voltage - Overhead energized crane rails run parallel to the canyon. The West Patch Panel patches power to the various

cells.

Power Tools

Thermal

Electrical equipment

Power tools

Corrosives

Decon Solution

Kinetic-Rotational

Motors

Pumps

Kinetic-Linear

Cranc loads - the SERF cask has an empty wcight of thirtecn

tons.

Electric Forklifts

Mass, Gravity, Height

Human Effort

Crane

Pressure - Volume

Gas bottles

Nuclear Criticality

Hot cells

Flammable Materials

Packaging materials

Isopropyl Alcohol

Epoxy Fixative

Portable LLW containers.

Rags

Ionizing Radiation Sources

Fissile material

Radioactive Material

Other 


\begin{tabular}{|c|c|}
\hline 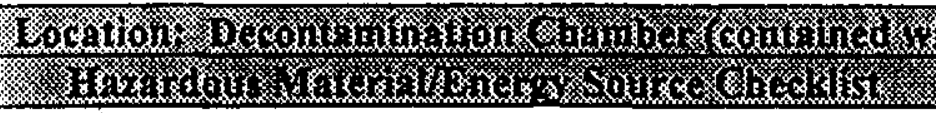 & 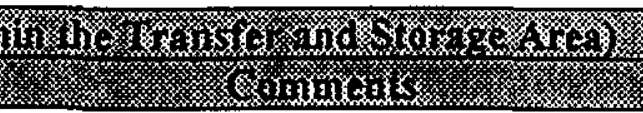 \\
\hline $\begin{array}{l}\text { Electrical } \\
\text { Electrical Equipment } \\
\text { High Voltage } \\
\text { Power Tools } \\
\text { Service outlets, Fittings } \\
\text { Wiring }\end{array}$ & 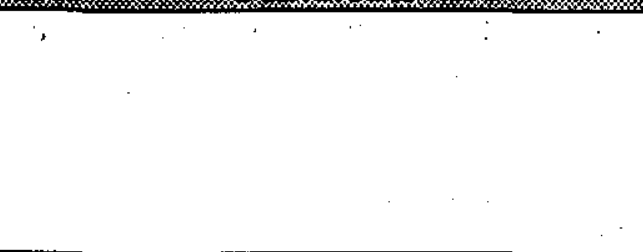 \\
\hline $\begin{array}{l}\text { Thermal } \\
\text { Steam lines } \\
\text { Power tools }\end{array}$ & \\
\hline $\begin{array}{l}\text { Friction } \\
\text { Power Tools }\end{array}$ & \\
\hline $\begin{array}{l}\text { Corrosives } \\
\text { Decon Solution }\end{array}$ & \\
\hline $\begin{array}{l}\text { Kinetic - Linear } \\
\text { Trucks; Electric Fork Lifts } \\
\text { Crane loads }\end{array}$ & ' \\
\hline $\begin{array}{l}\text { Mass, Gravity, Height } \\
\text { Crane } \\
\text { Truck }\end{array}$ & 4 \\
\hline $\begin{array}{l}\text { Pressure - Volume } \\
\text { Steam headers and lines }\end{array}$ & $\therefore \quad \cdots$ \\
\hline $\begin{array}{l}\text { Nuclear Criticality } \\
\text { Shipping and receiving area } \\
\text { Decon Solution }\end{array}$ & $-\cdots$ \\
\hline $\begin{array}{l}\text { Ionizing Radiation Sources } \\
\text { Radioactive Material }\end{array}$ & $\begin{array}{l}\text { There are two ion resin columns ( } 35-40 \text { gal. } \\
\text { capacity each) located next to the } \\
\text { decontamination chamber. They are used to } \\
\text { purify the water in the basins. The ion } \\
\text { columns use red bead resin (Donex). Extra } \\
\text { resin is stored in the basement. }\end{array}$ \\
\hline $\begin{array}{l}\text { Other } \\
\text { The Decontamination Chamber has not been in use for the past } \\
\text { five years. According to the BOE the equipment in the chamber } \\
\text { has been de-energized, but services and utilities have not been } \\
\text { isolated. }\end{array}$ & $\begin{array}{lllll} & \cdots & \cdots & \\
& \cdots & \cdots & \cdots\end{array}$ \\
\hline
\end{tabular}




\begin{tabular}{|c|c|}
\hline 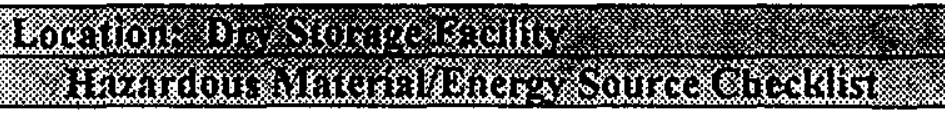 & (2) \\
\hline $\begin{array}{l}\text { Electrical } \\
\text { Motor }\end{array}$ & \\
\hline Kinetic-Linear & $\begin{array}{l}\text { A cask is used to transfer samples from the } \\
\text { storage facility to the cells. }\end{array}$ \\
\hline $\begin{array}{l}\text { Explosives/Pyrophorics } \\
\text { Hydrogen }\end{array}$ & \\
\hline $\begin{array}{l}\text { Nuclear Criticality } \\
\text { Storage racks }\end{array}$ & \\
\hline $\begin{array}{l}\text { Flammable Materials } \\
\text { Organics - Epoxy Mounts }\end{array}$ & \\
\hline $\begin{array}{l}\text { Ionizing Radiation Sources } \\
\text { Fissile material } \\
\text { Radioactive Material }\end{array}$ & $\begin{array}{l}432.7 \mathrm{~g} \mathrm{U}-235,319.5 \mathrm{~g} \mathrm{Pu}, 4,559.5 \mathrm{Ci} \mathrm{FP}, \\
701.3 \mathrm{~g} \text { Enriched U (<20\%) per HNF-3480 } \\
\text { Rev. } 0\end{array}$ \\
\hline Other & $\begin{array}{l}\text { Liquid was introduced into the dry storage } \\
\text { facility as the result of a past spill in the } \\
\text { canyon. The cans on the lower two racks } \\
\text { may diminished physical integrity. }\end{array}$ \\
\hline
\end{tabular}

\begin{tabular}{|c|c|}
\hline 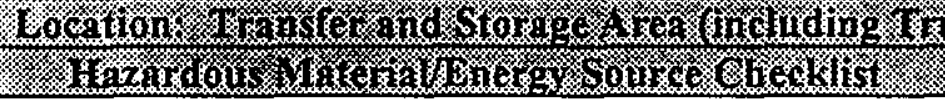 & 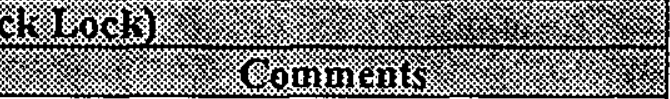 \\
\hline $\begin{array}{l}\text { Electrical } \\
\text { Electrical Equipment } \\
\text { Motors }\end{array}$ & (3) \\
\hline $\begin{array}{l}\text { Thermal } \\
\text { High pressure steam line along west end of the } 327 \text { Building }\end{array}$ & \\
\hline $\begin{array}{l}\text { Friction } \\
\text { Bearings } \\
\text { Motors }\end{array}$ & \\
\hline Kinetic-Rotational & \\
\hline $\begin{array}{l}\text { Kinetic-Linear } \\
\text { Truck, Electric Fork Lifts } \\
\text { Crane loads }\end{array}$ & \\
\hline $\begin{array}{l}\text { Mass, Gravity, Height } \\
\text { Crane } \\
\text { Trucks }\end{array}$ & \\
\hline $\begin{array}{l}\text { Nuclear Criticality } \\
\text { Shipping and receiving area } \\
\text { Trucks, forklifts } \\
\text { Cranes }\end{array}$ & \\
\hline $\begin{array}{l}\text { Flammable Materials } \\
\text { Lube oil } \\
\text { Diesel fuel }\end{array}$ & \\
\hline $\begin{array}{l}\text { Ionizing Radiation Sources } \\
\text { Fissile material } \\
\text { Radioactive Material }\end{array}$ & \\
\hline Other & \\
\hline
\end{tabular}




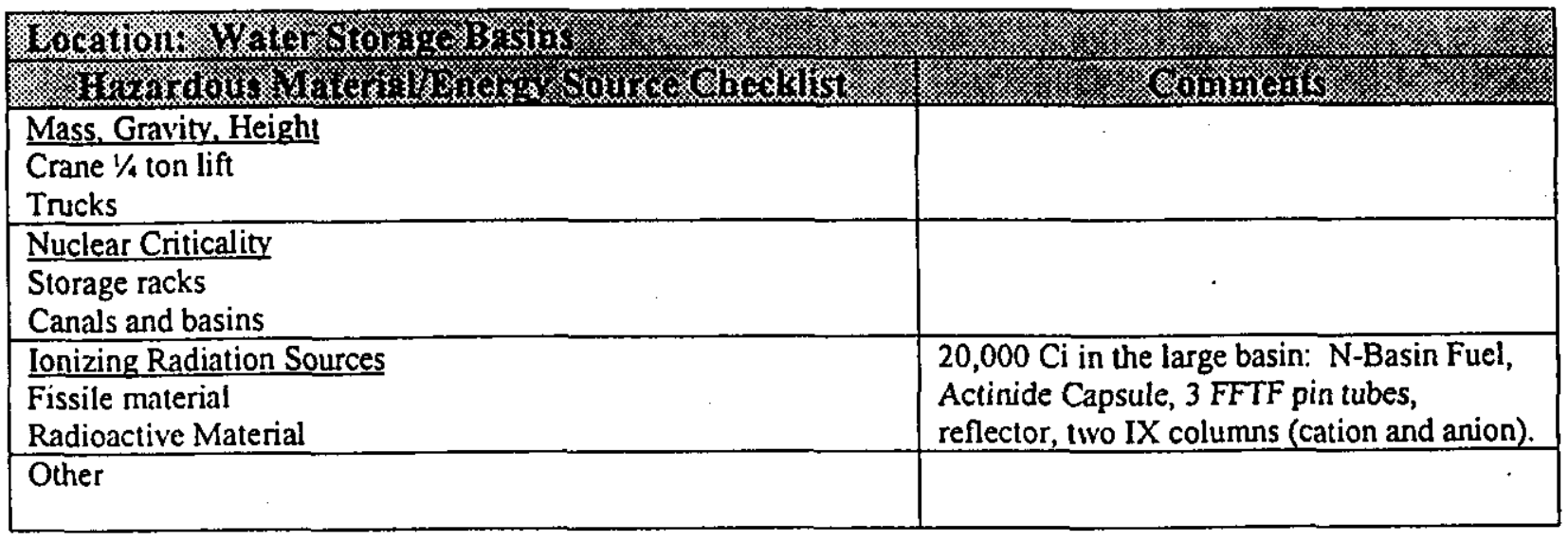

\begin{tabular}{|c|c|}
\hline 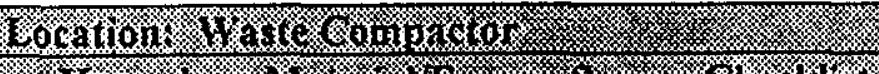 & 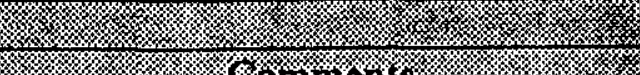 \\
\hline 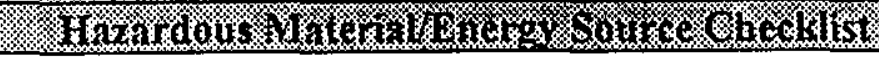 & r. \\
\hline $\begin{array}{l}\text { Electrical } \\
\text { Electrical Equipment } \\
\text { Motors }\end{array}$ & \\
\hline $\begin{array}{l}\text { Thermal } \\
\text { Electrical equipment }\end{array}$ & The compactor is not explosion proof rated. \\
\hline$\frac{\text { Kinetic-Rotational }}{\text { Motors }}$ & $\because$ \\
\hline $\begin{array}{l}\text { Kinetic-Linear } \\
\text { Ram for the compactor }\end{array}$ & +2 \\
\hline $\begin{array}{l}\text { Flammable Materials } \\
\text { Waste materiäs to be compacted. } \\
\text { Lube oil } \\
\text { Grease }\end{array}$ & $\begin{array}{l}20 \text { gallons of oil in waste compactor. The } \\
\text { FHA states } 15 \text { drums may be stored in this } \\
\text { area. Personnel indicated that the most that } \\
\text { would normally be stored in this area is } \\
\text { seven to ten drums. }\end{array}$ \\
\hline $\begin{array}{l}\text { Ionizing Radiation Sources } \\
\text { Radioactive Material }\end{array}$ & \\
\hline Other & \\
\hline
\end{tabular}




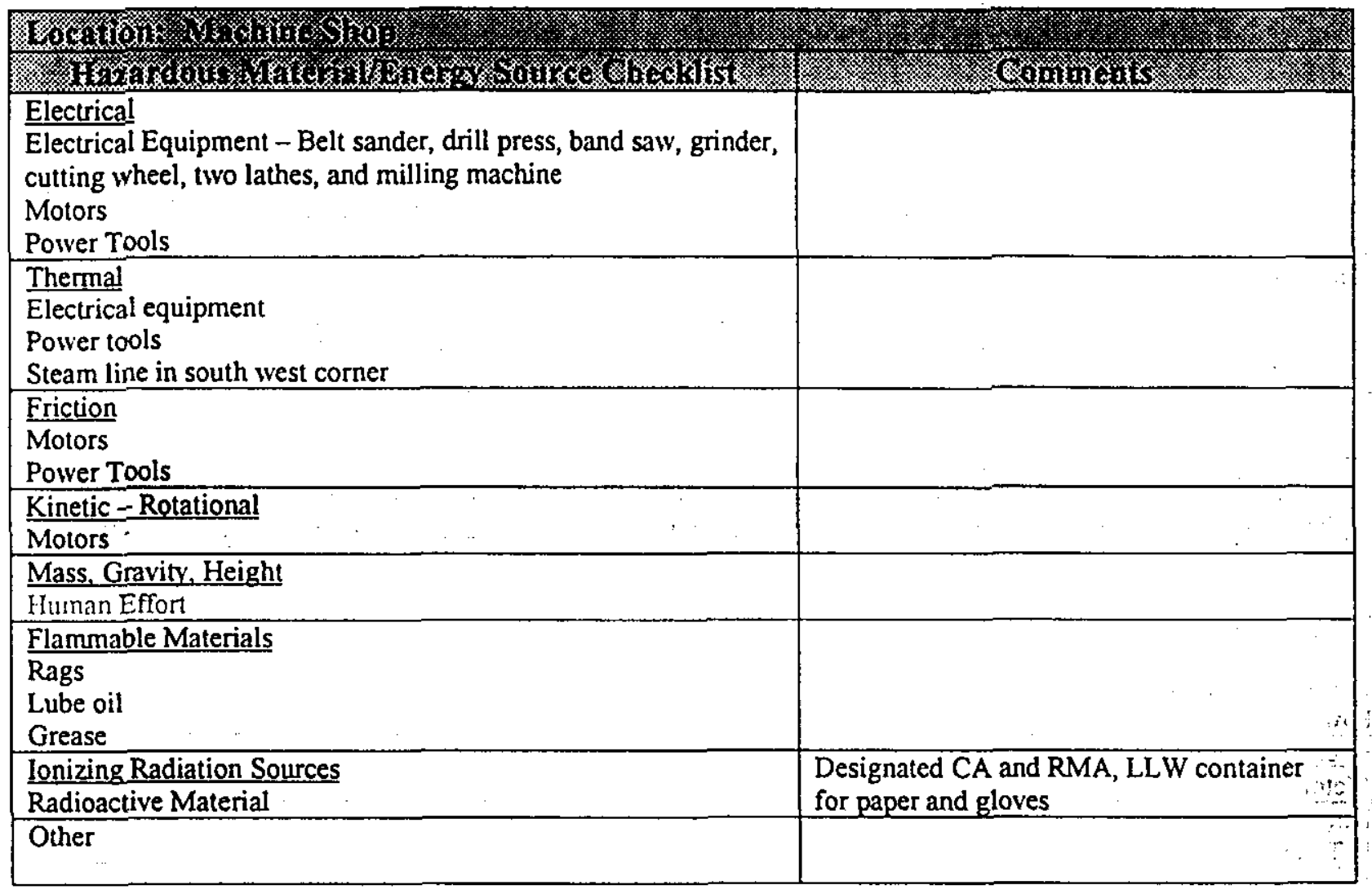




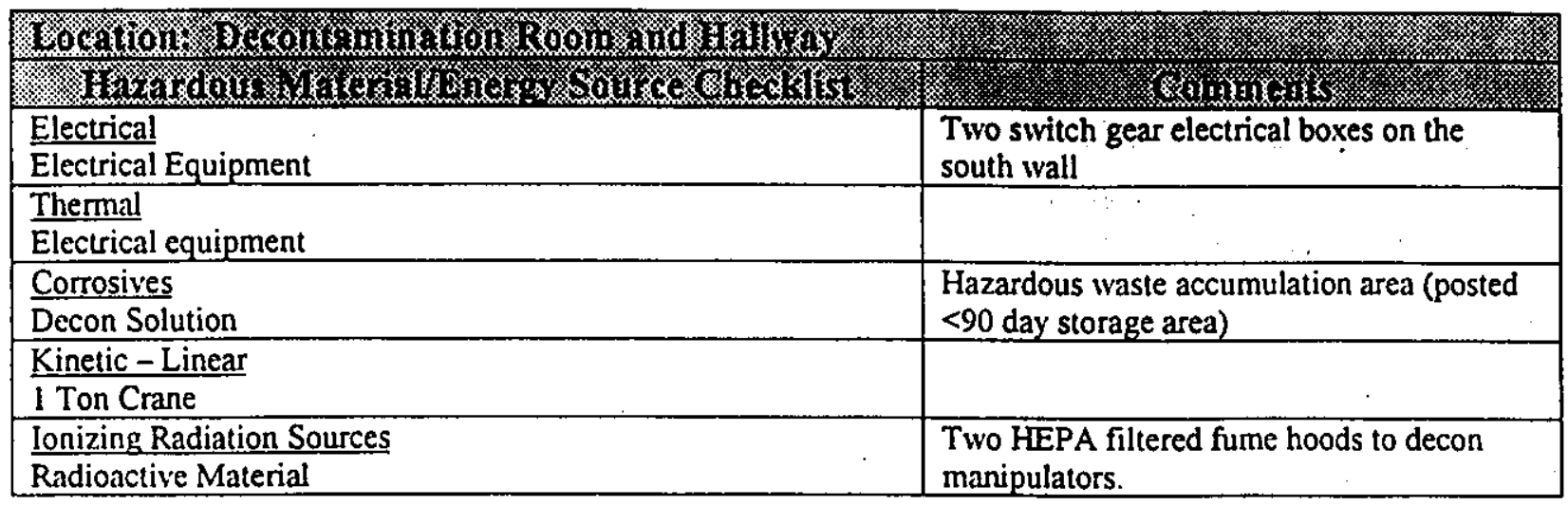

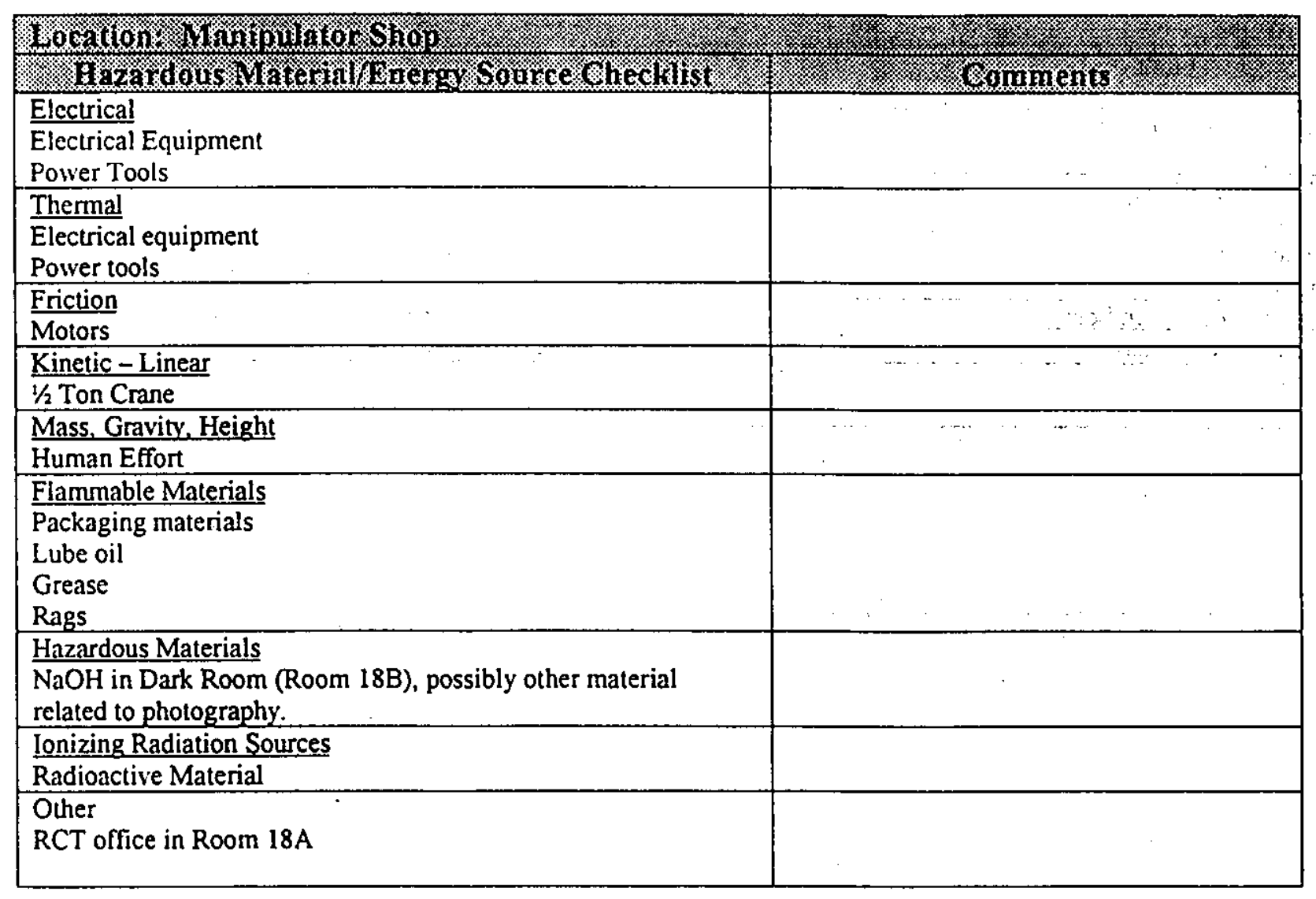




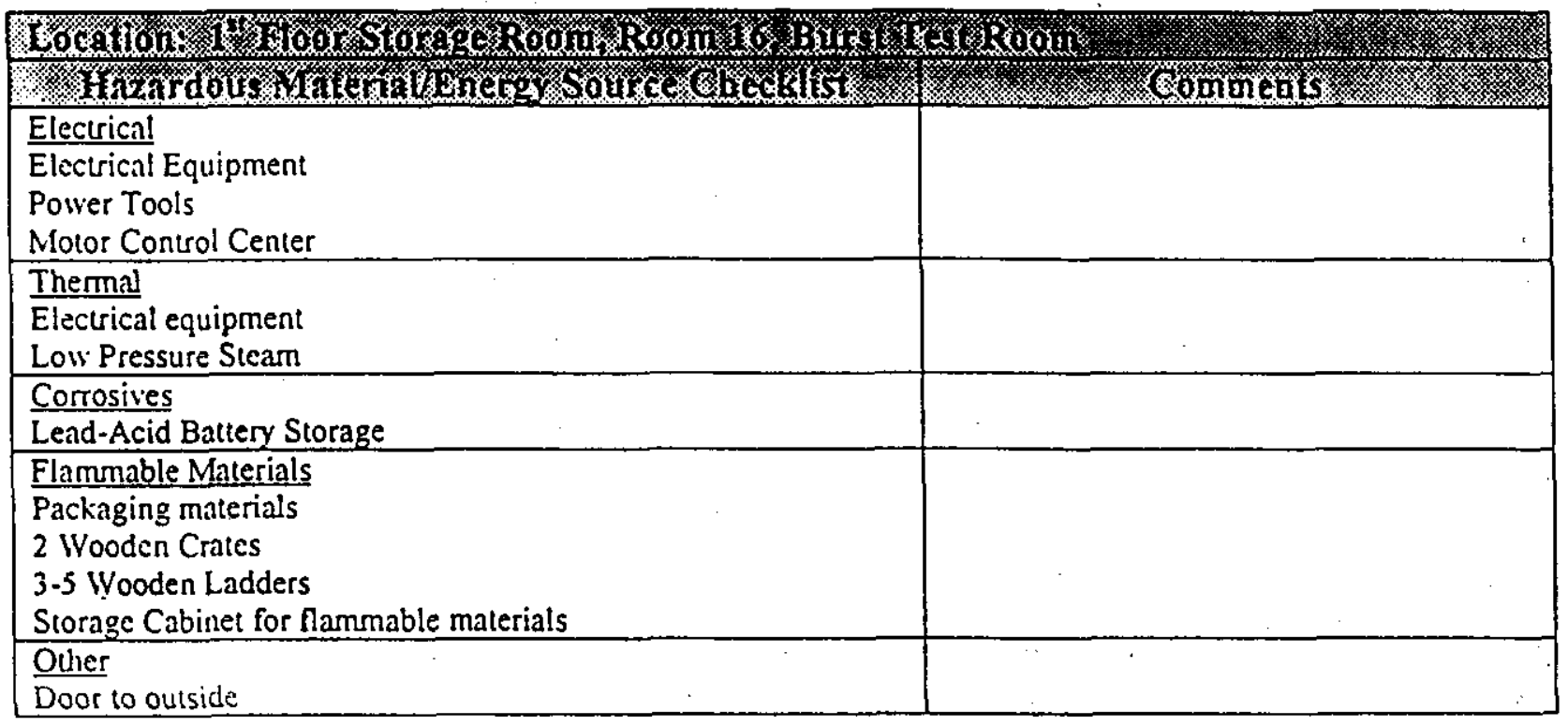

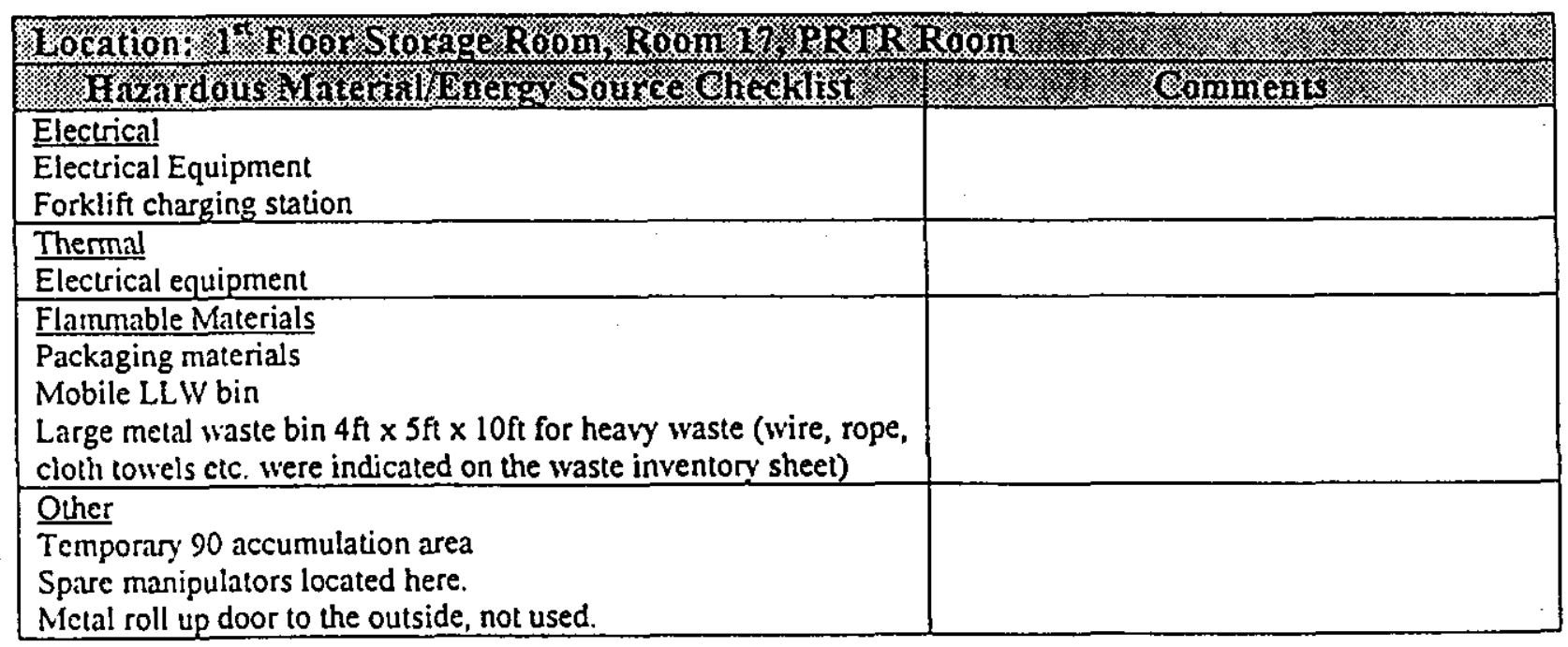




\begin{tabular}{|c|c|}
\hline \multicolumn{2}{|l|}{ 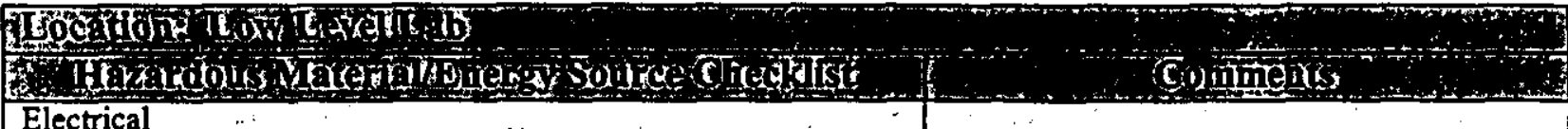 } \\
\hline $\begin{array}{l}\text { Electrical } \\
\text { Electrical Equipment } \\
\text { Computers }\end{array}$ & \\
\hline $\begin{array}{l}\text { Thermal } \\
\text { Electrical equipment }\end{array}$ & \\
\hline $\begin{array}{l}\text { Corrosives } \\
\text { Decon Solution }\end{array}$ & $\begin{array}{l}\text { Fume hood located in this room, is not in } \\
\text { active use except for small quantities of } \\
\text { chemicals stored in bottles located in the } \\
\text { hood. }\end{array}$ \\
\hline $\begin{array}{l}\text { Flammable Materials } \\
\text { Isopropyl Alcohol } \\
\text { Epoxy Fixative } \\
\text { Rags }\end{array}$ & $\begin{array}{l}\text { Up to } 500 \mathrm{~mL} \text { of Isopropyl Alcohol routinely } \\
\text { allowed in the cells. The introduction of } \\
\text { other chemicals requires approval. }\end{array}$ \\
\hline $\begin{array}{l}\text { lonizing Radiation Sources } \\
\text { Radioactive Material }\end{array}$ & $\begin{array}{l}\text { The tour reveled that low level waste was } \\
\text { being packaged in this room. }\end{array}$ \\
\hline $\begin{array}{l}\text { Other } \\
\text { A metal storage cabinet was located in this room which contained } \\
\text { a small quantity of ordinary combustibles. }\end{array}$ & \\
\hline
\end{tabular}




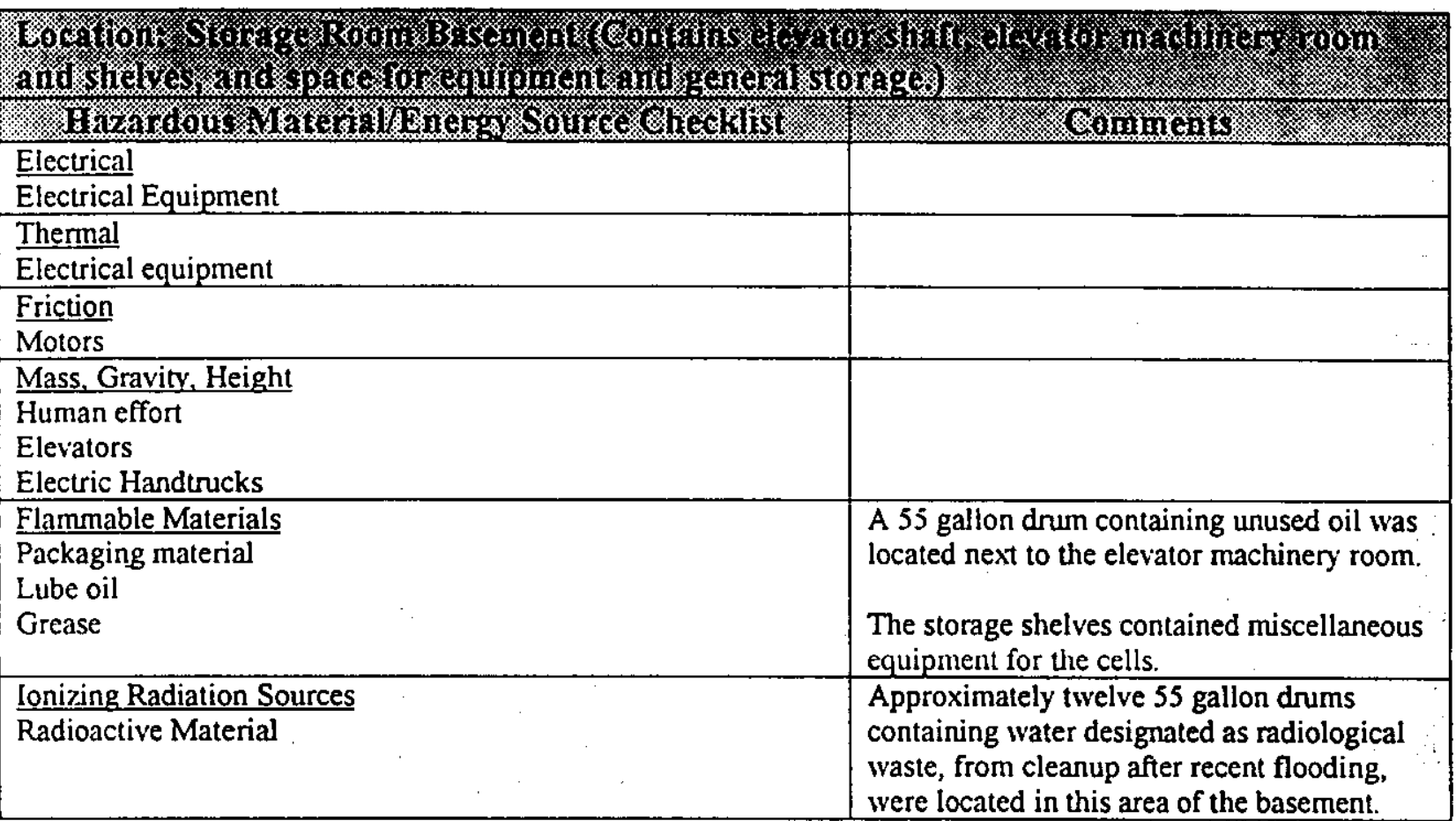

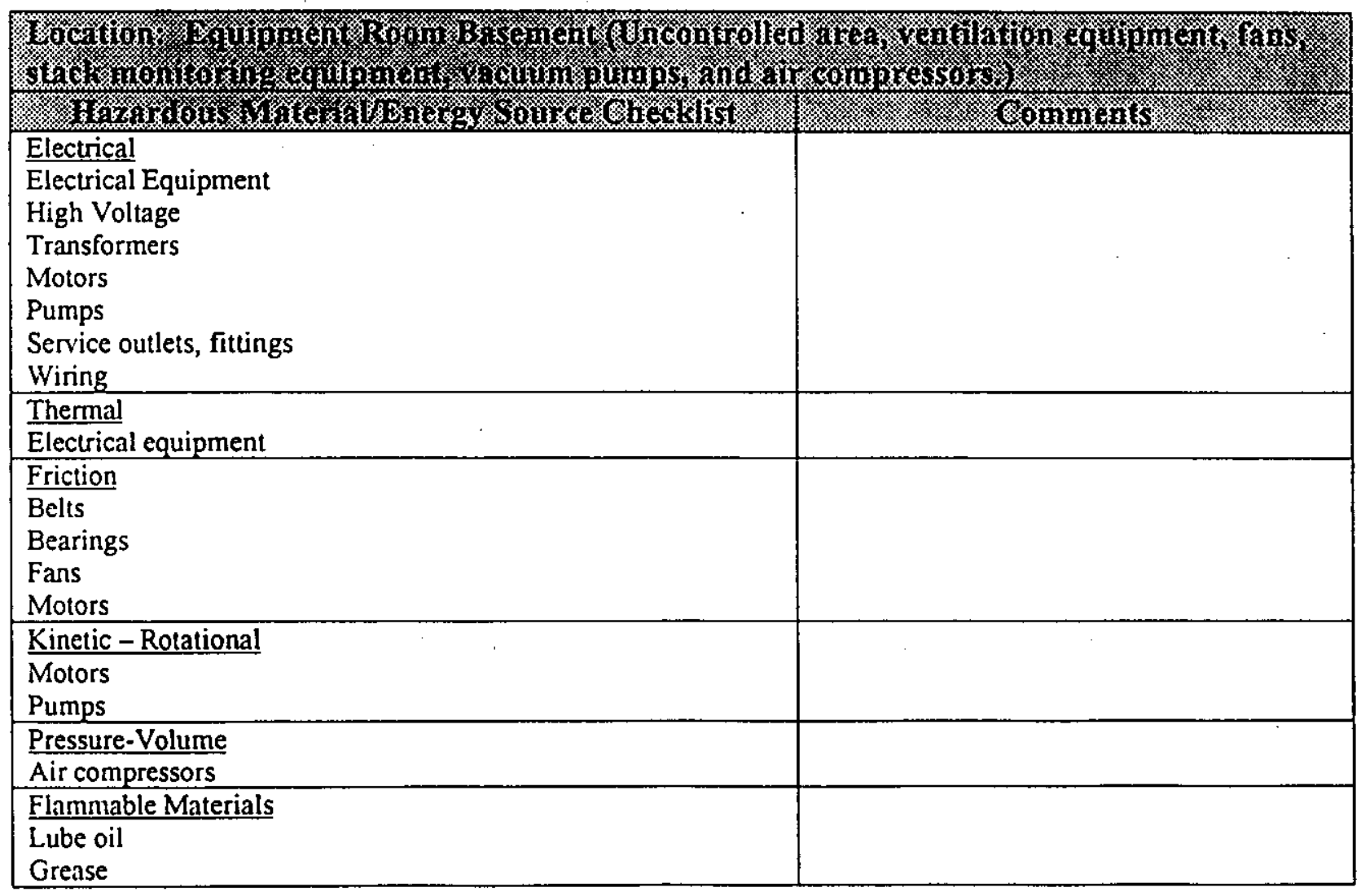




\begin{tabular}{|c|c|}
\hline 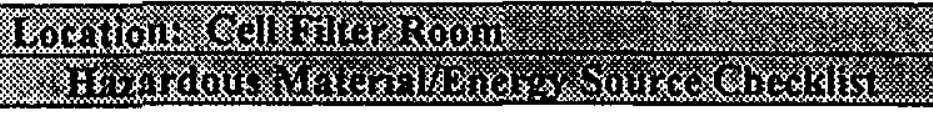 & 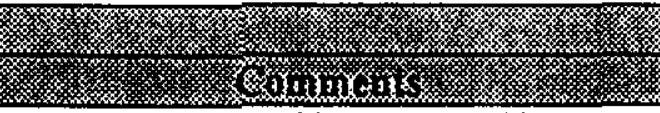 \\
\hline $\begin{array}{l}\text { Electrical } \\
\text { Electrical Equipment } \\
\text { High Voltage } \\
\text { Switchgear } \\
\text { Wiring } \\
\end{array}$ & $\begin{array}{l}\text { An arc-welding machine was stored in the } \\
\text { basement. }\end{array}$ \\
\hline $\begin{array}{l}\text { Thermal } \\
\text { Electrical equipment }\end{array}$ & \\
\hline $\begin{array}{l}\text { Mass, Gravity, Height } \\
\text { Human Effort }\end{array}$ & \\
\hline Nuclear Criticality & \\
\hline $\begin{array}{l}\text { Flammable Materials } \\
\text { Charcoal Filters } \\
\text { Packing Materials } \\
\text { Eight } 2 \text { " } \times 10^{\prime \prime} \times 8 \text { ' scaffolding boards in the SE corner. } \\
\text { Shelf with log books were also located in the SE comer. } \\
\text { Three } 40 \text { gallon cardboard drums of Donex ion exchange resin } \\
\text { beads were stored along the south wall ( } 20 \text { ft from the SE corner). }\end{array}$ & $\begin{array}{l}\text { Building personnel indicated that differential } \\
\text { pressure readings indicate that there is no } \\
\text { charcoal media in the filters at this time. } \\
\text { PVC tubes for storing manipulators were } \\
\text { located underricath duct work and beside } \\
\text { filter houses. }\end{array}$ \\
\hline $\begin{array}{l}\text { Ionizing Radiation Sources } \\
\text { Radioactive Material }\end{array}$ & $\begin{array}{l}\text { Approximately ten } 55 \text { gallon drums } \\
\text { containing water designated as radiological } \\
\text { waste, from cleanup after recent flooding, } \\
\text { were located in this area of the basement. } \\
\text { Temporary radiation shielding was located } \\
\text { undemeath some of the cells and around the } \\
\text { associated HEPA filters. Building personnel } \\
\text { indicated that a concrete box in this area } \\
\text { contained } 39 \text { legacy waste cans (with a } \\
\text { conservative estimate given of } 1 \text { g plutonium } \\
\text { per can). The other two boxes contained } \\
\text { used HEPA filters. }\end{array}$ \\
\hline
\end{tabular}




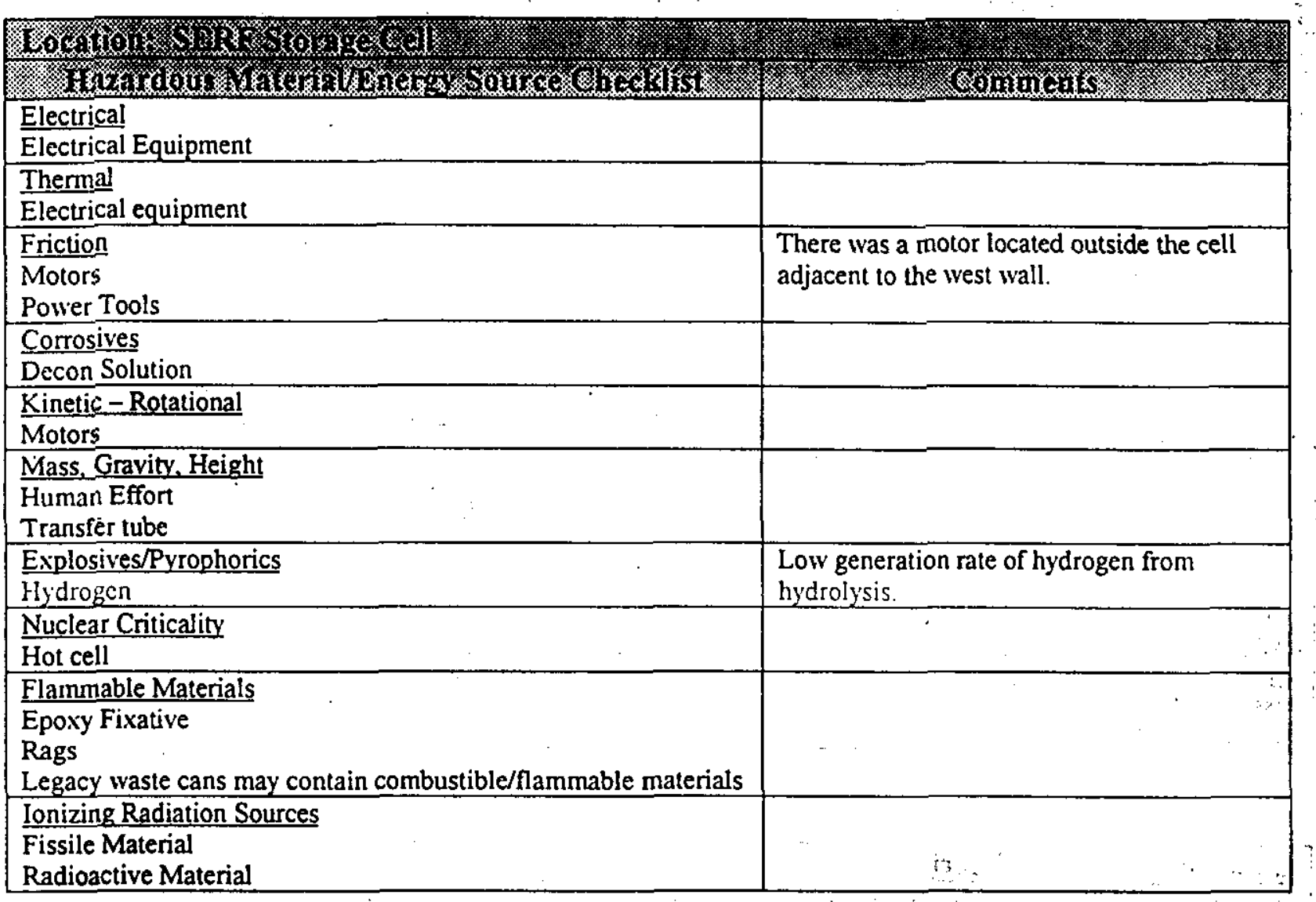




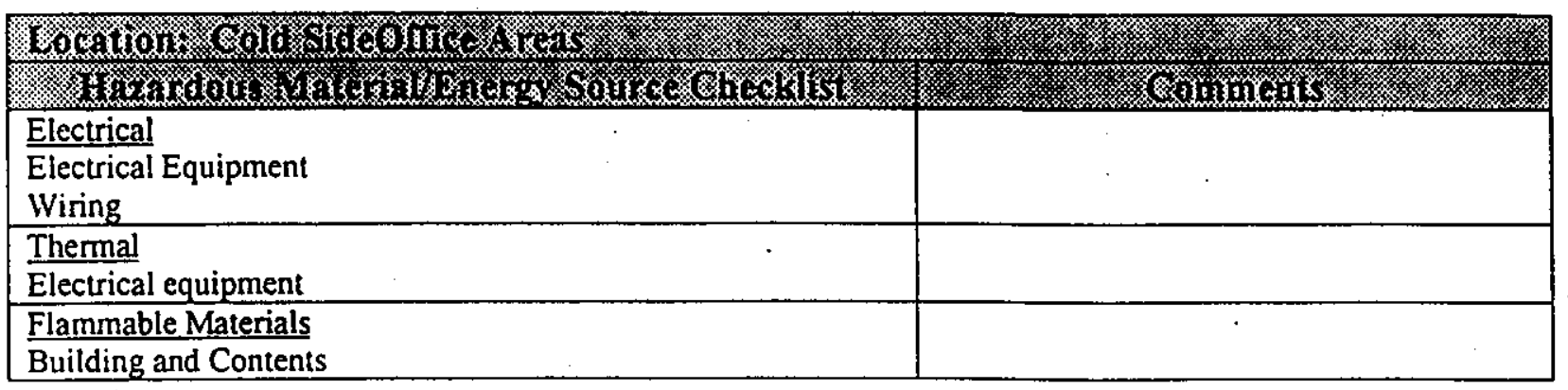

\begin{tabular}{|c|c|}
\hline 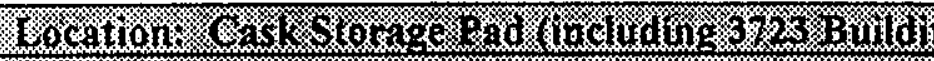 & \\
\hline 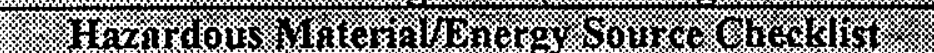 & Comments \\
\hline $\begin{array}{l}\text { Cortosives } \\
\text { Acids } \\
\text { Solvents }\end{array}$ & $\begin{array}{l}\text { Minor quantities of acids and solvents are } \\
\text { stored in Building } 3723 \text {. A hazardous } \\
\text { material inventory is maintained for the } \\
\text { Building. }\end{array}$ \\
\hline $\begin{array}{l}\text { Nuclear Criticality } \\
\text { Temporary storage areas }\end{array}$ & \\
\hline $\begin{array}{l}\text { Ionizing Radiation Sources } \\
\text { Fissile Material } \\
\text { Radioactive Material }\end{array}$ & $\begin{array}{l}\text { Drums of waste were stored on wooden } \\
\text { pallets. }\end{array}$ \\
\hline
\end{tabular}

\begin{tabular}{|c|c|}
\hline 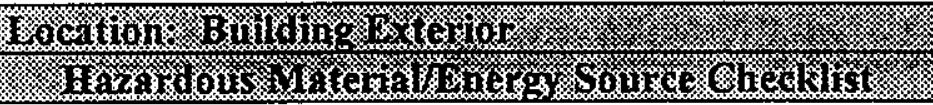 & (1) \\
\hline $\begin{array}{l}\text { Electrical } \\
\text { Transformers }\end{array}$ & \\
\hline$\frac{\text { Thermal }}{\text { Cryogenic }}$ & $\begin{array}{l}\text { Liquid nitrogen storage tank (capacity } 6,000 \\
\text { gallons). }\end{array}$ \\
\hline $\begin{array}{l}\text { Kinetic-Linear } \\
\text { Cars, trucks, buses } \\
\text { Forklifts, dollies, carts }\end{array}$ & \\
\hline $\begin{array}{l}\text { Mass, Gravity, Height } \\
\text { Trucks } \\
\text { Lifts and cranes }\end{array}$ & \\
\hline $\begin{array}{l}\text { Pressure - Volume } \\
\text { Compressed Gas storage area }\end{array}$ & $\begin{array}{l}\text { A number of cylinders of P-10 gas were } \\
\text { located on the loading dock. Also there were } \\
\text { some other non-flammable gasses such as } \\
\text { argon and } 3 \% \text { hydrogen in helium. }\end{array}$ \\
\hline $\begin{array}{l}\text { Ionizing Radiation Sources } \\
\text { Fissile Material } \\
\text { Radioactive Material }\end{array}$ & $\begin{array}{l}\text { Waste drums were stored in a fenced area on } \\
\text { the southwest comer of the } 327 \text { Building. } \\
\text { There was a radiological buffer area chain set } \\
\text { up around the drums. }\end{array}$ \\
\hline
\end{tabular}




\section{Appendix B}

\section{Preliminary Hazard Analysis}




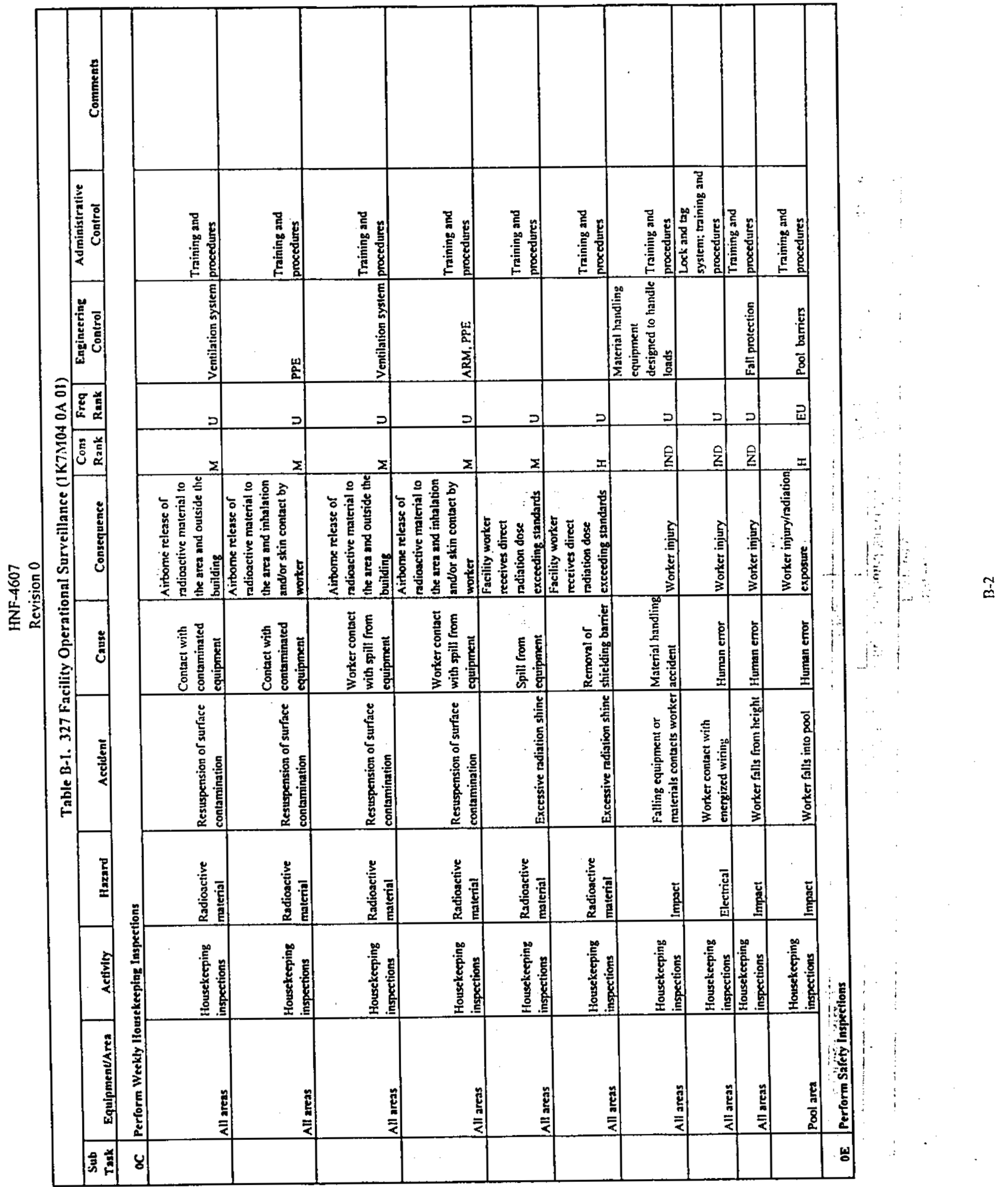




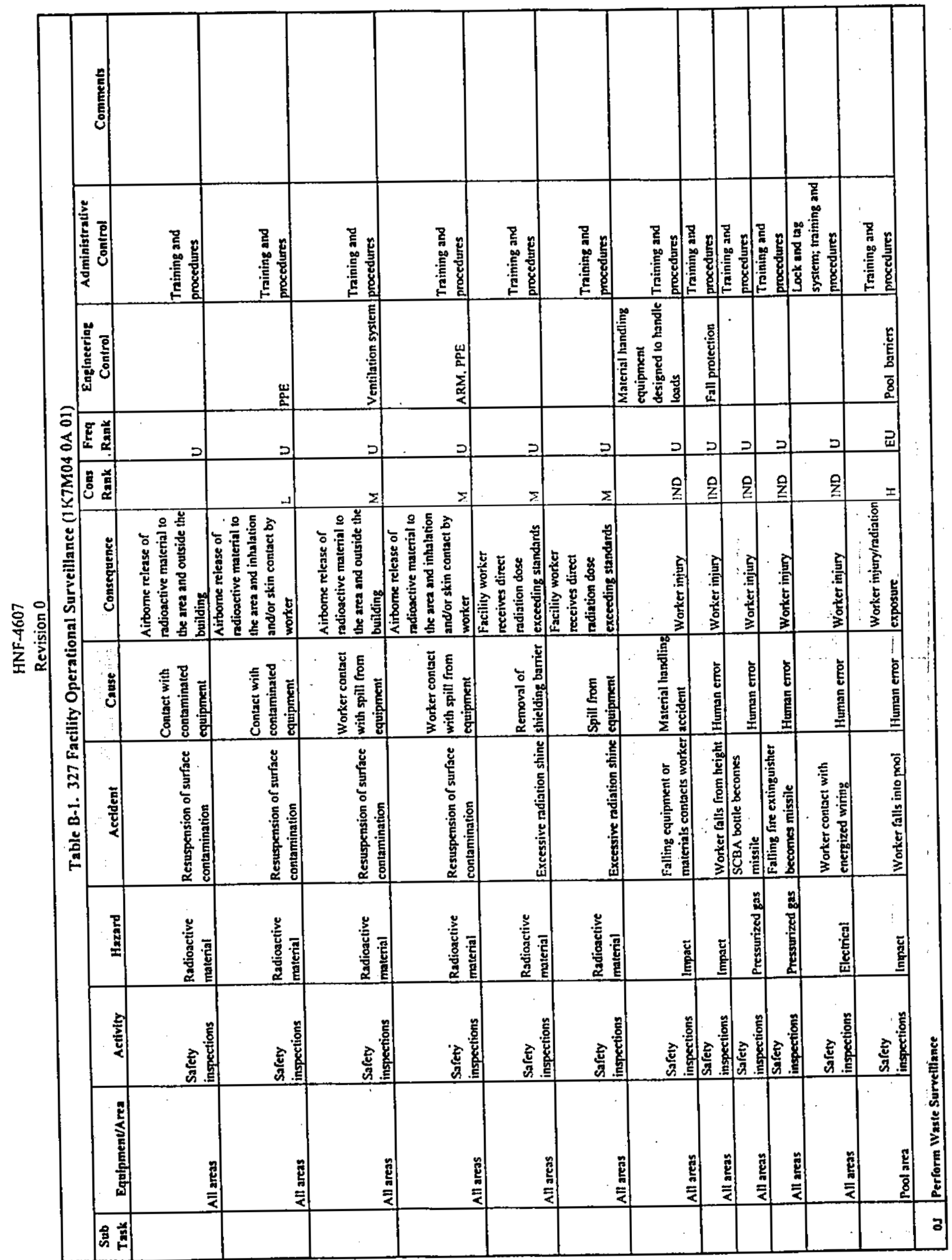




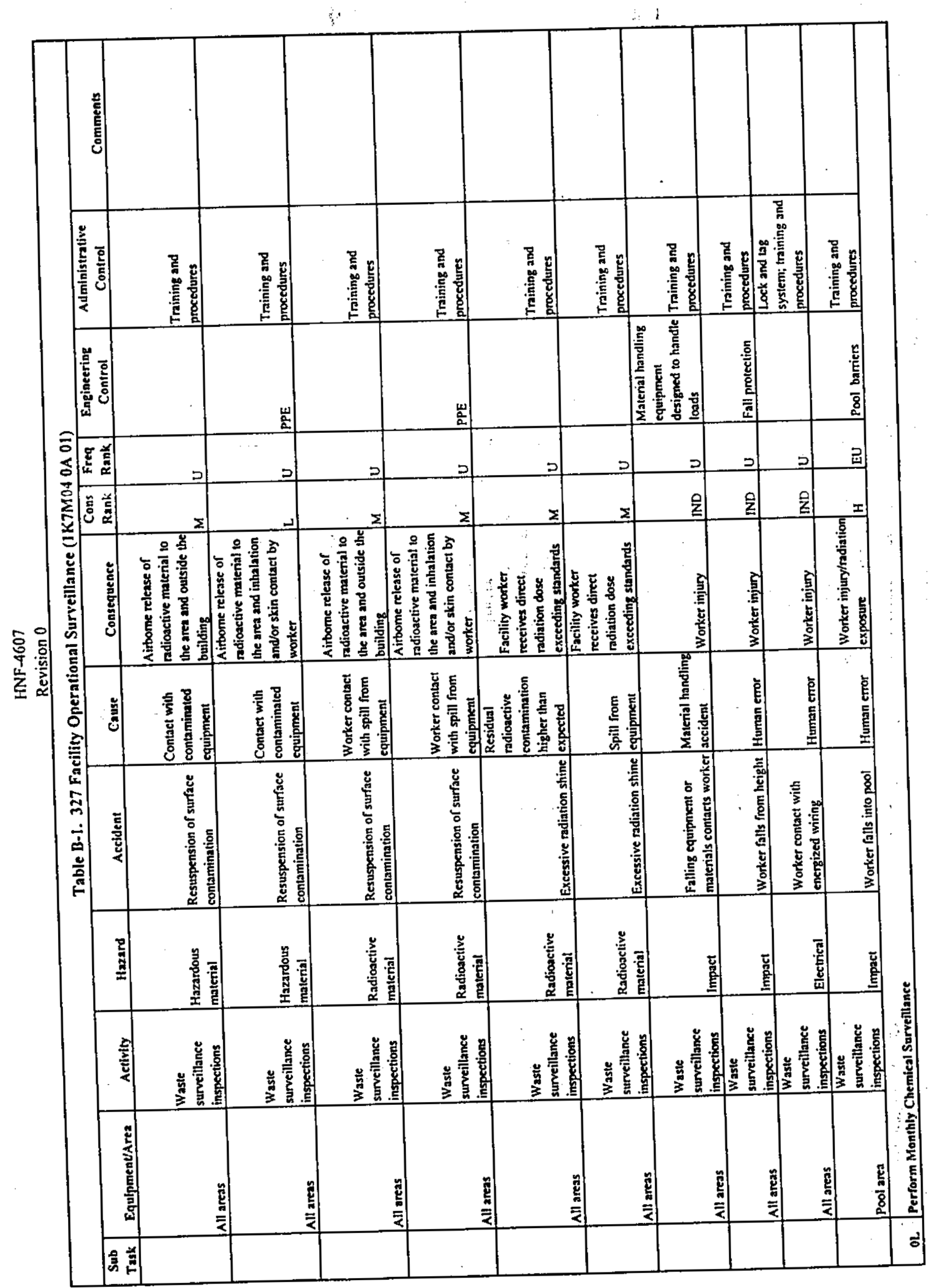




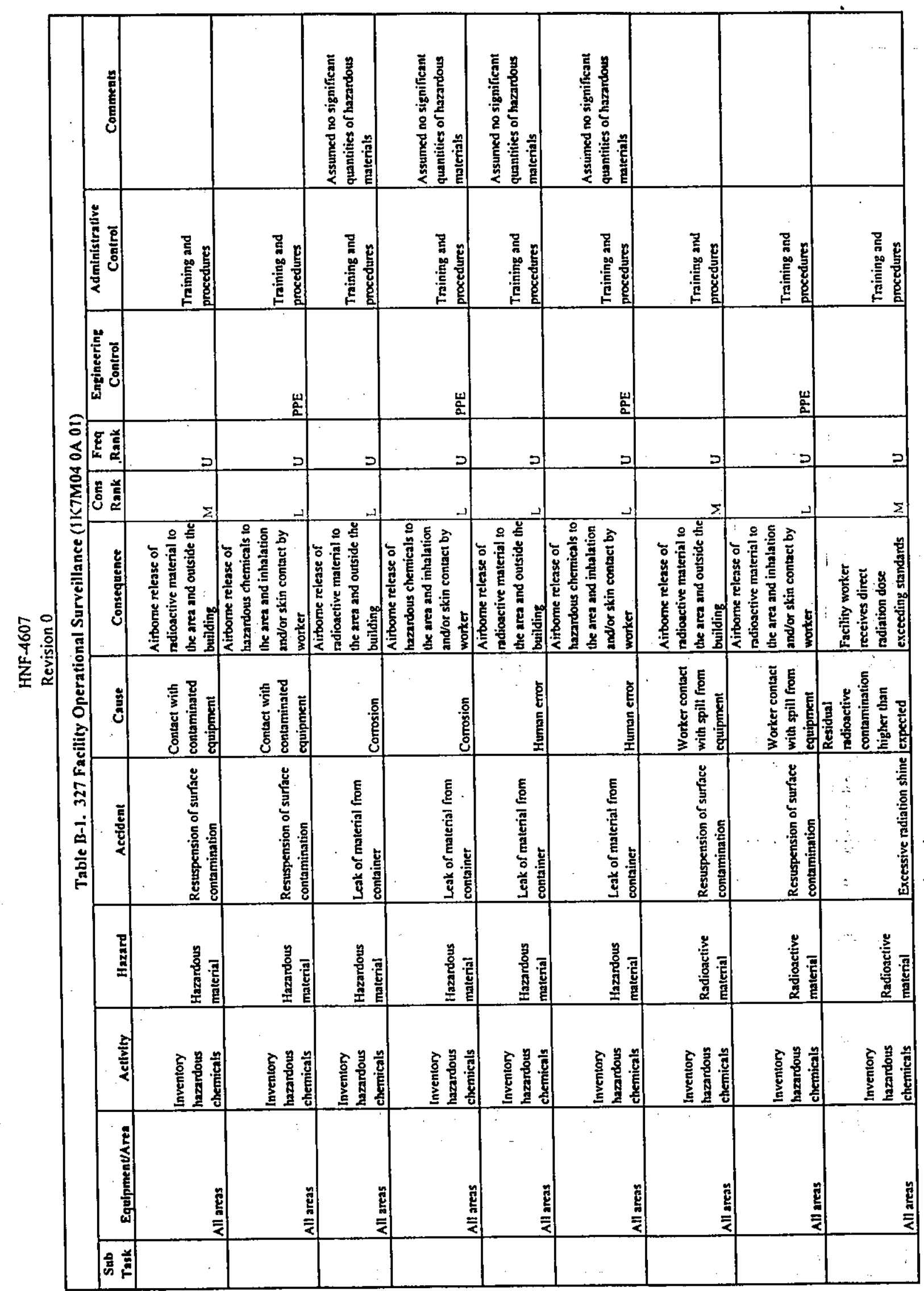




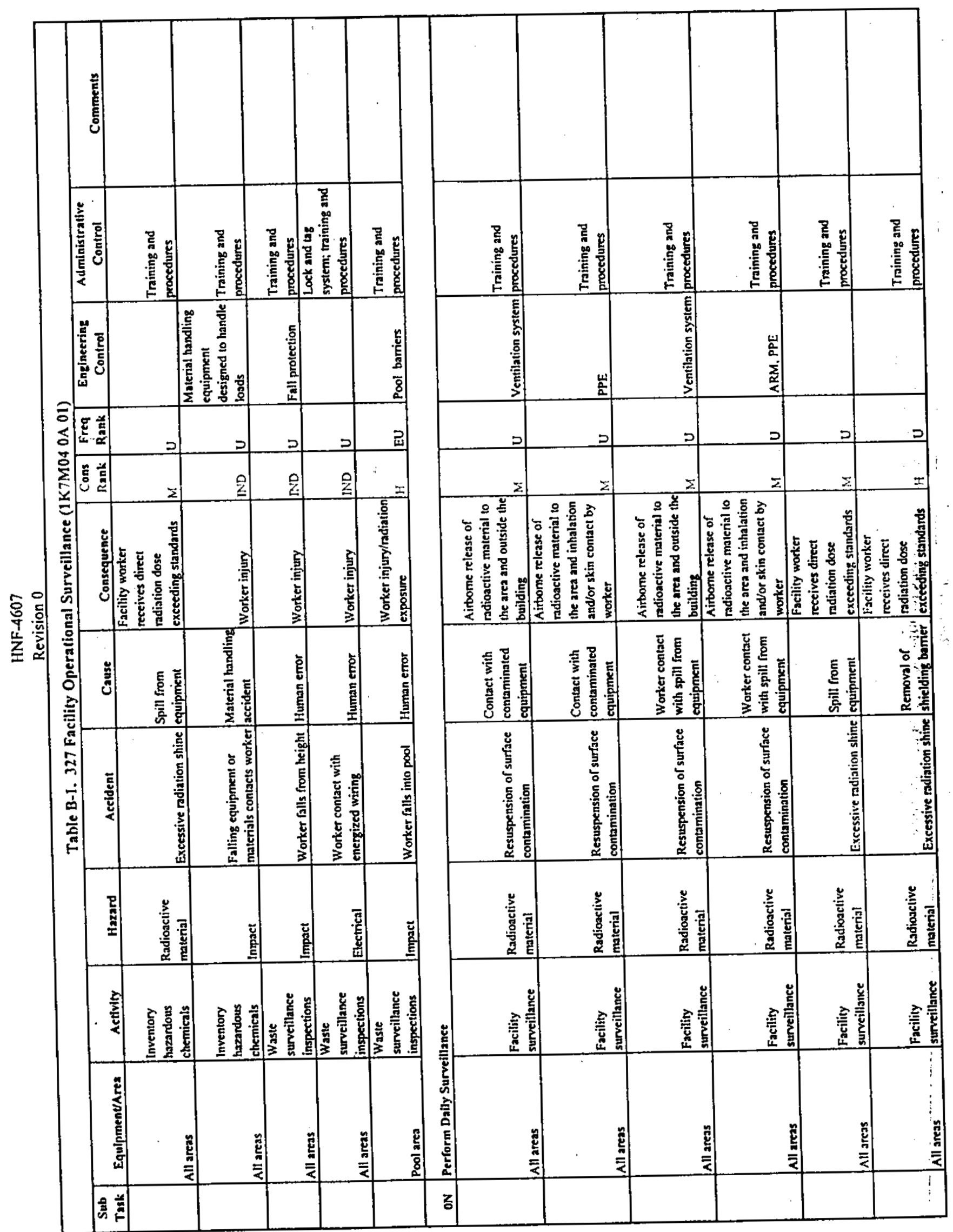




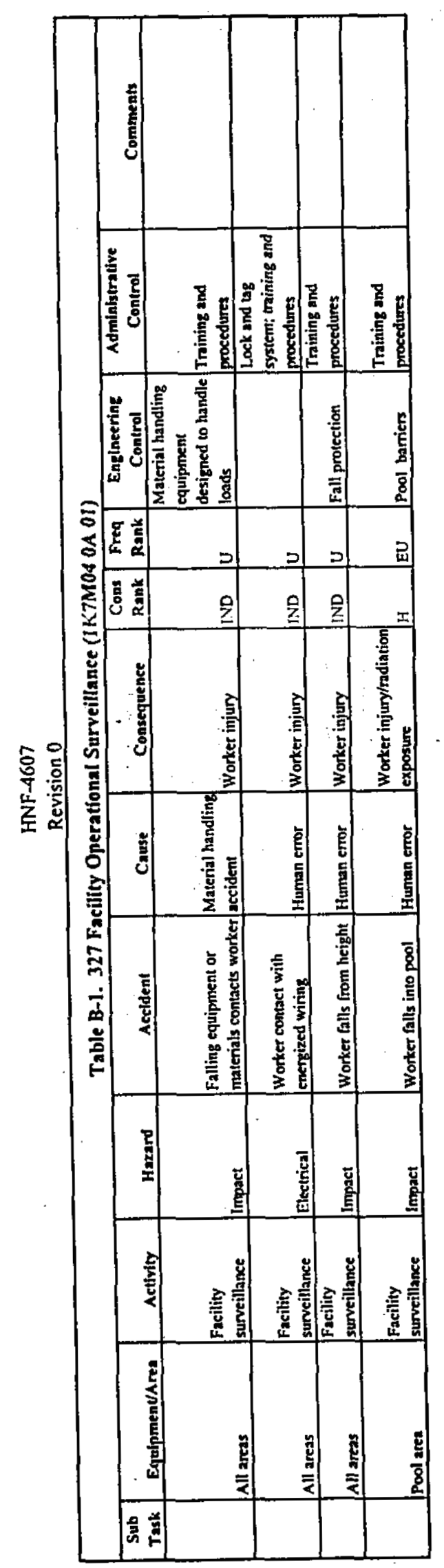




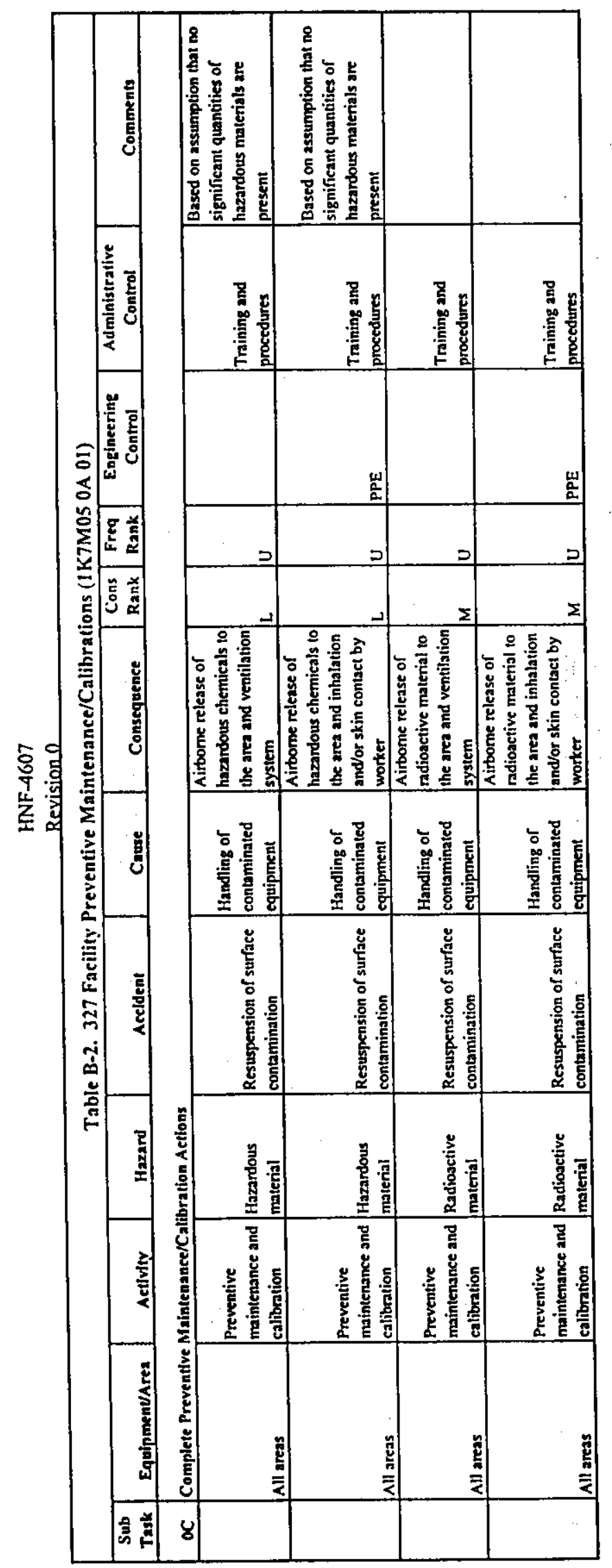




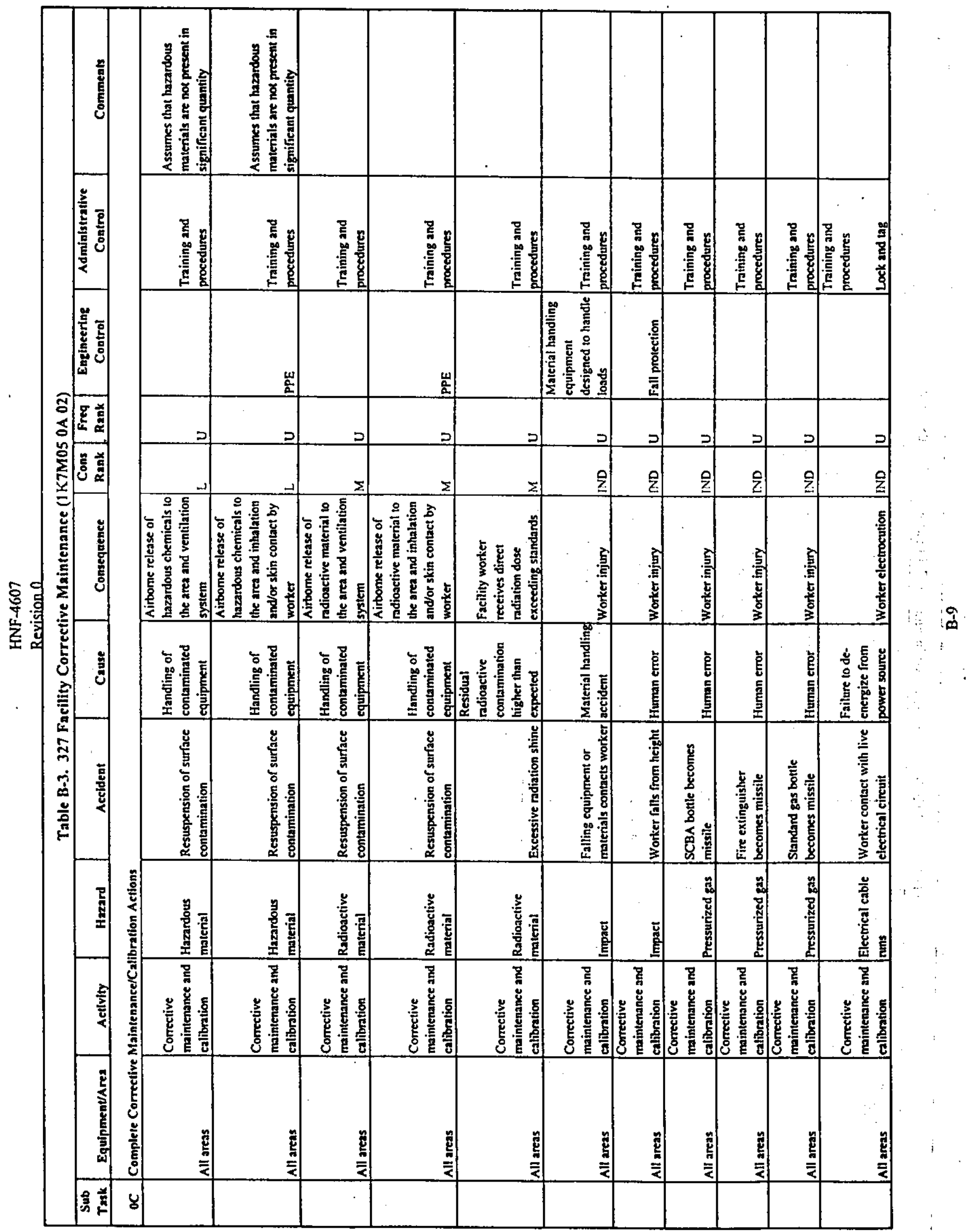




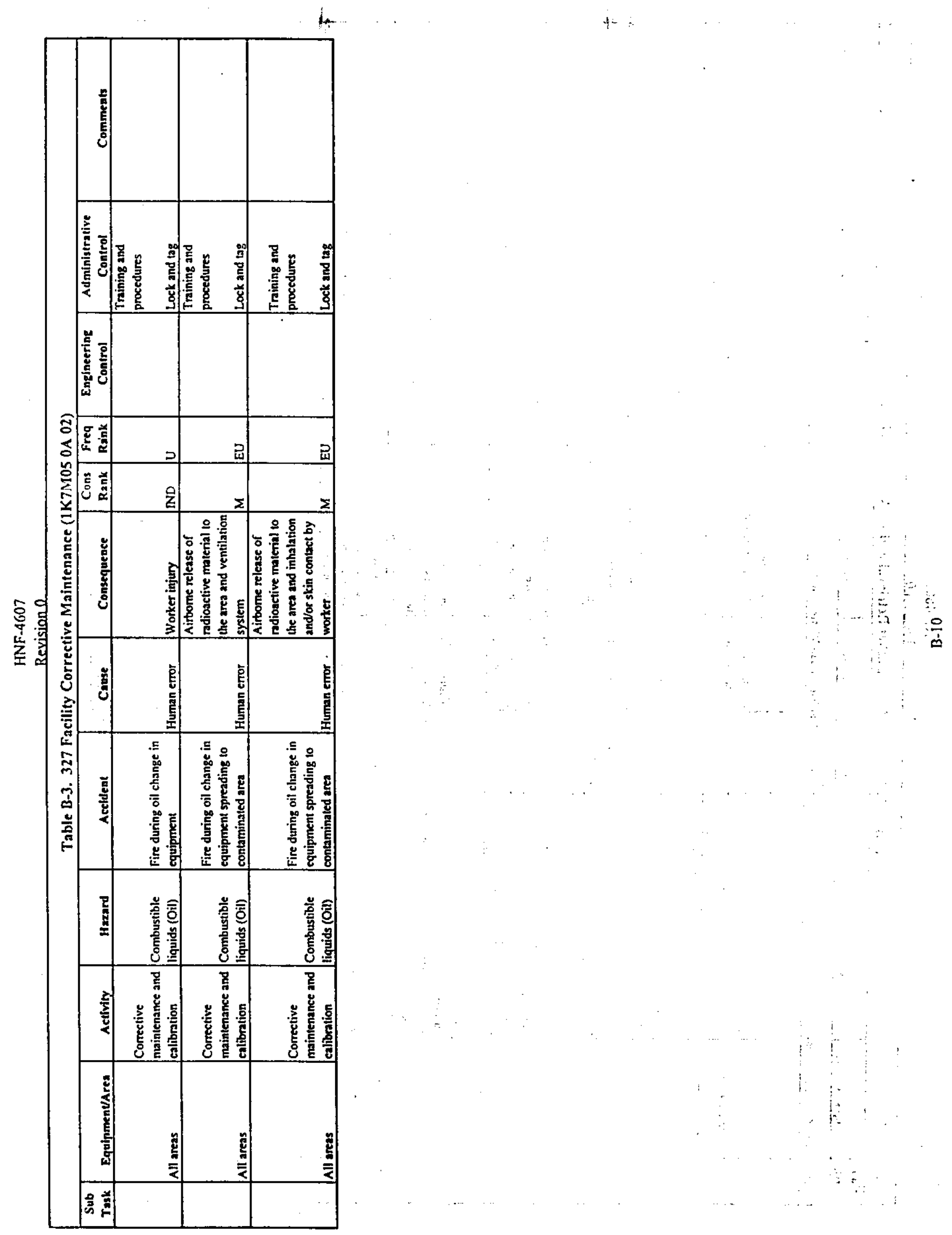




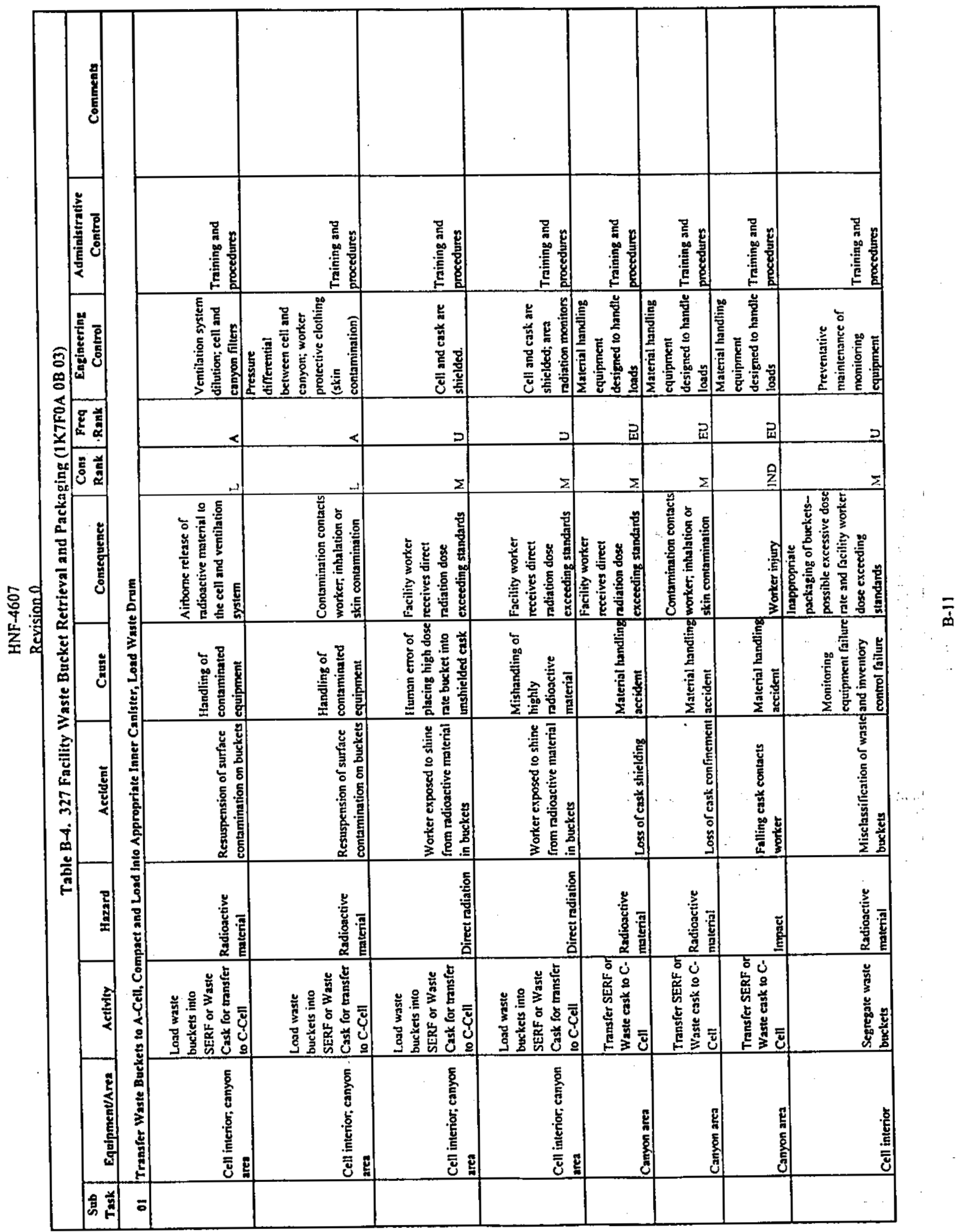




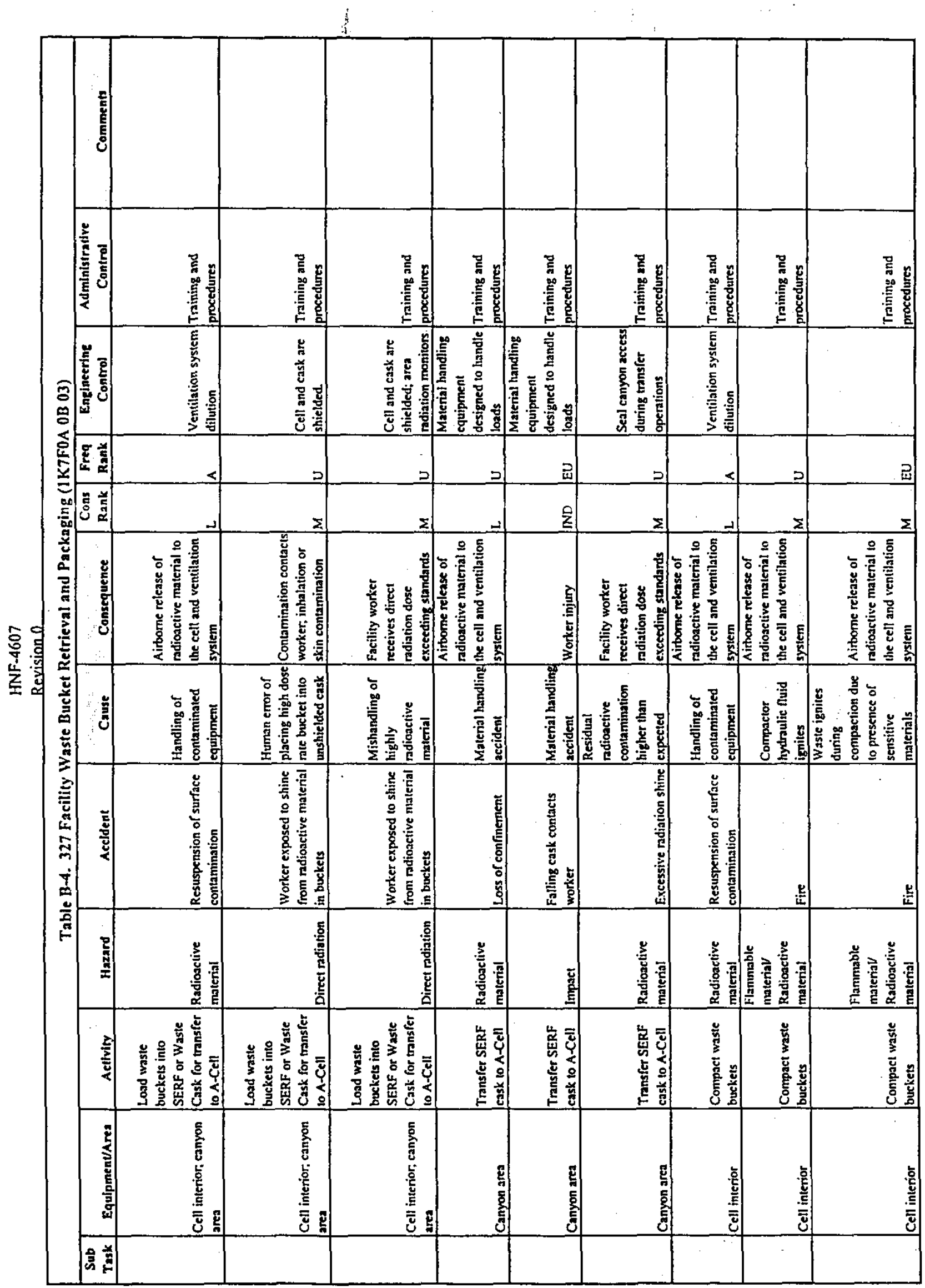




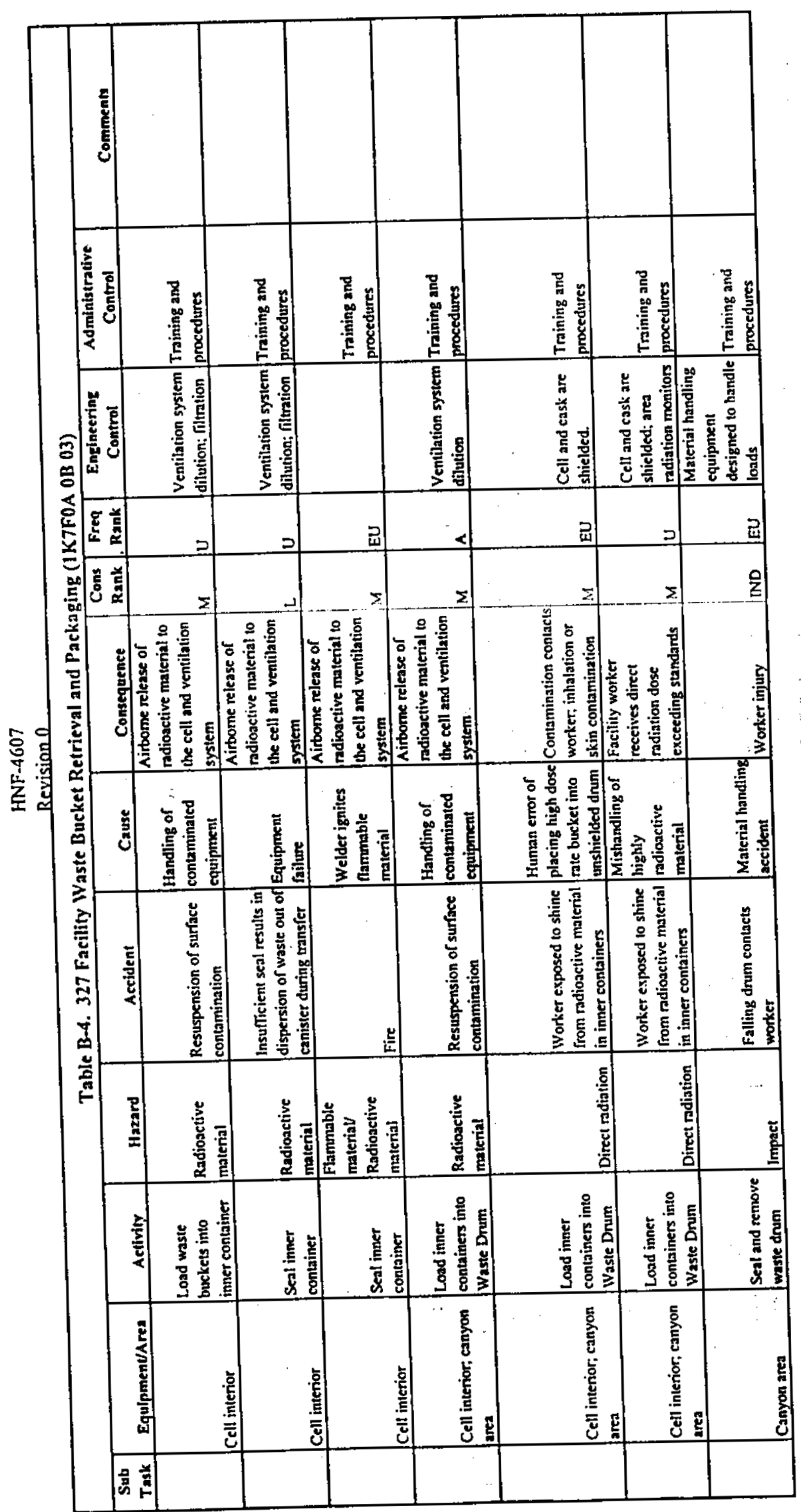

$\frac{m}{m}$ 


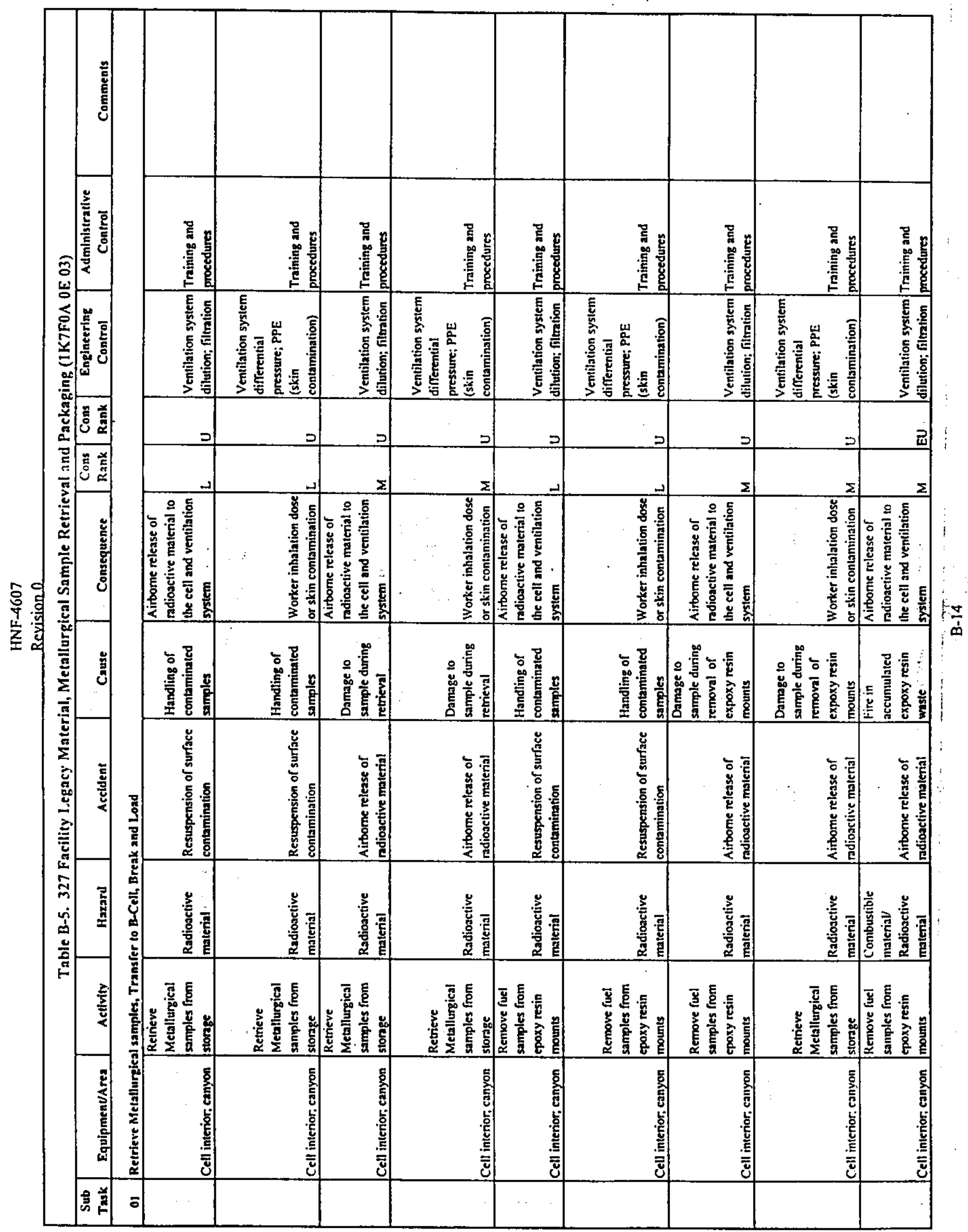




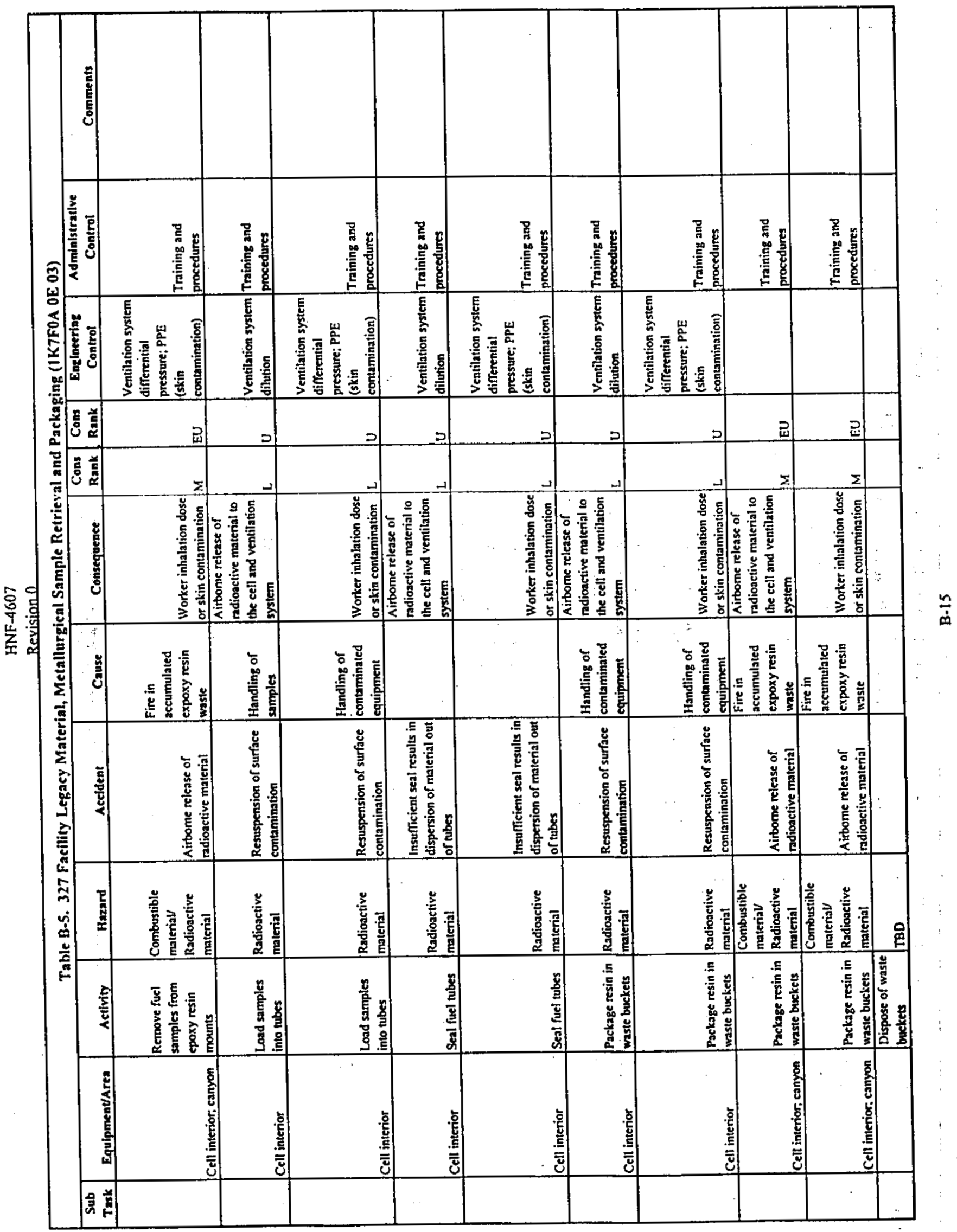




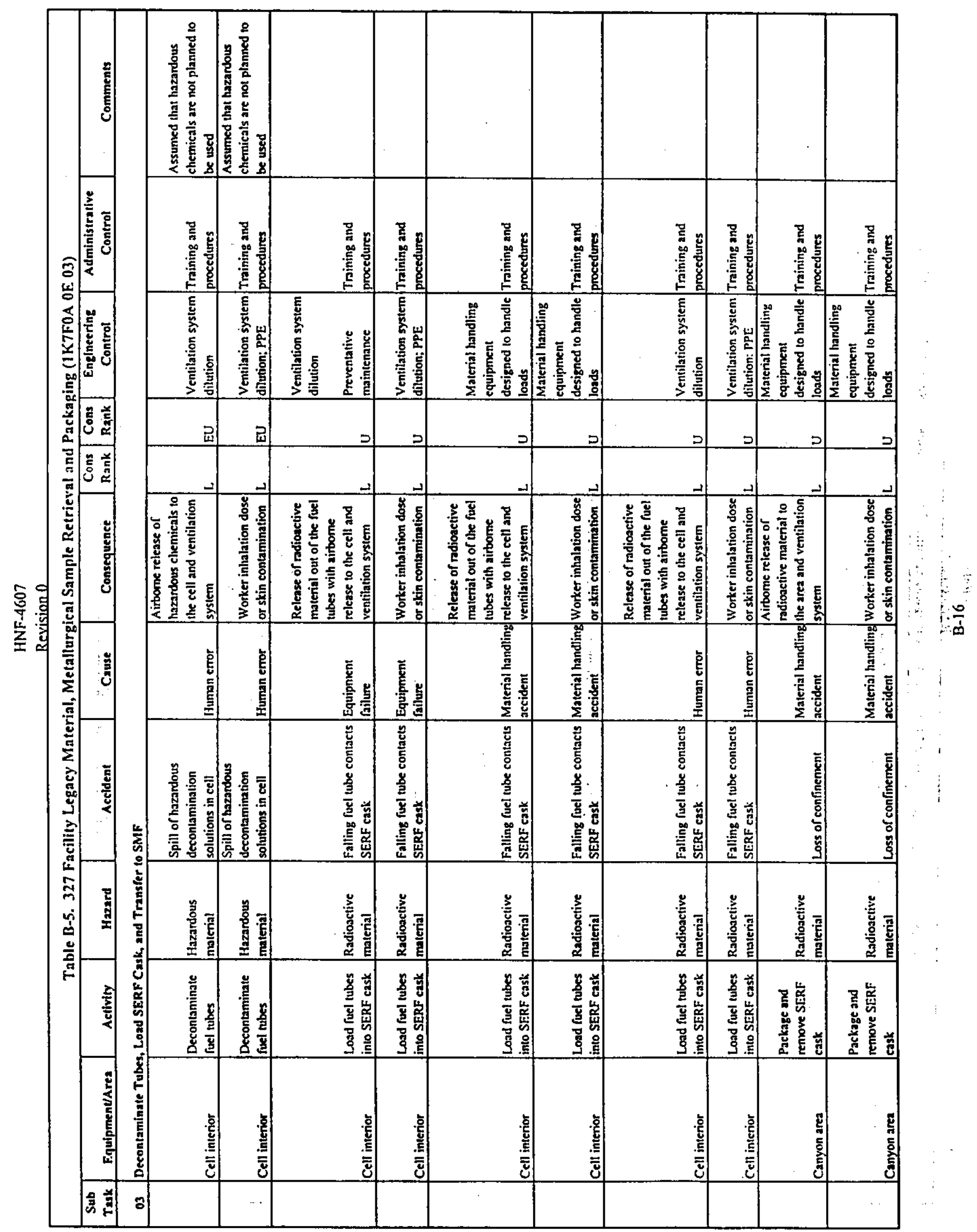




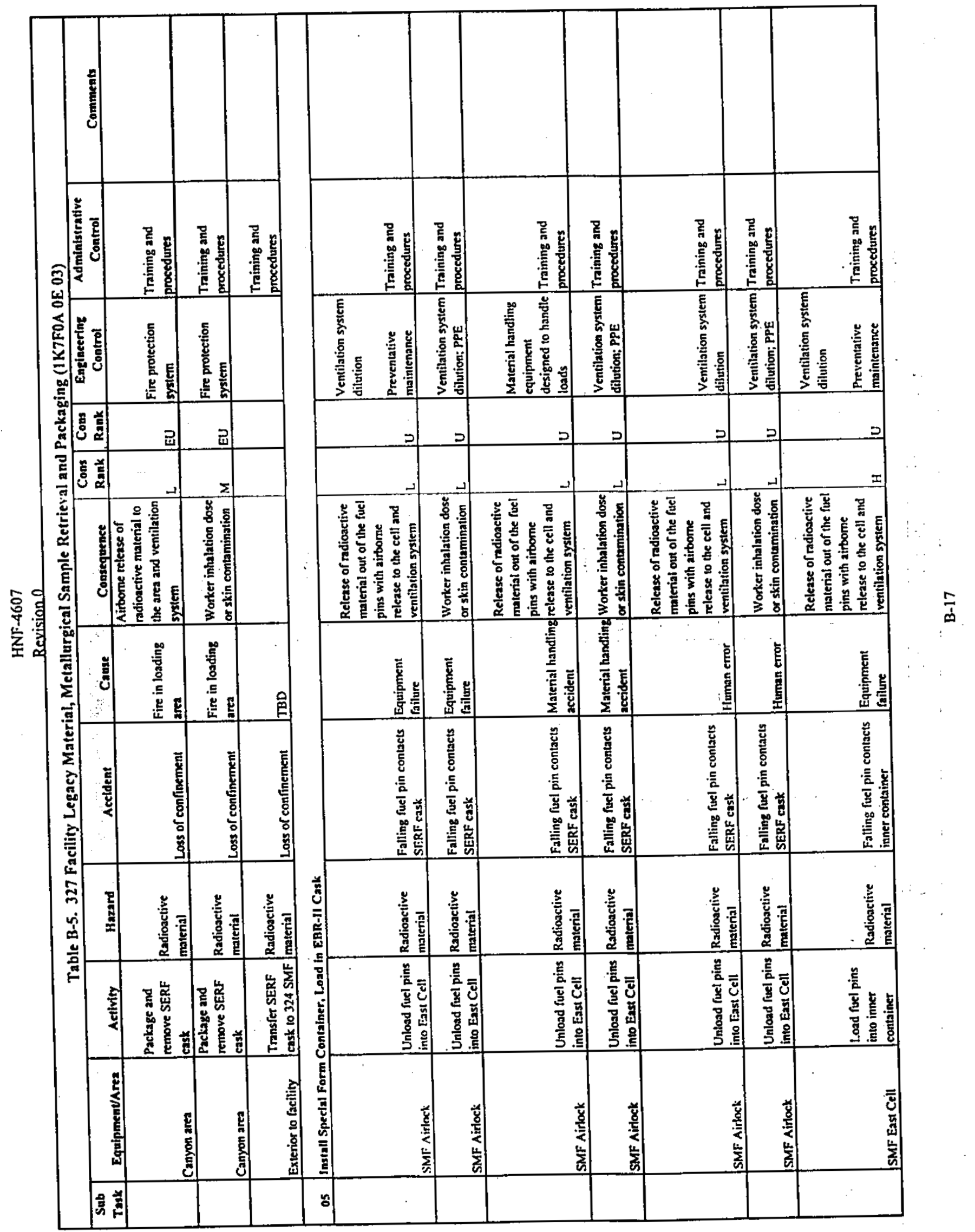




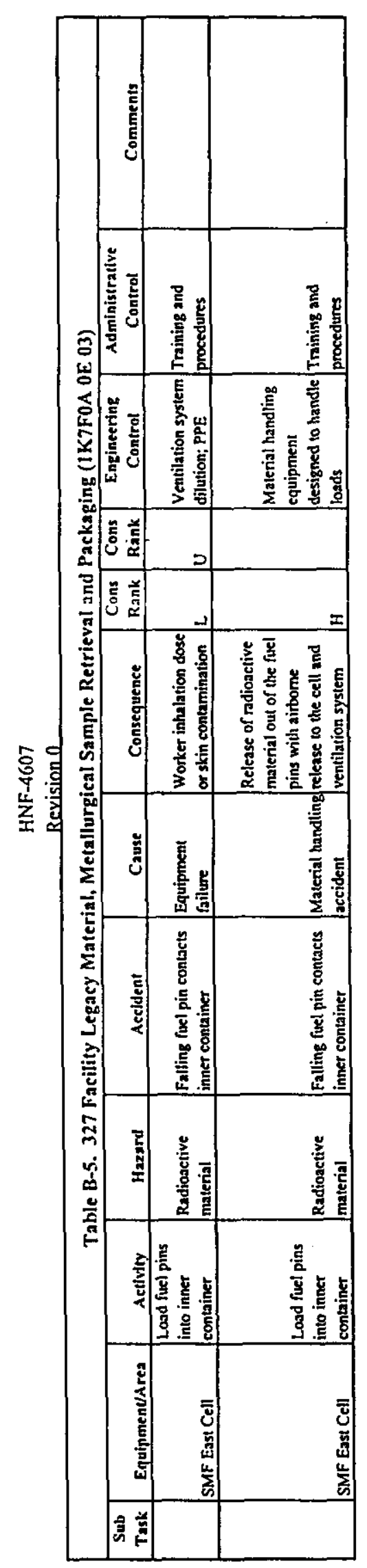




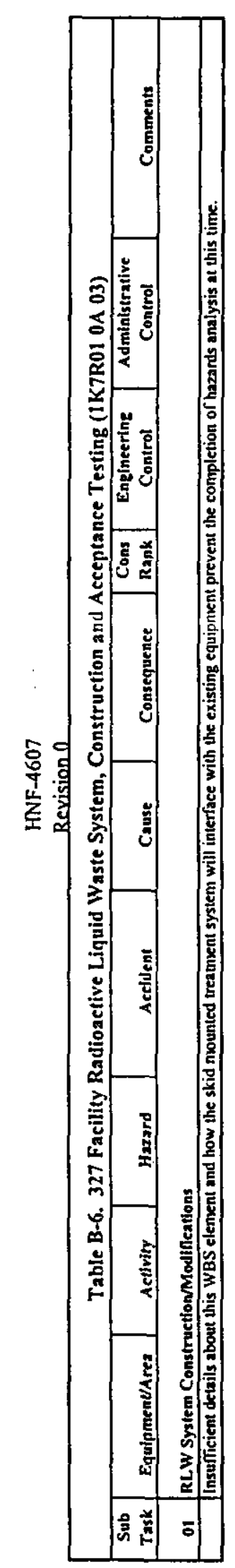

$\frac{9}{\dot{\phi}}$ 


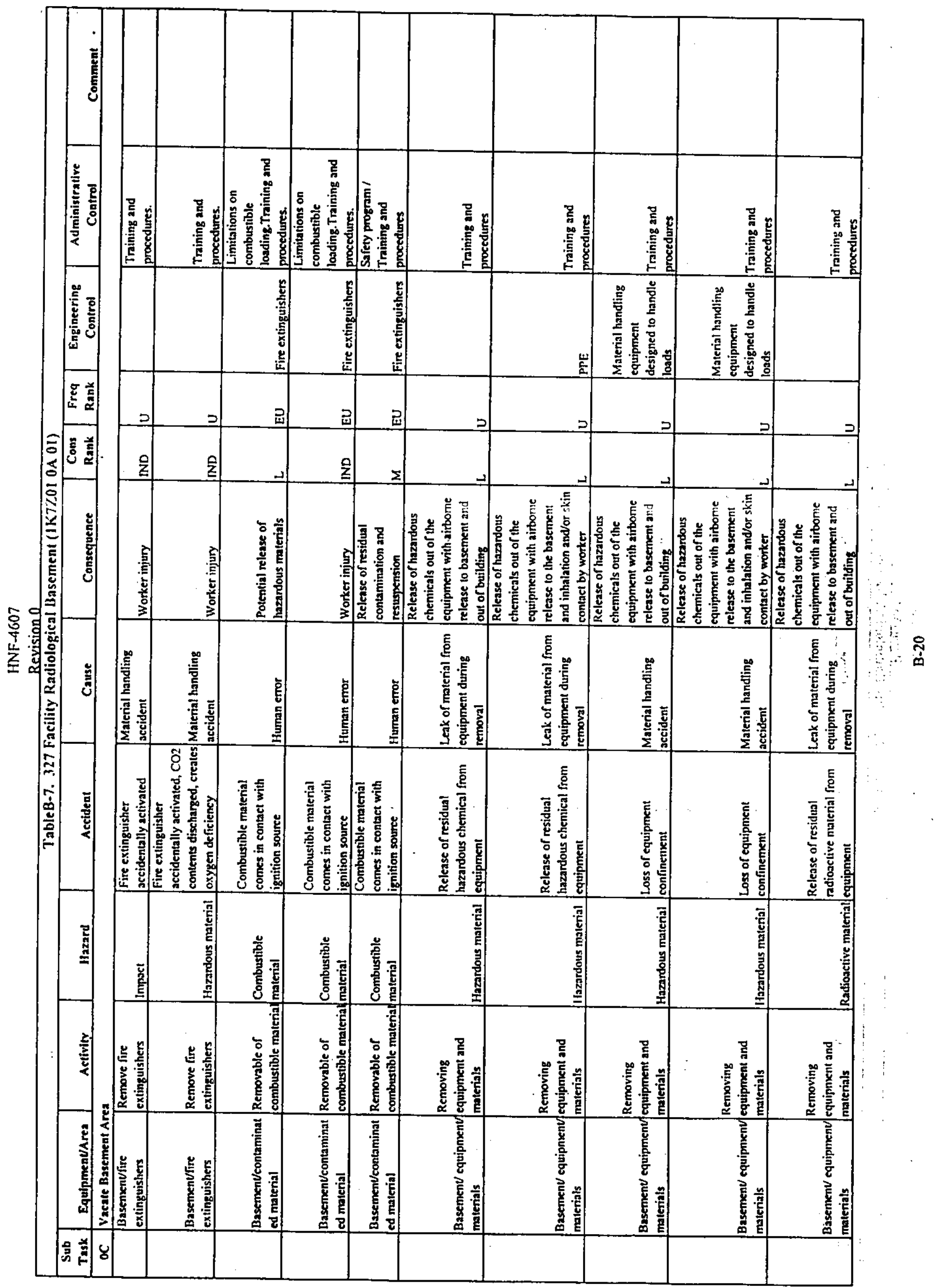




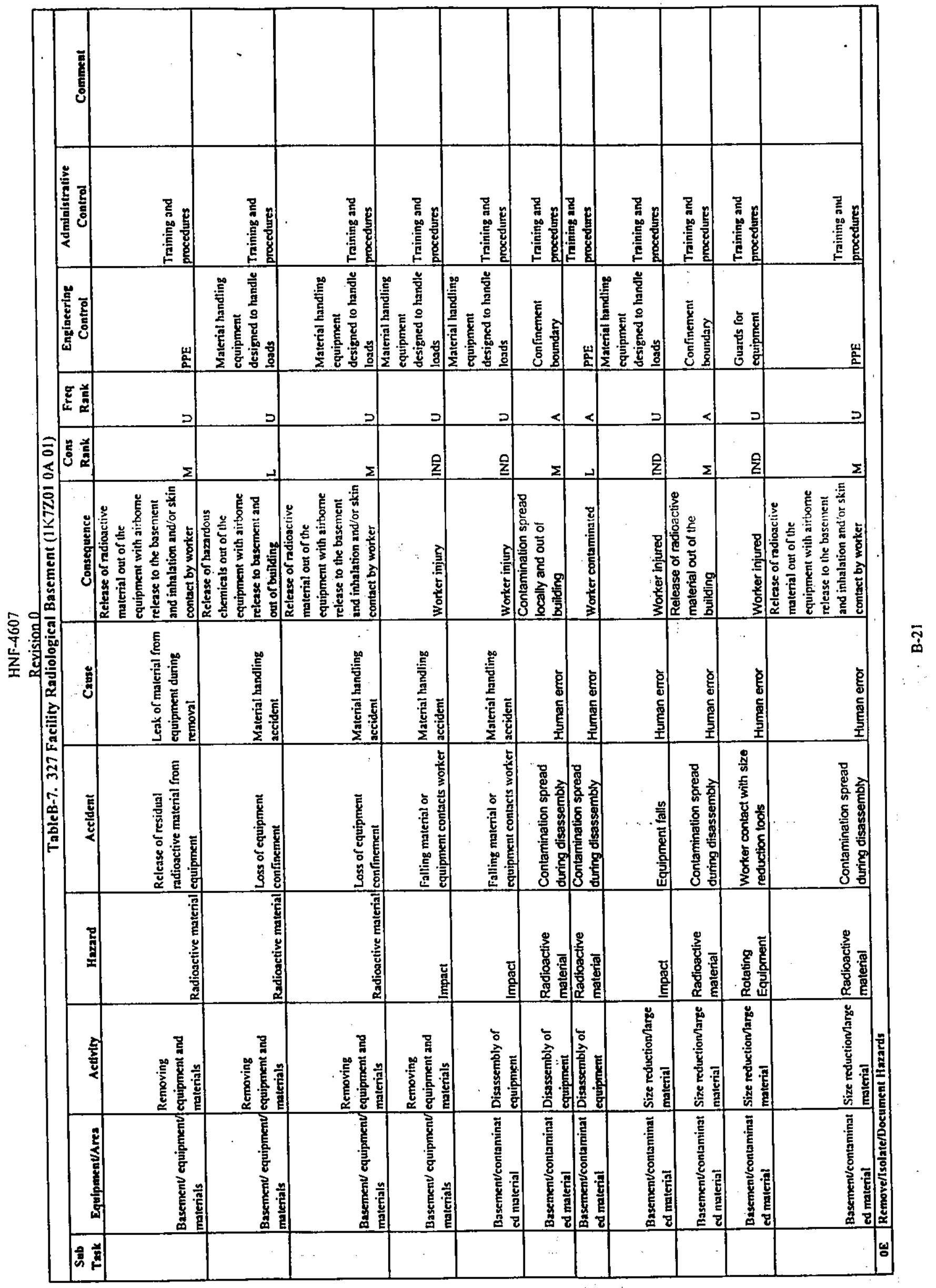




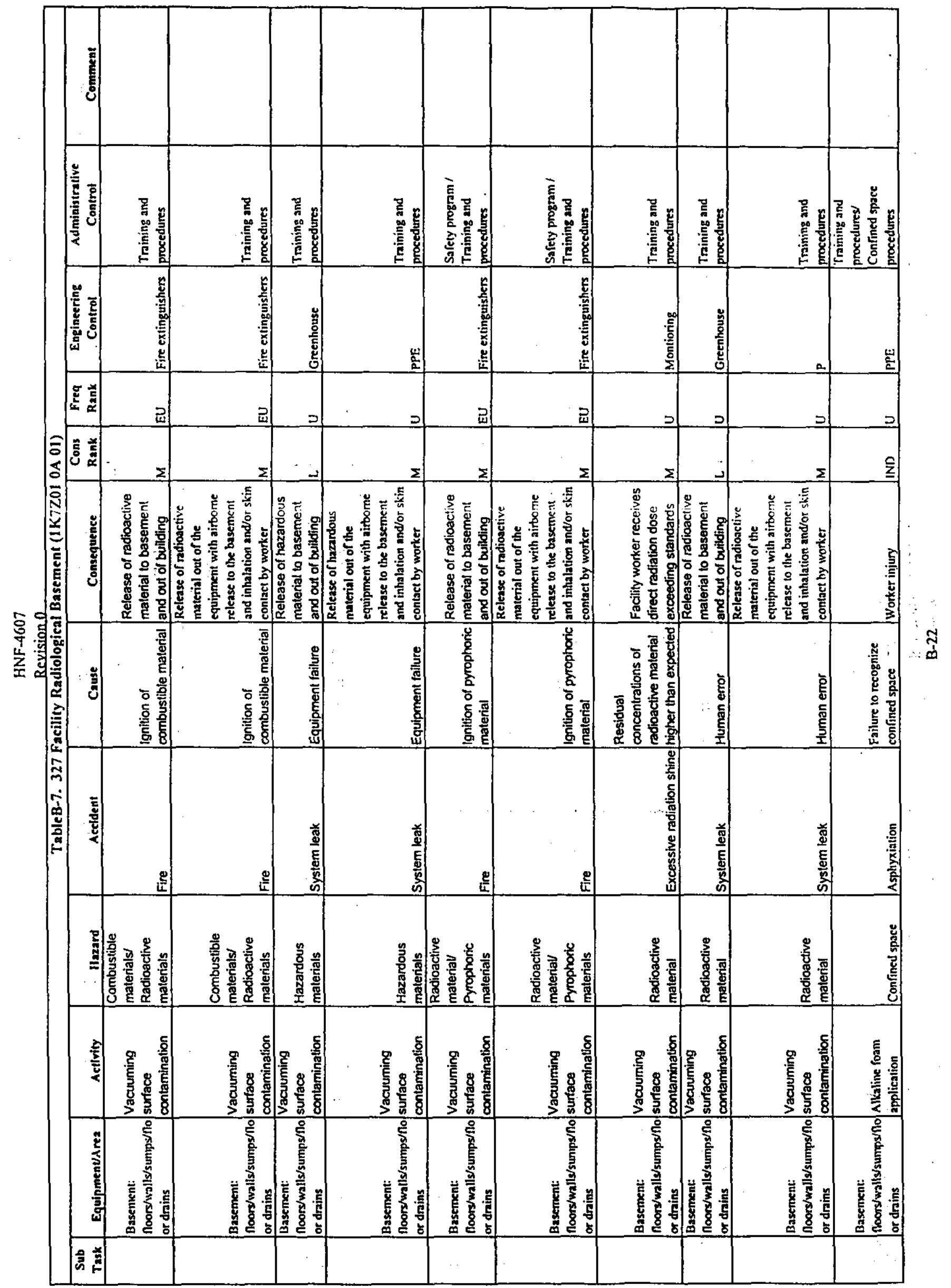




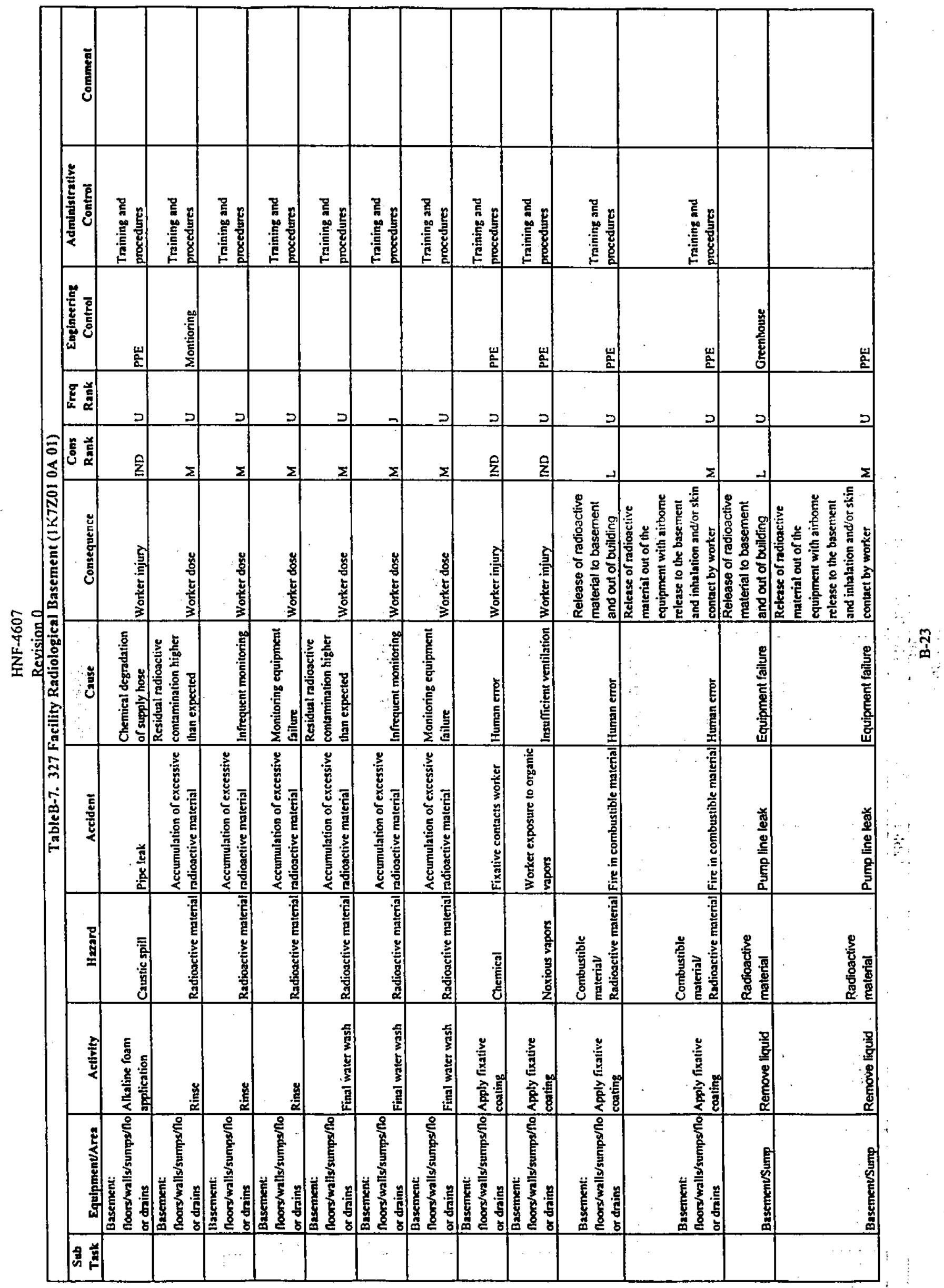




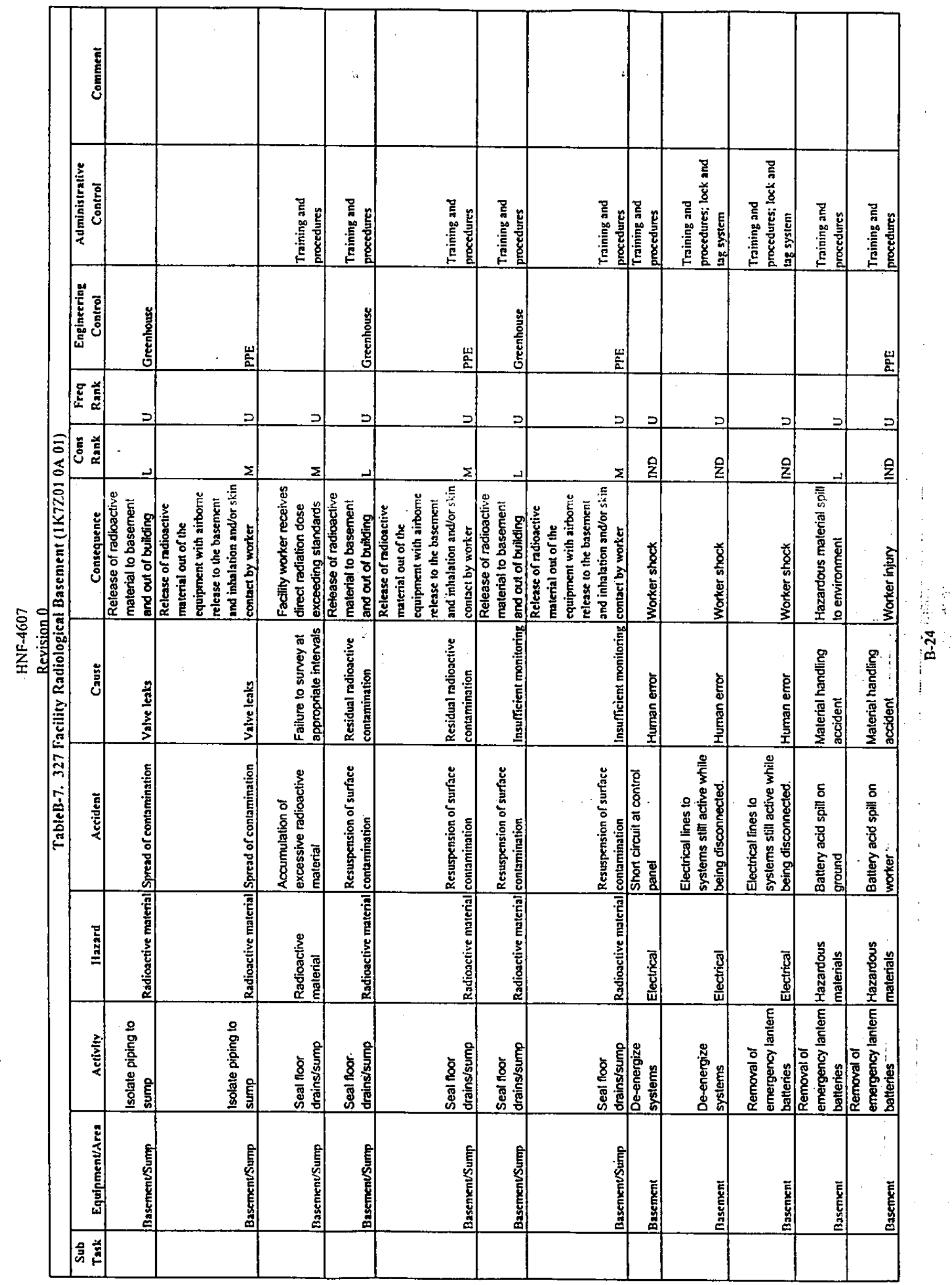




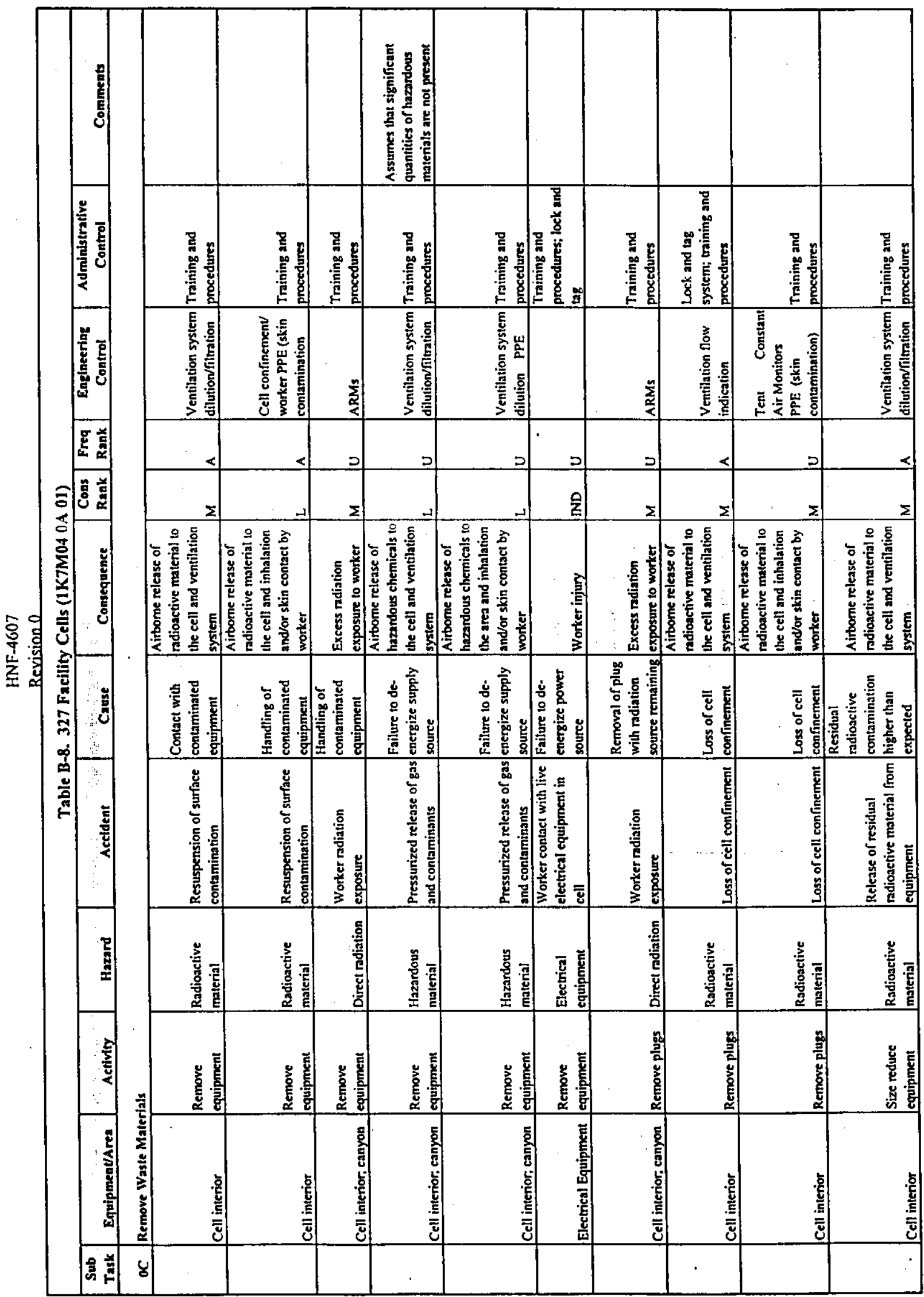




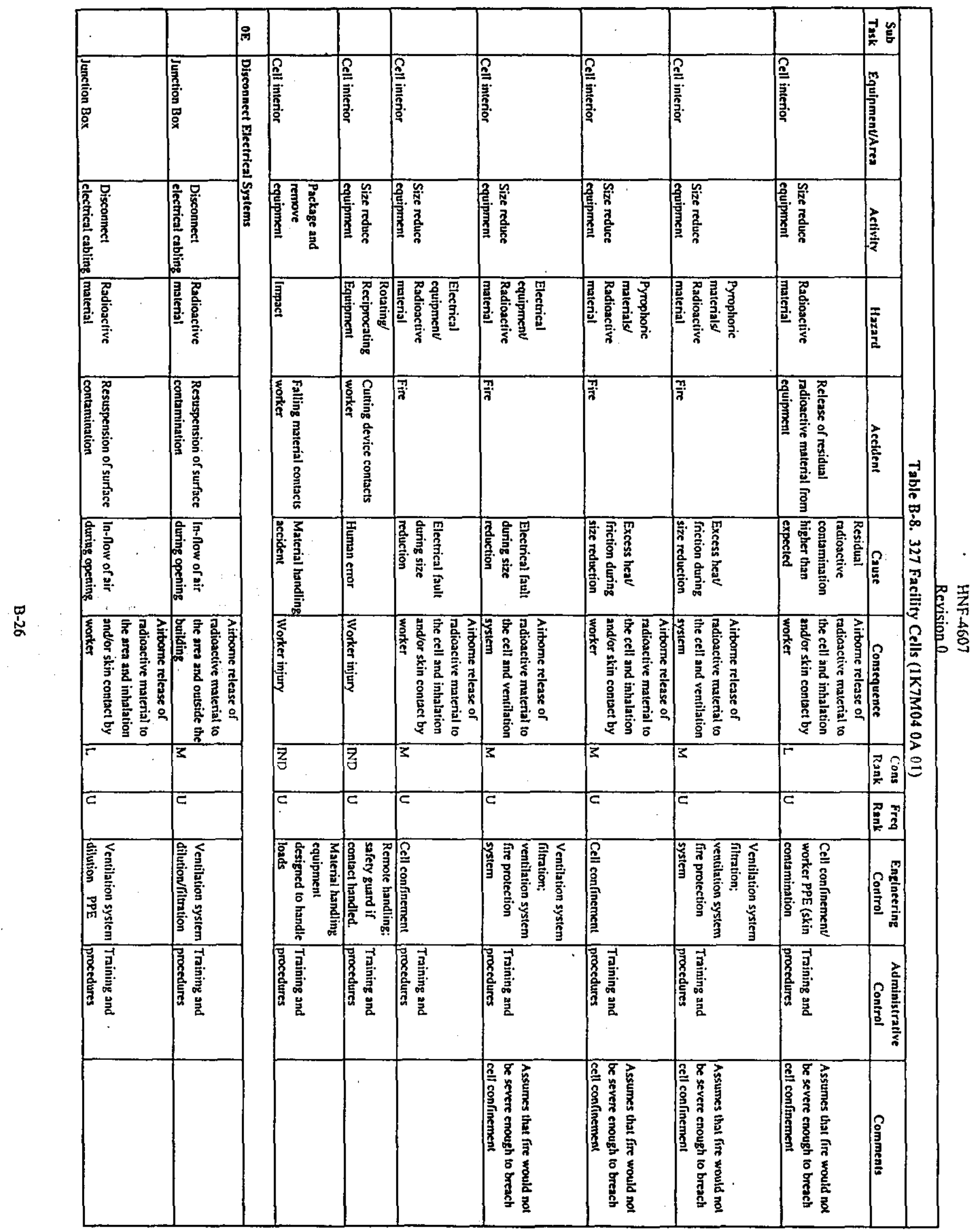




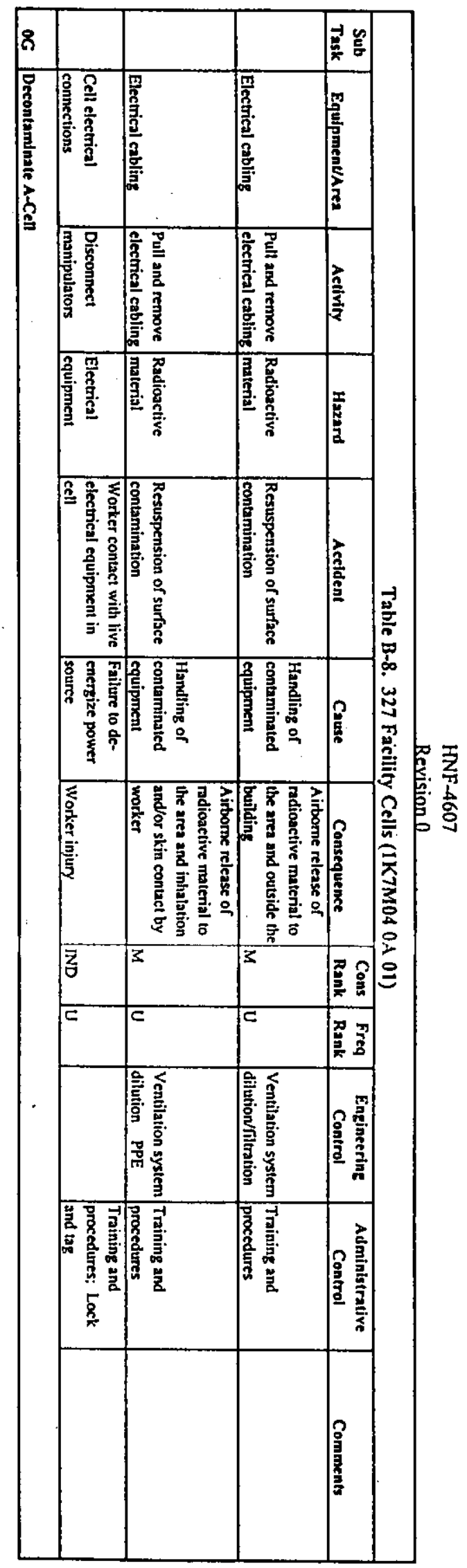




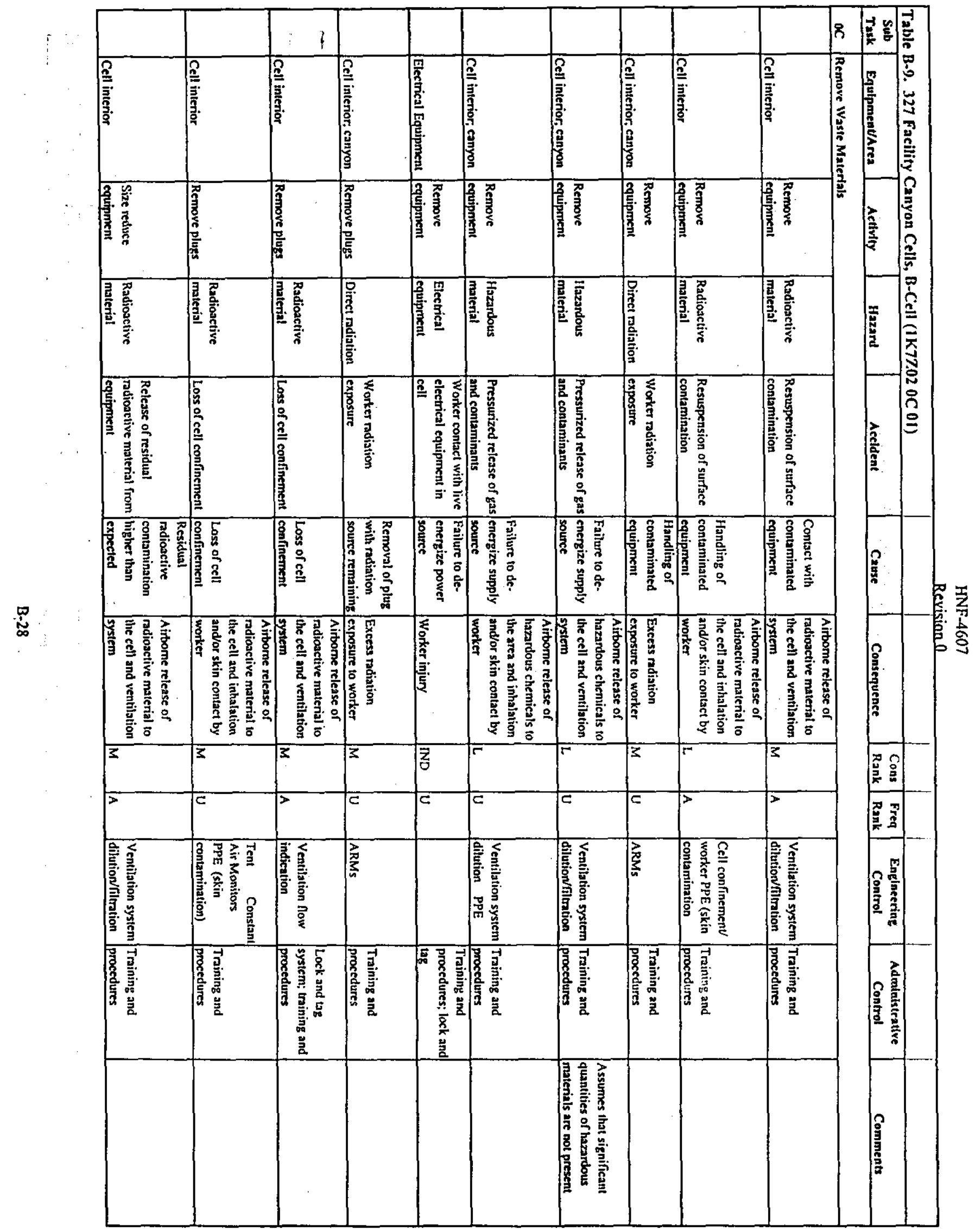




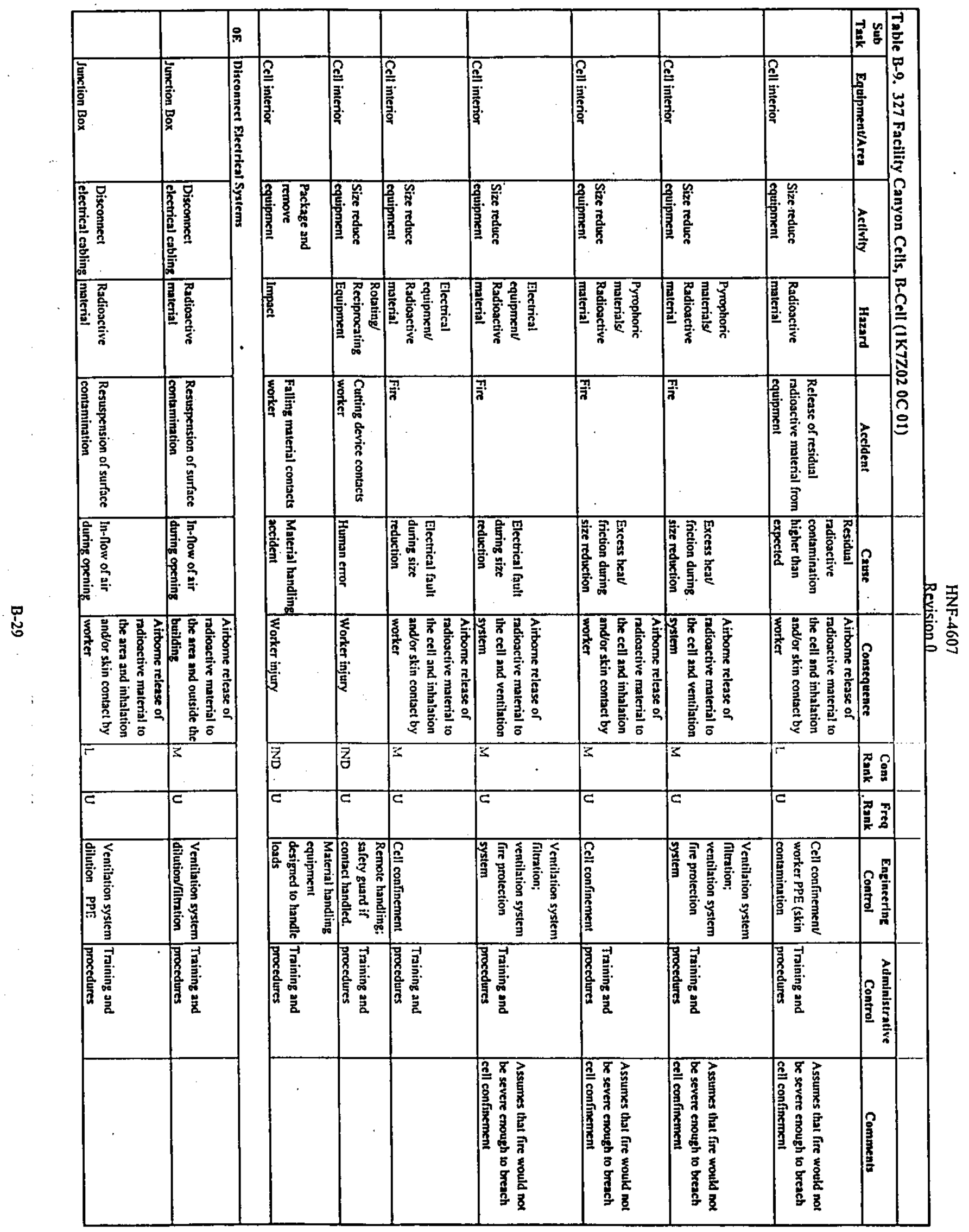




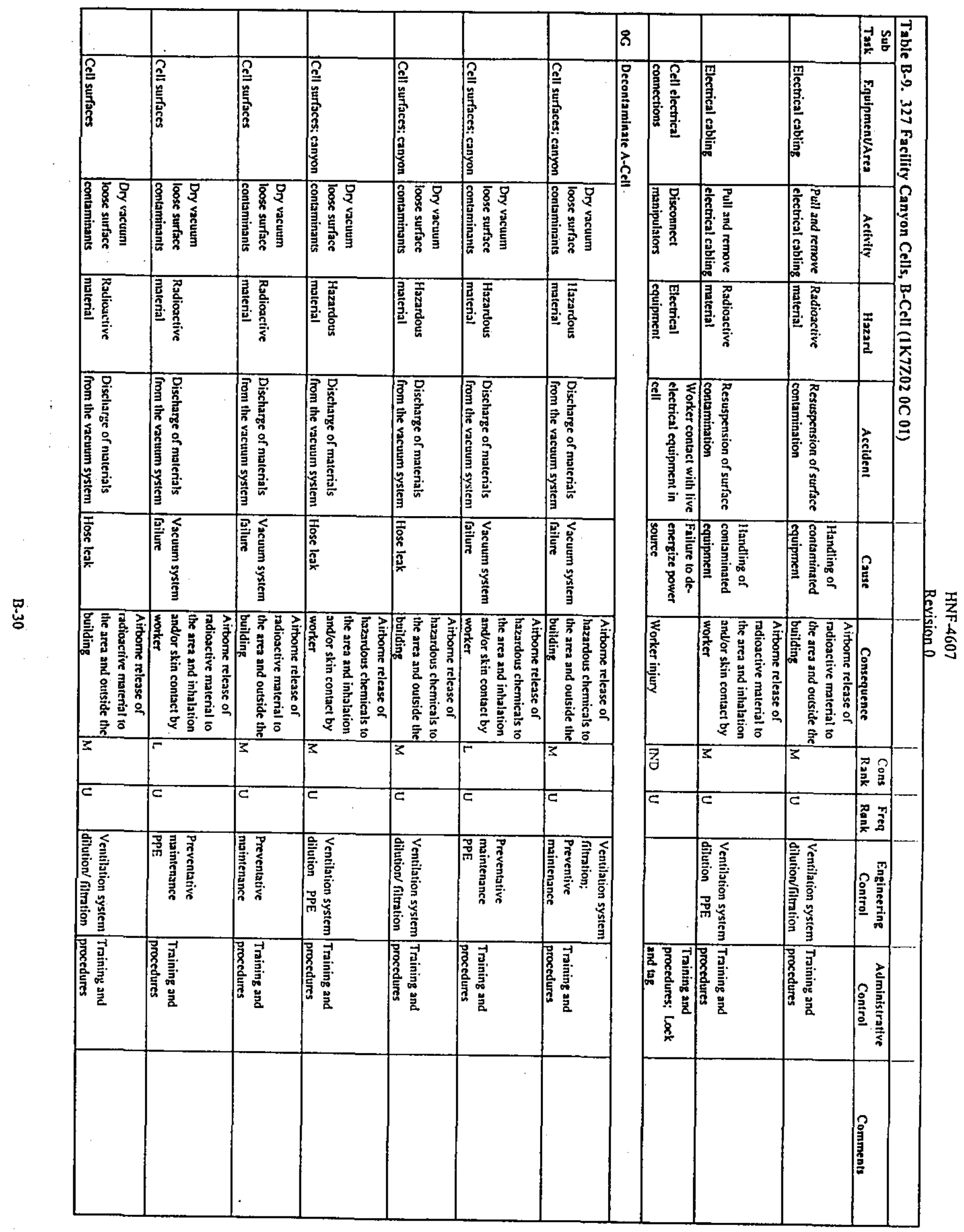


品

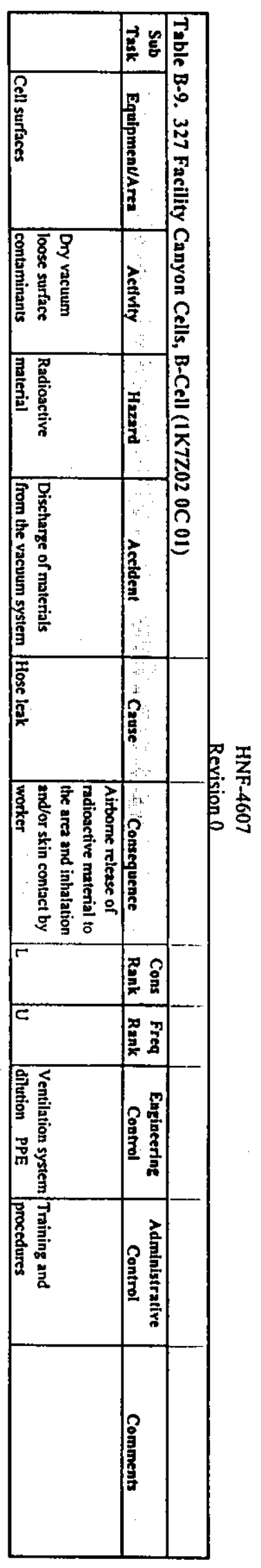




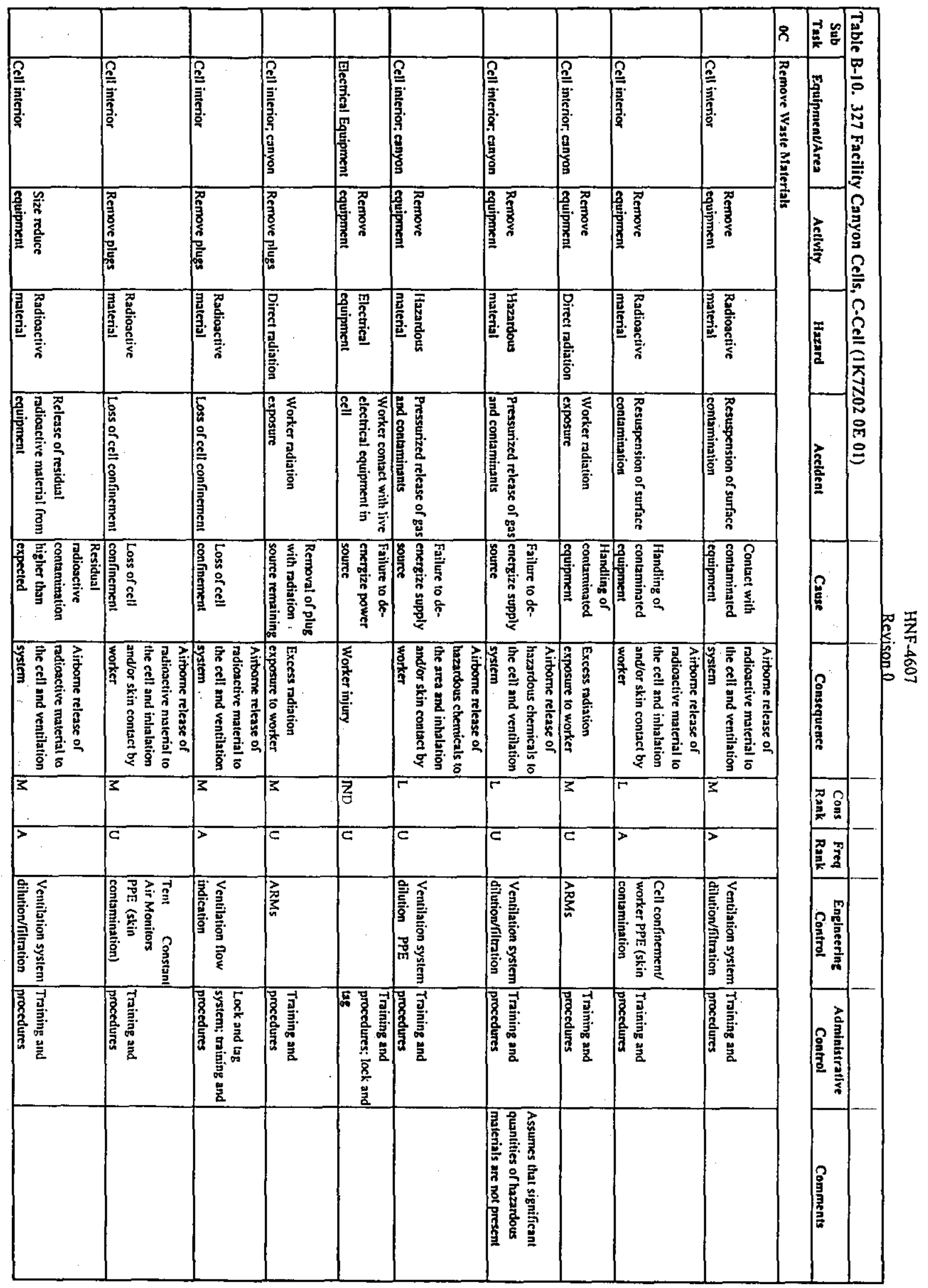




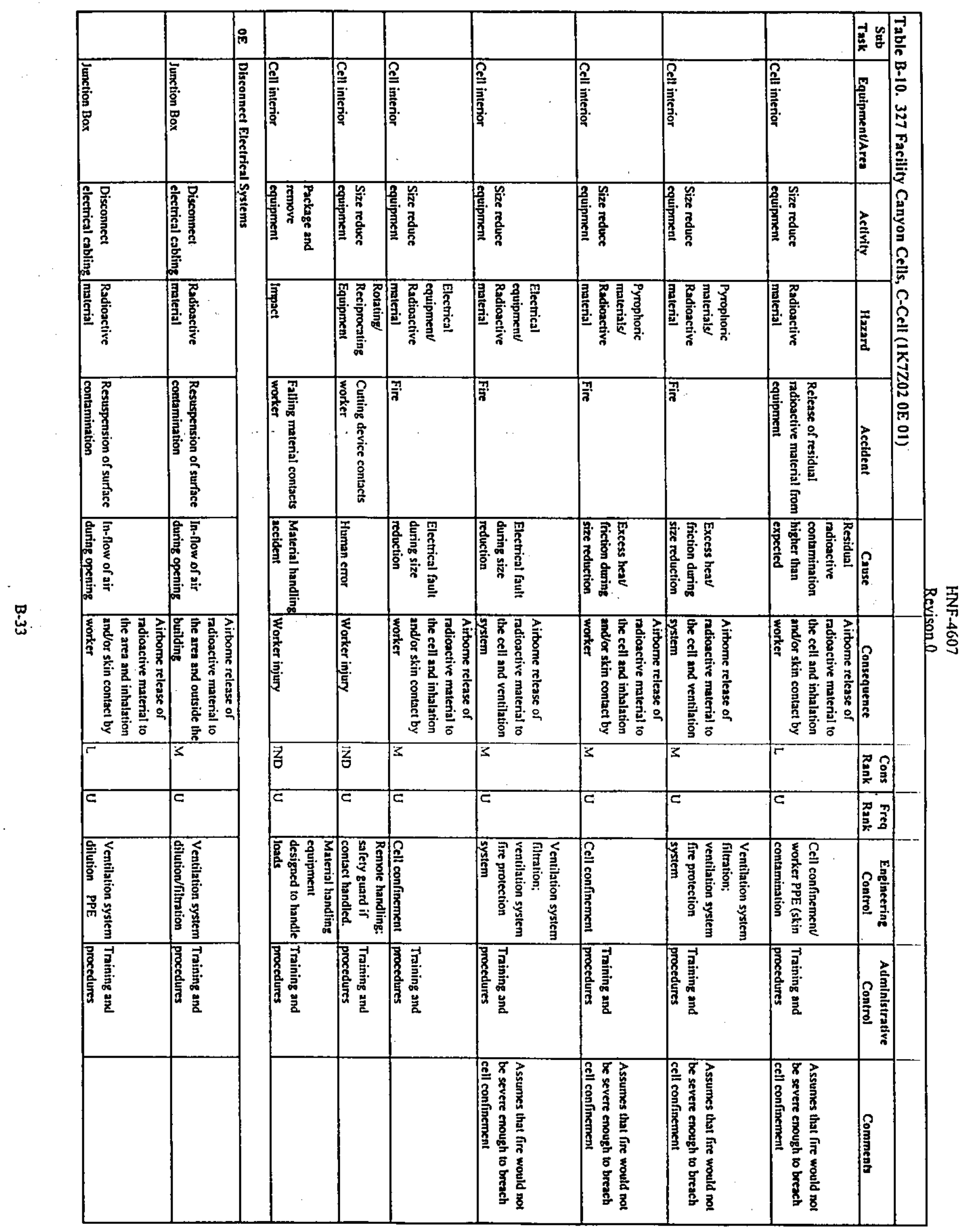




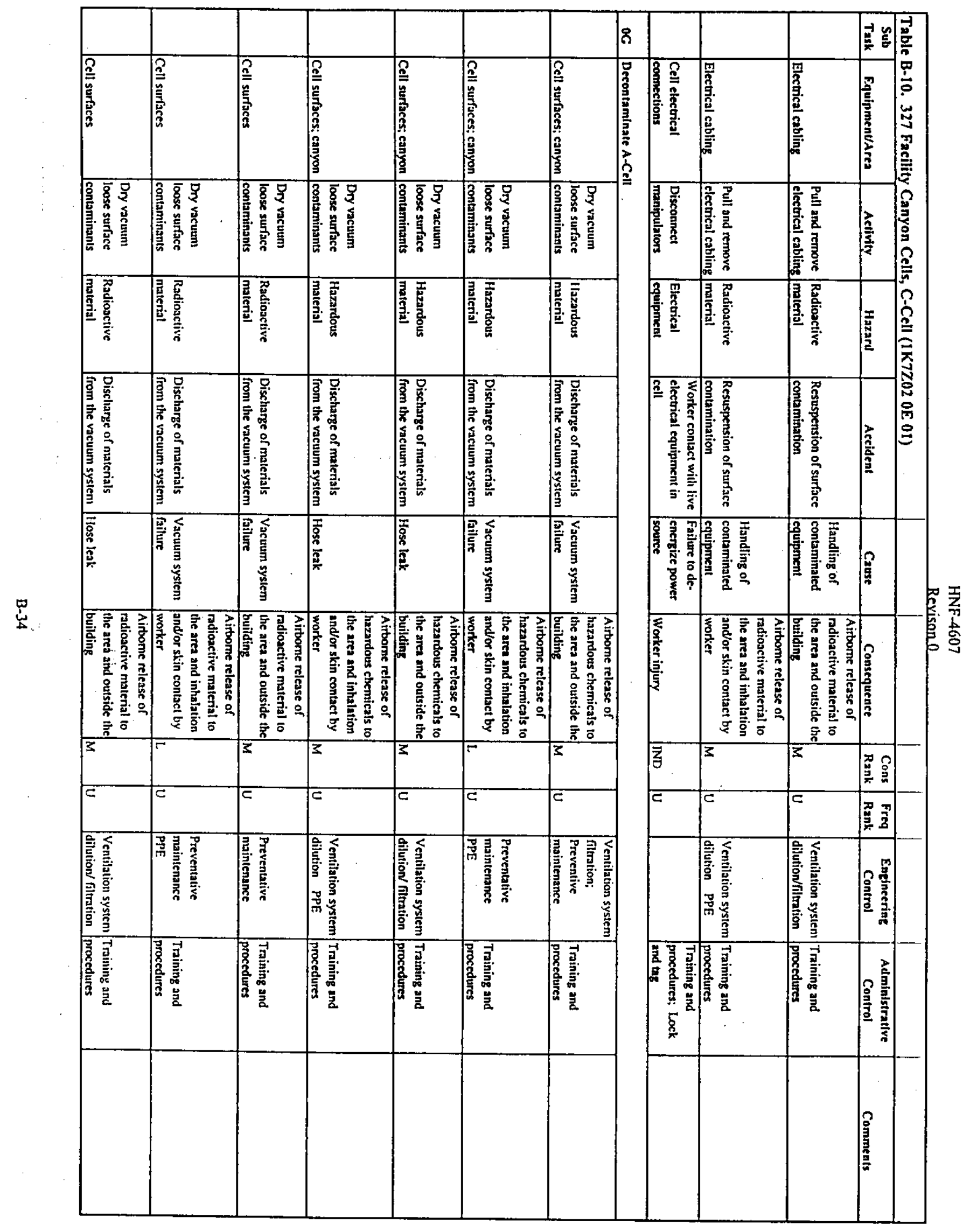




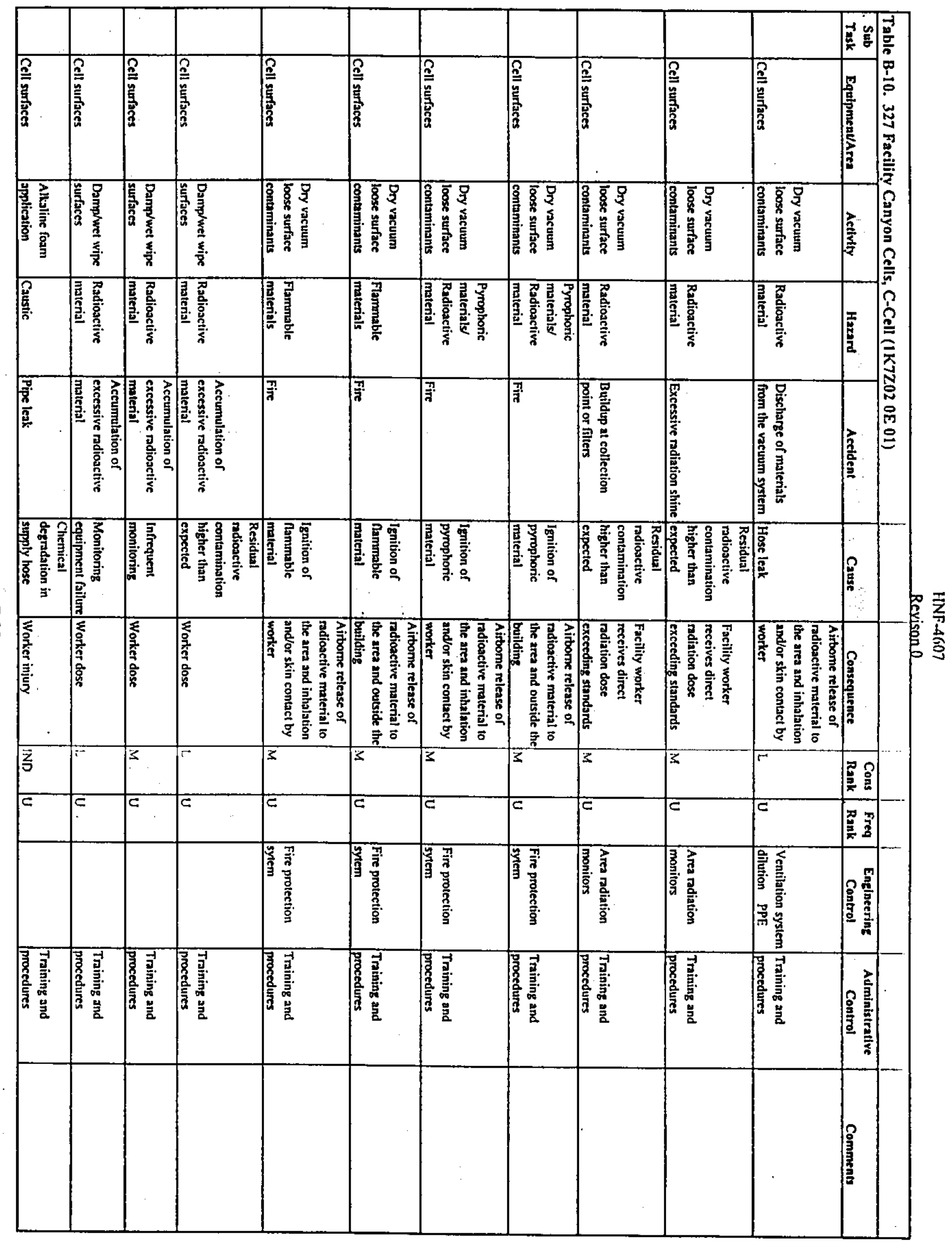




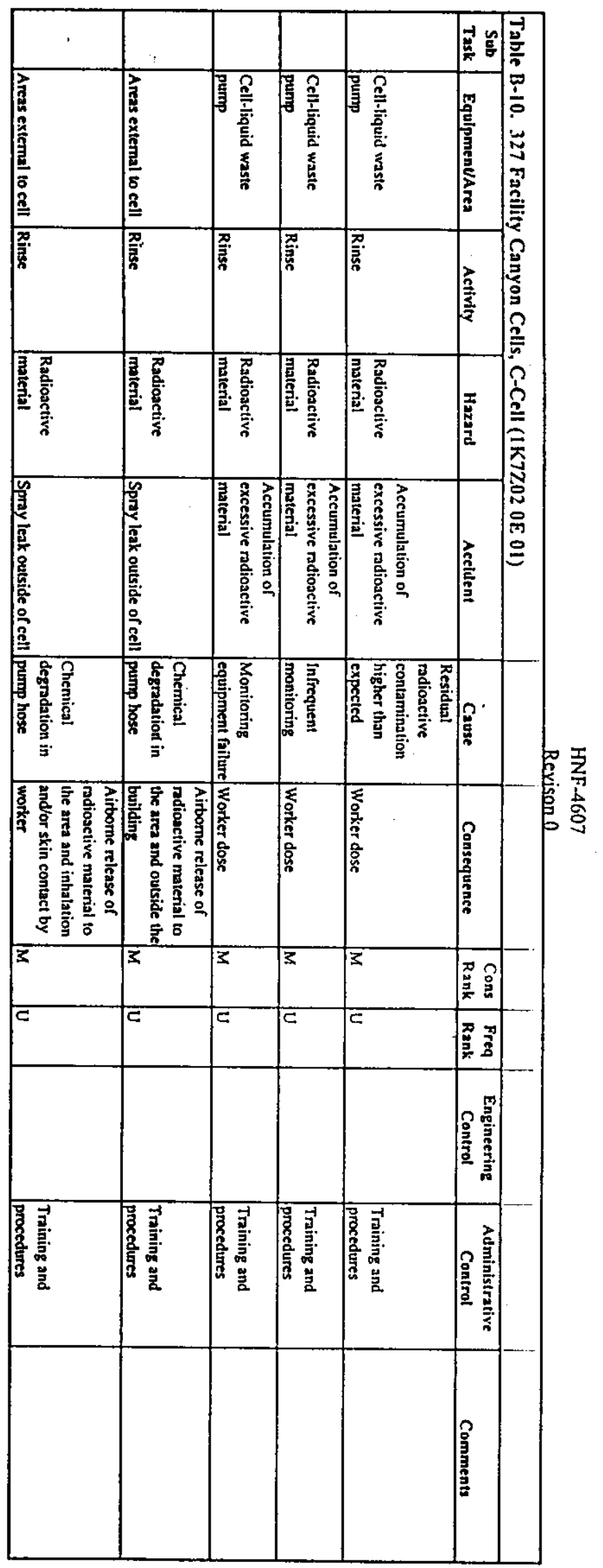




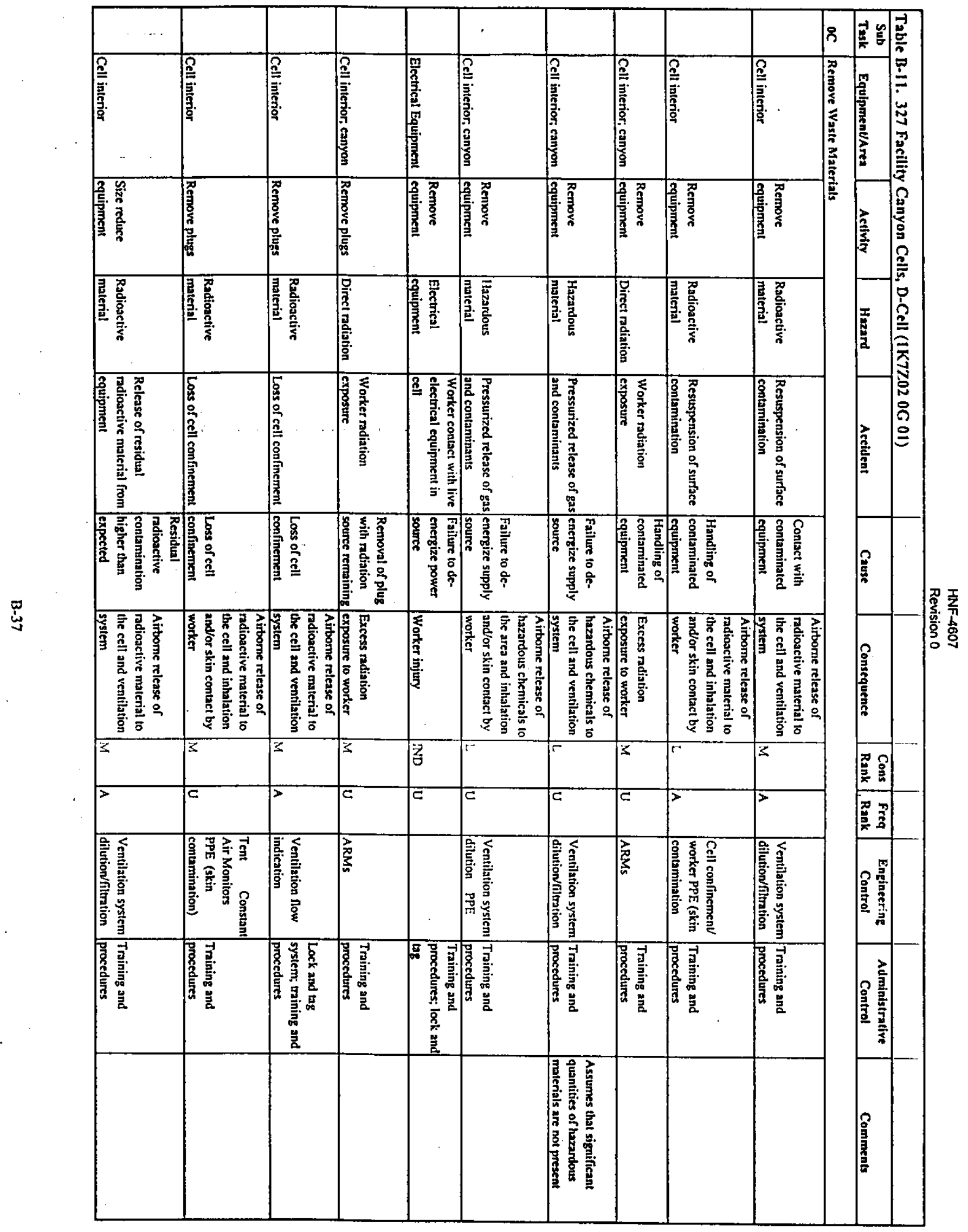




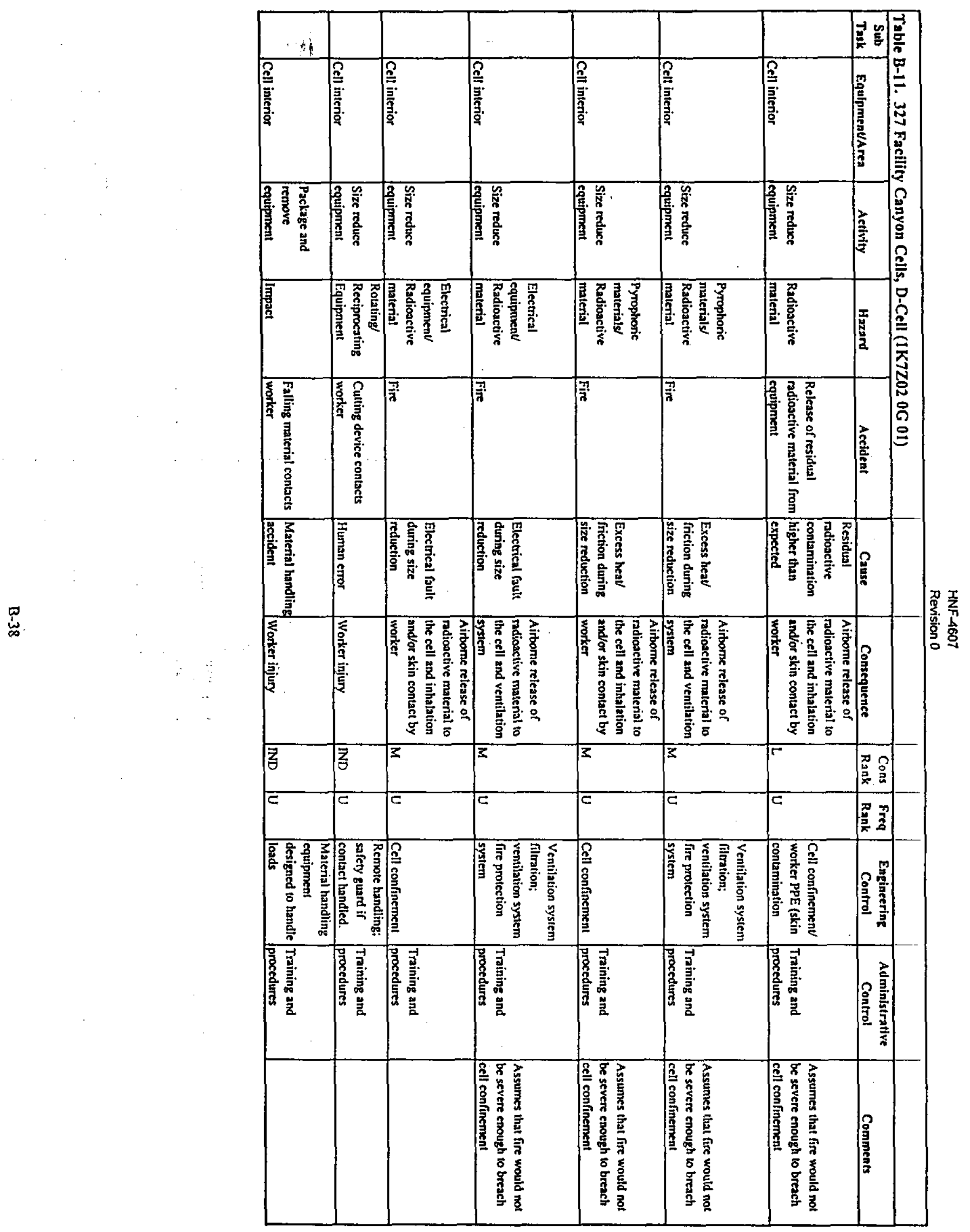




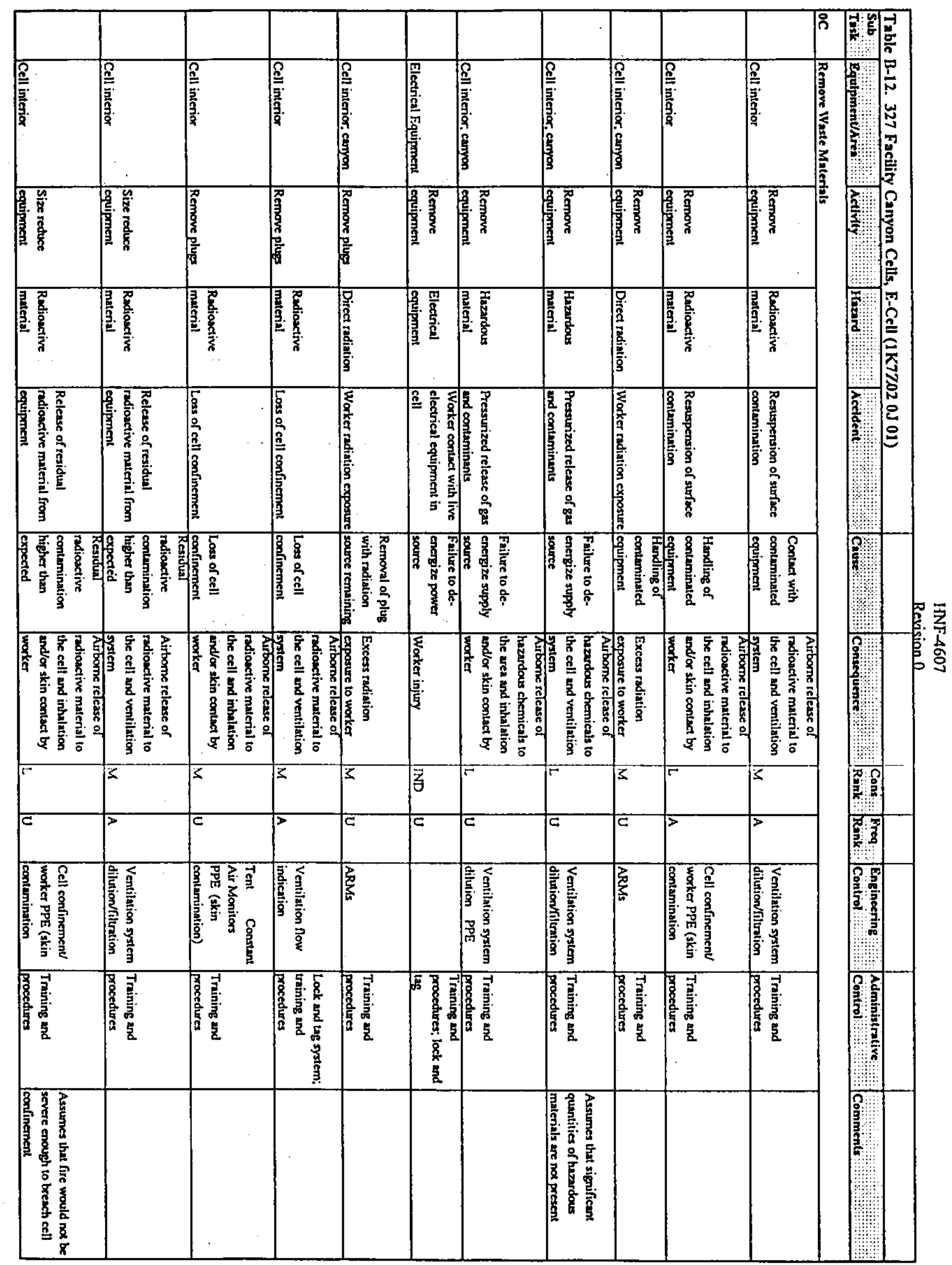




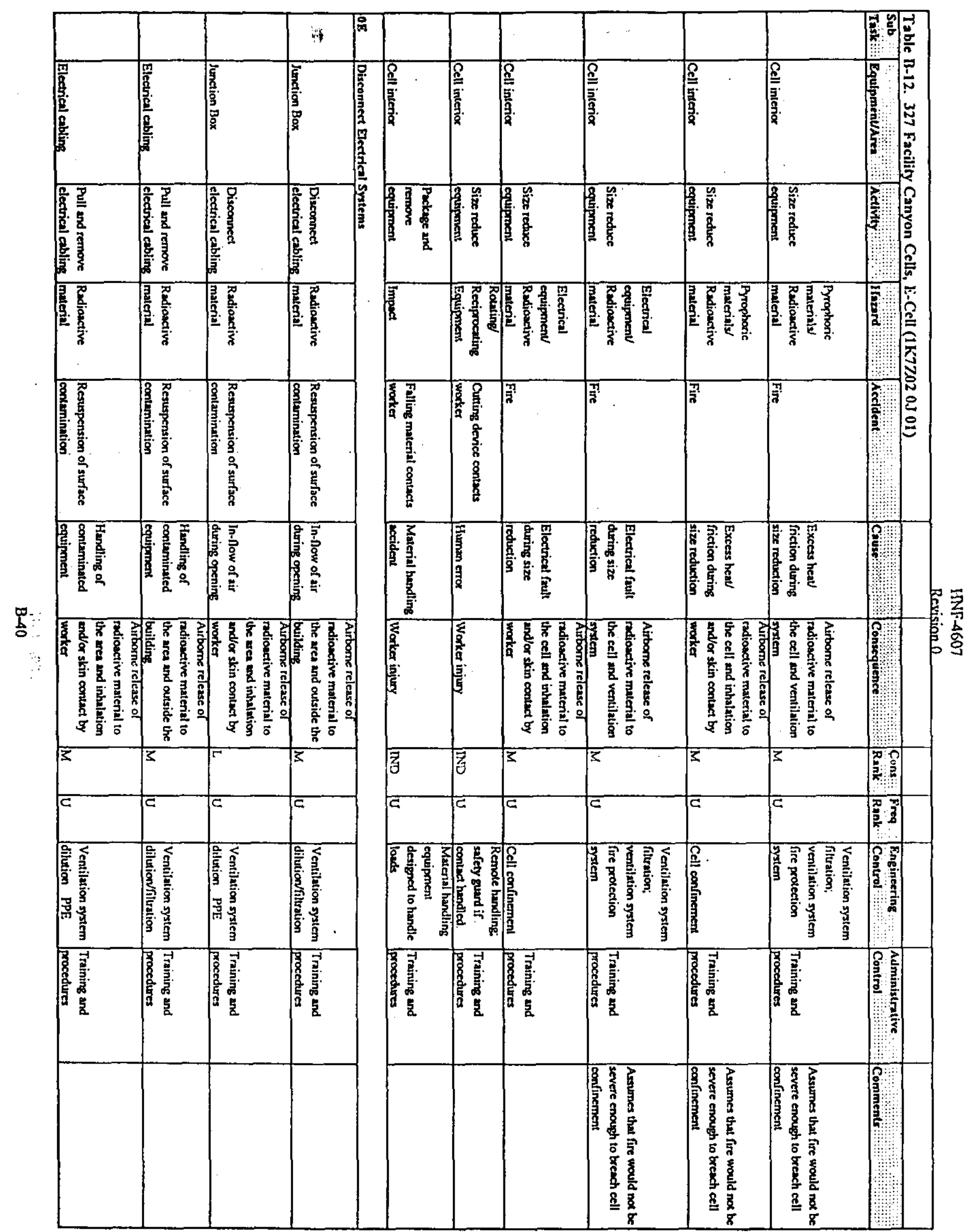




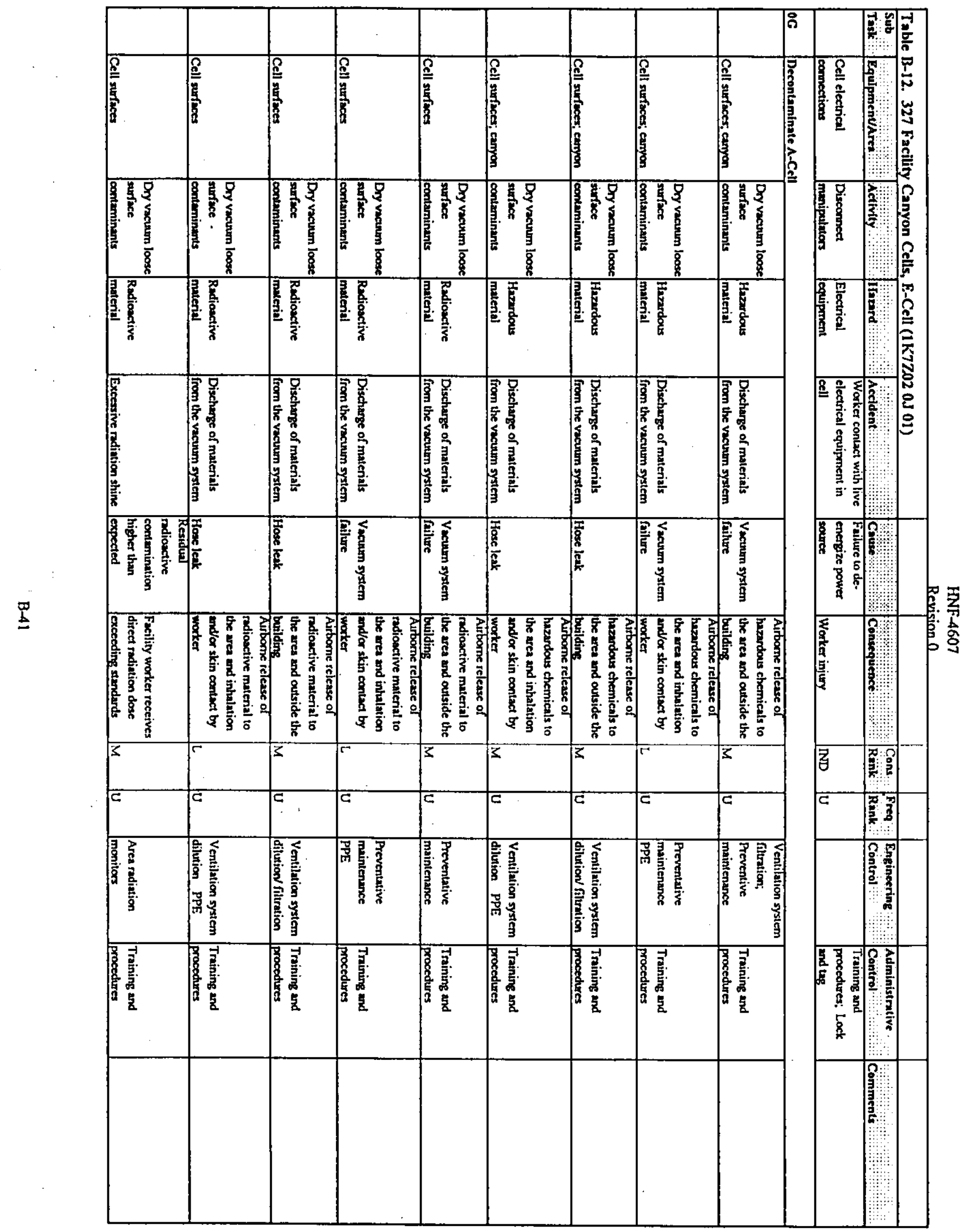




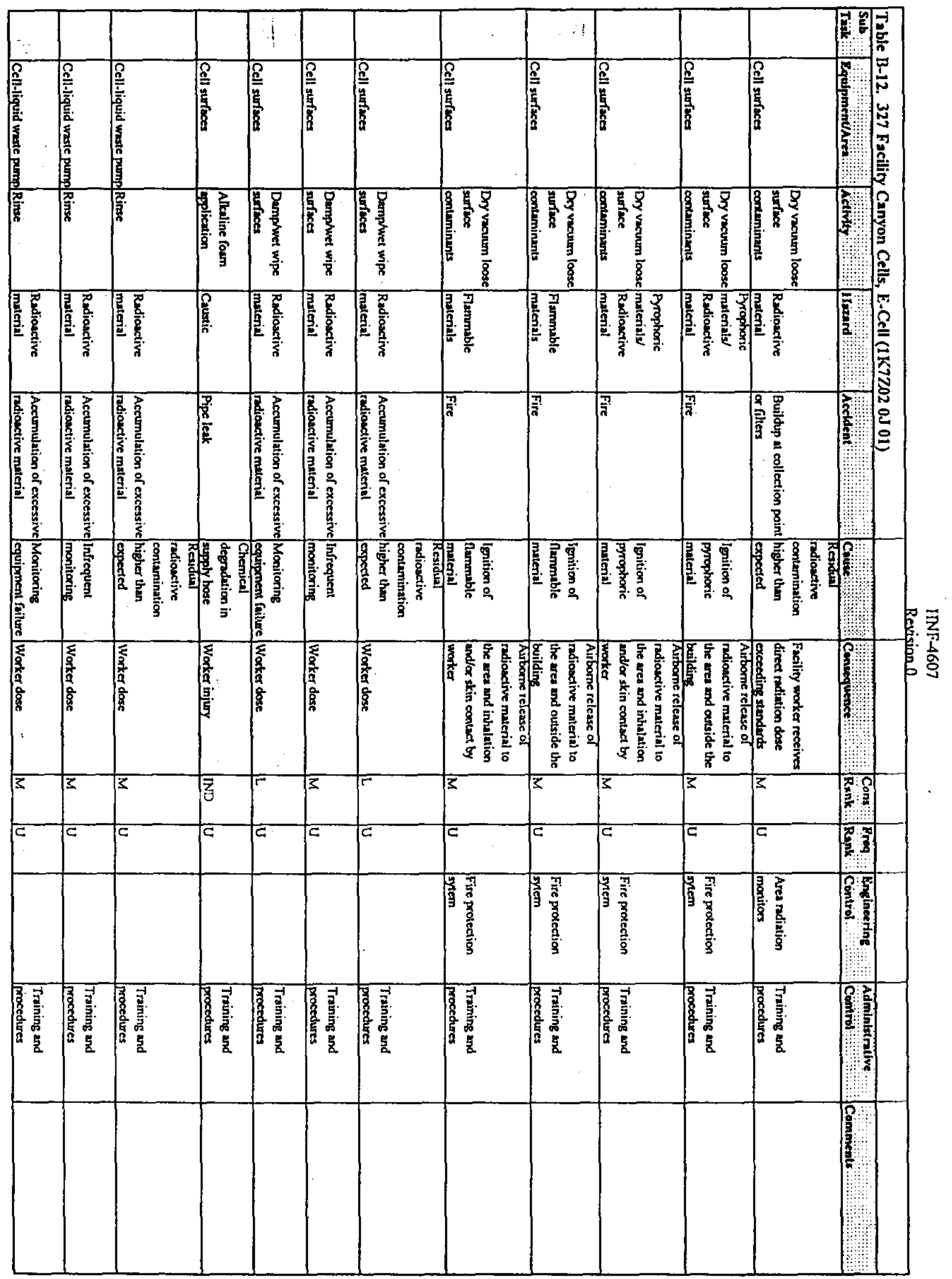




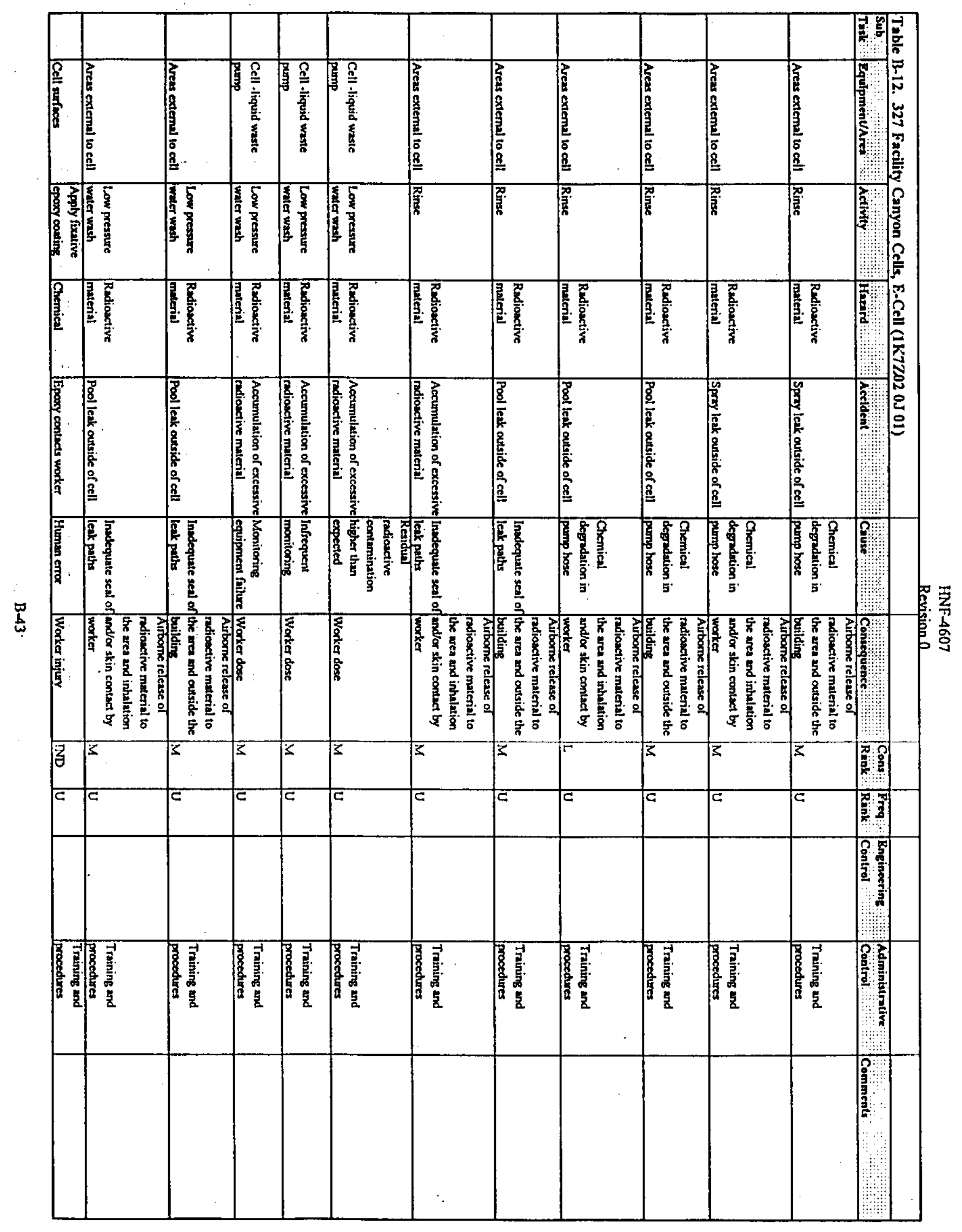




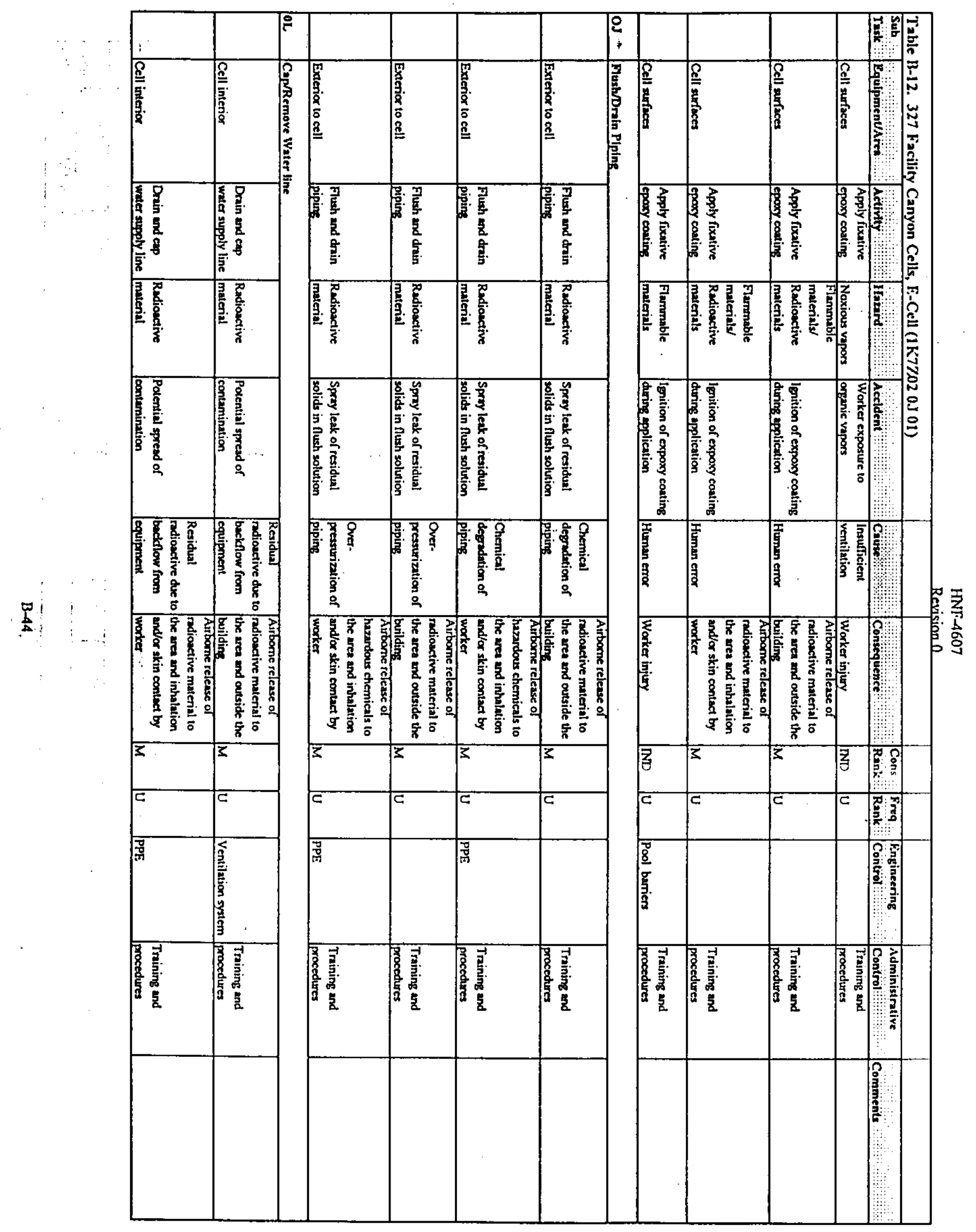




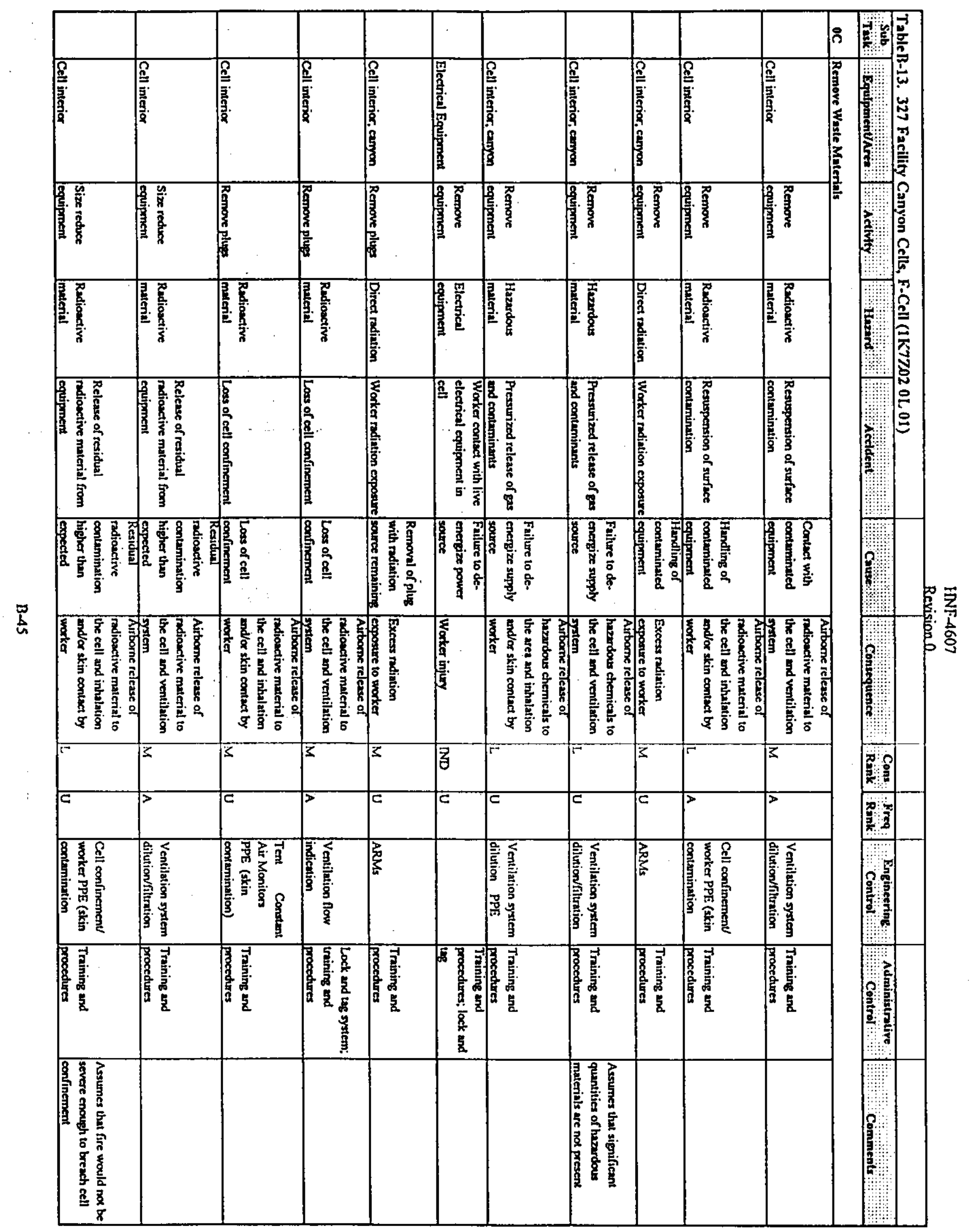




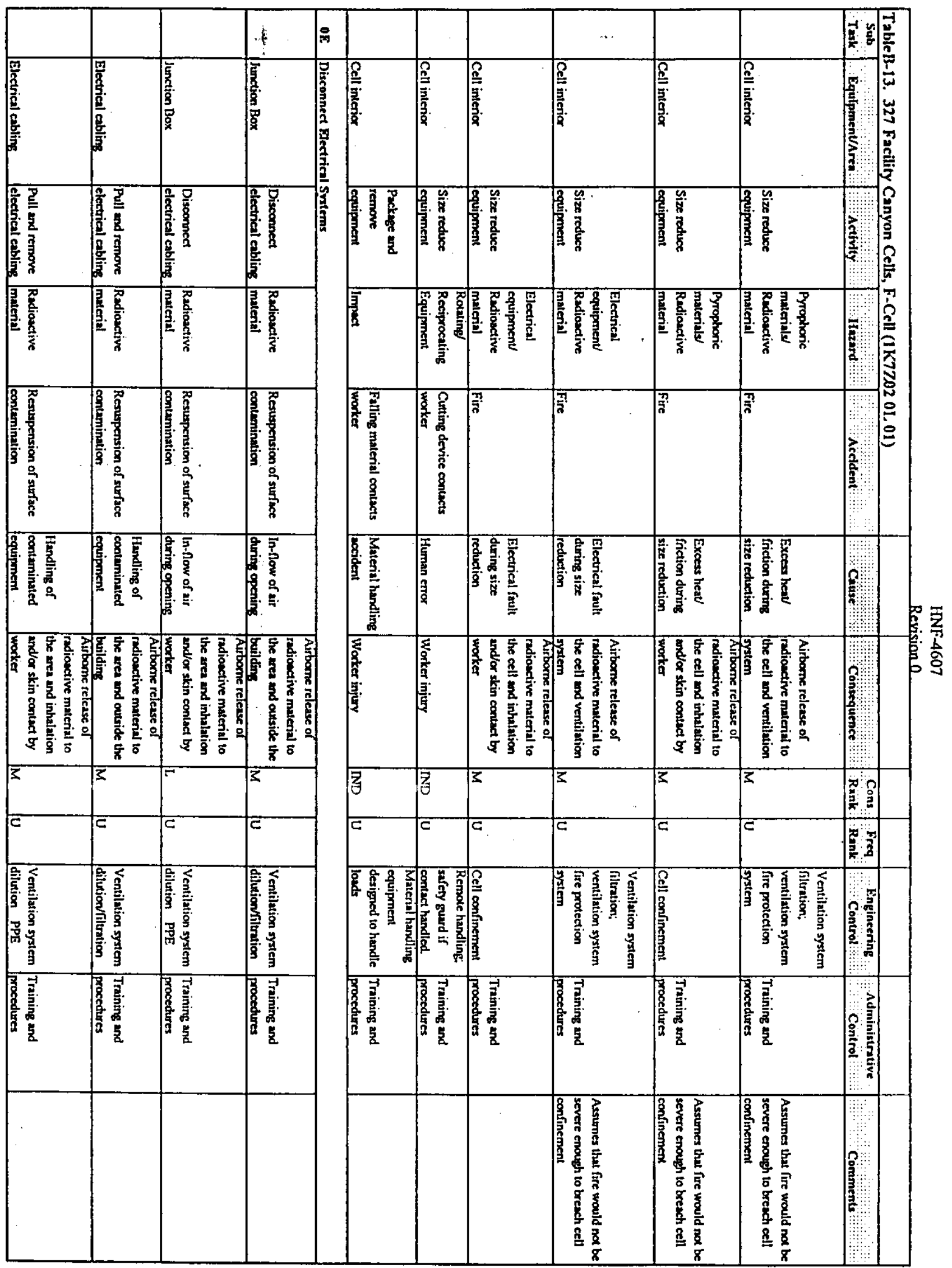




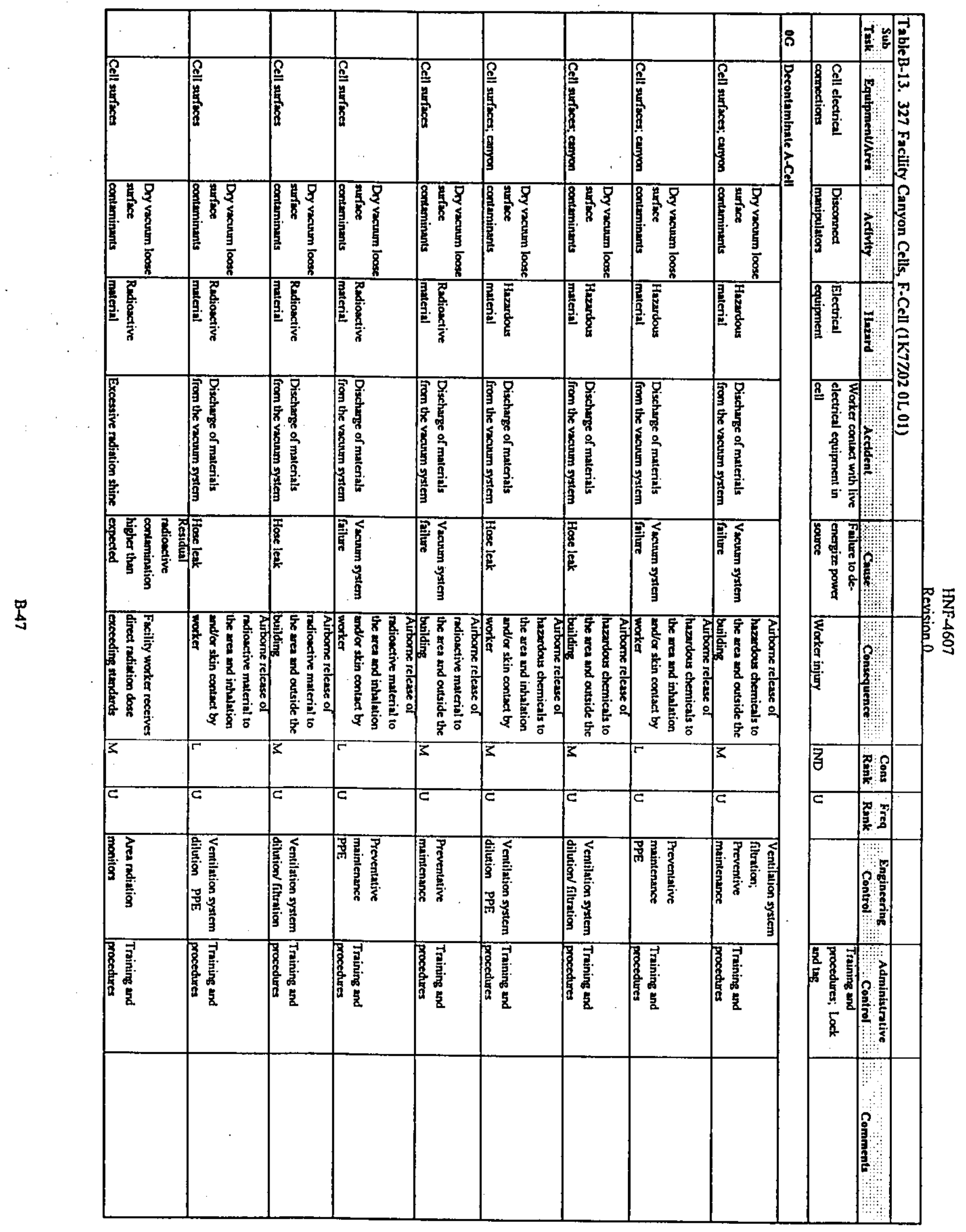




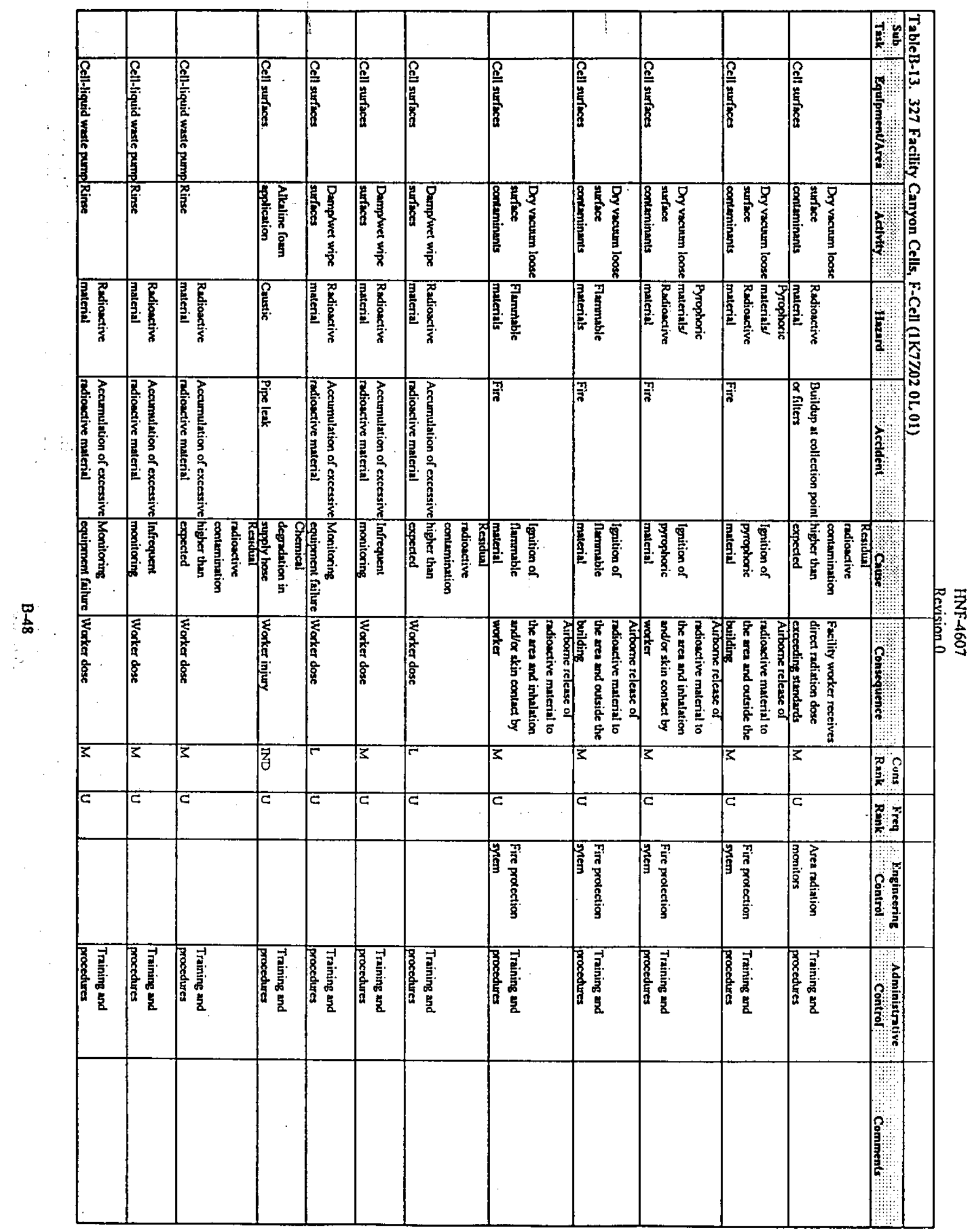




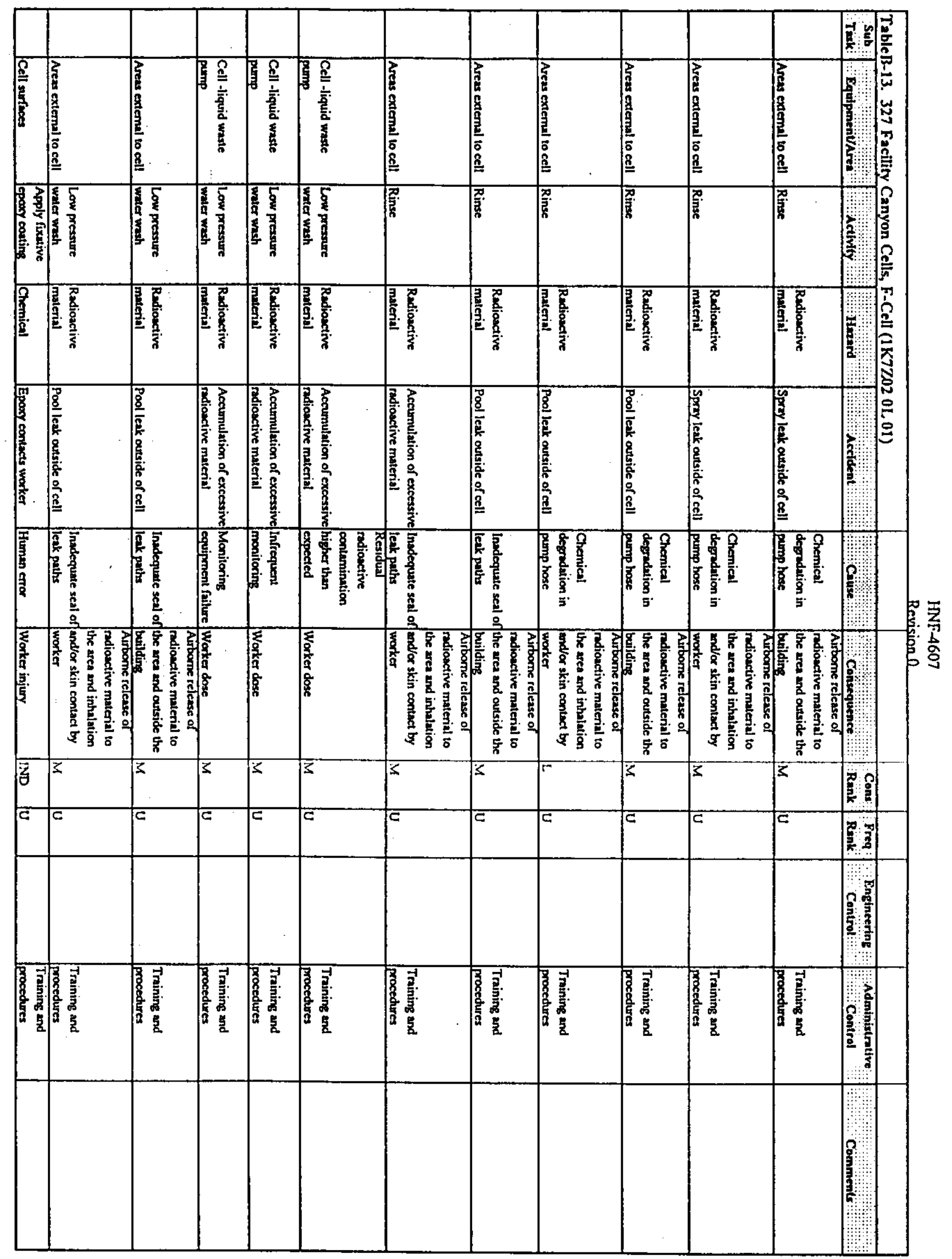




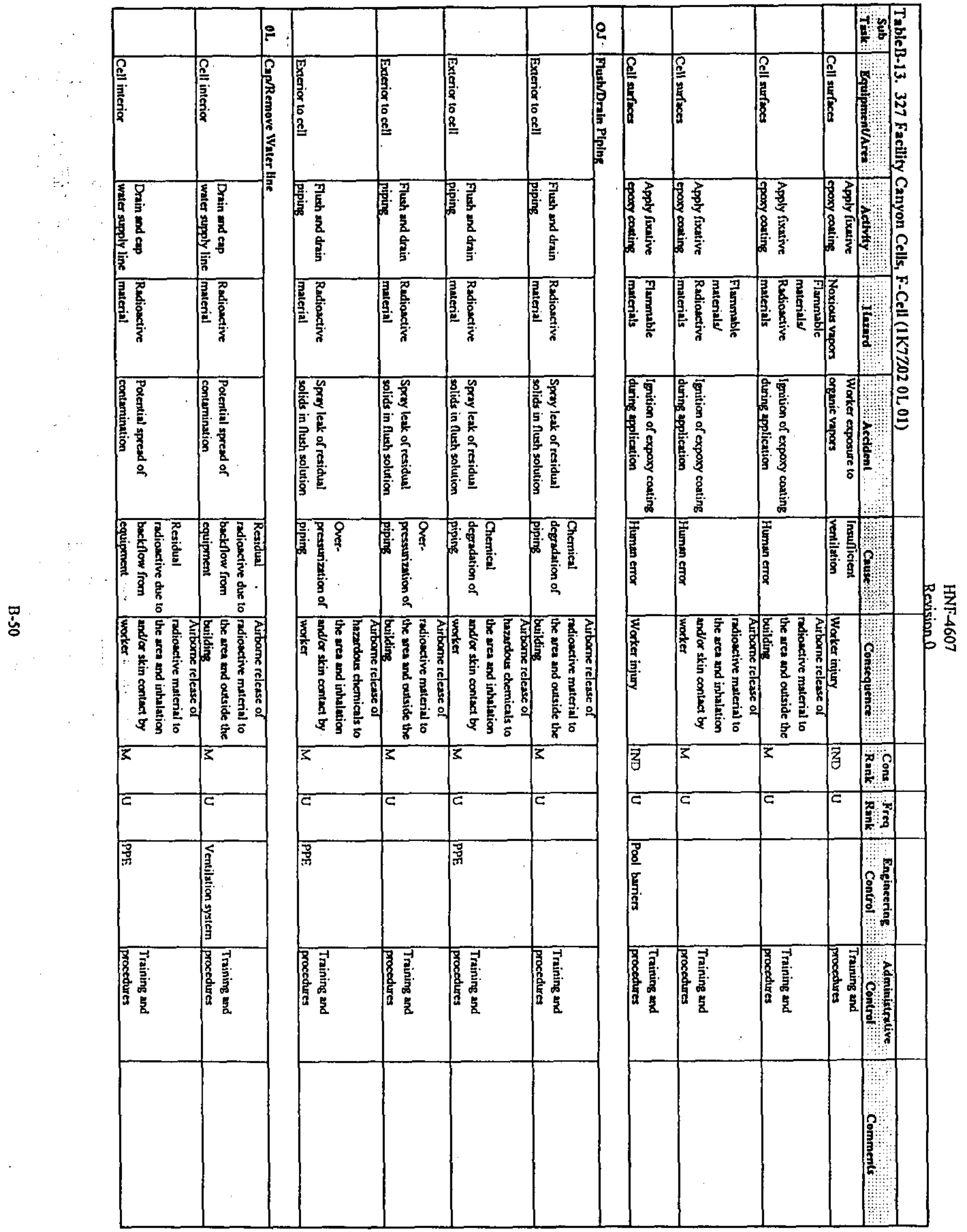




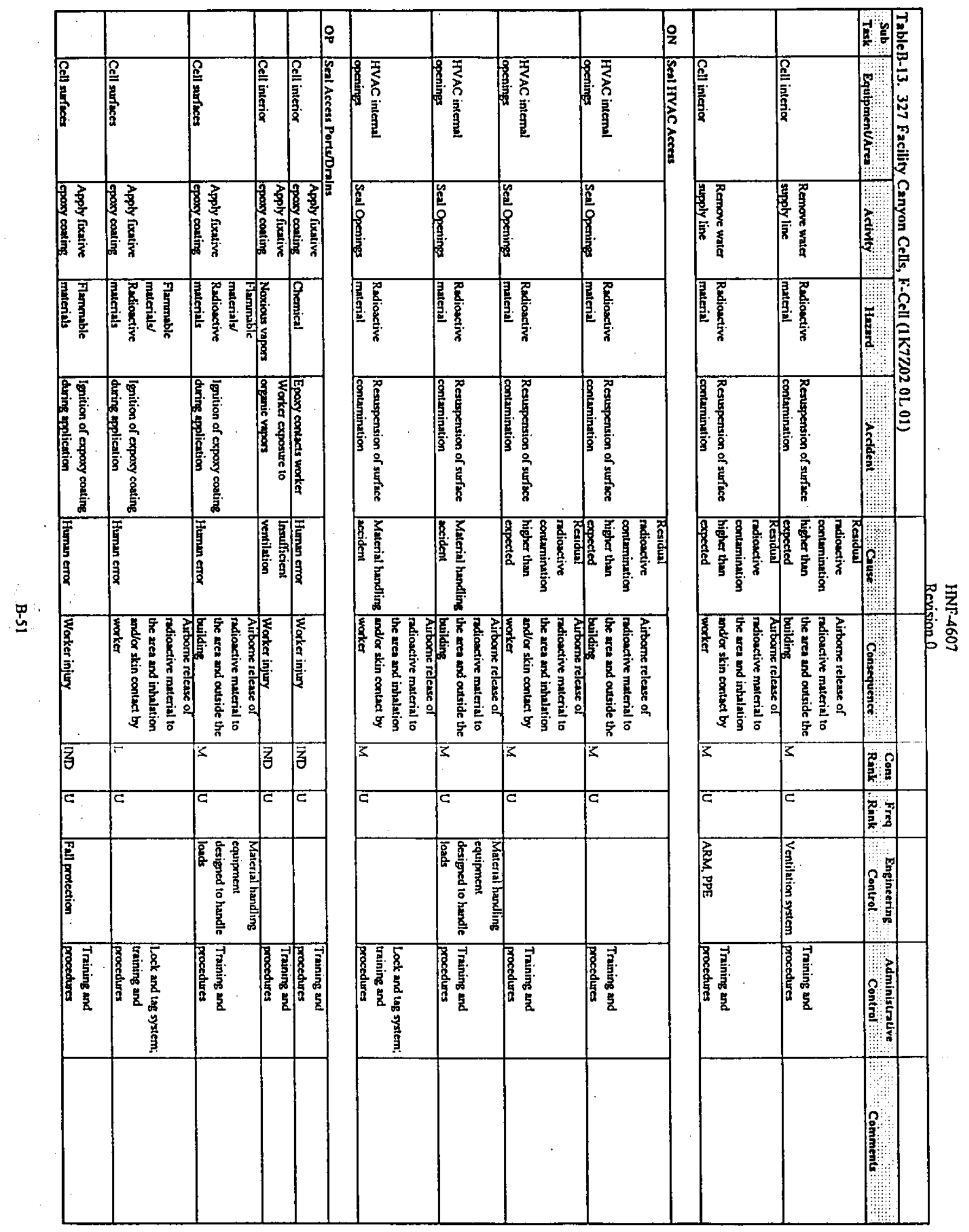




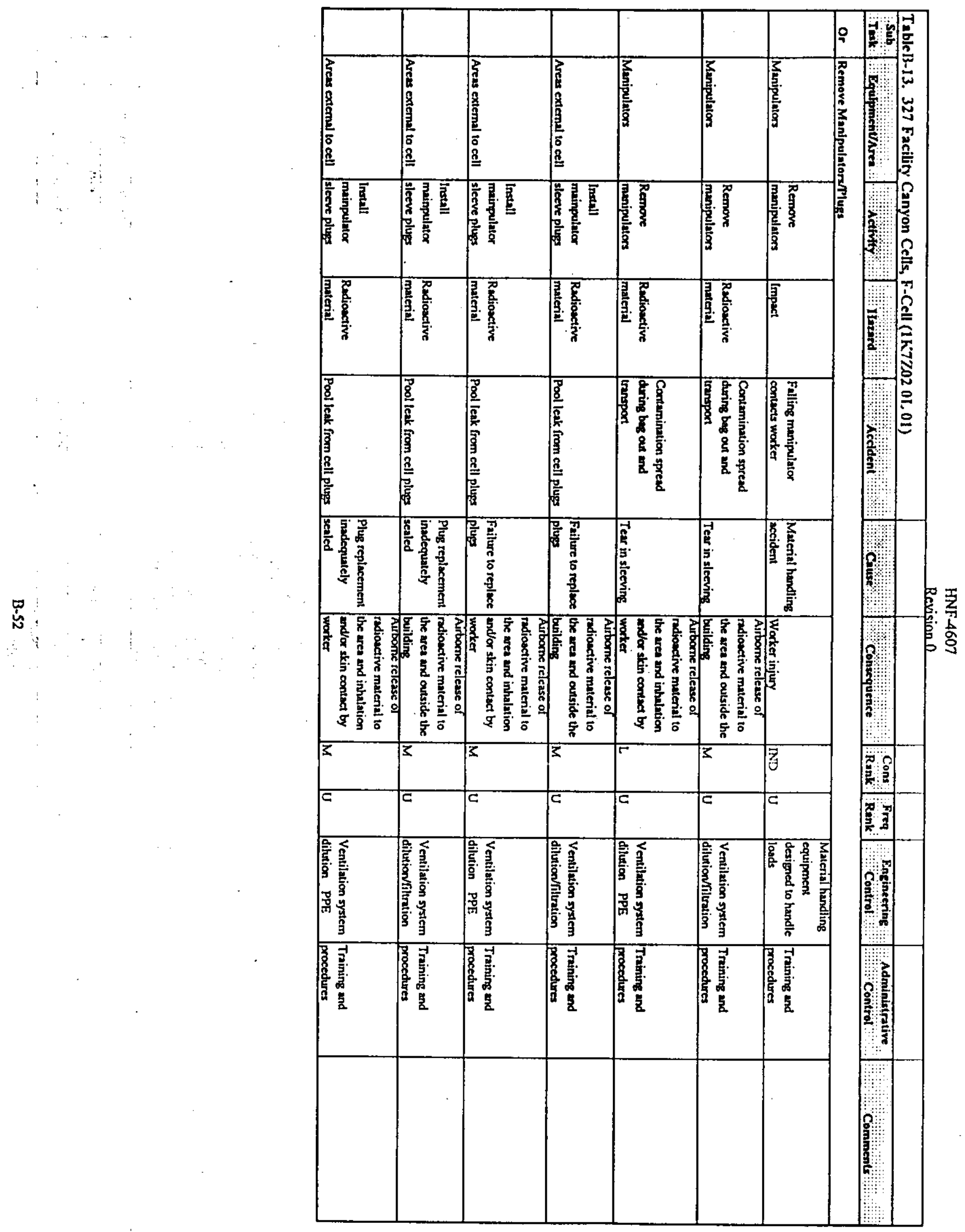




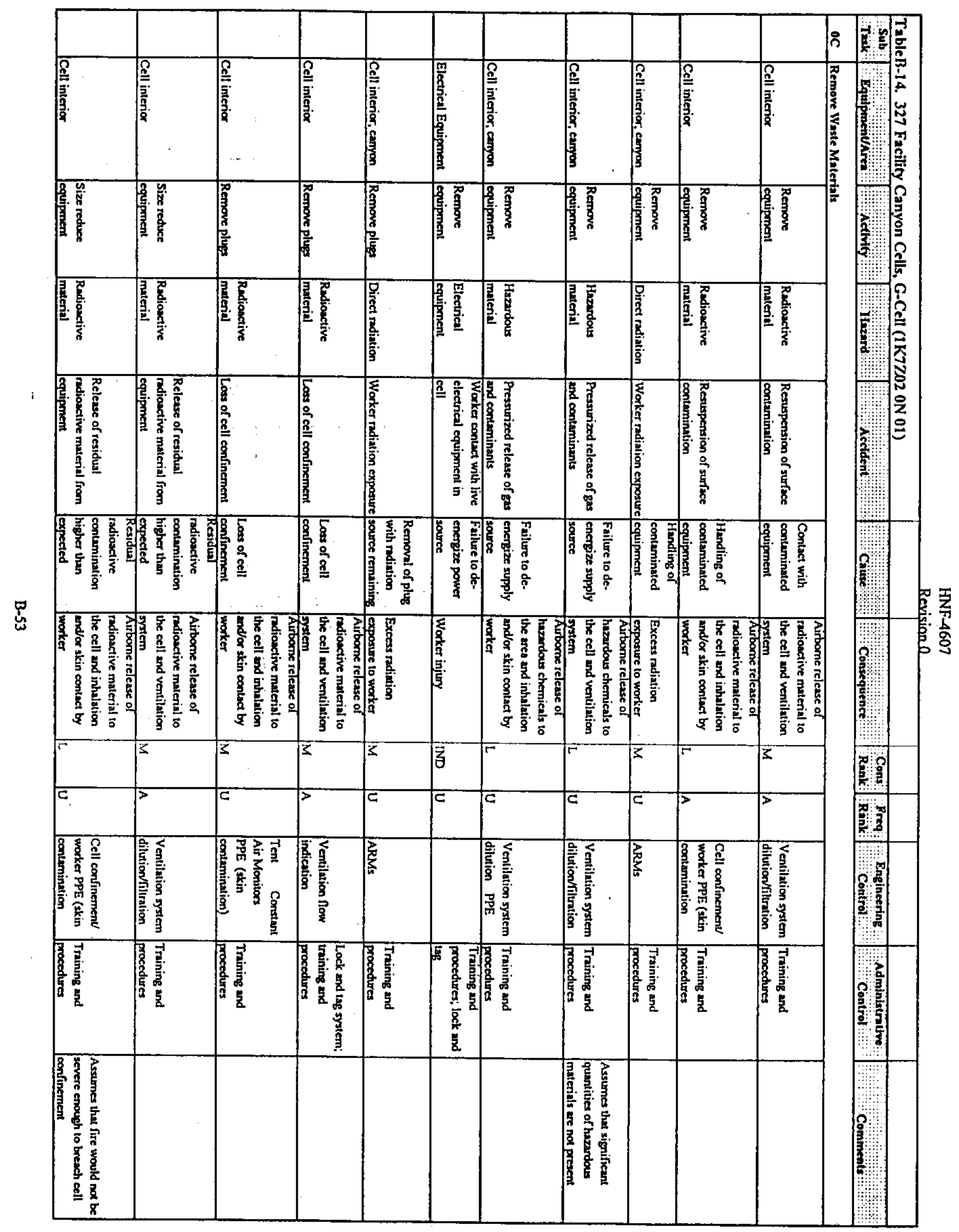




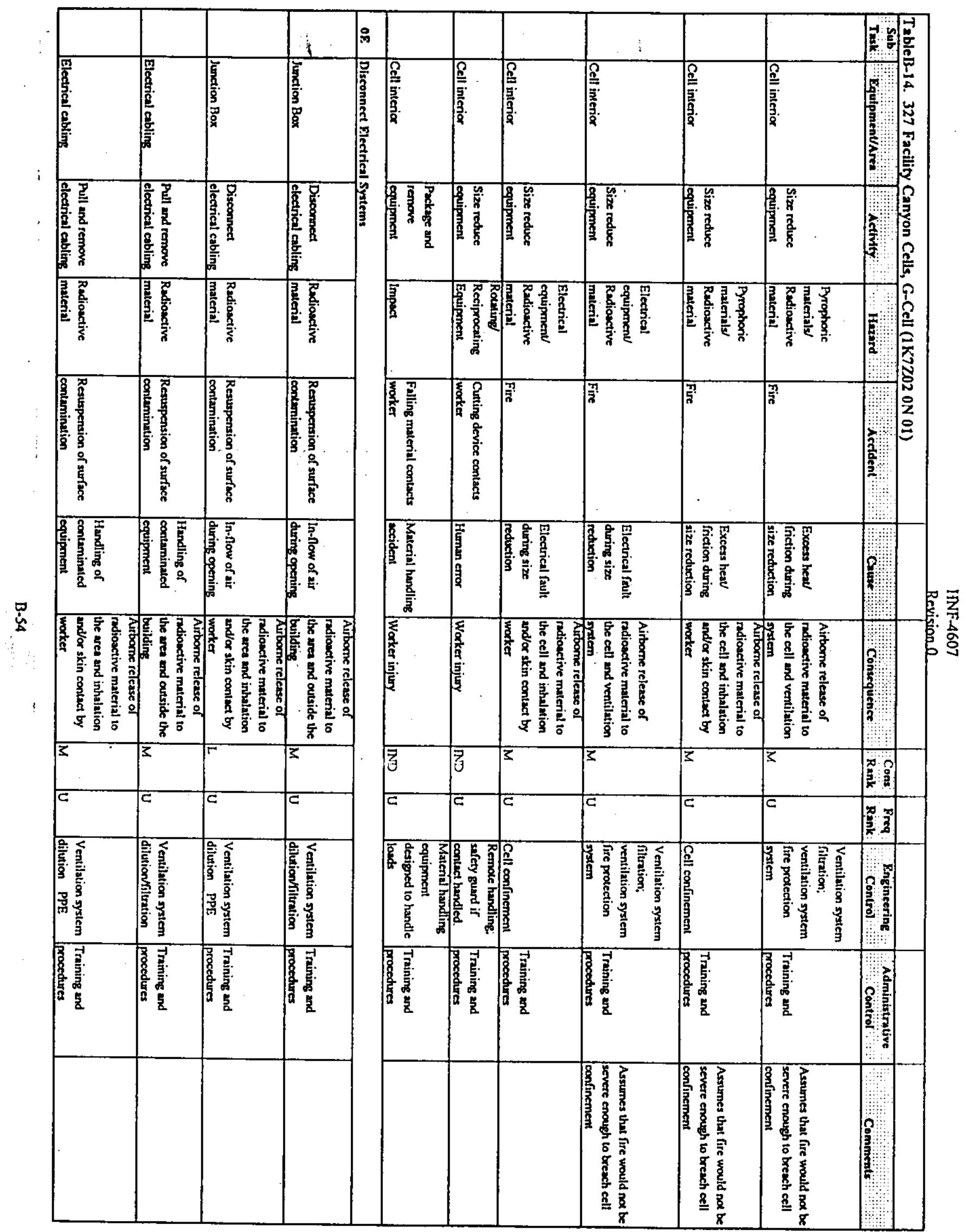




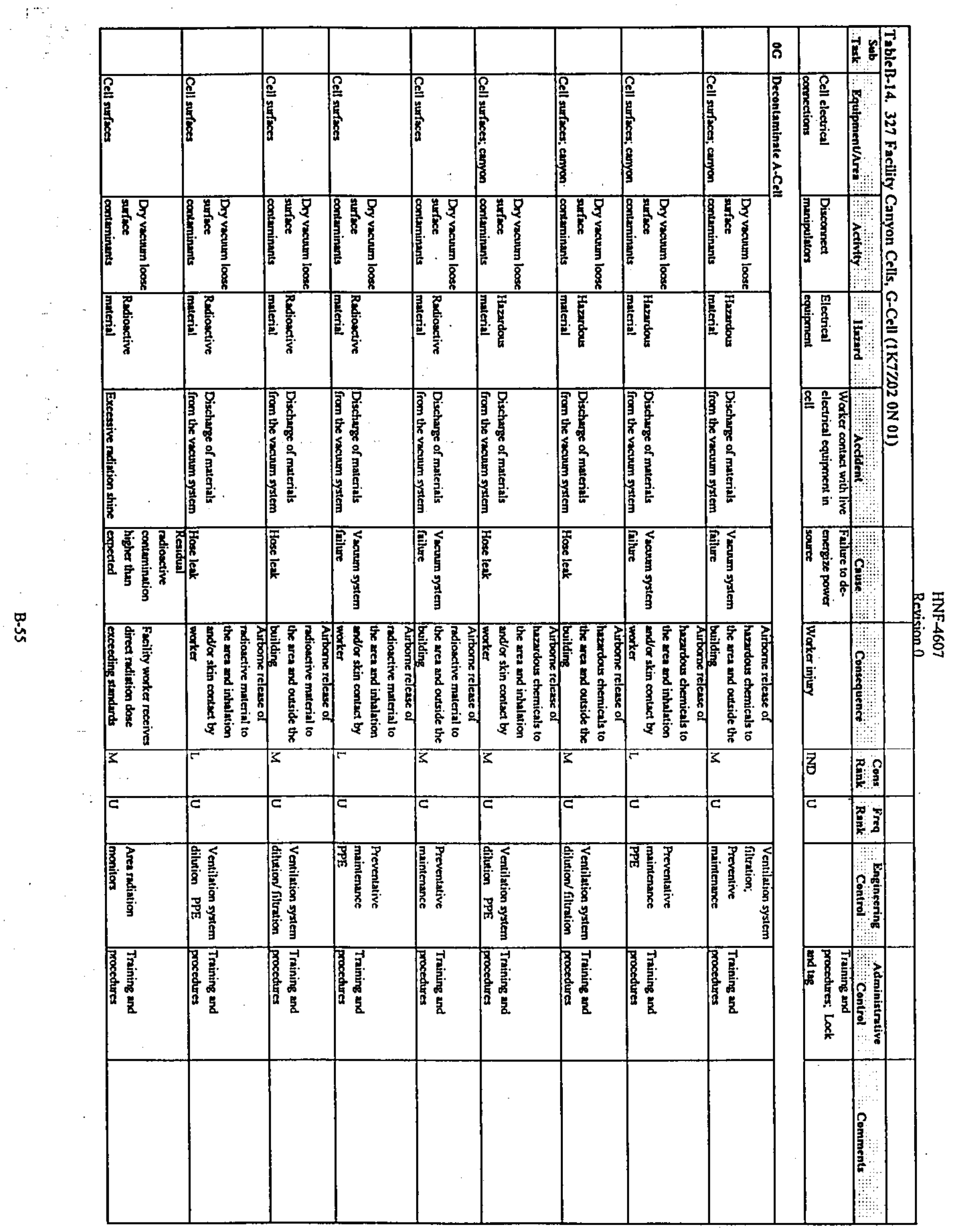




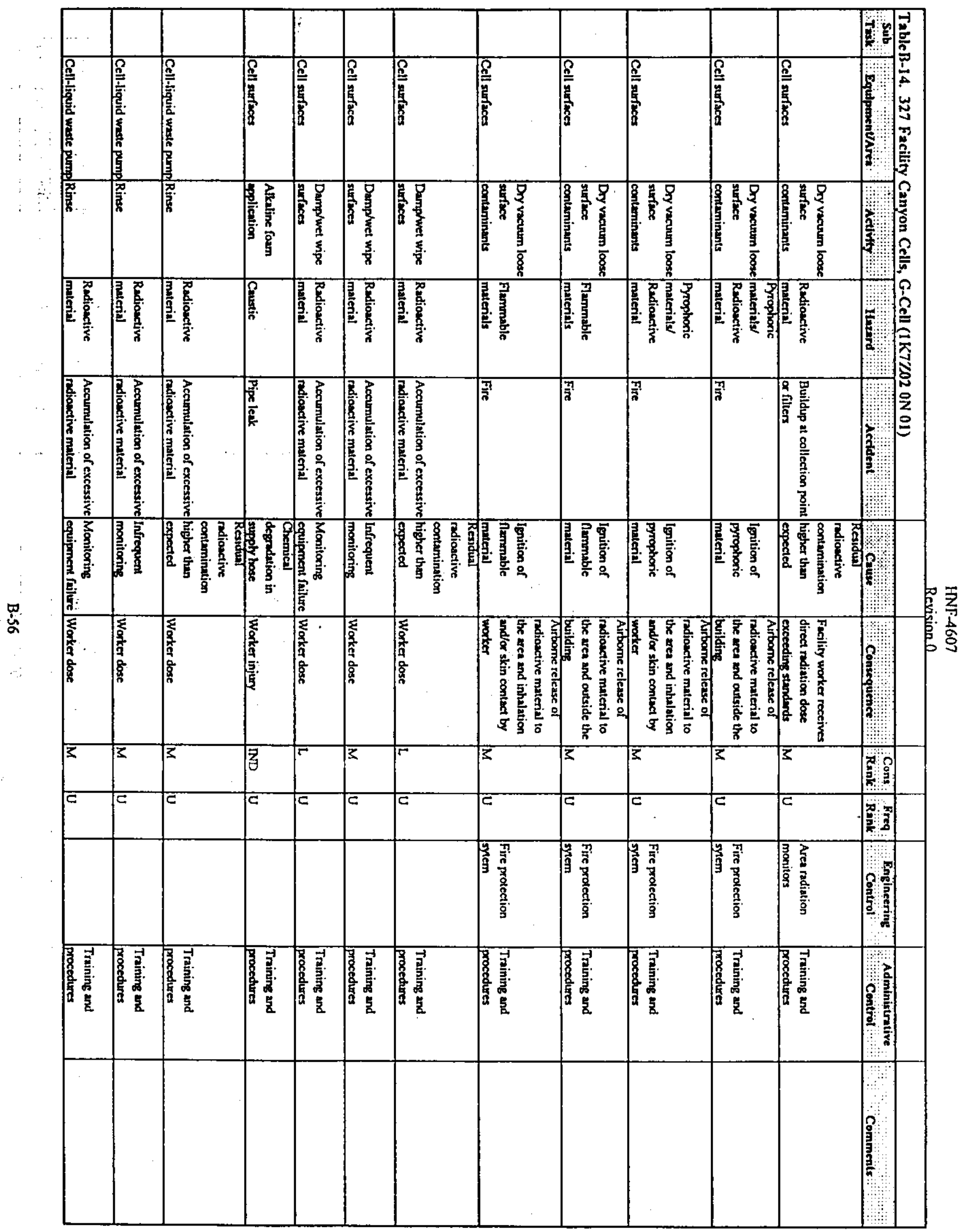




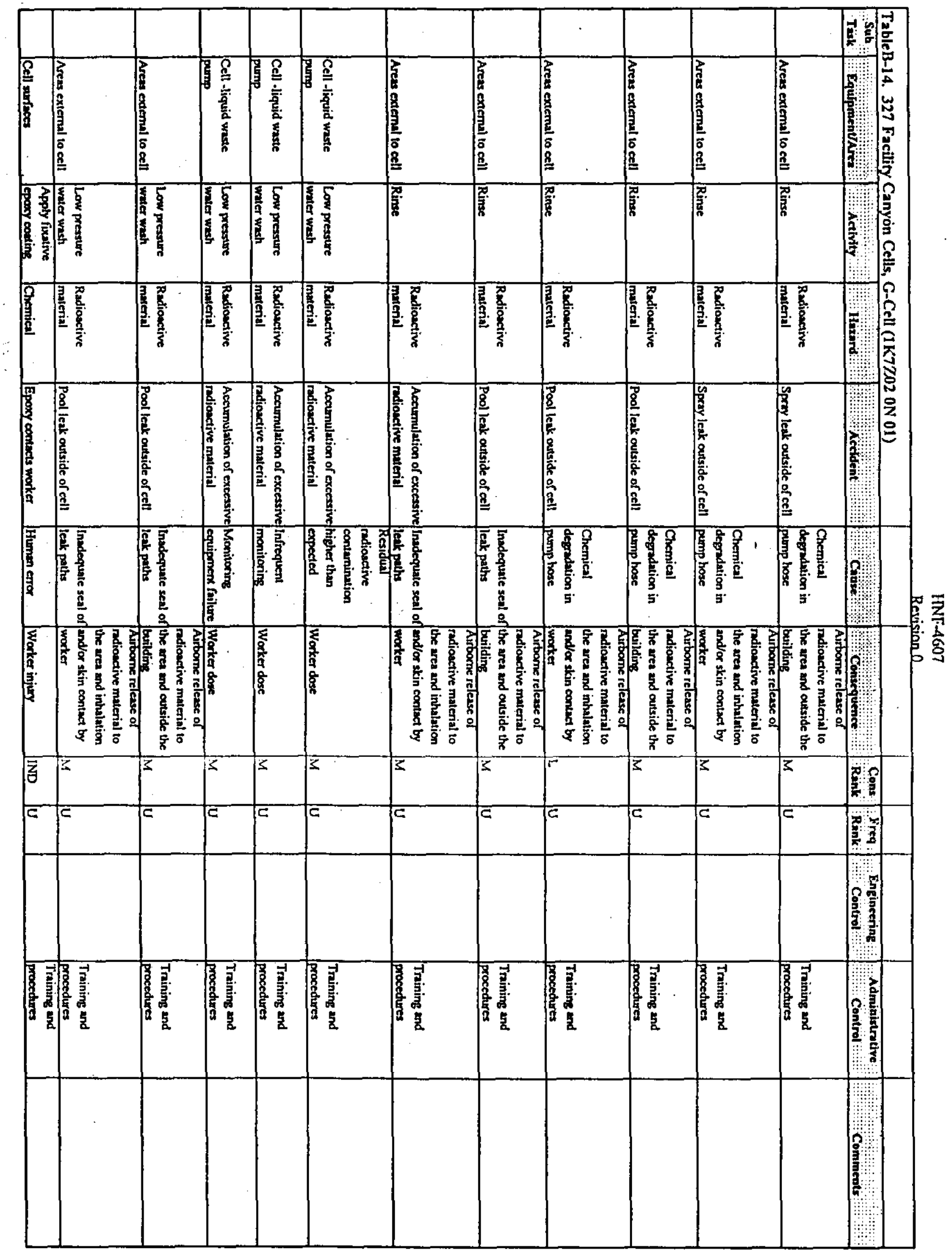




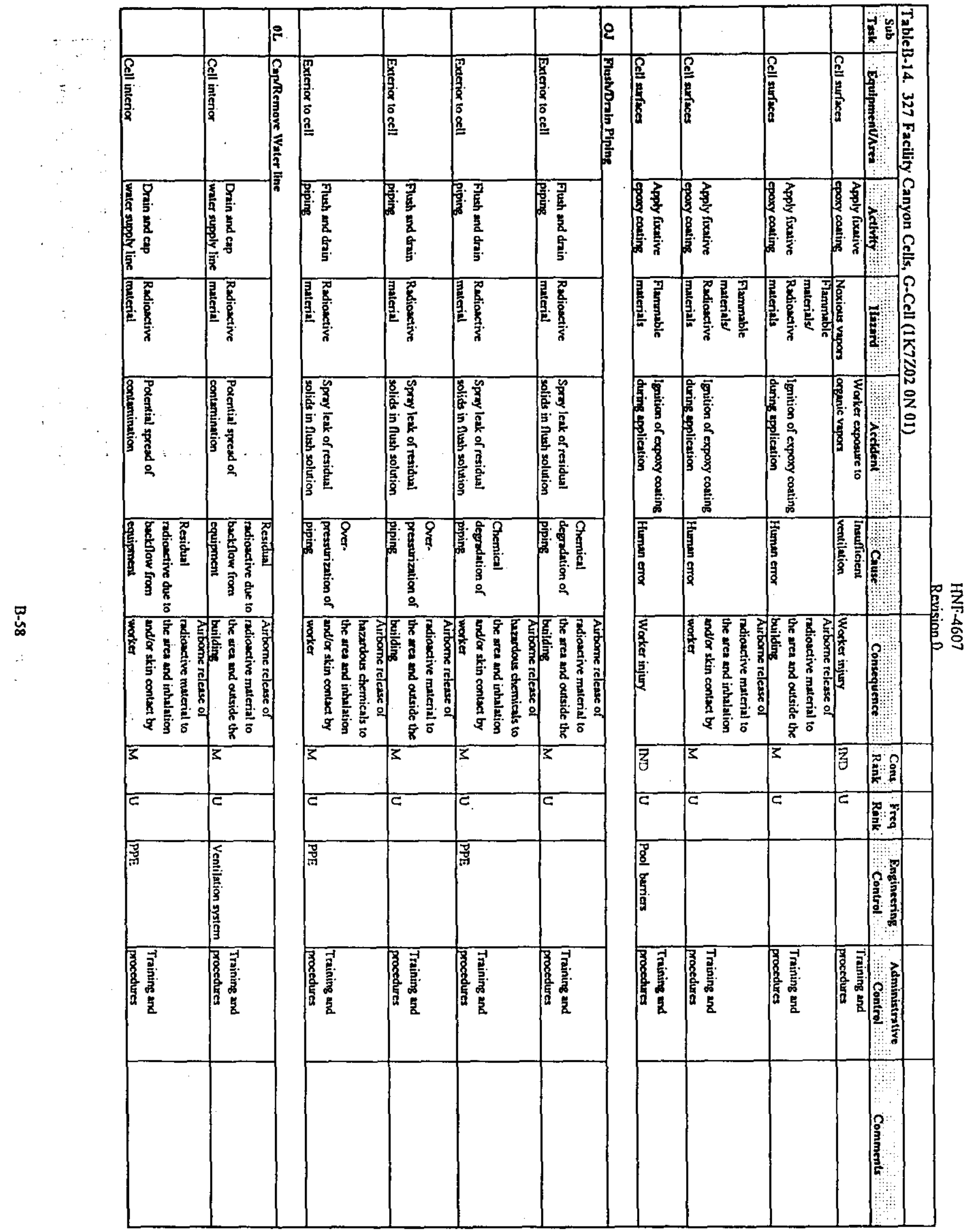




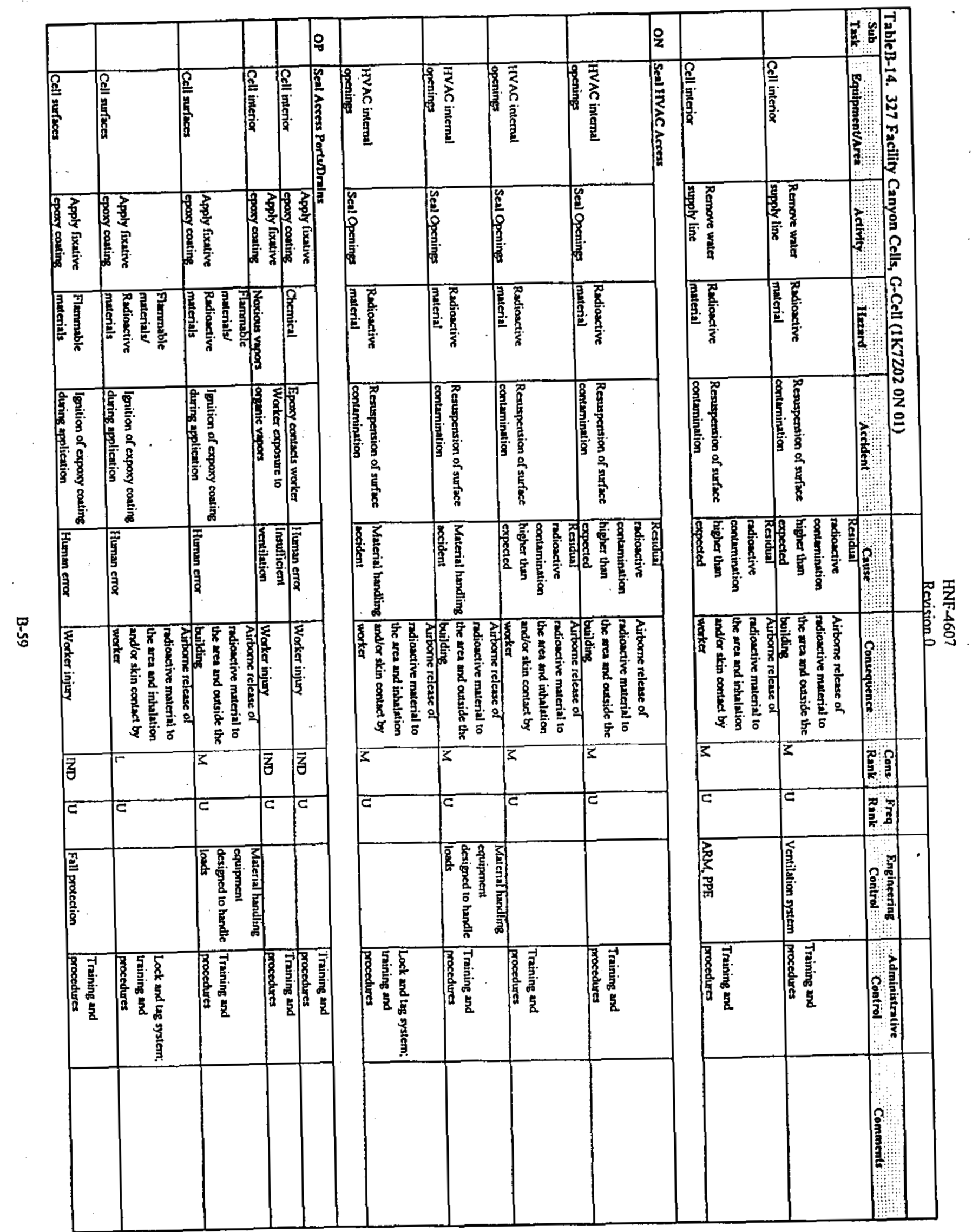




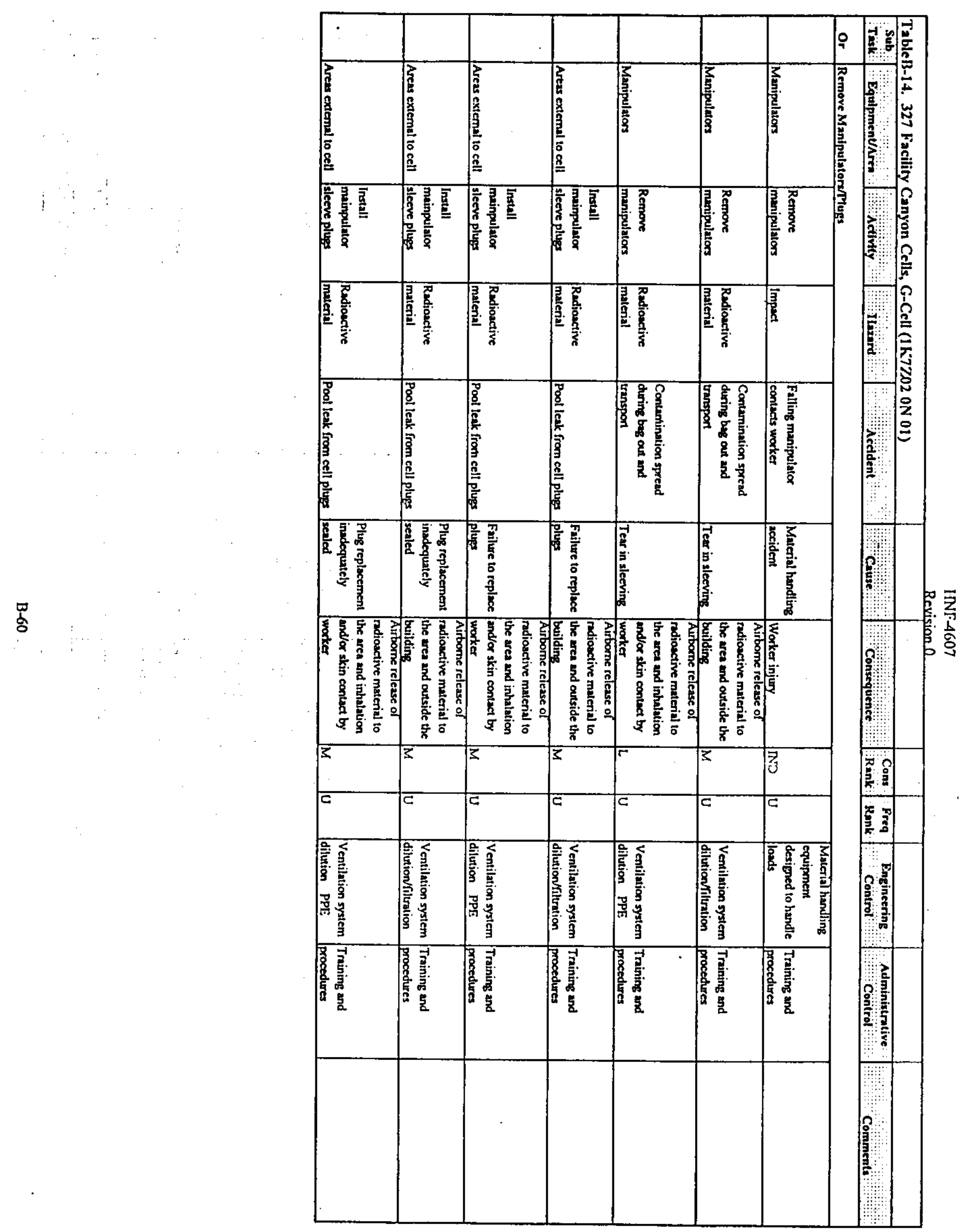




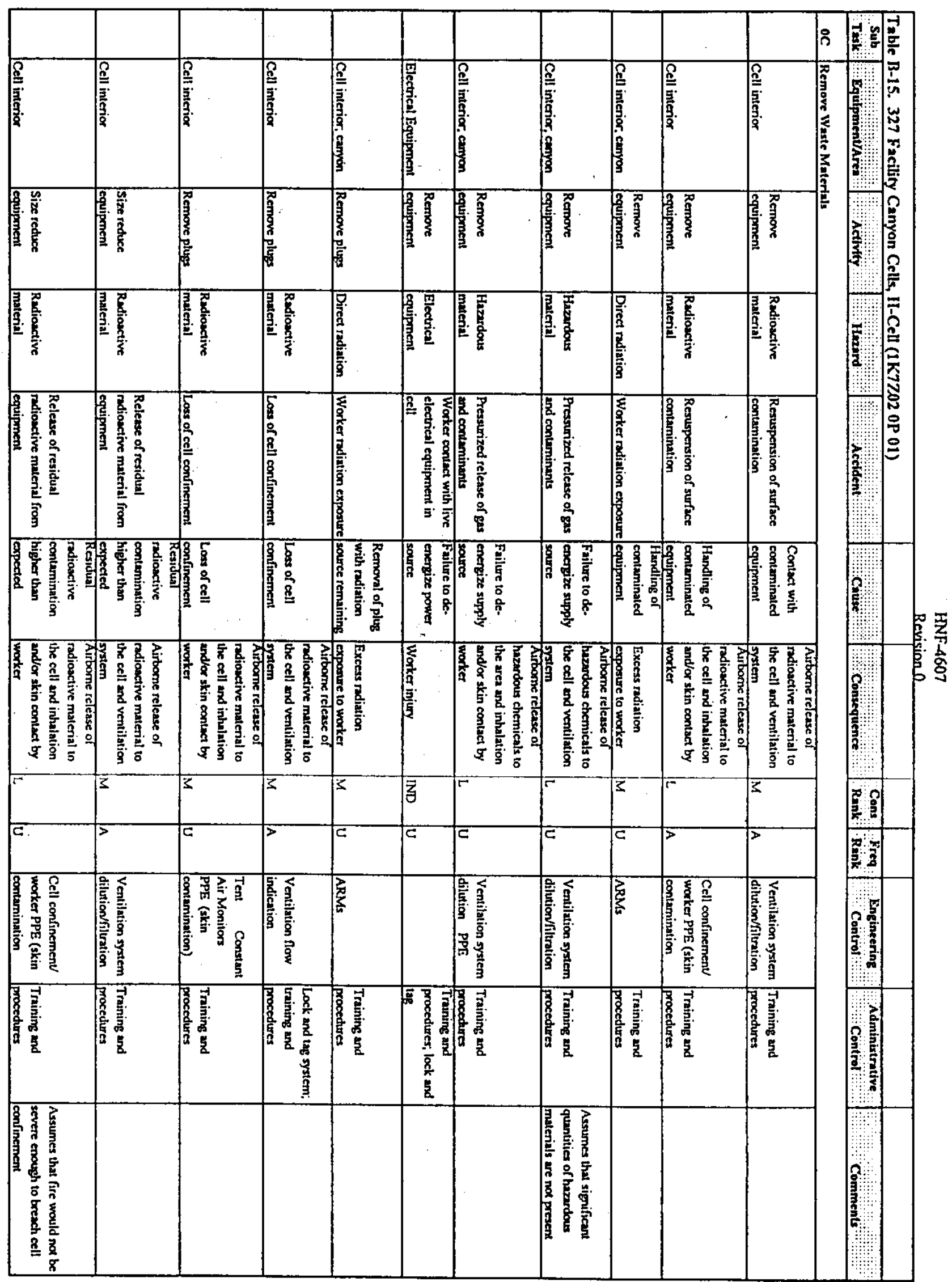




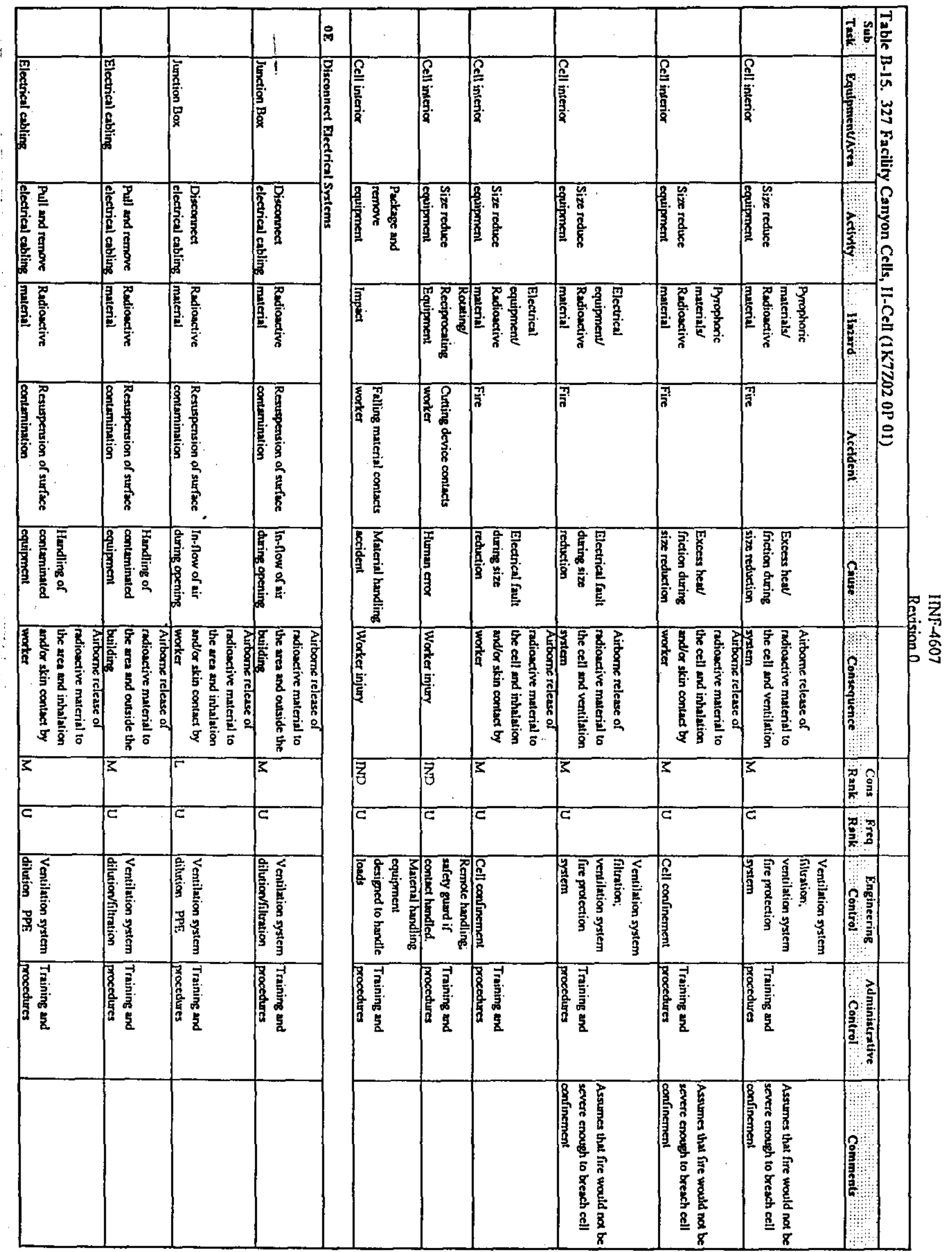




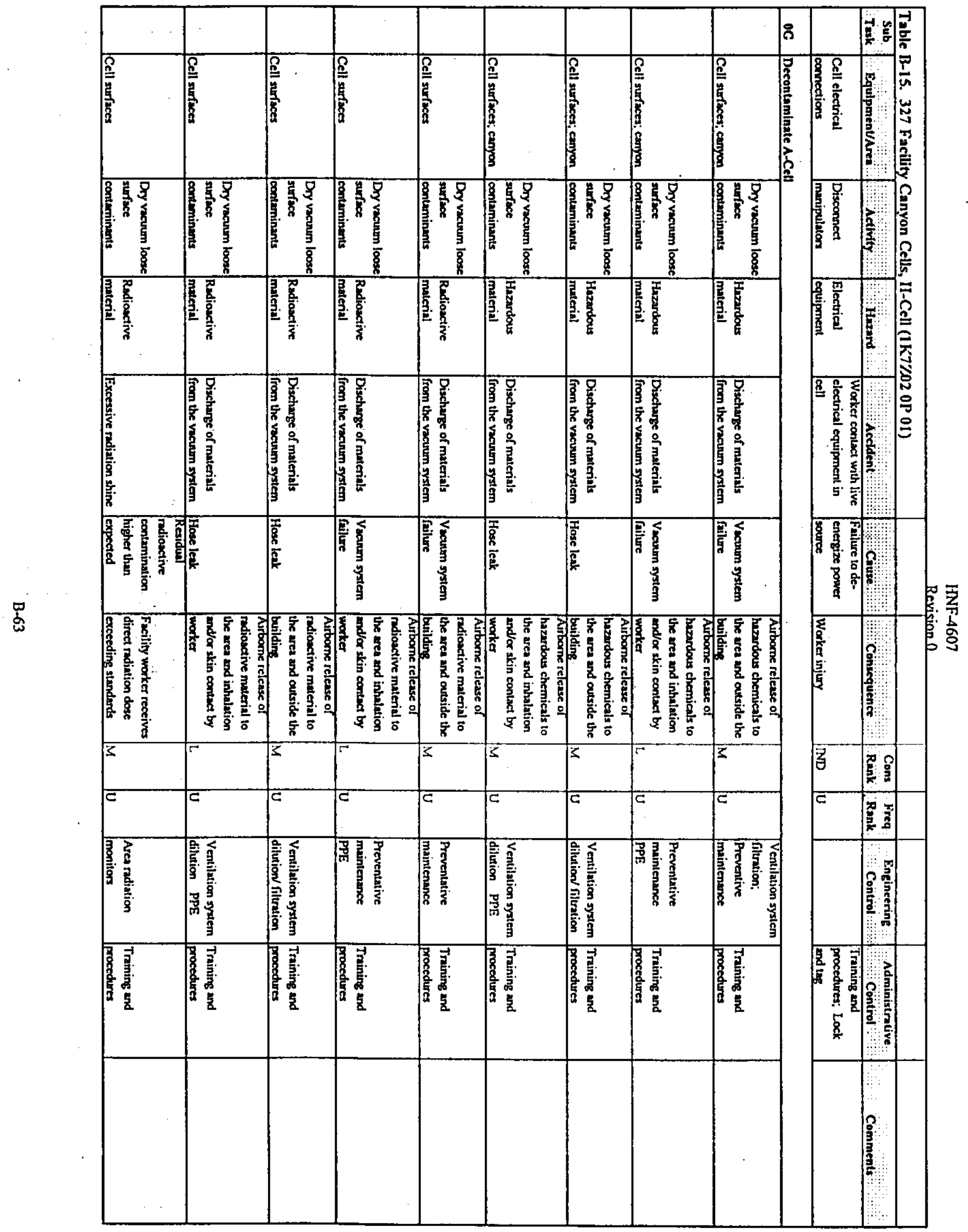




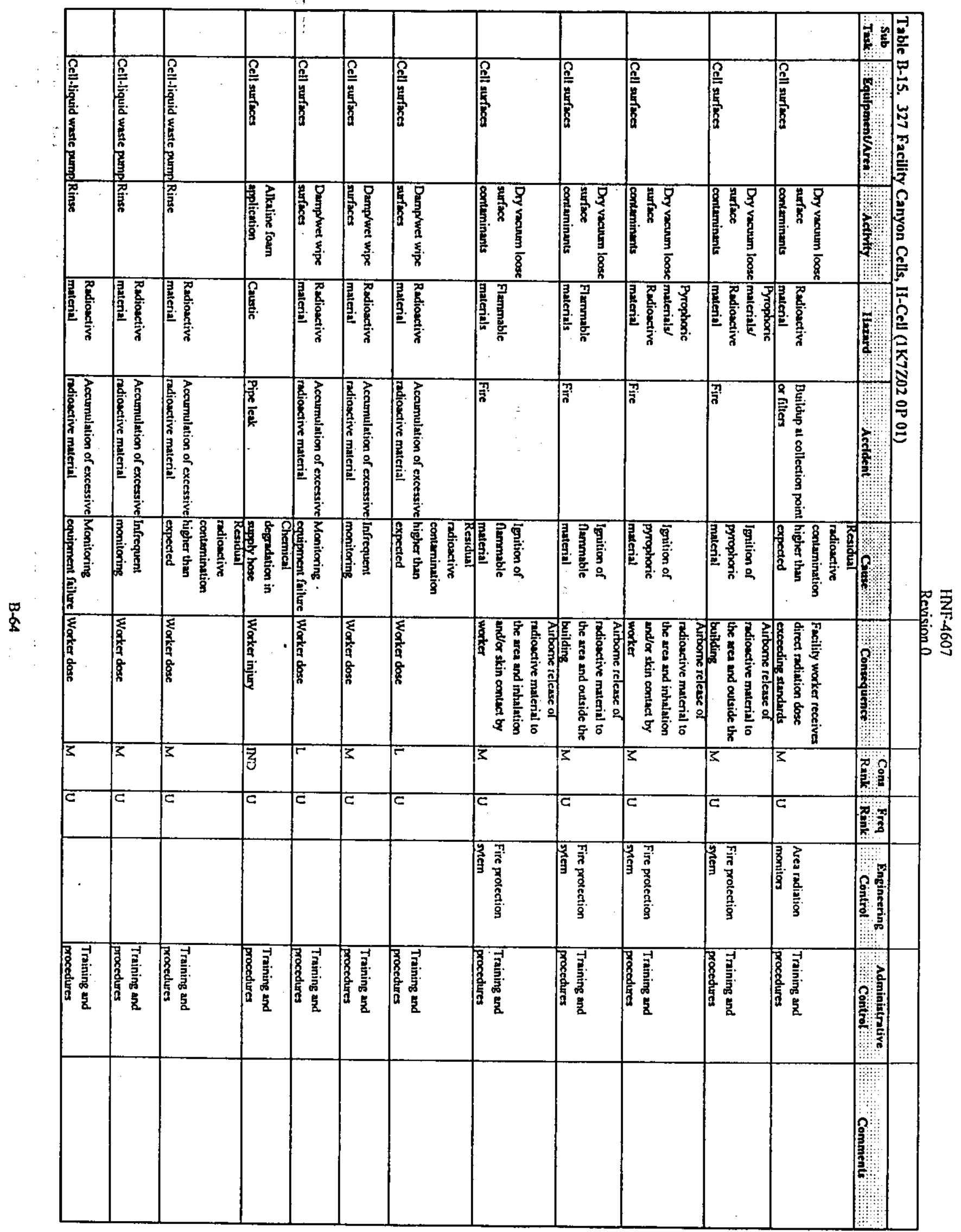




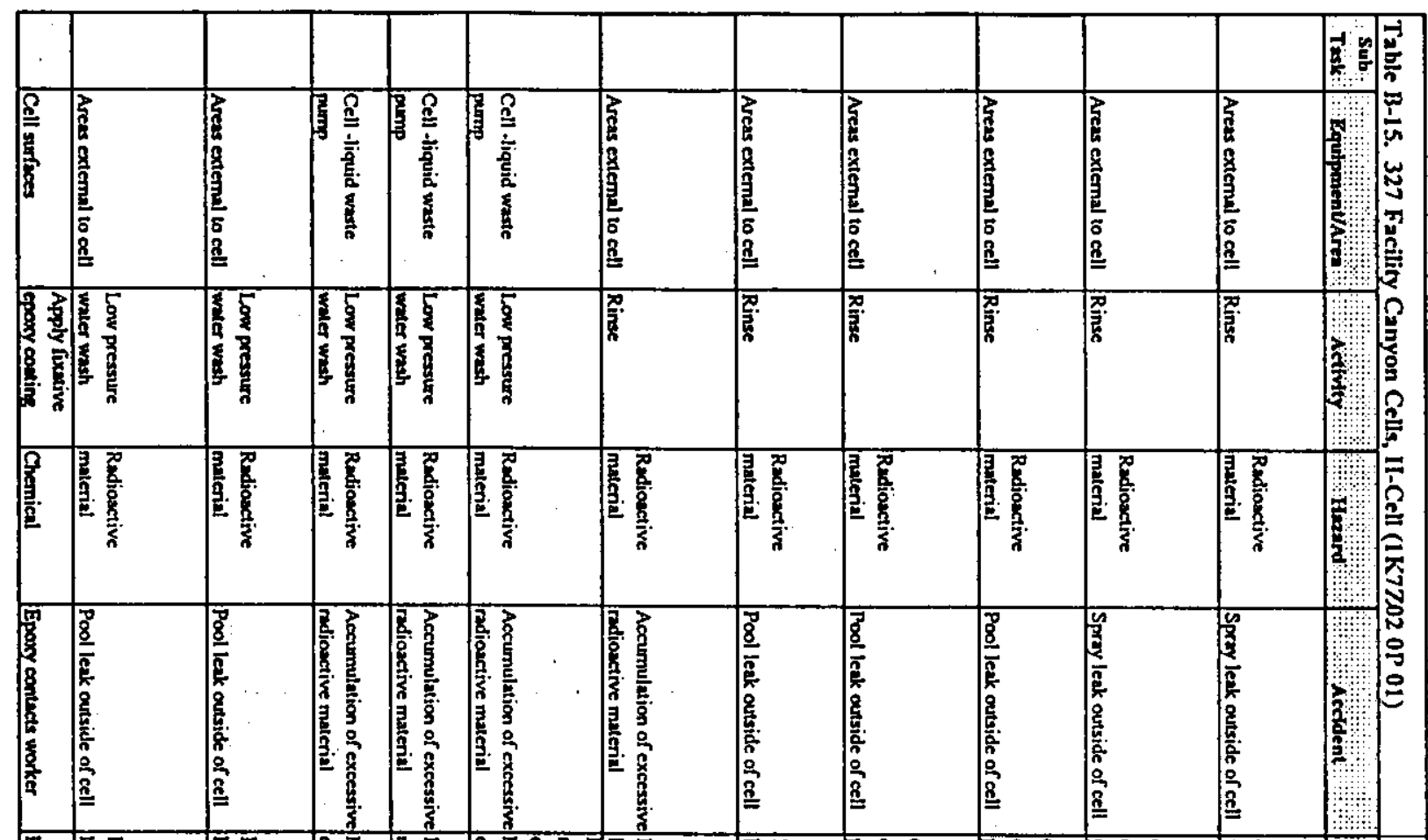

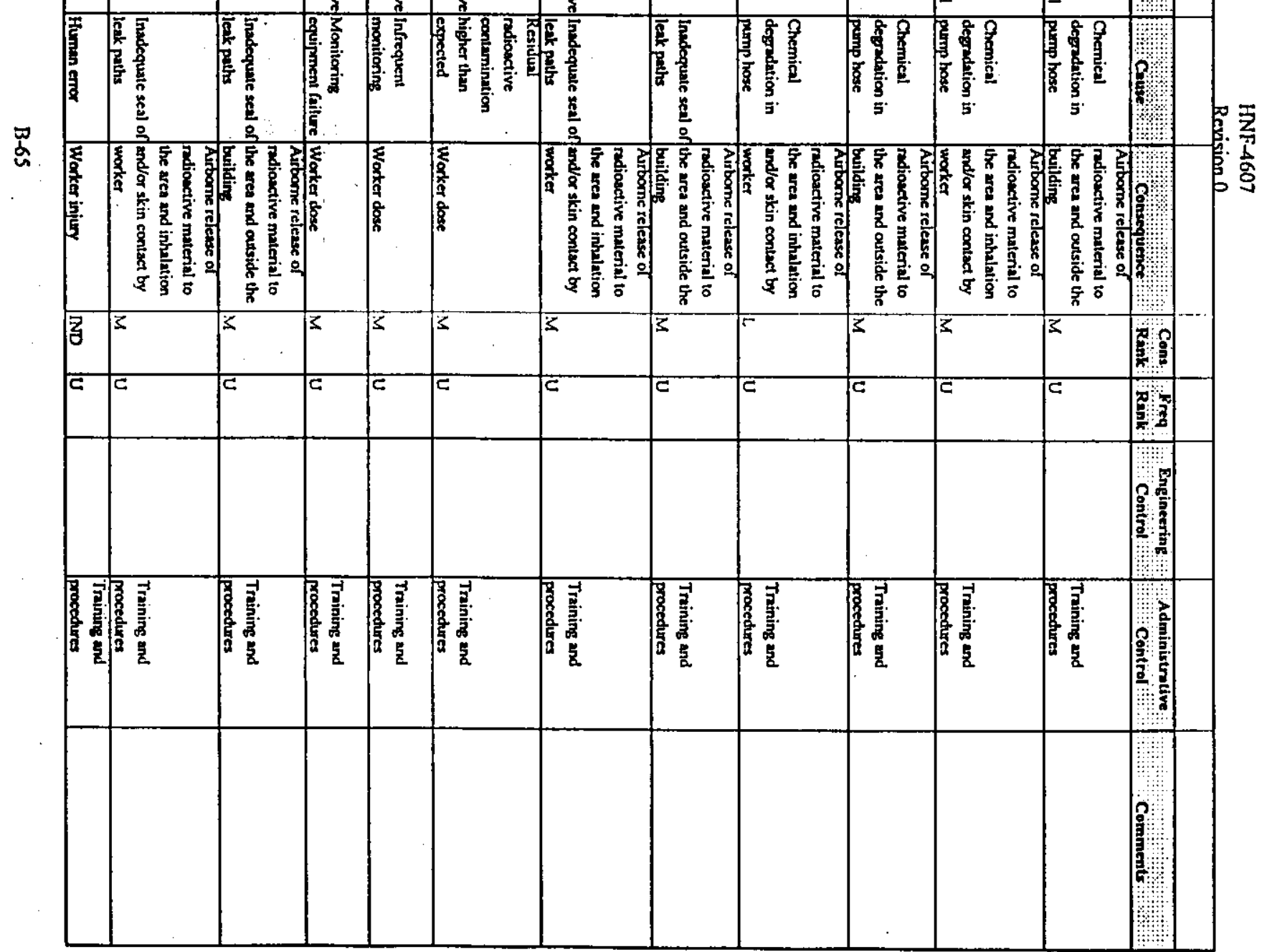




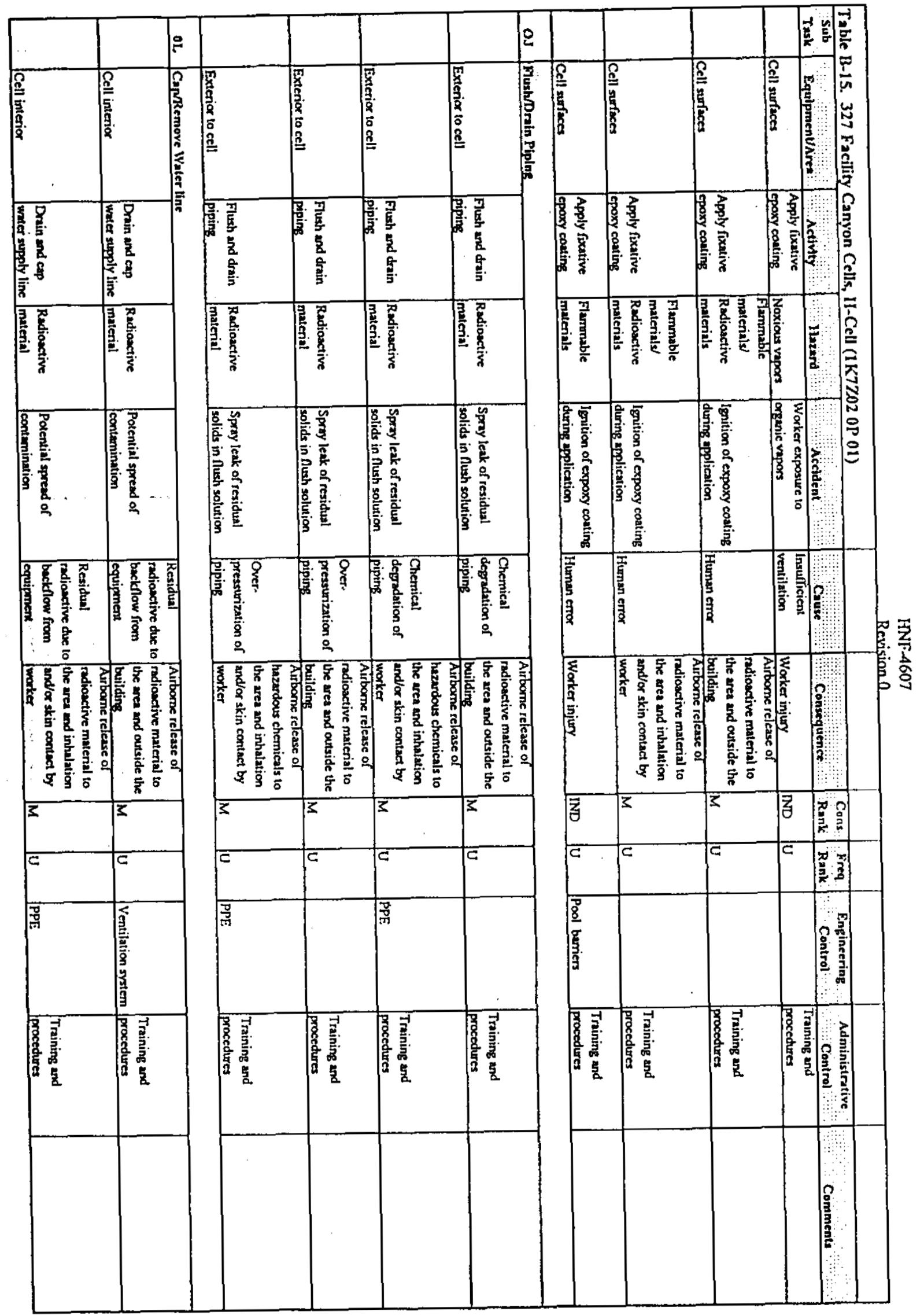




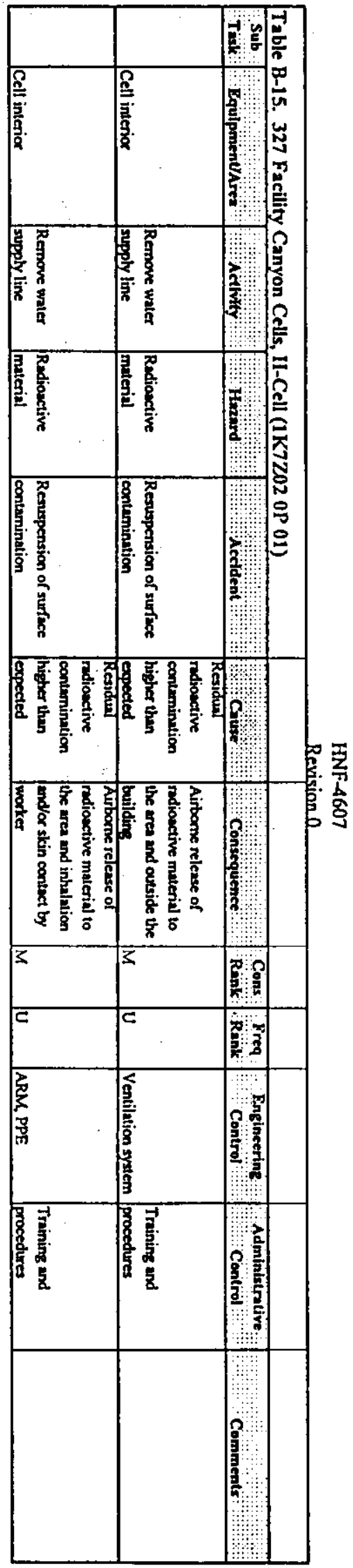




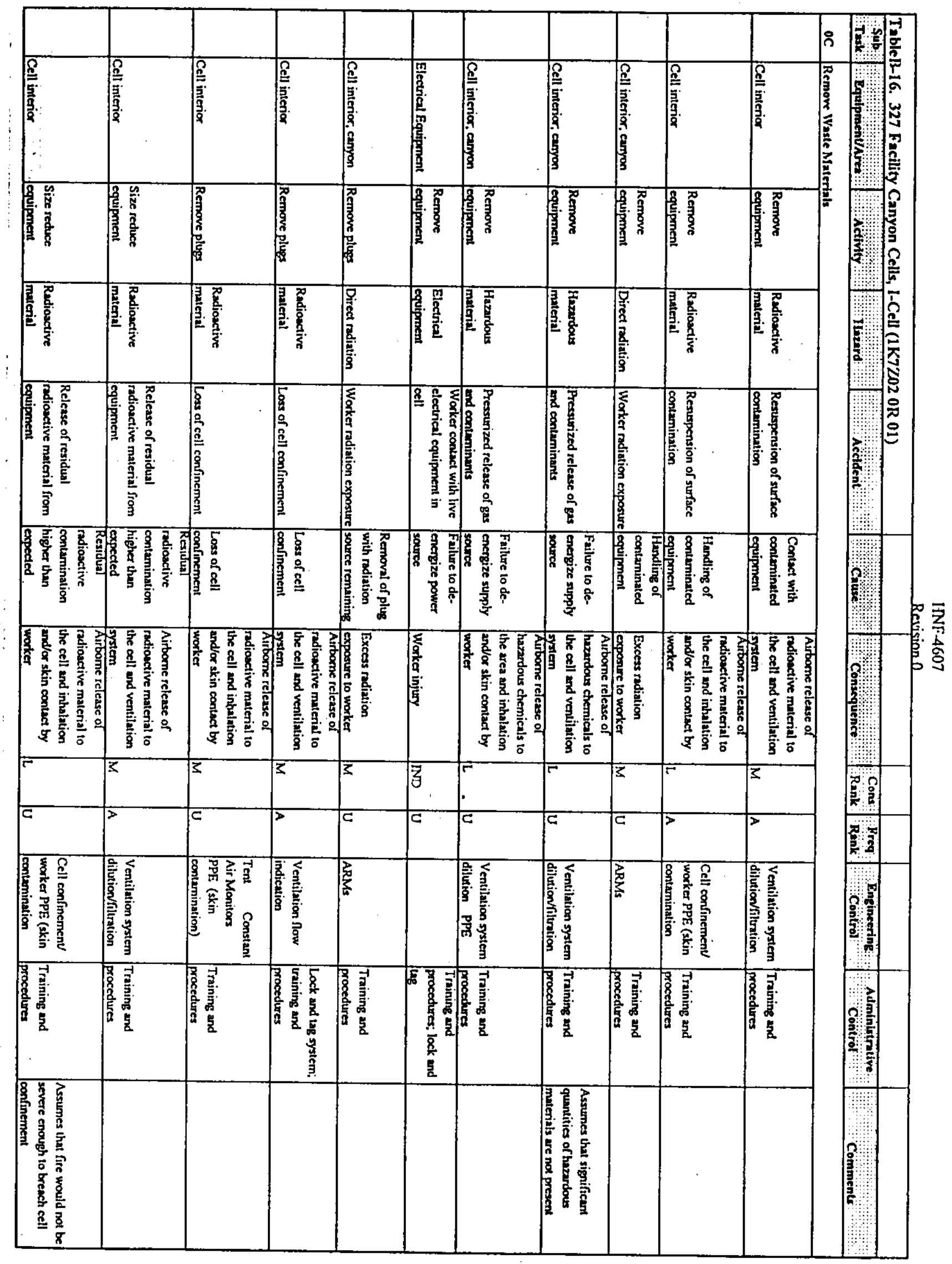




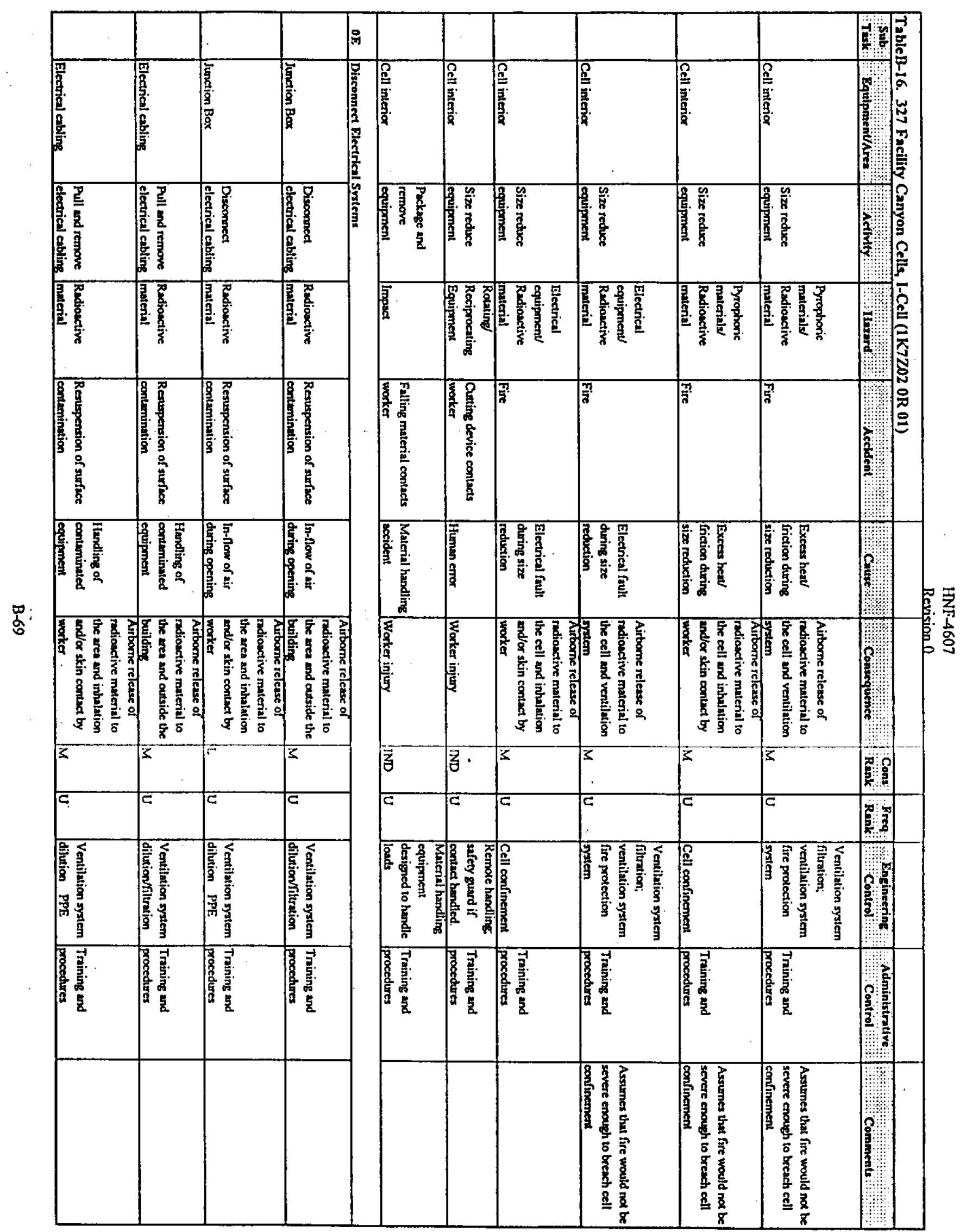




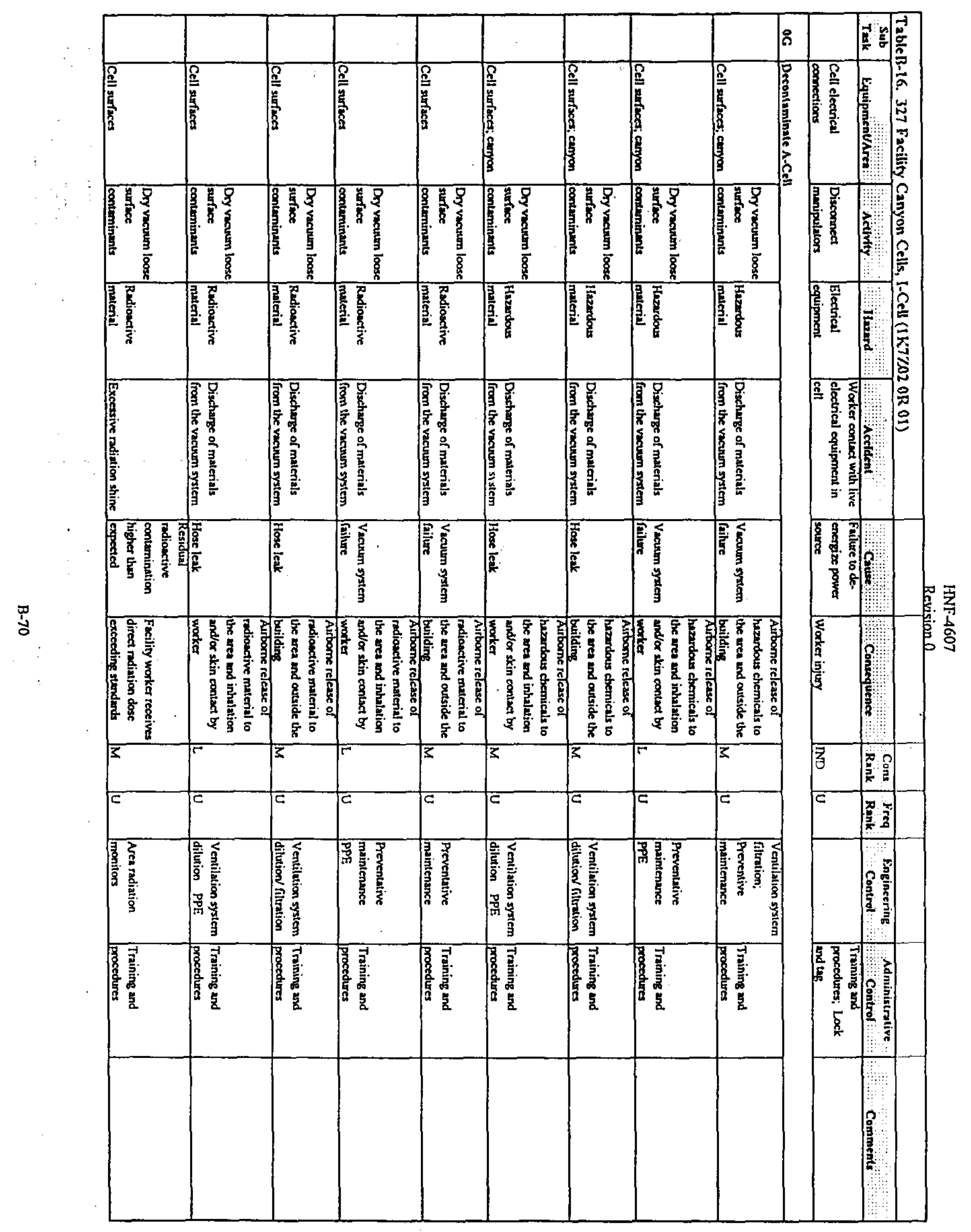




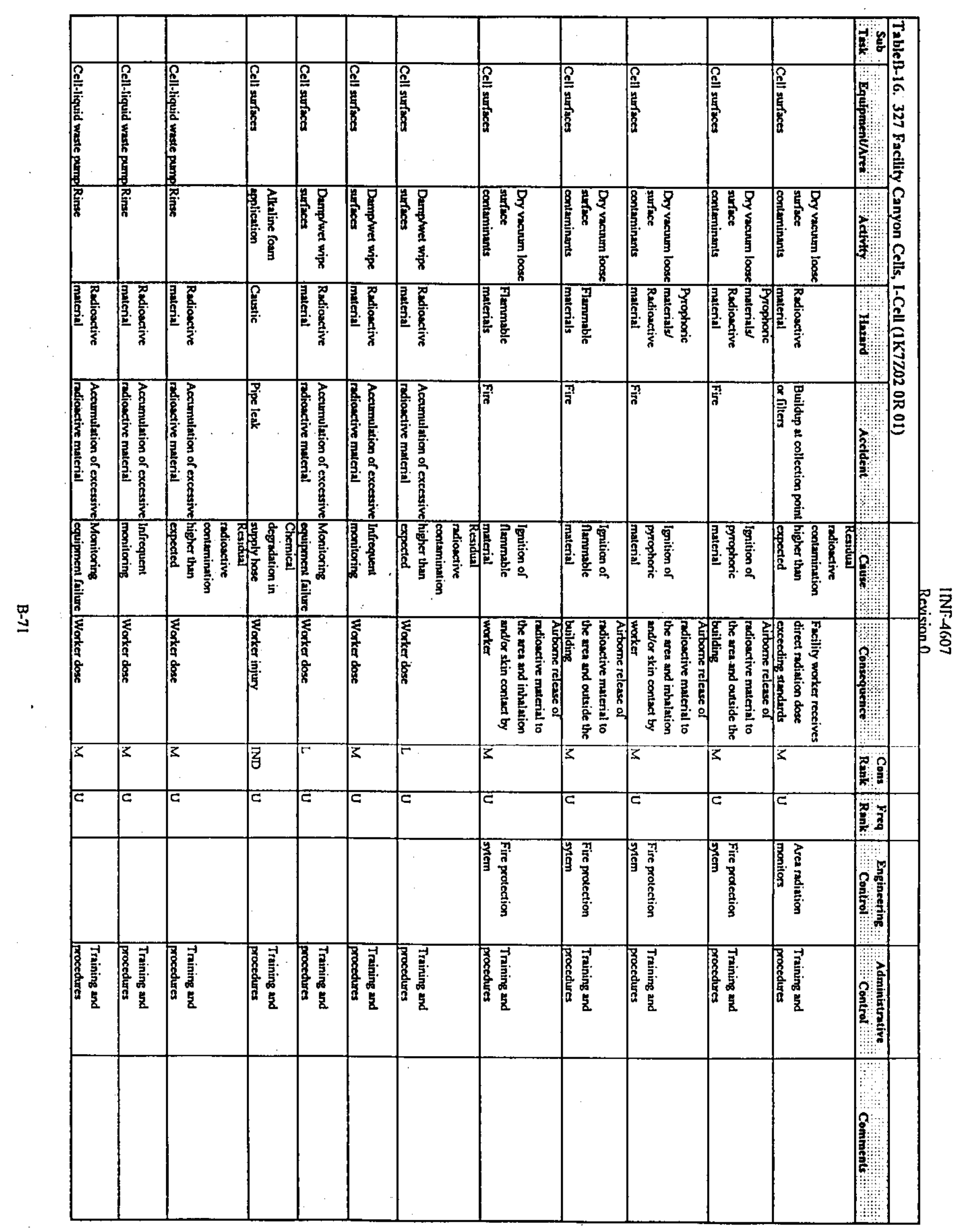




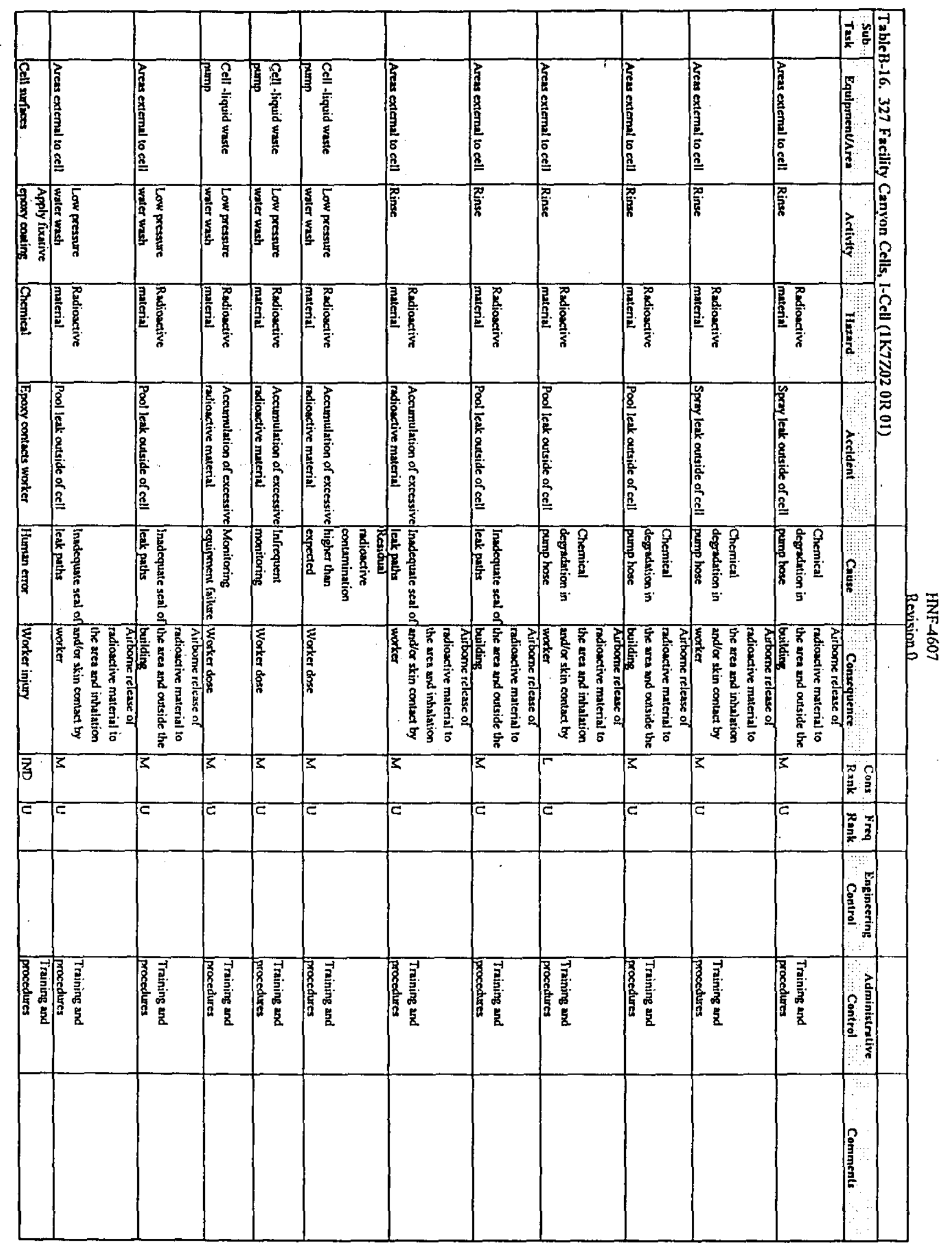




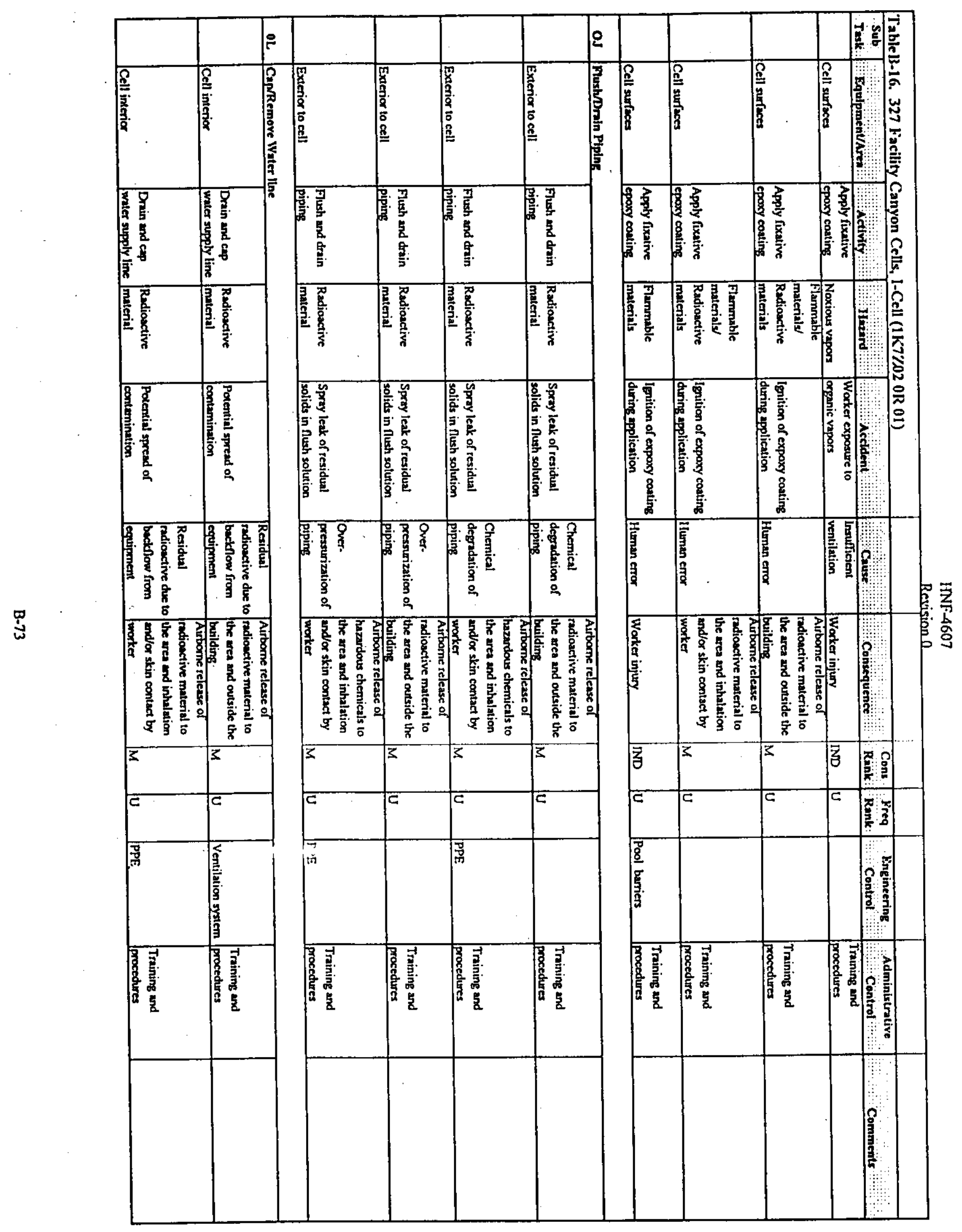




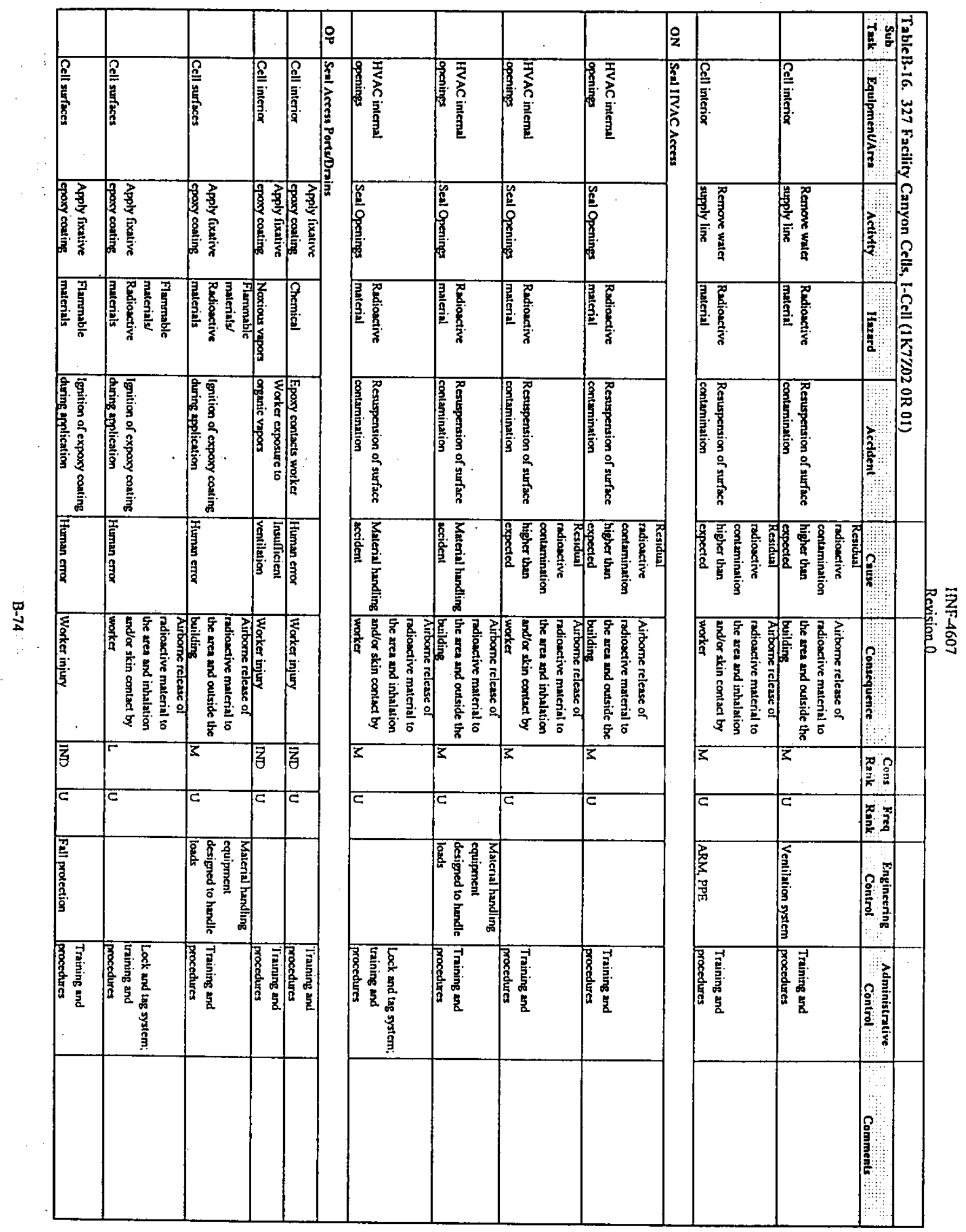


罜

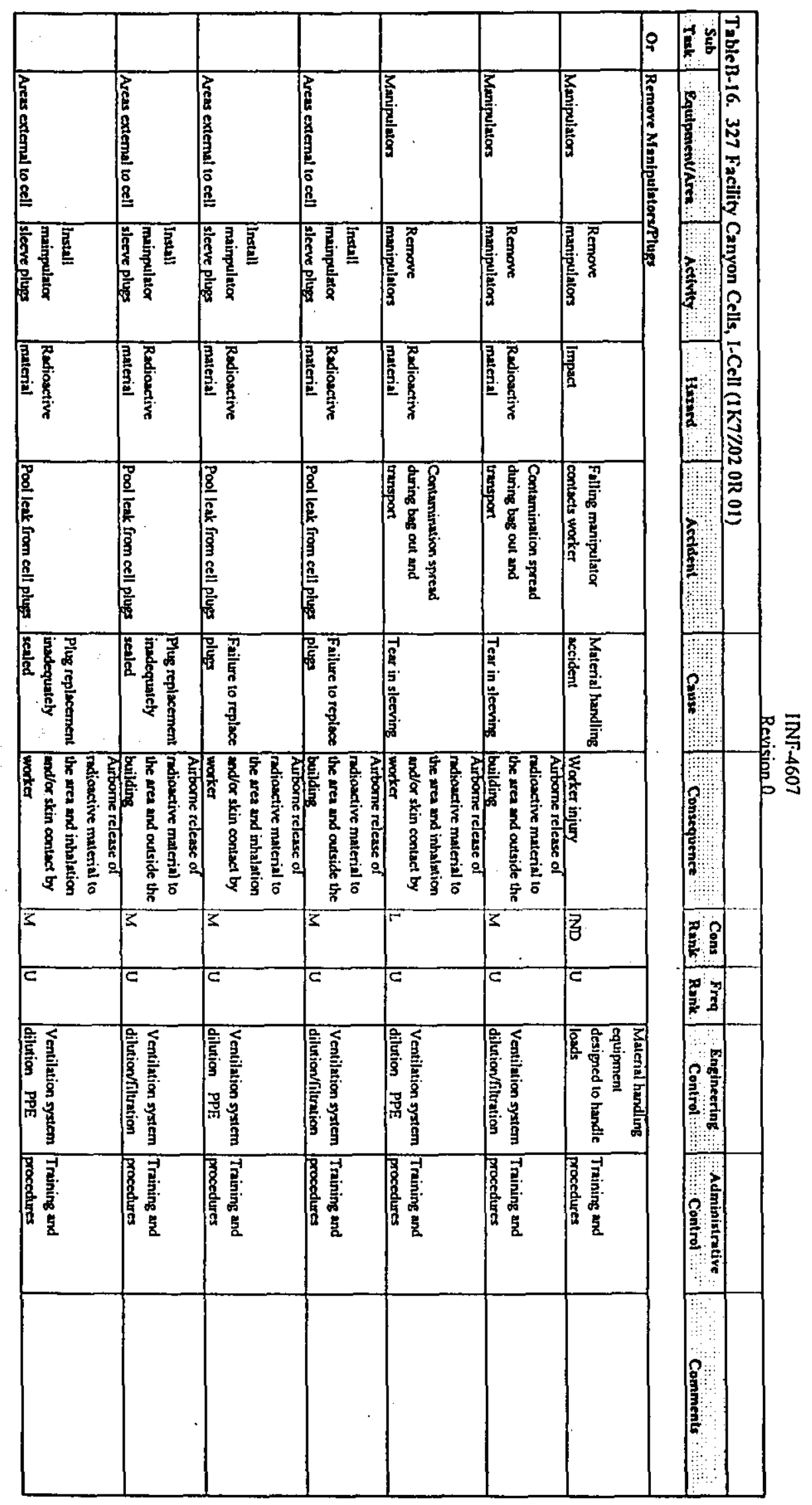




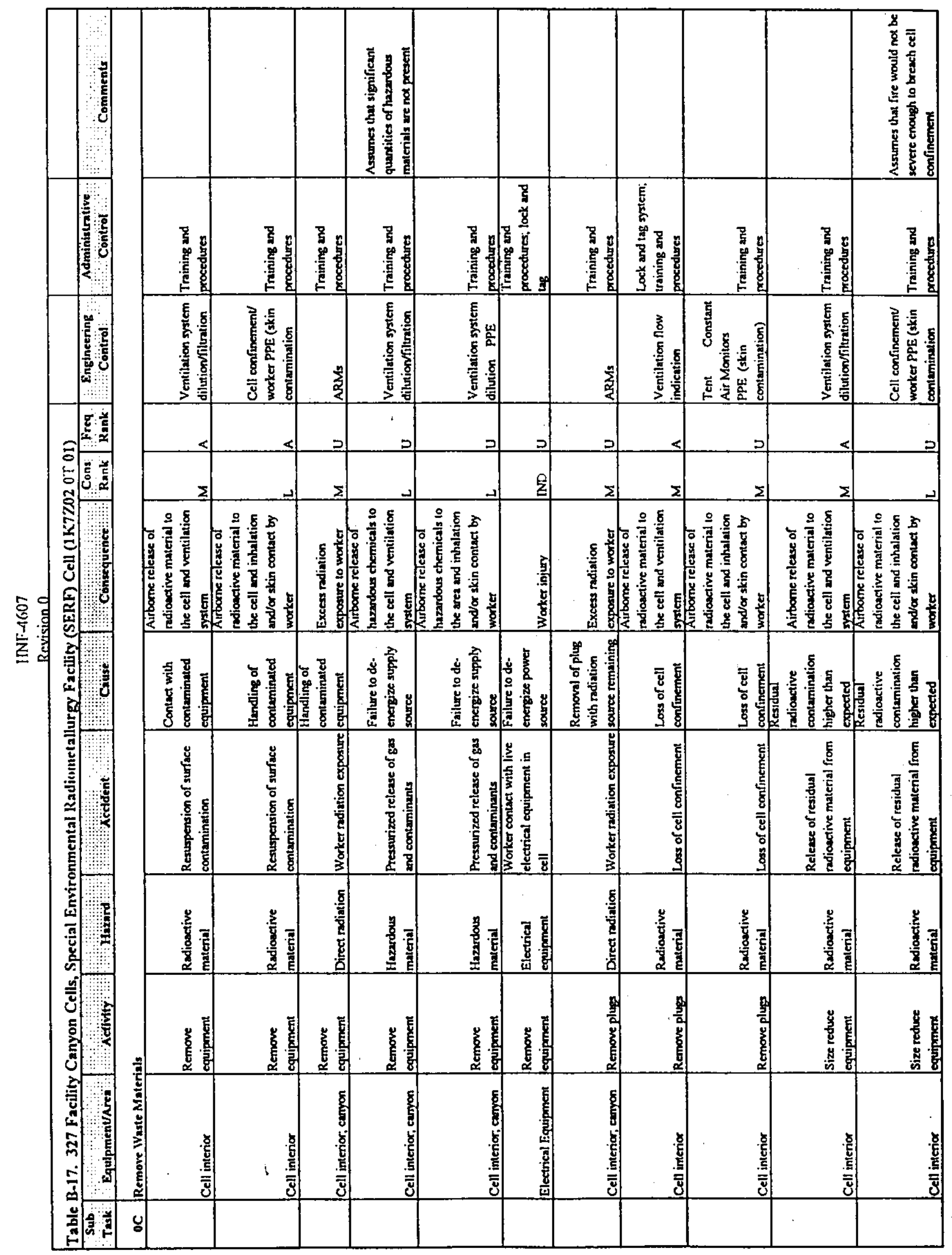

$\frac{\circ}{\omega}$ 


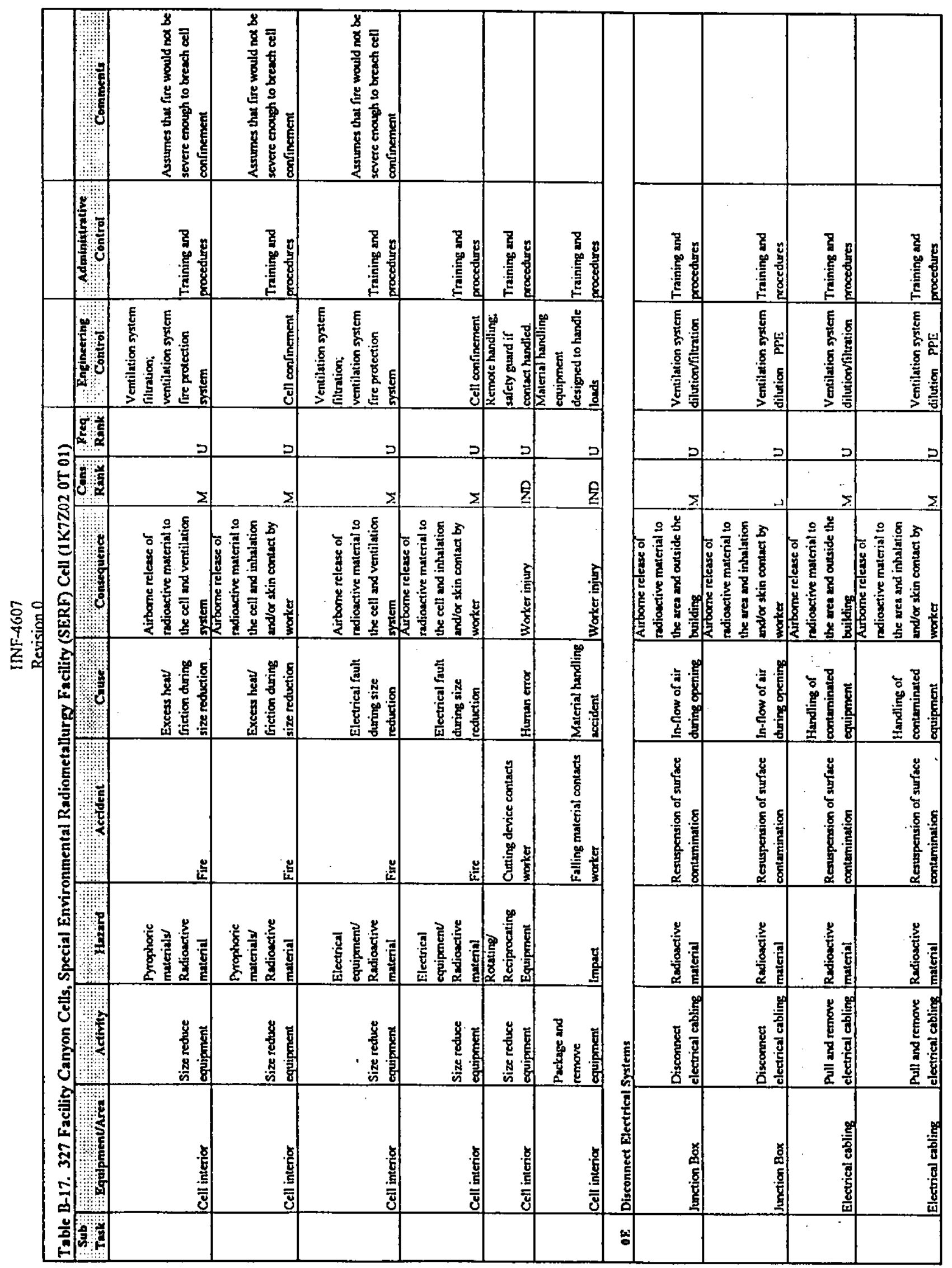




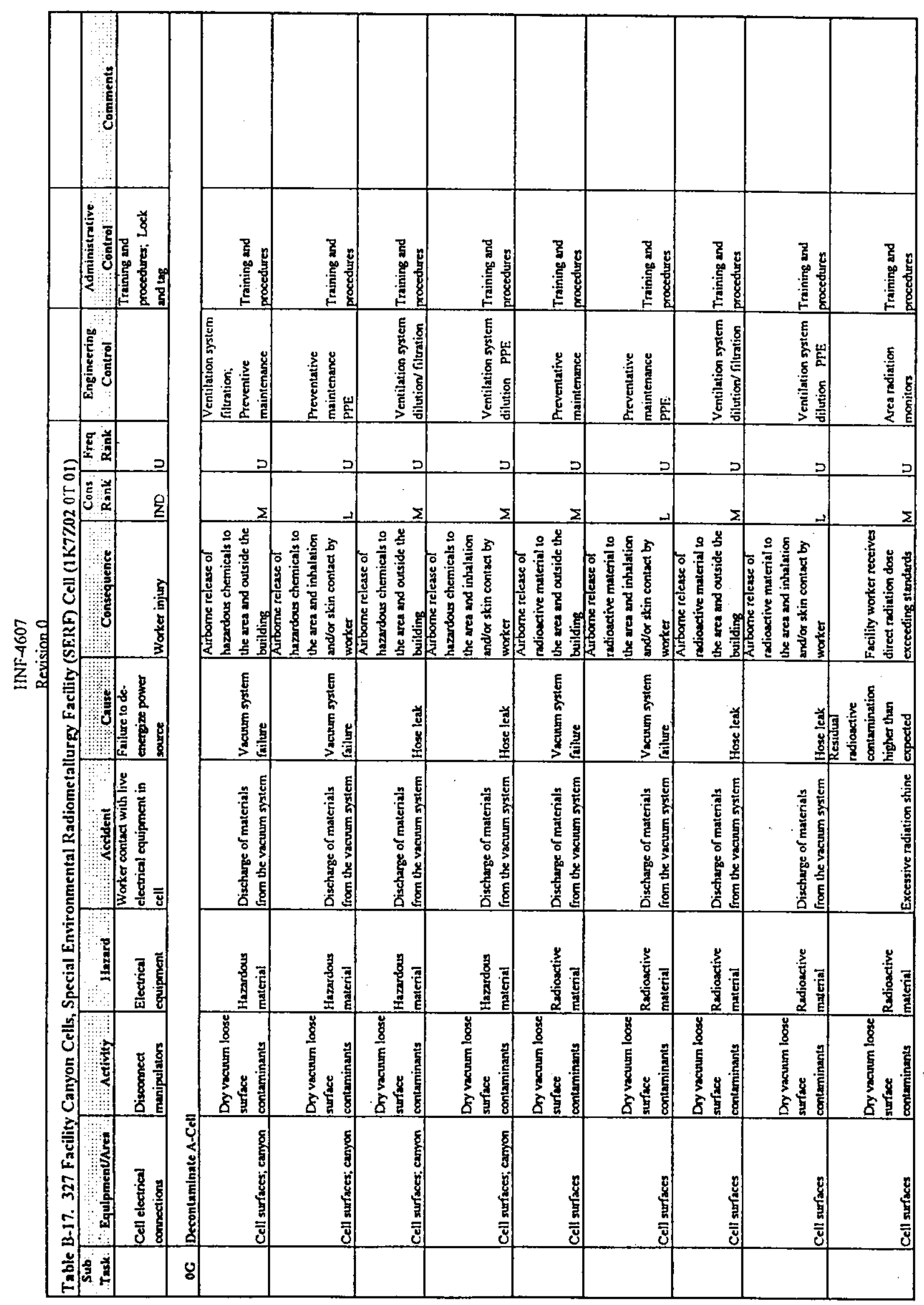




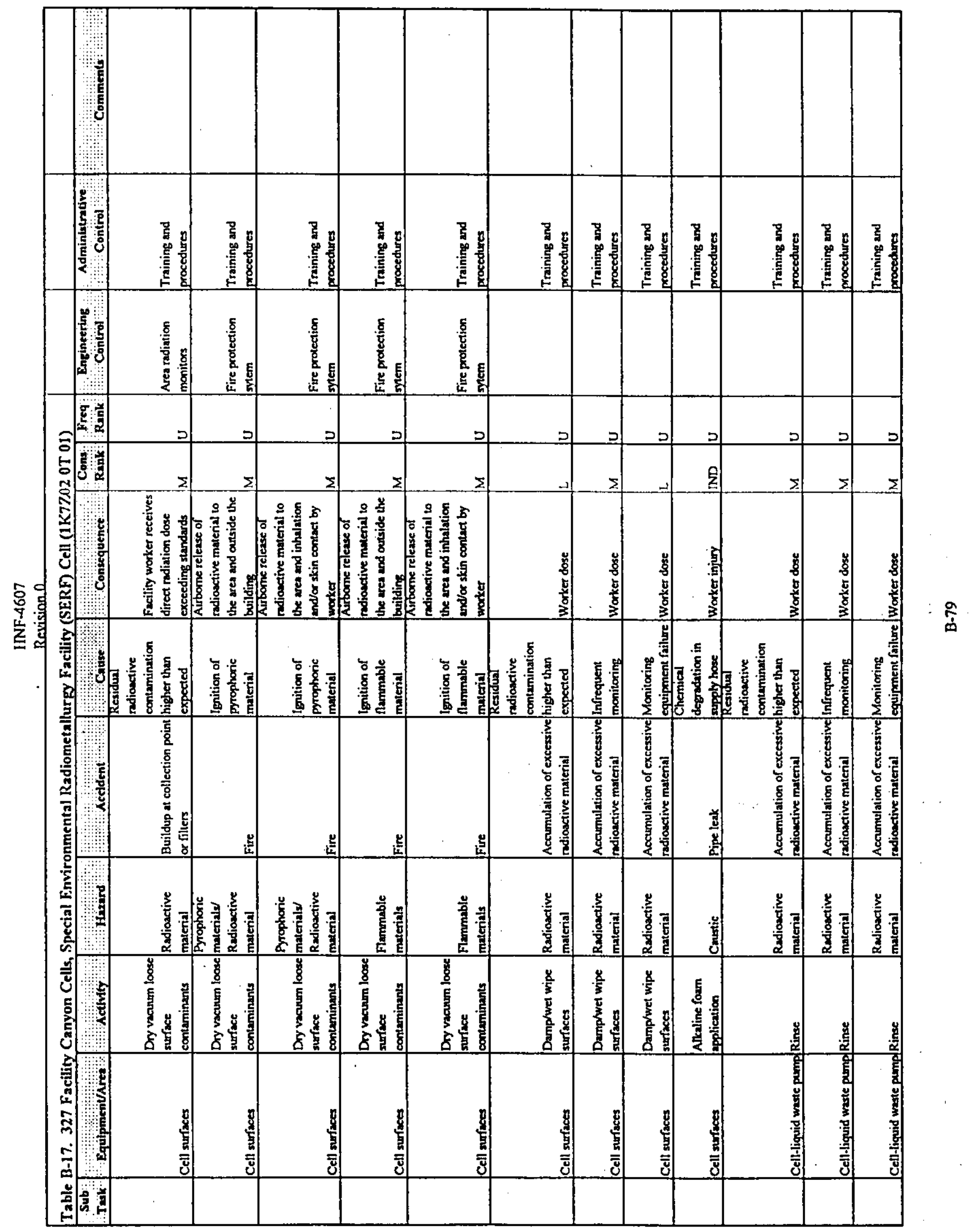




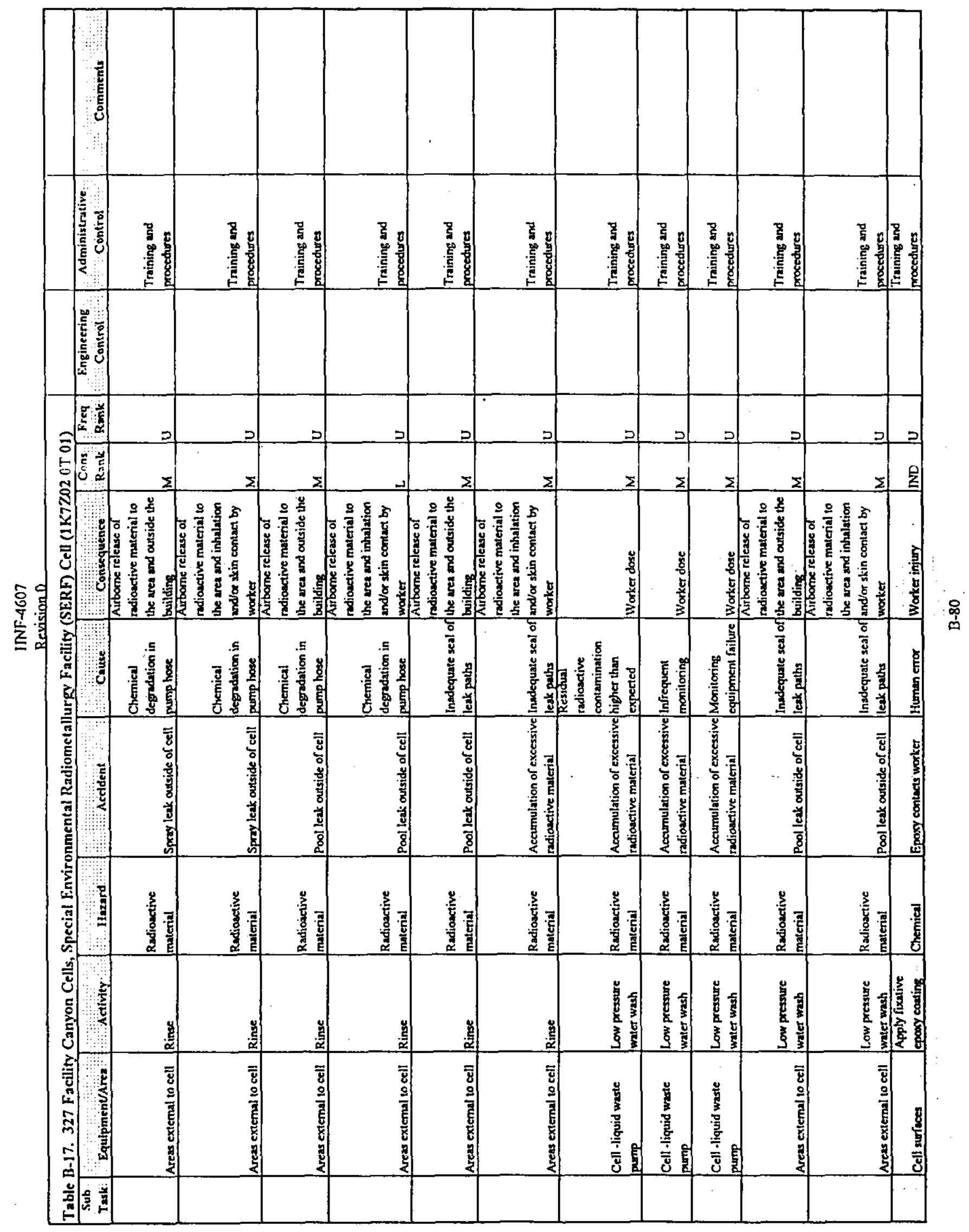




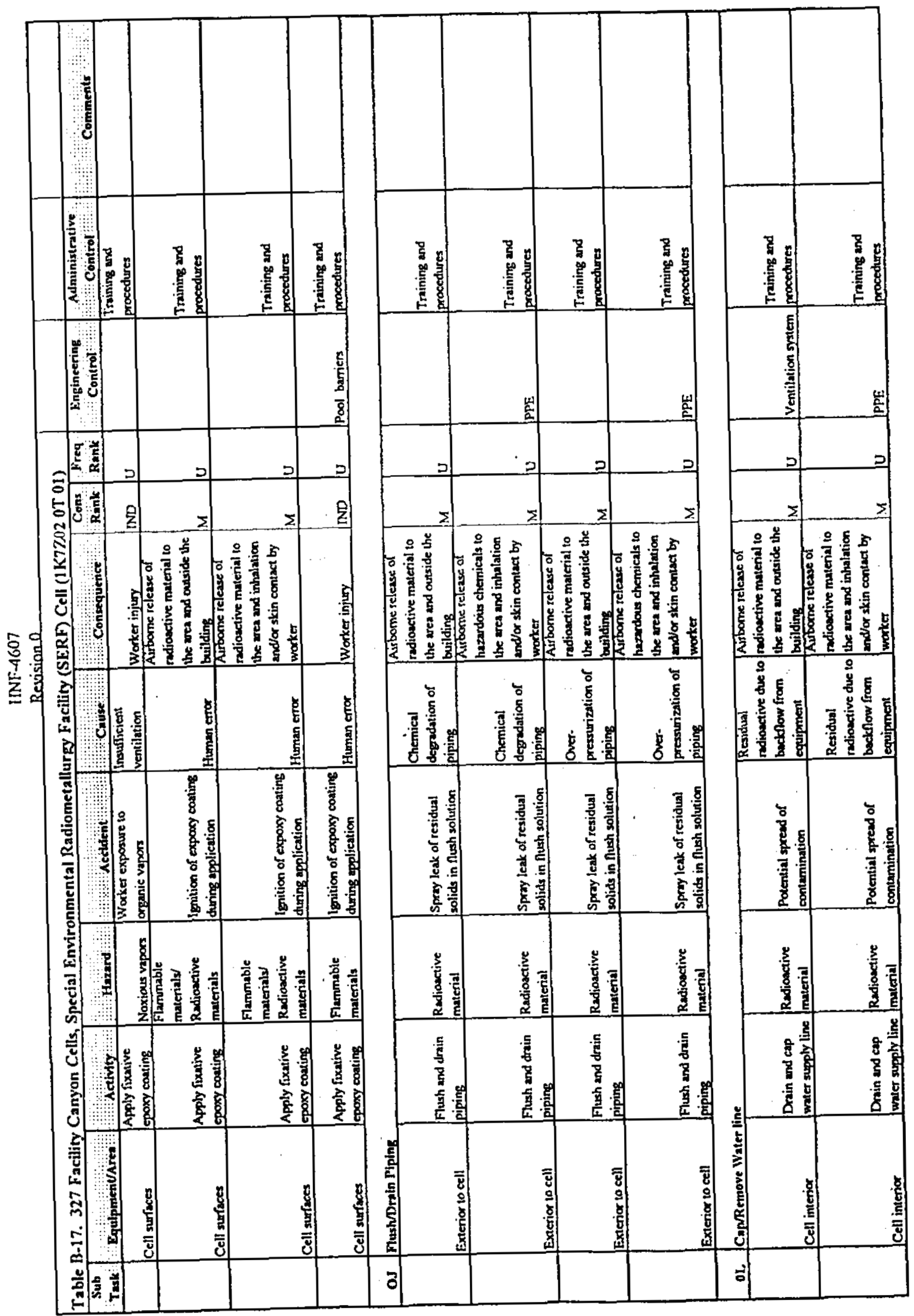




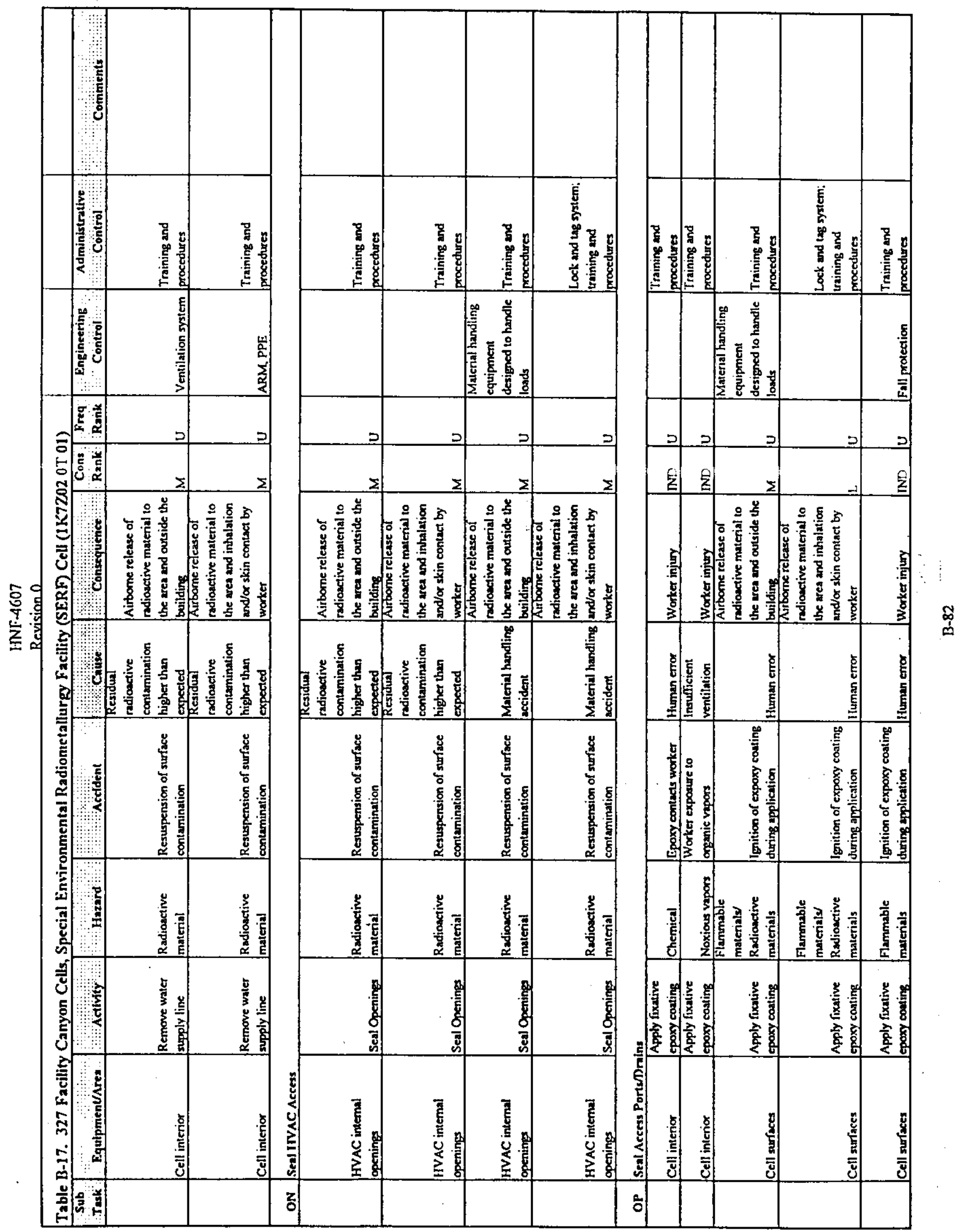




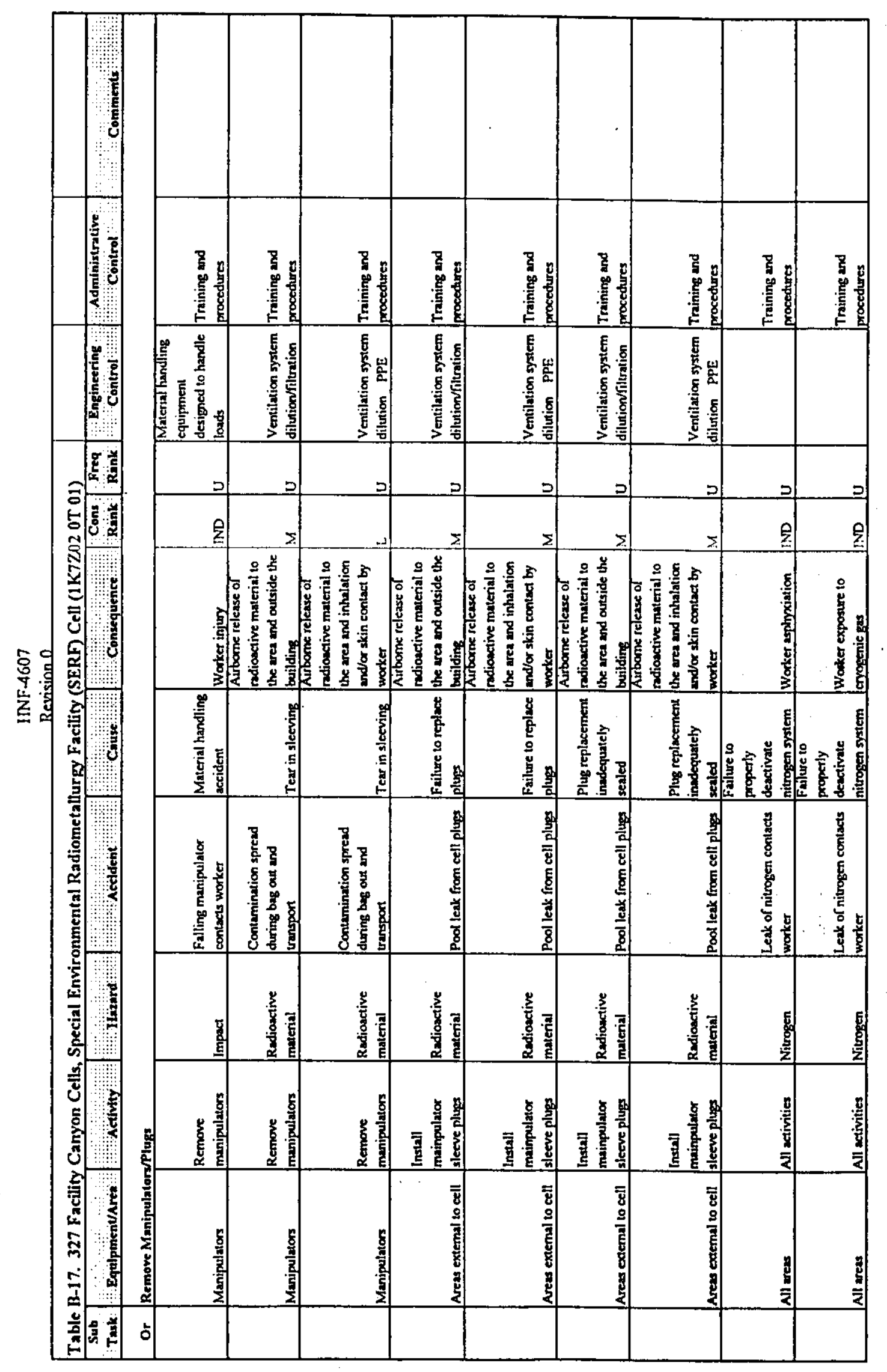




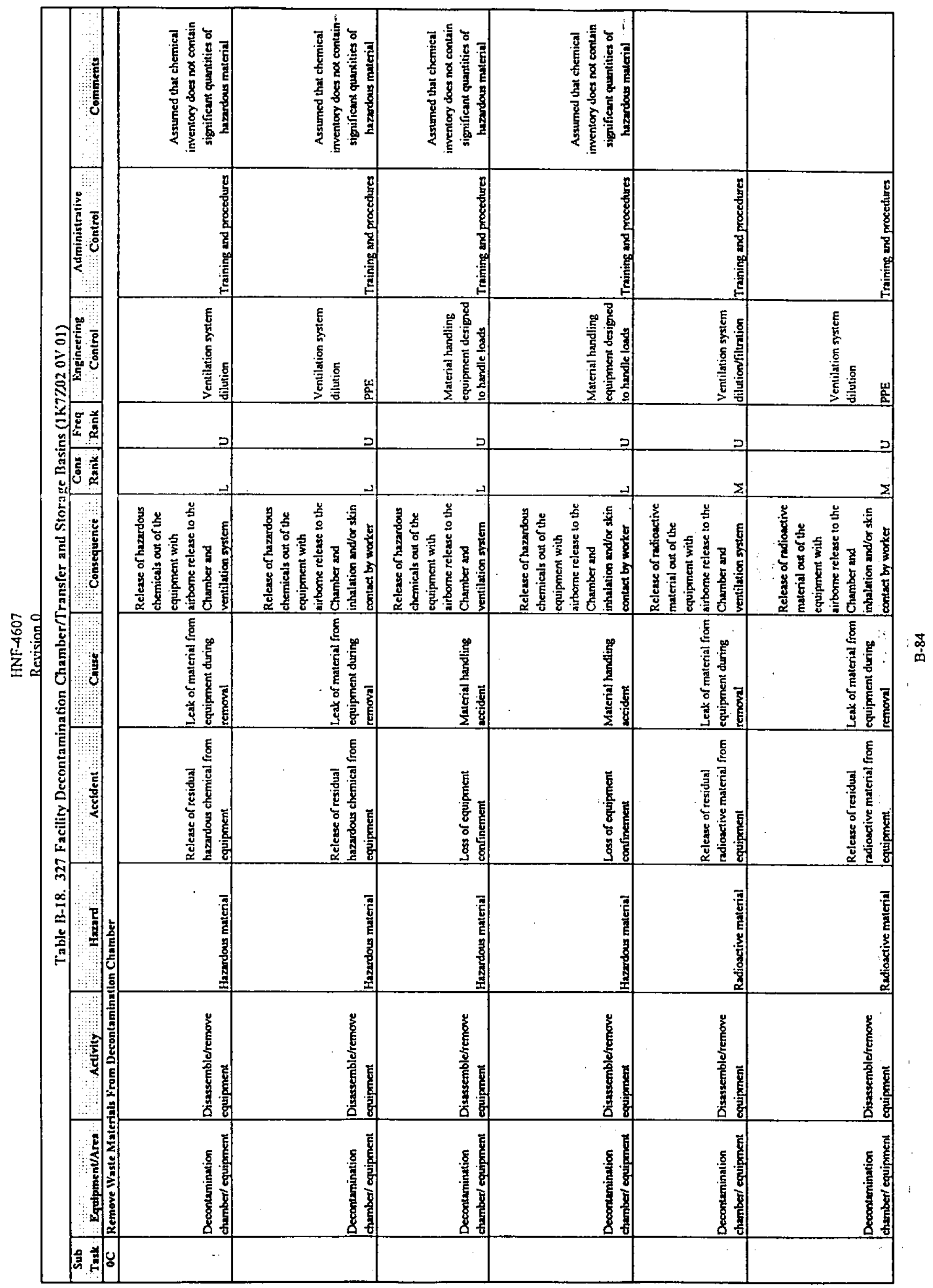




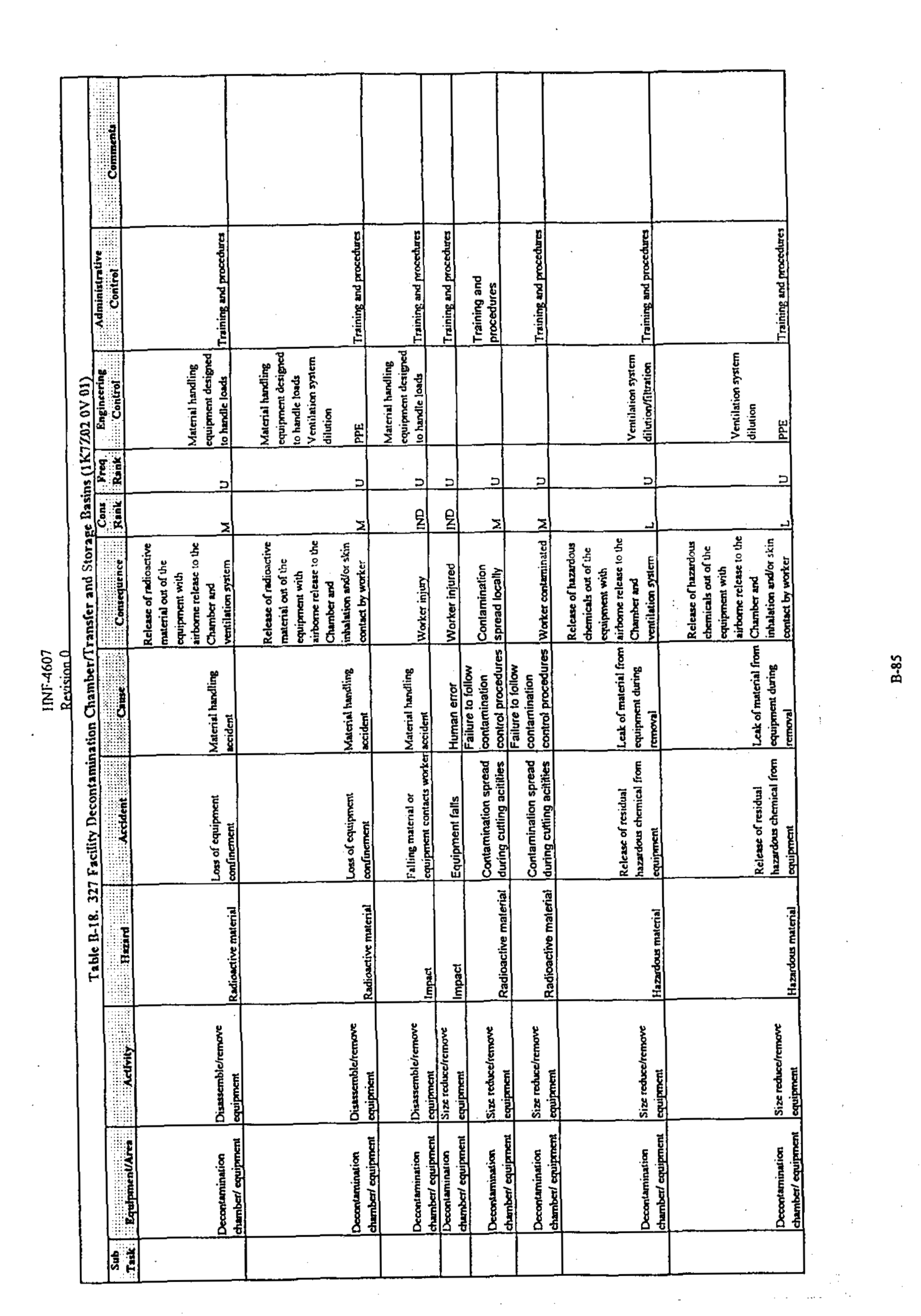




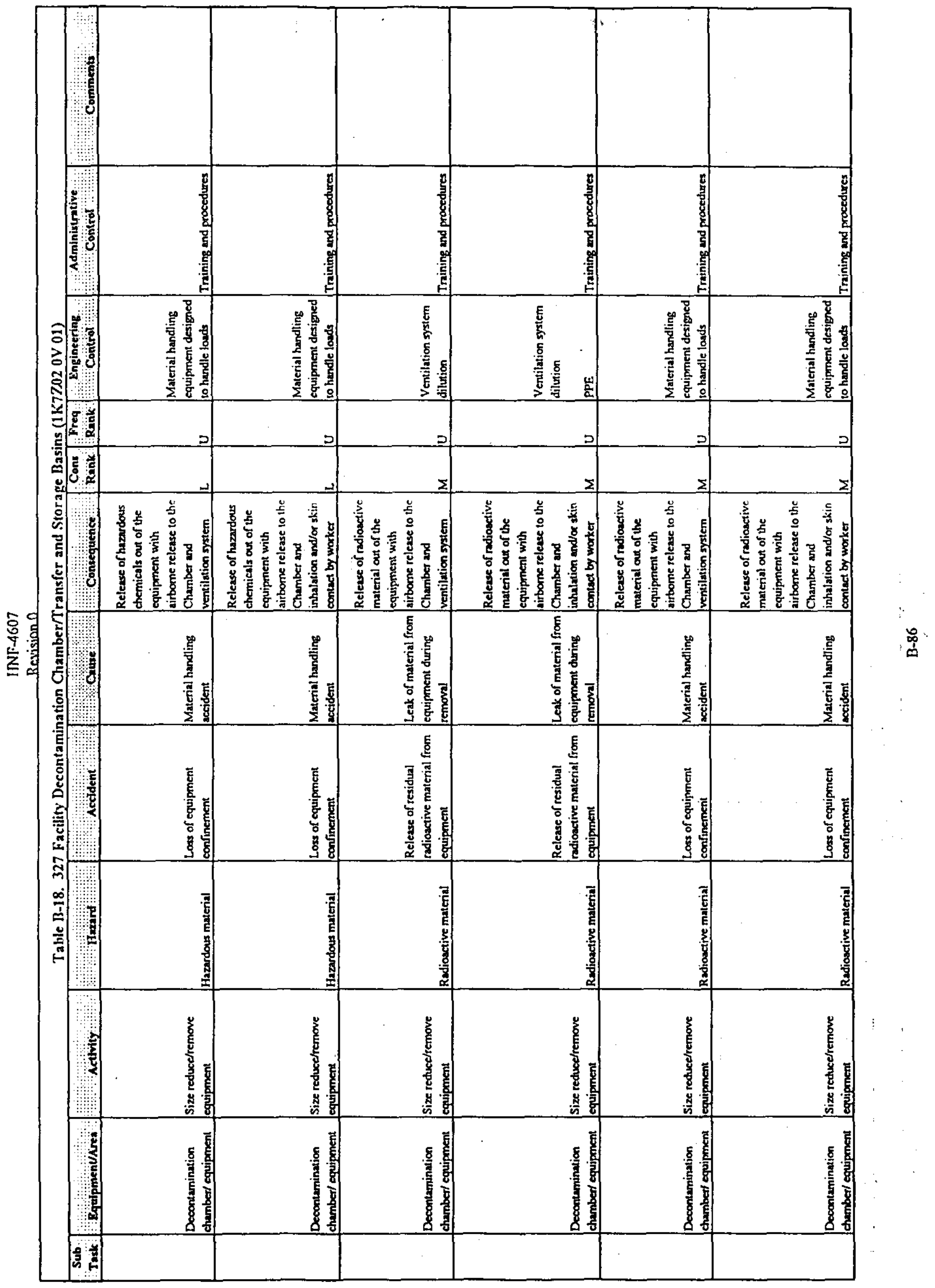




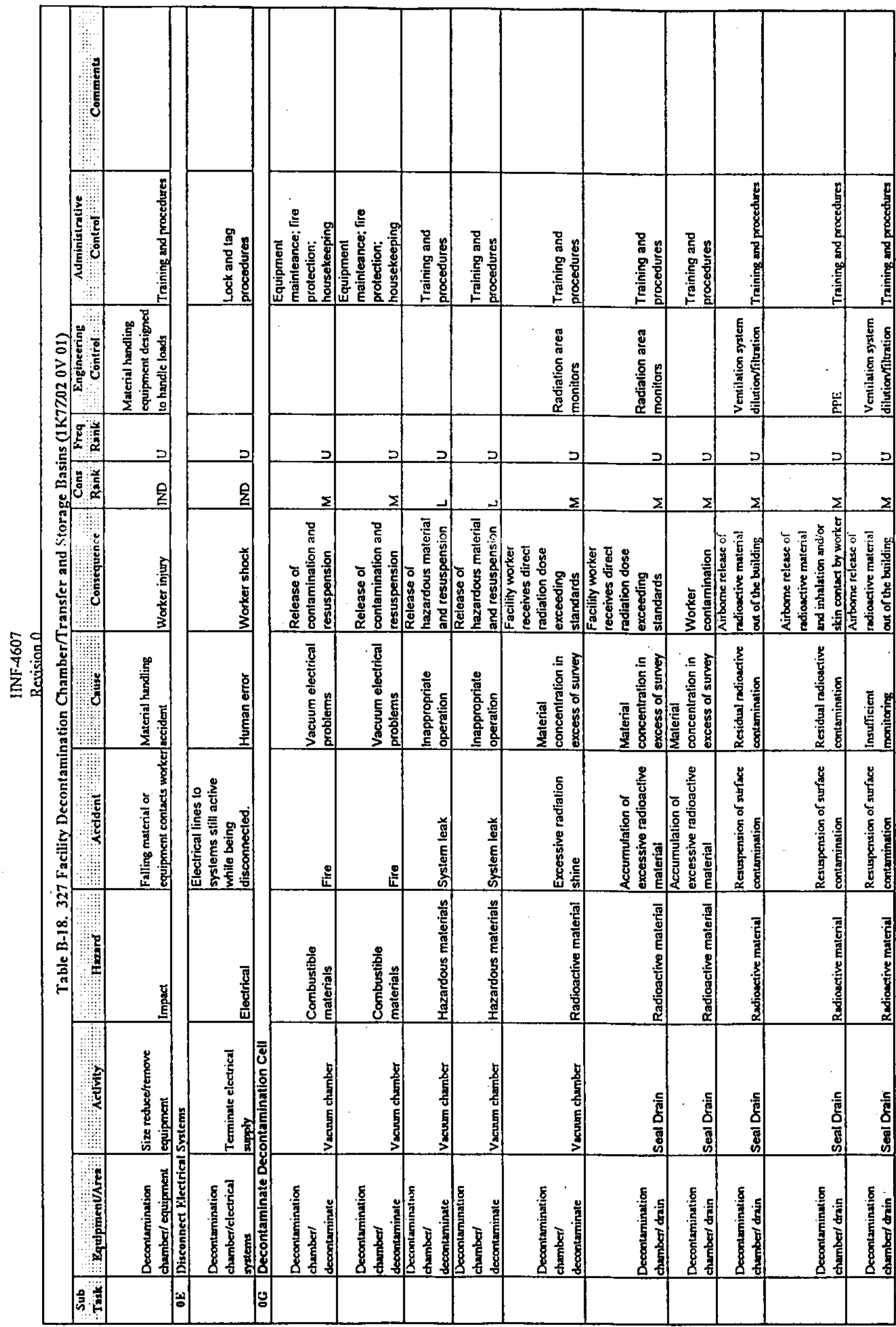




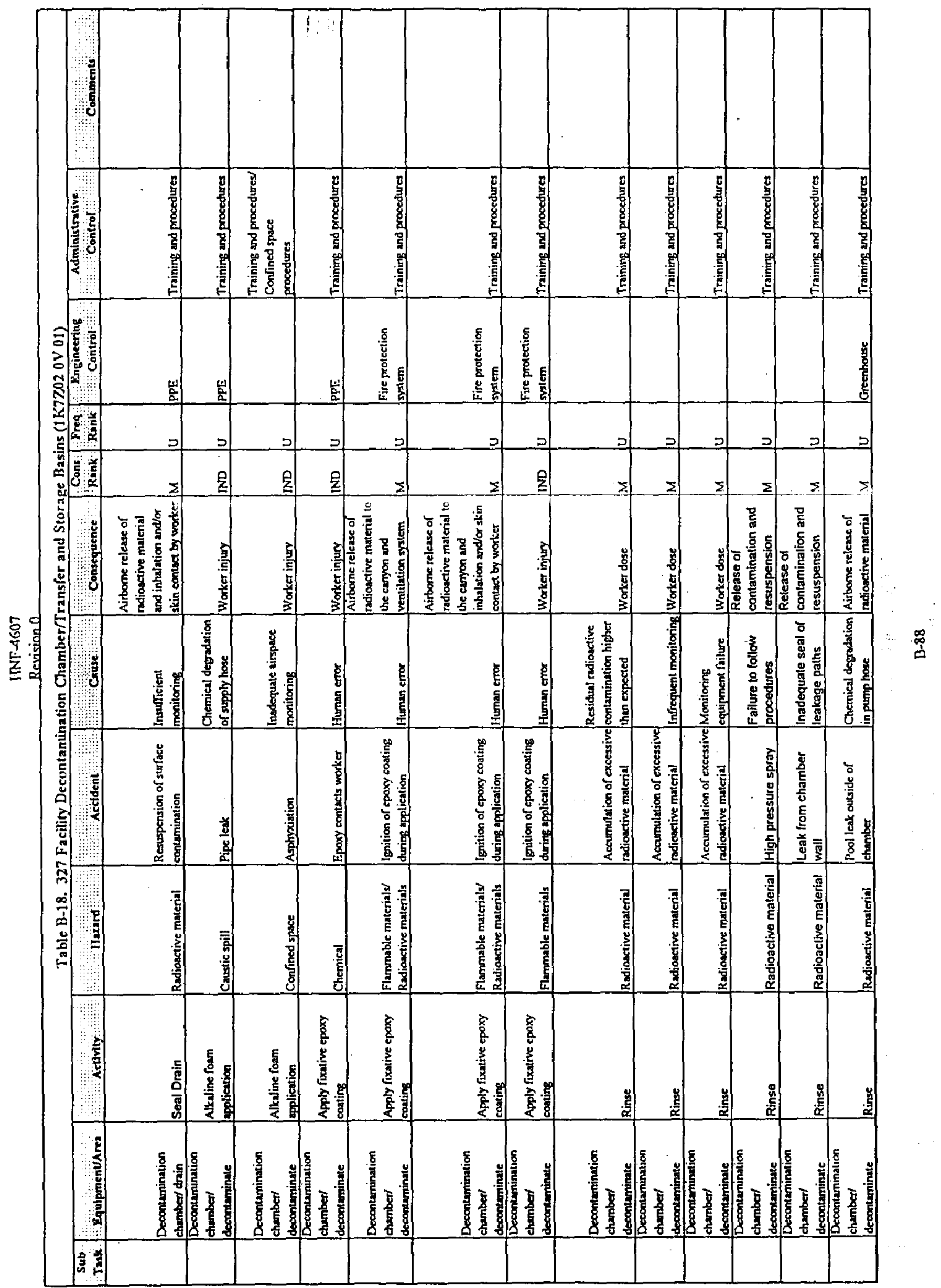




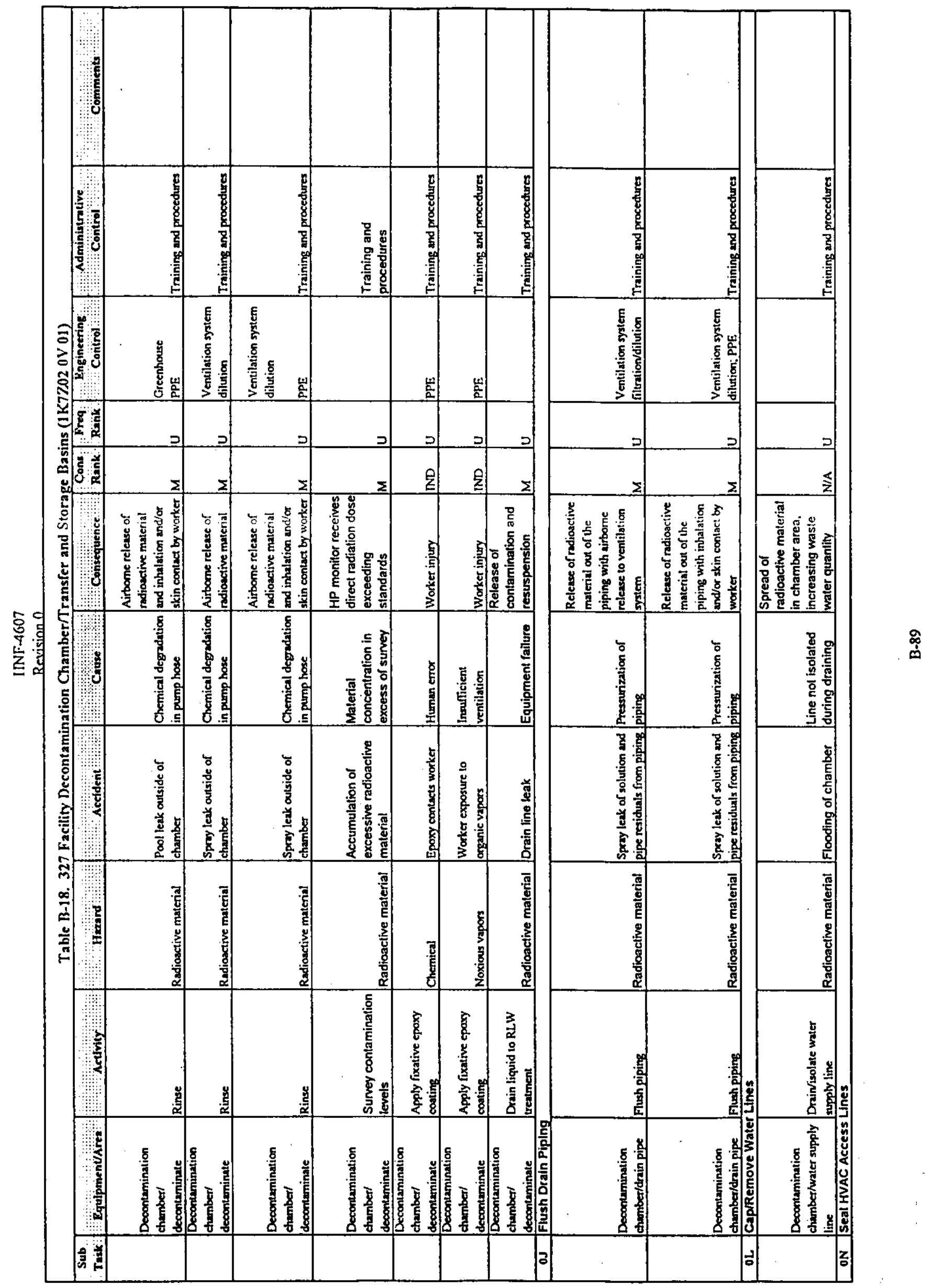




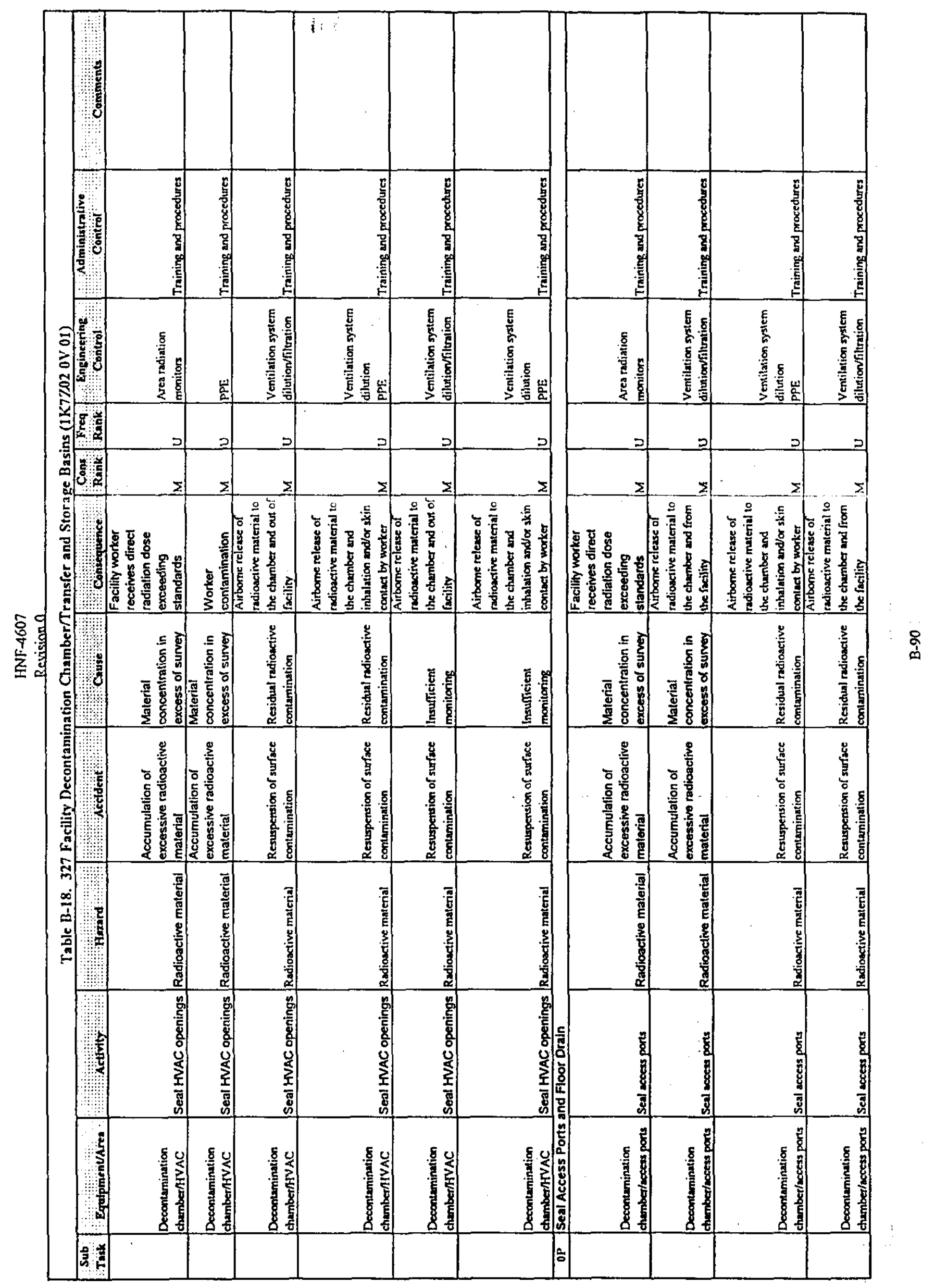




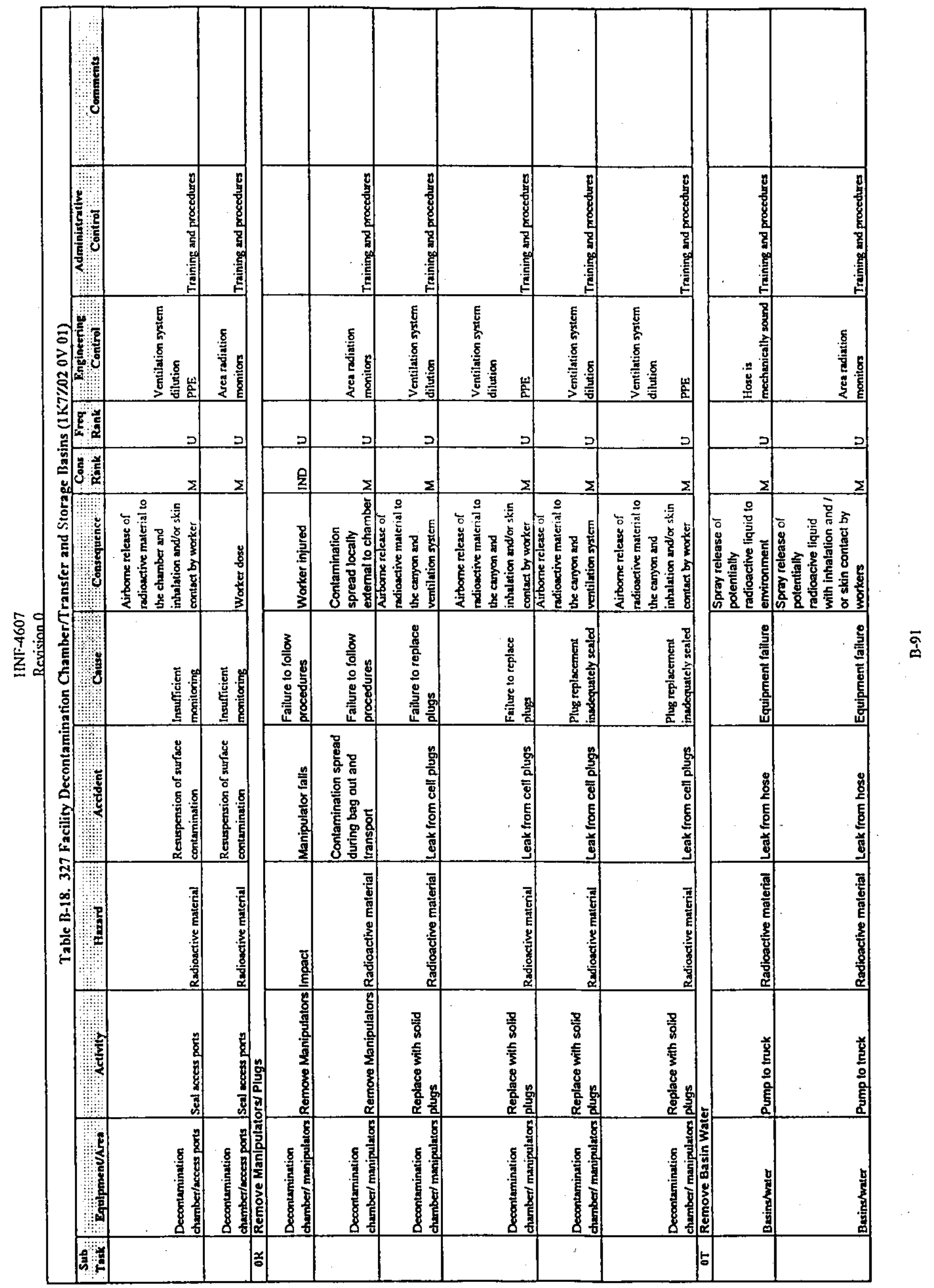




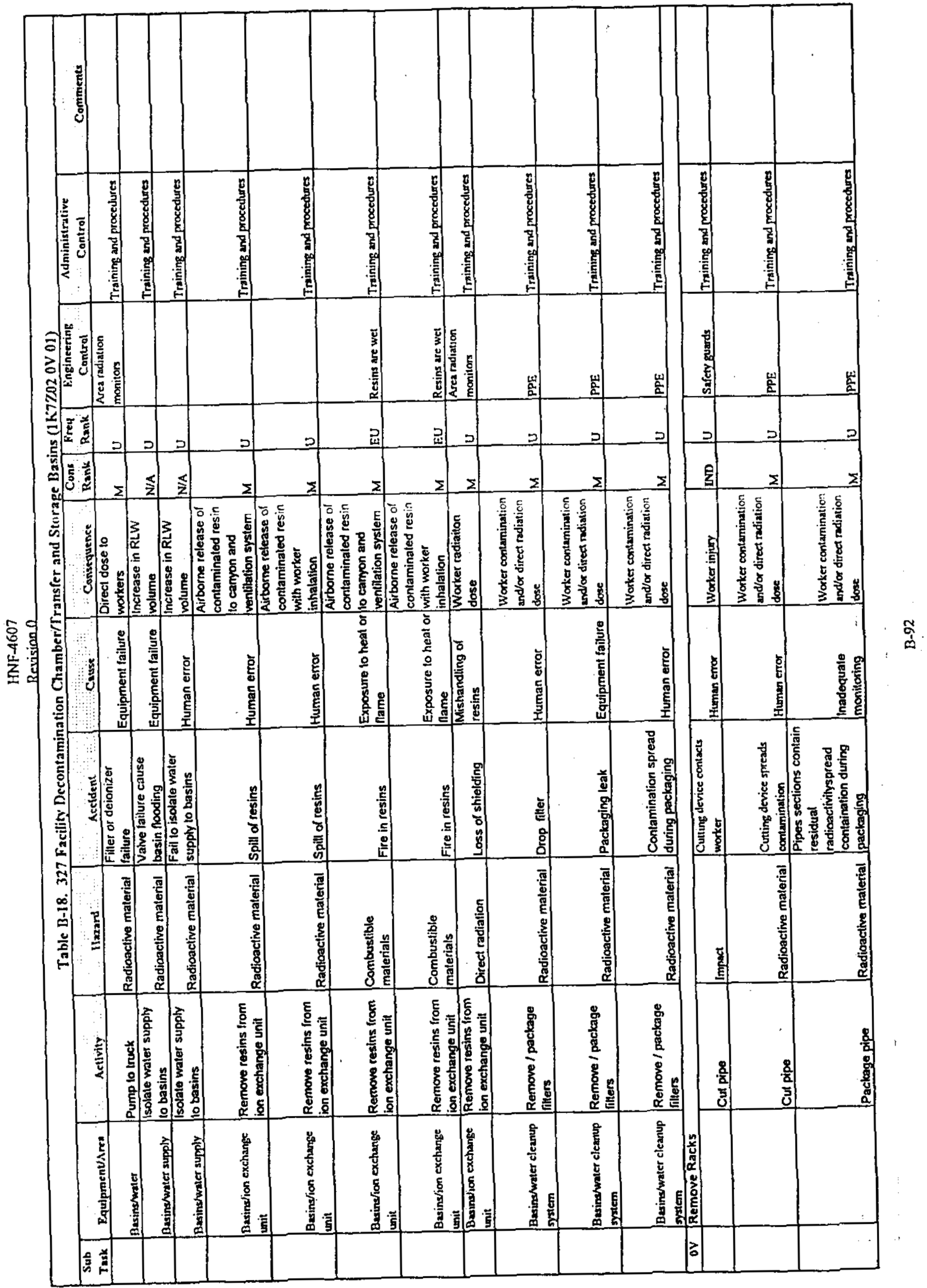




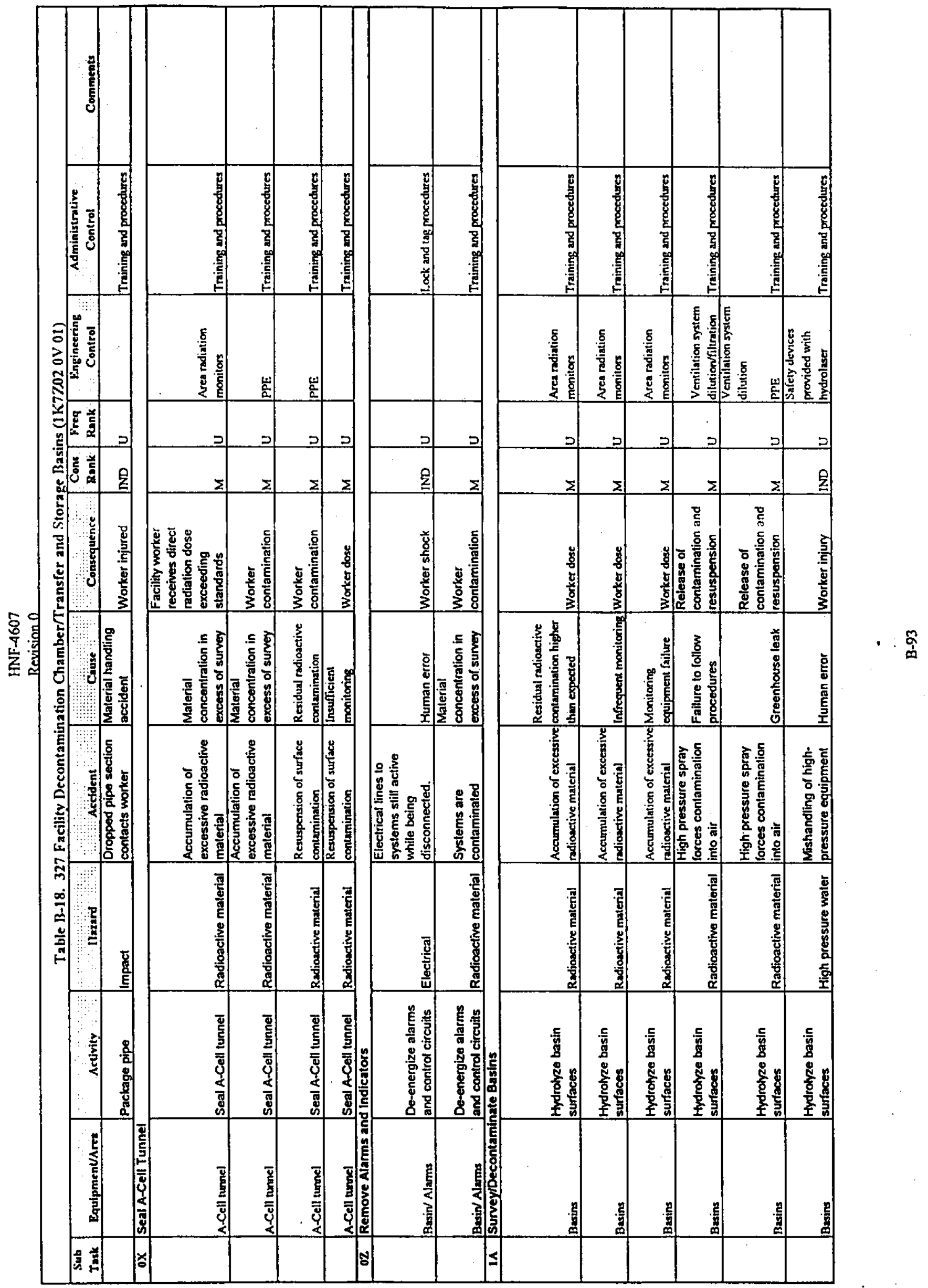




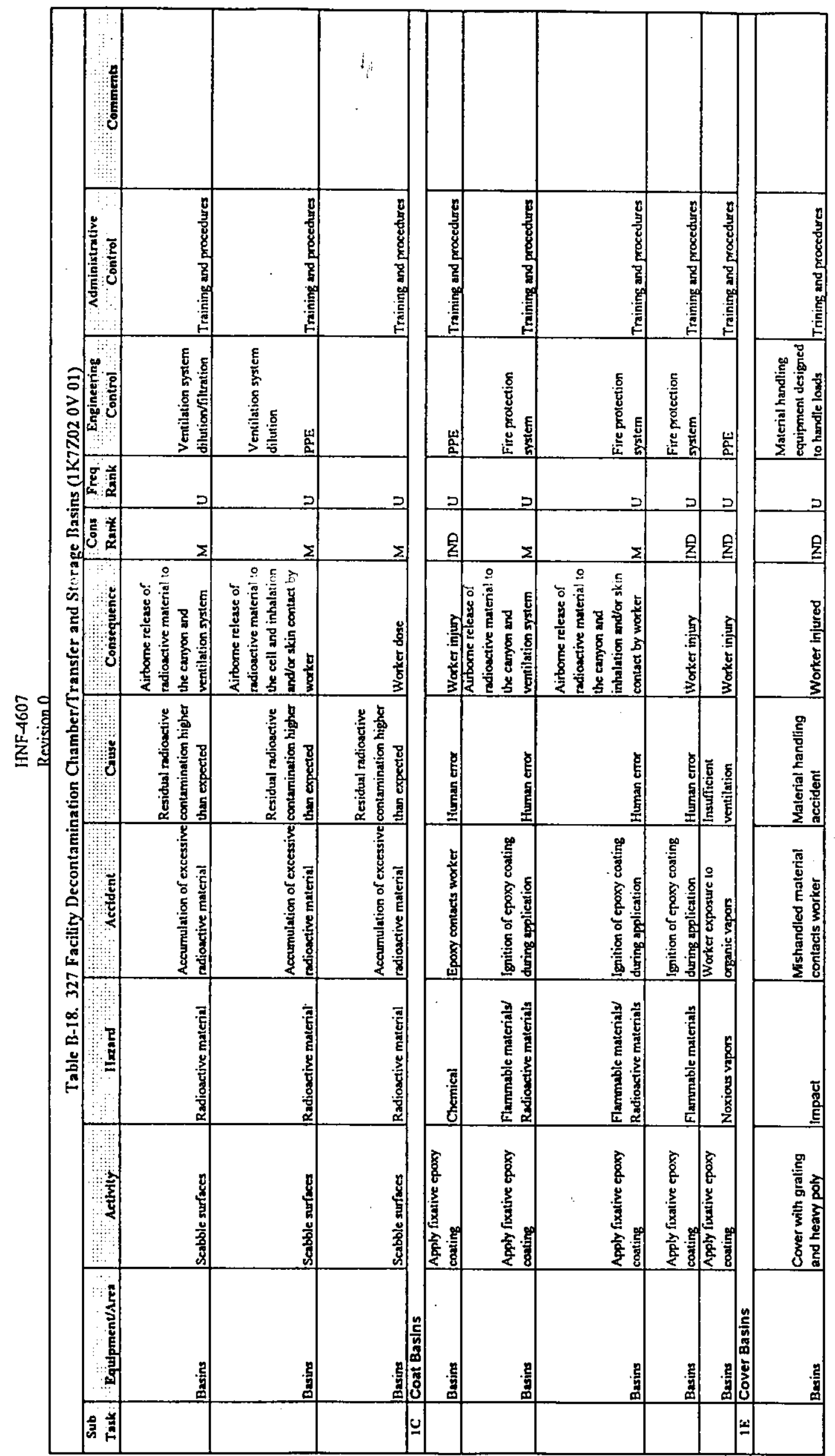




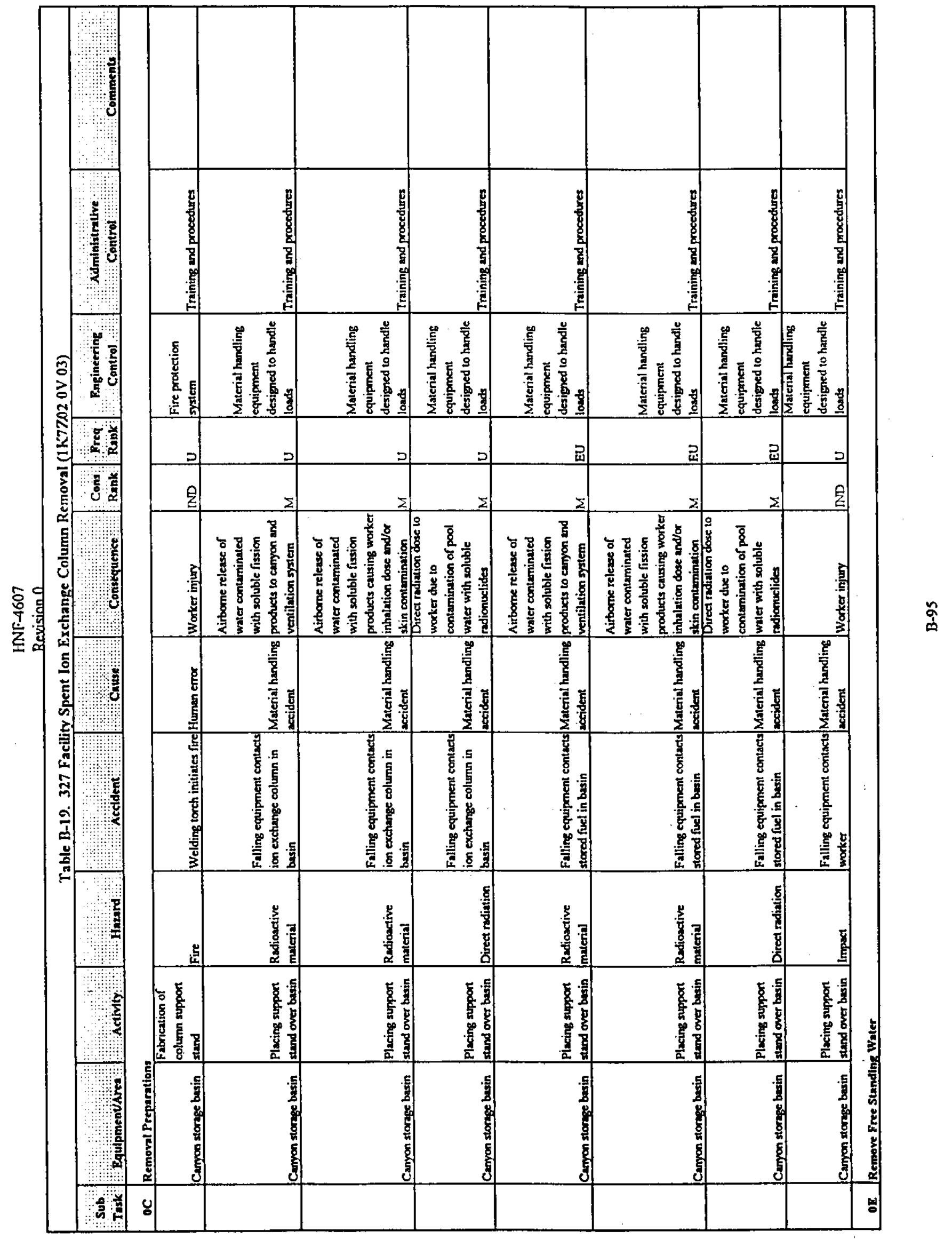




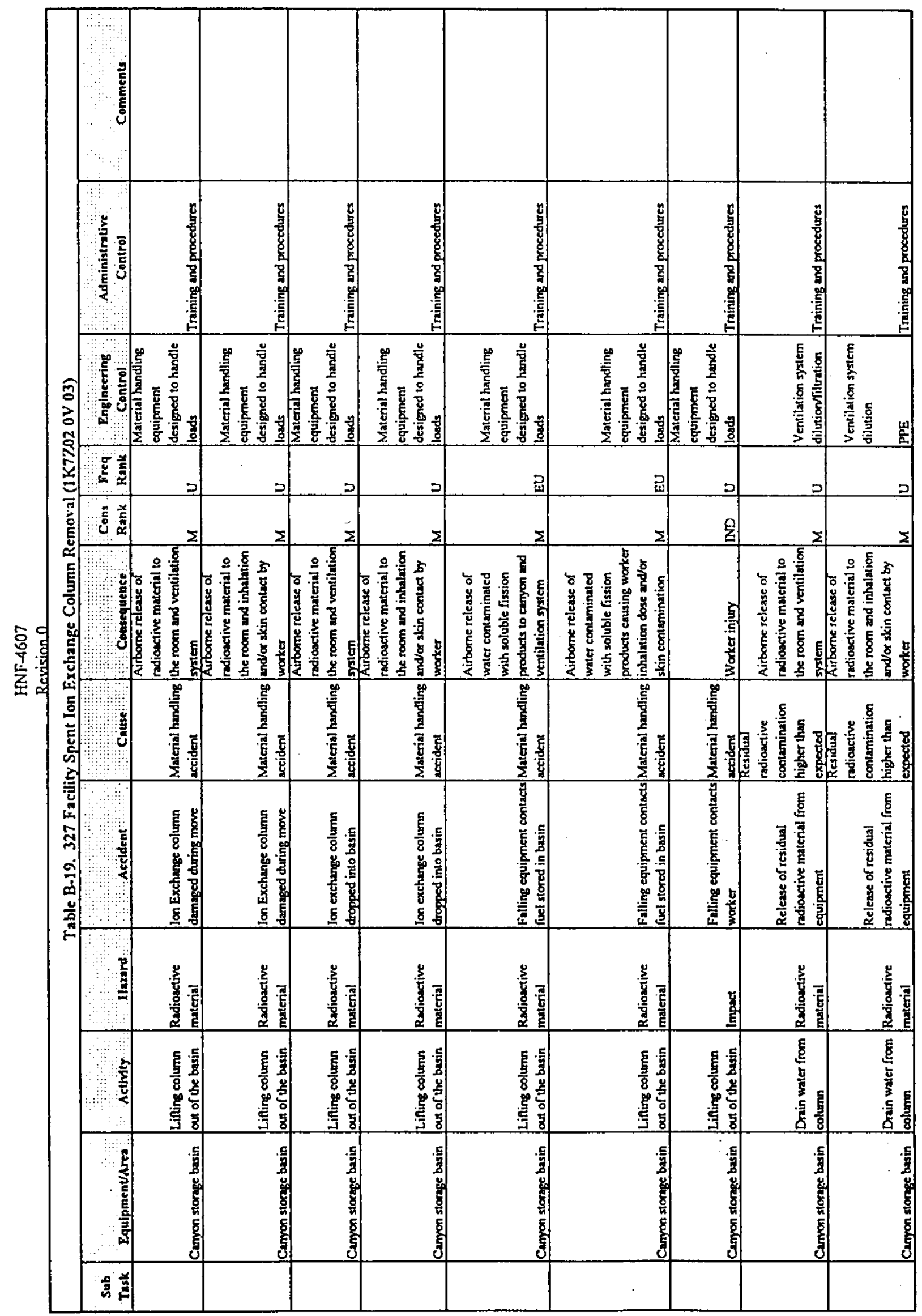

คั 


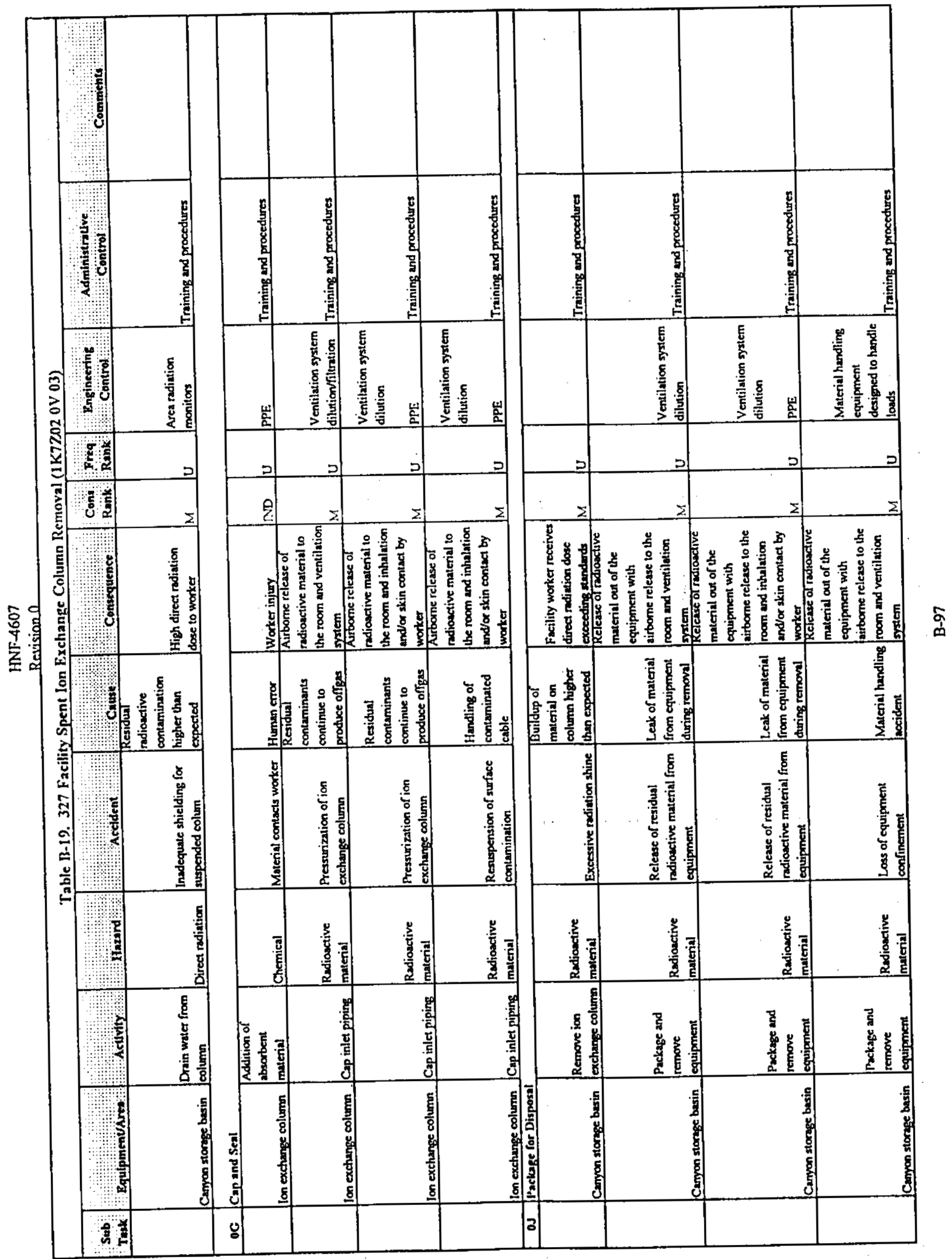




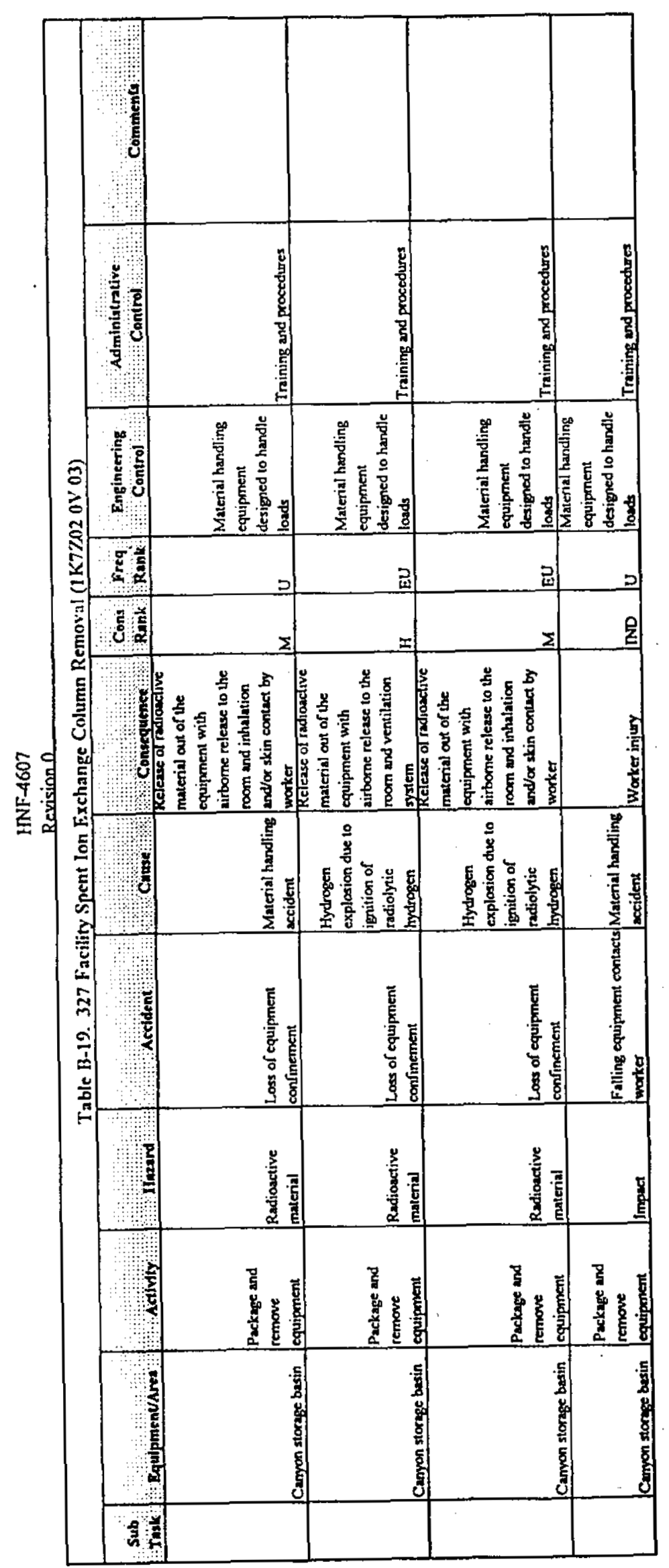

a 


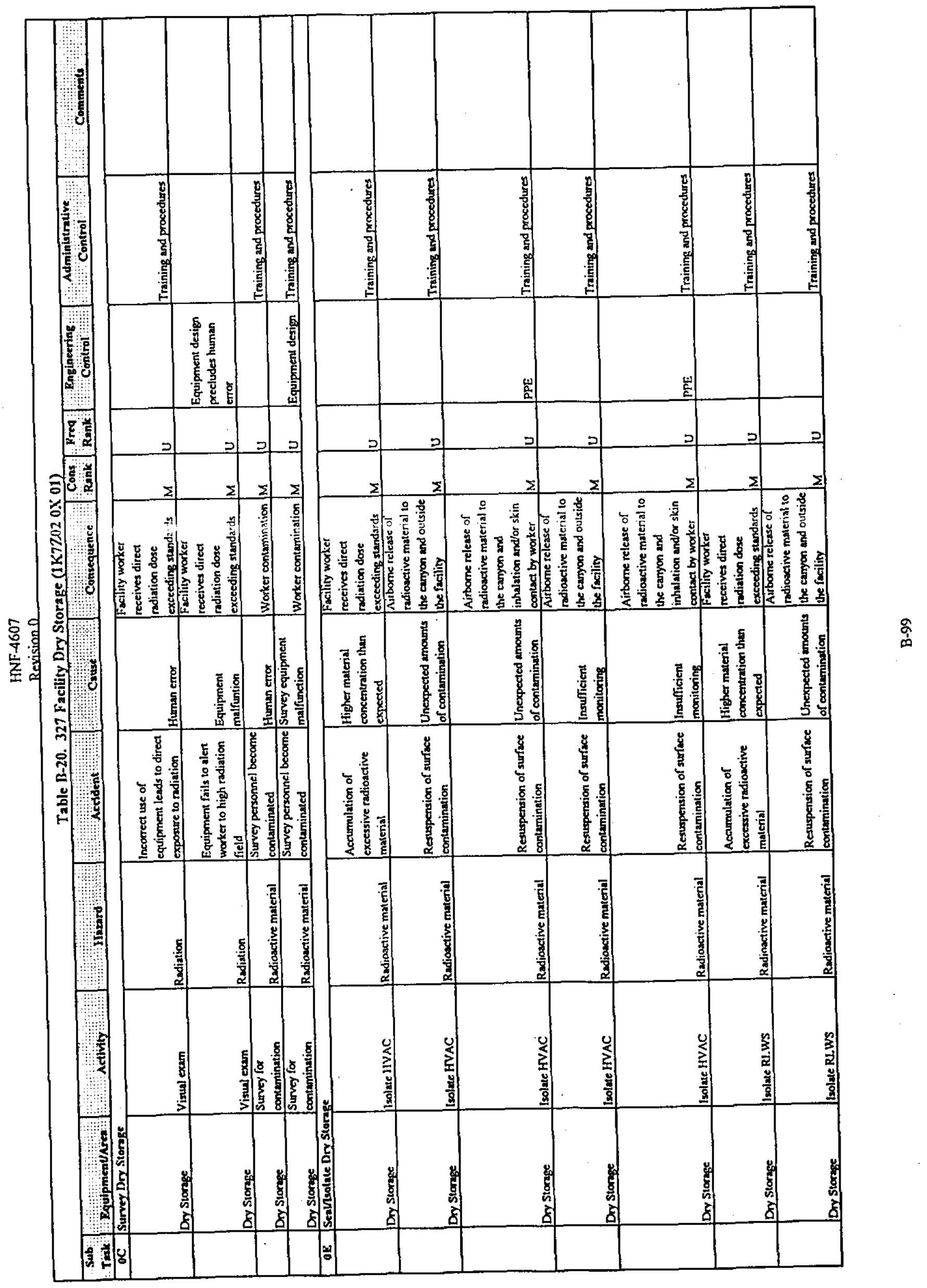




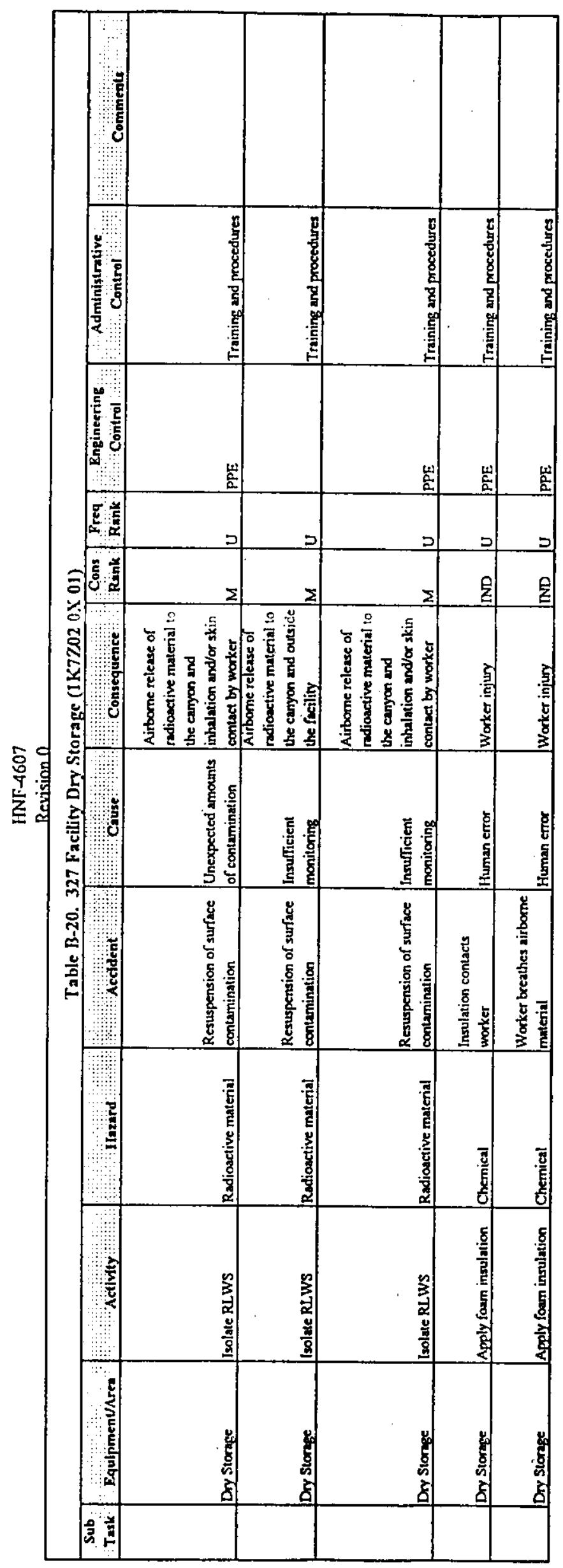

$\frac{8}{9}$ 


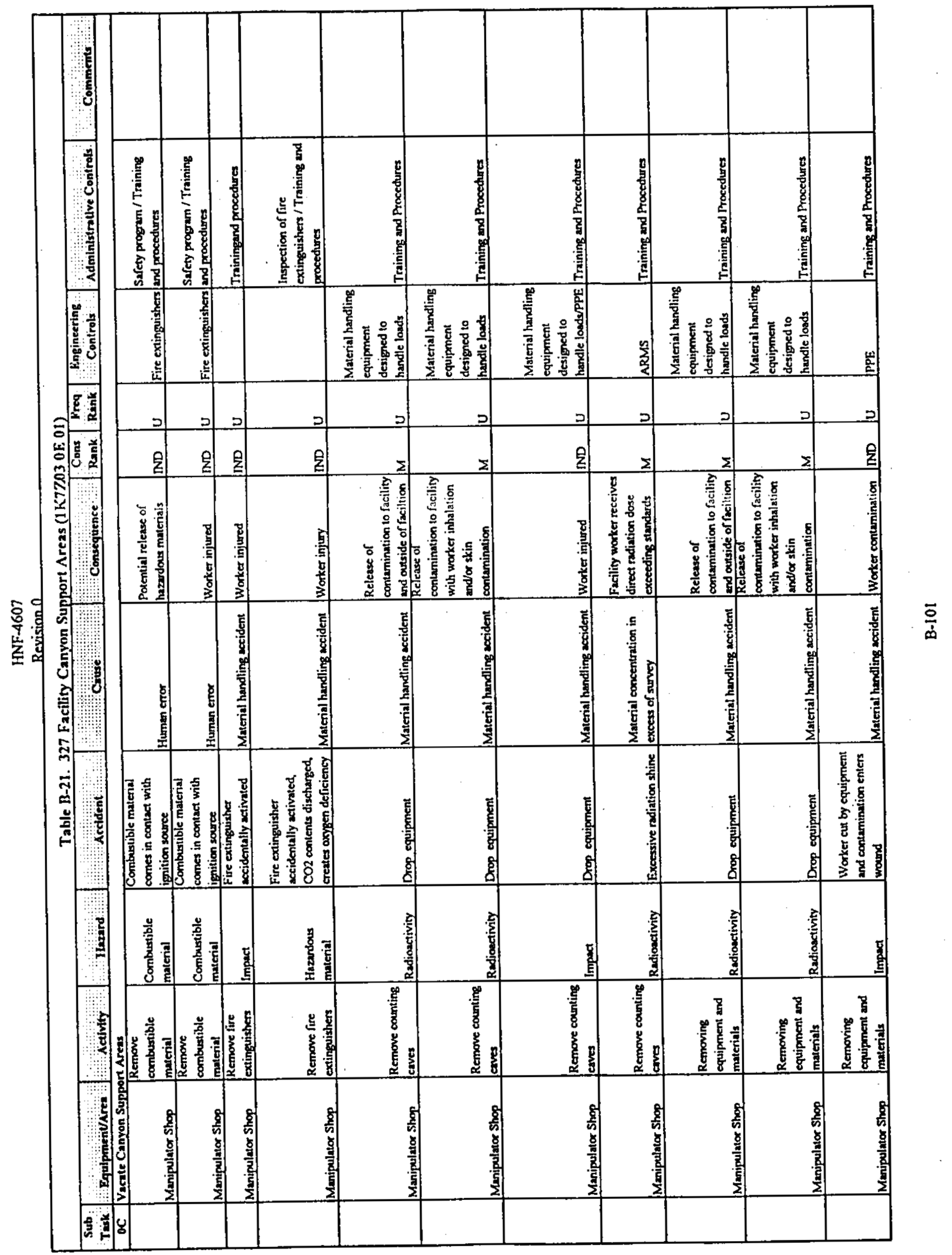




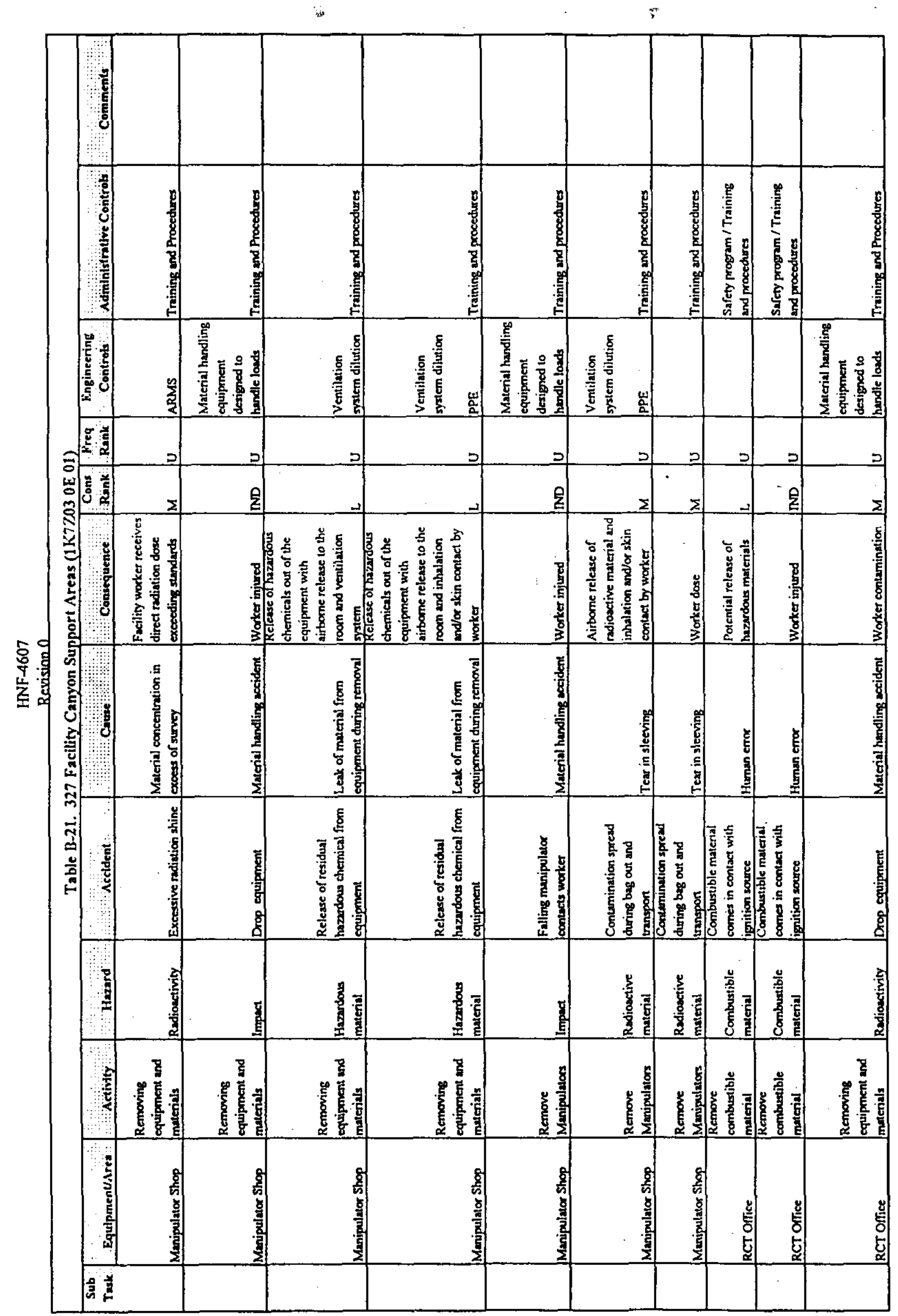




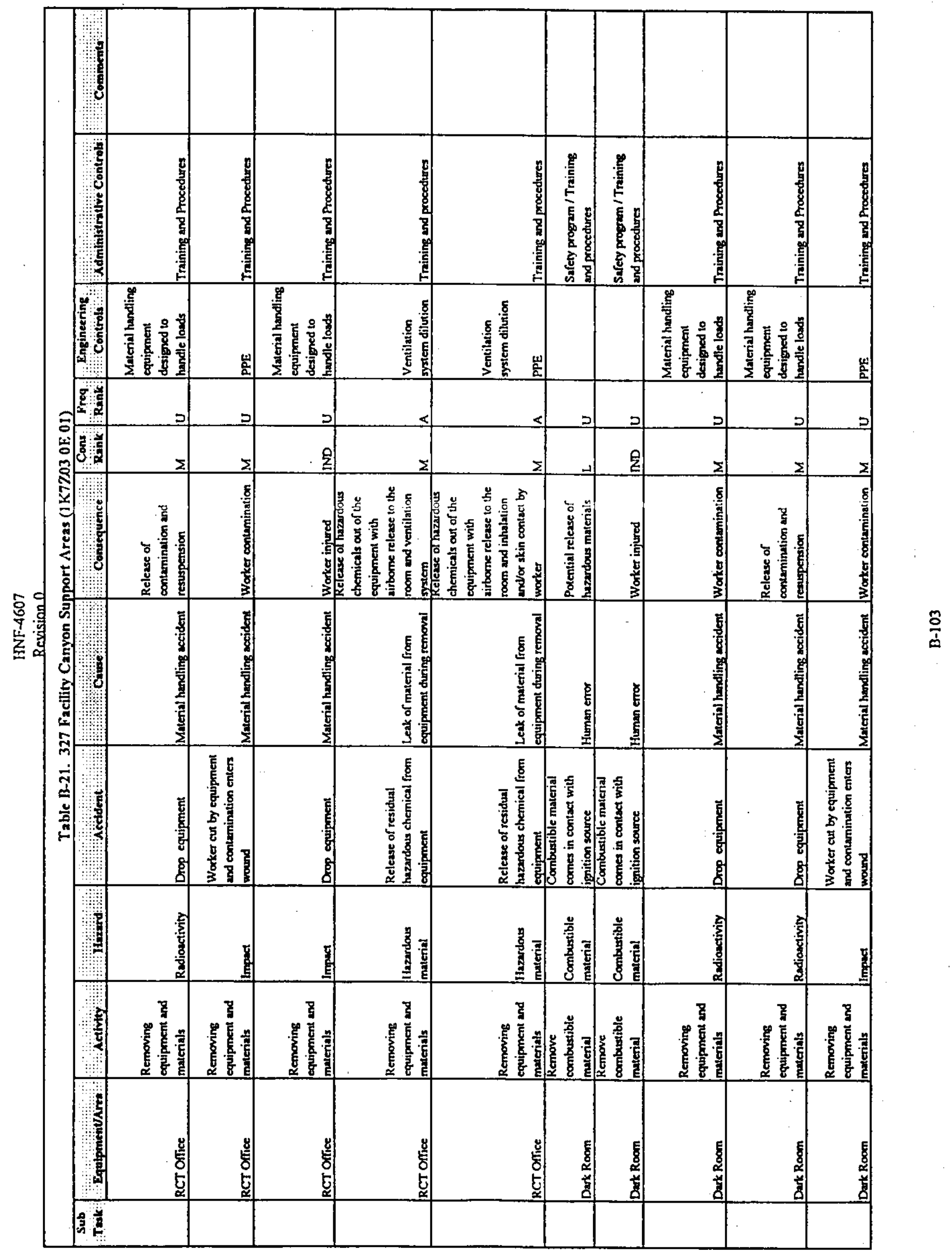




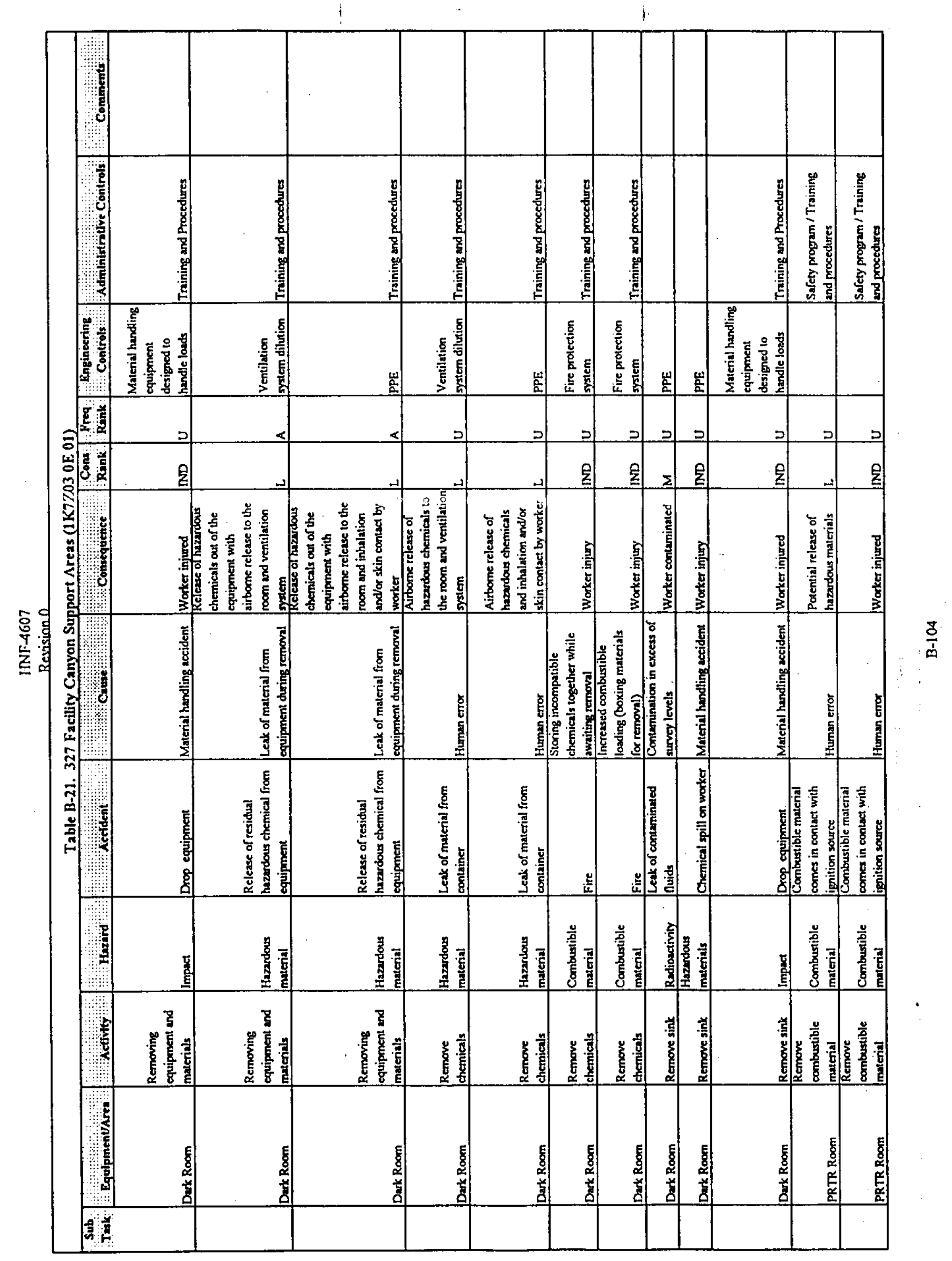




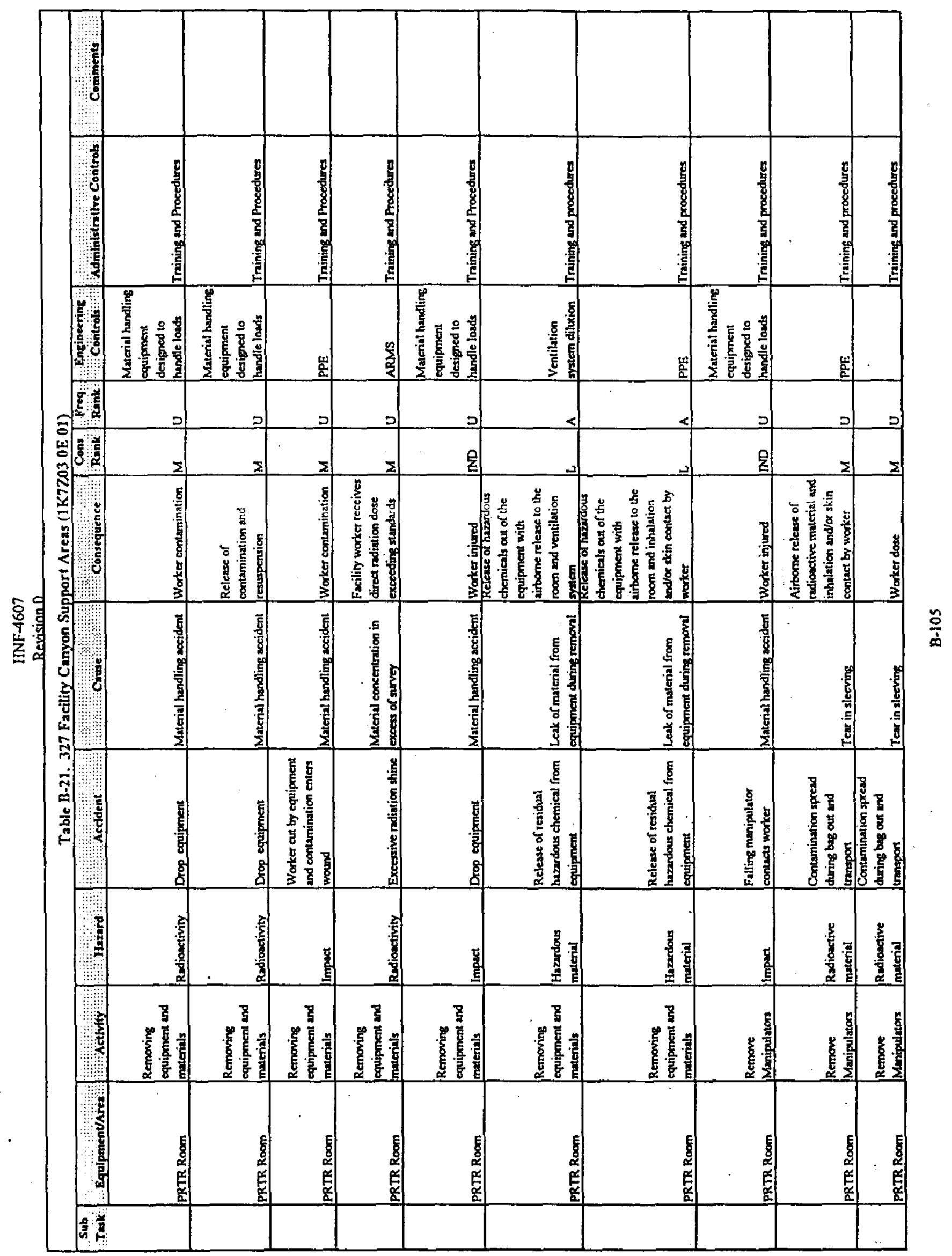




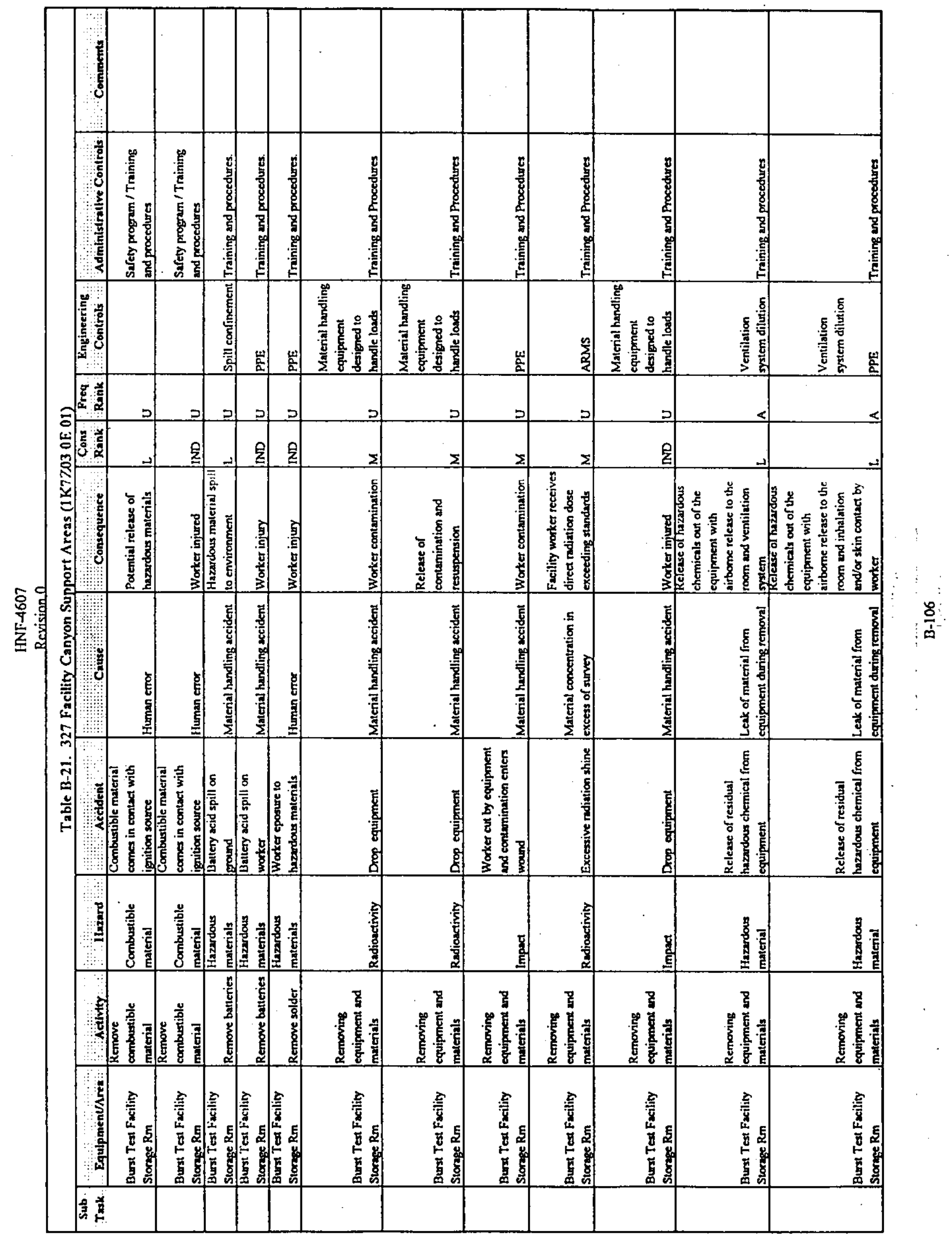




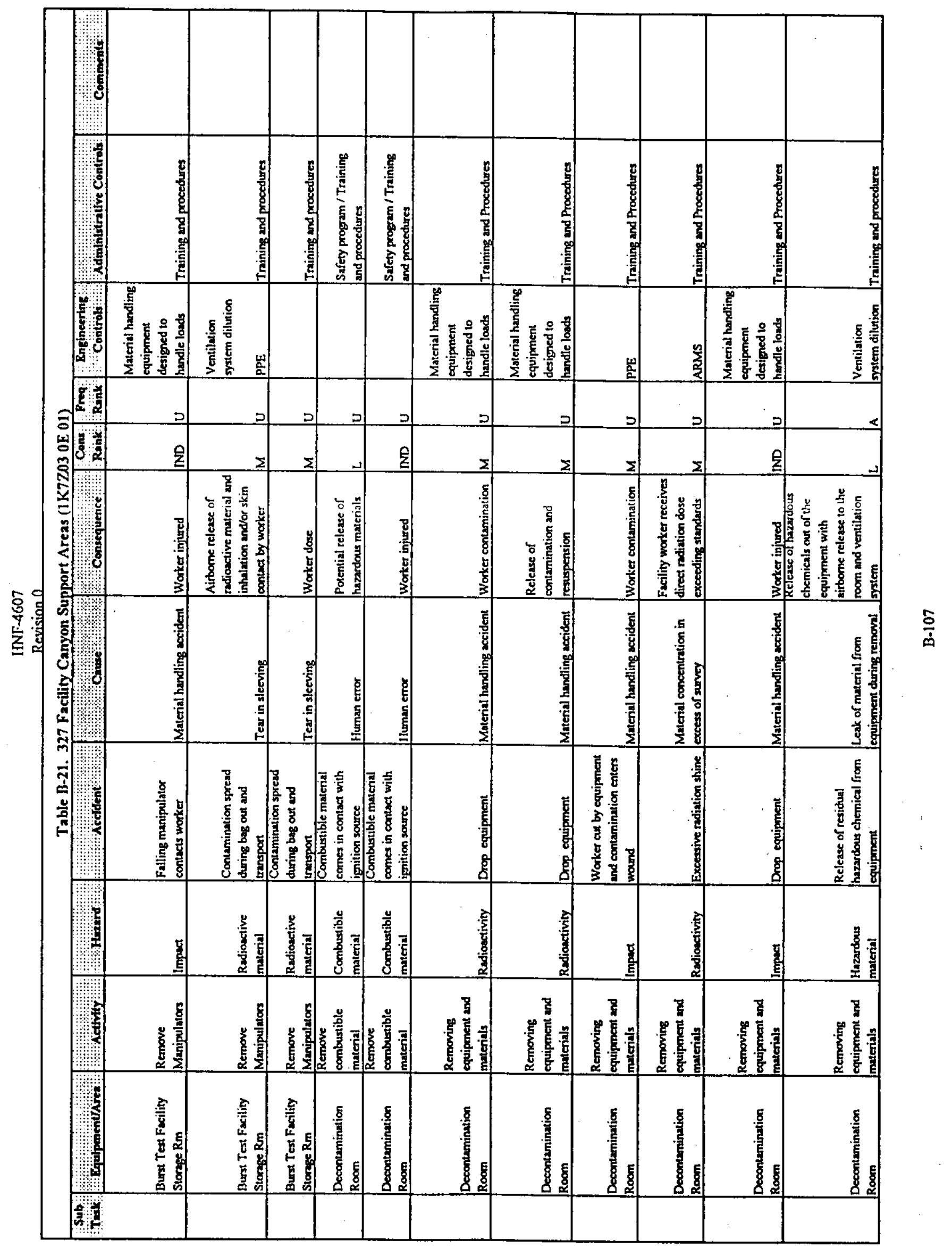




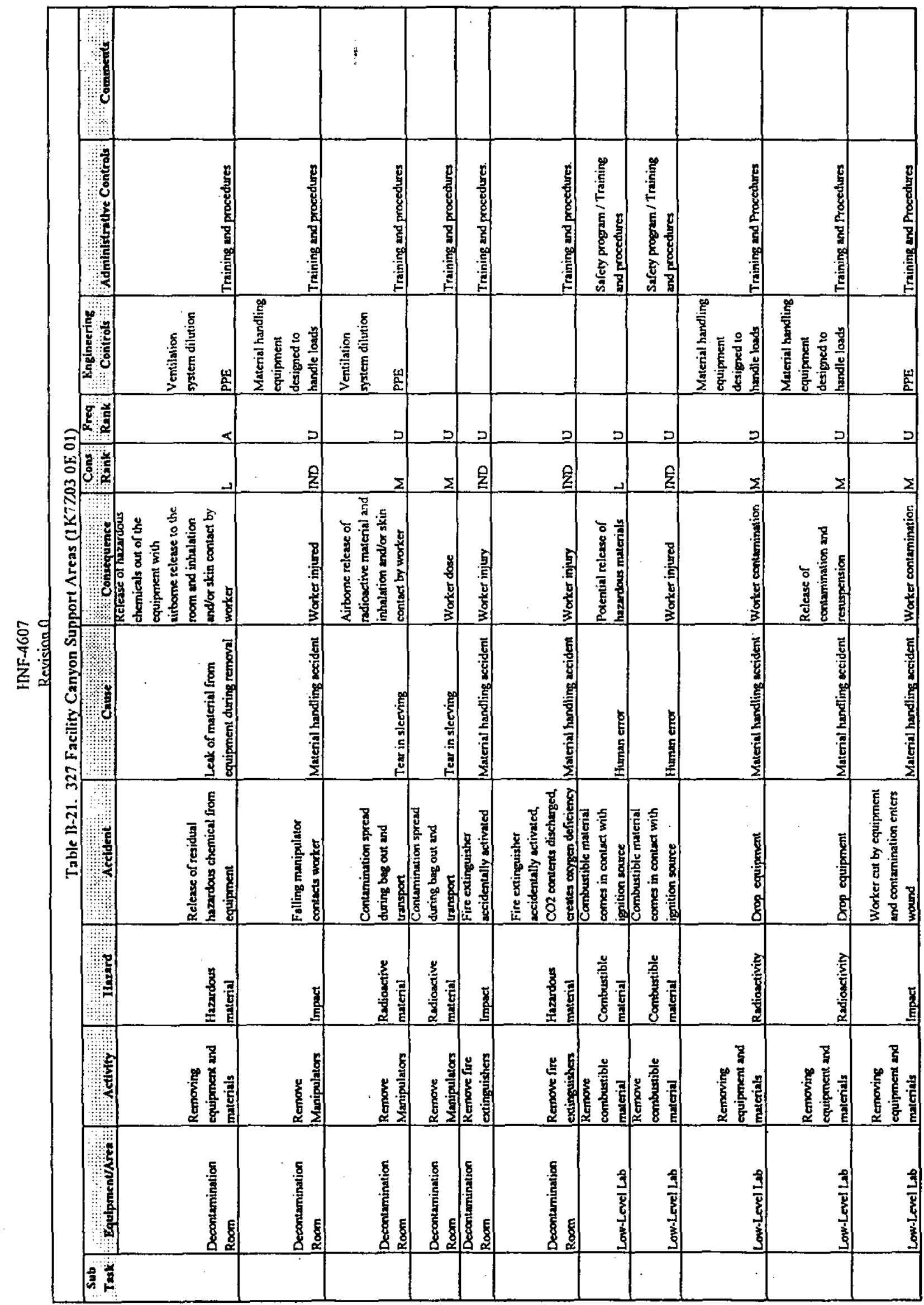




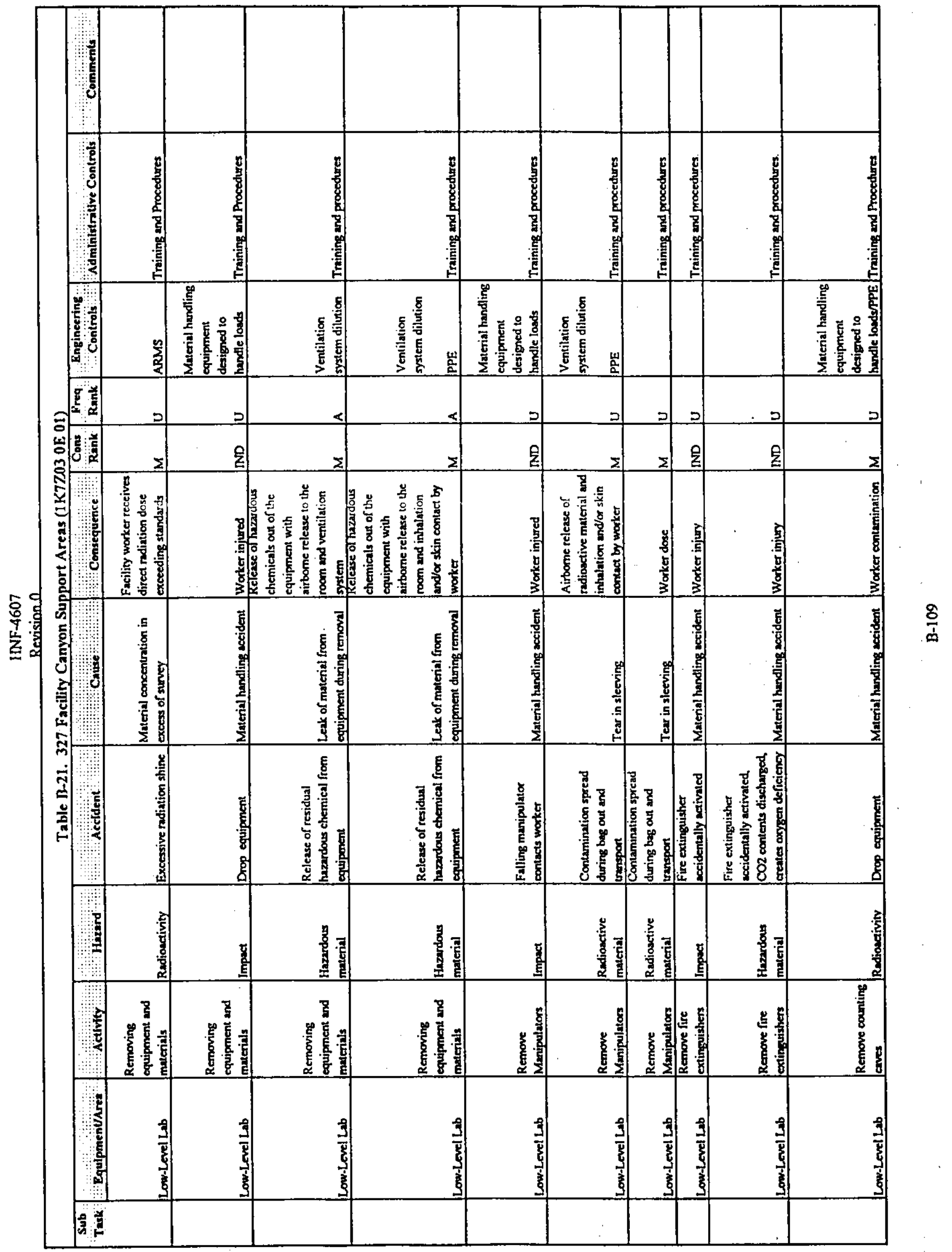




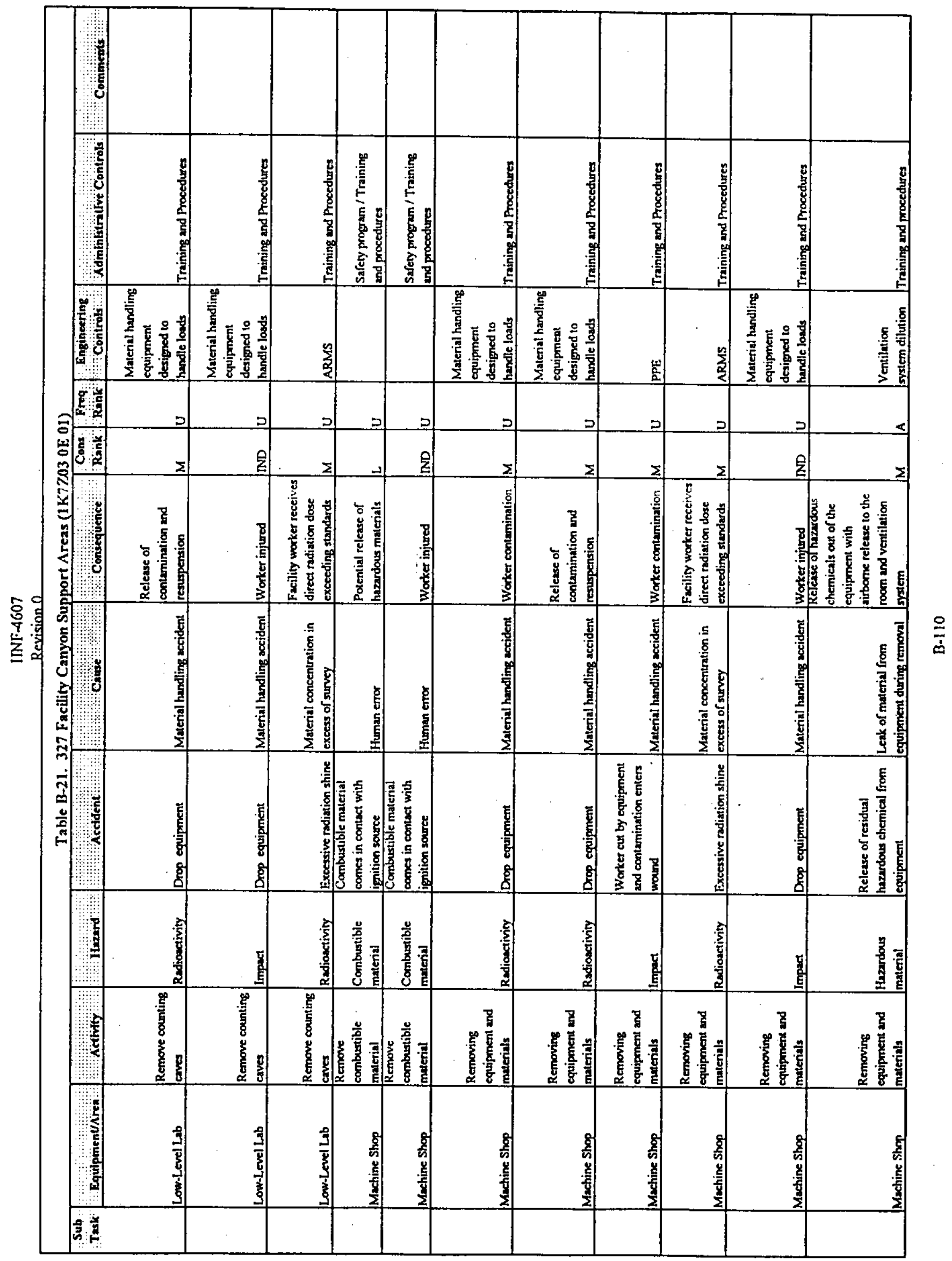




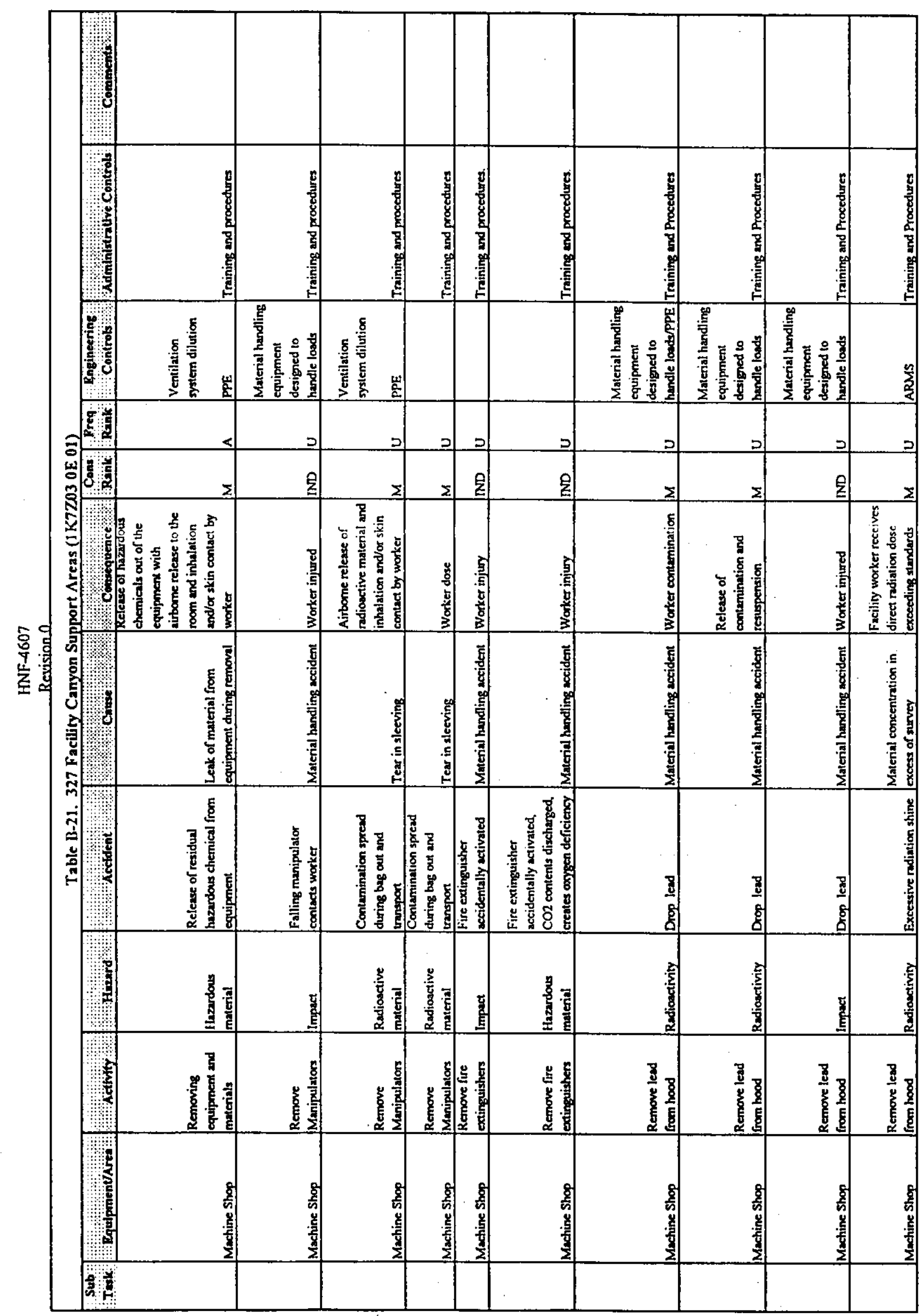




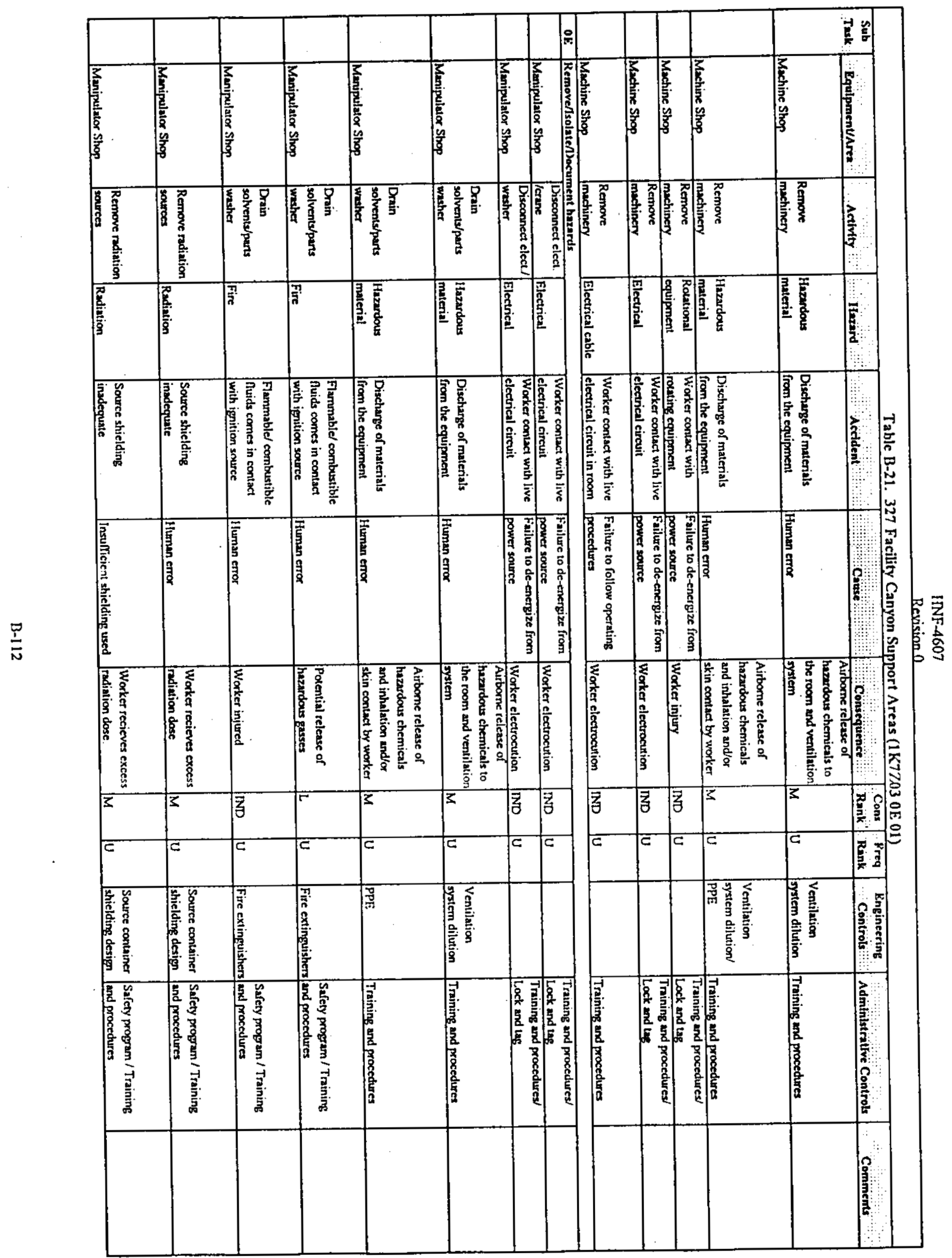




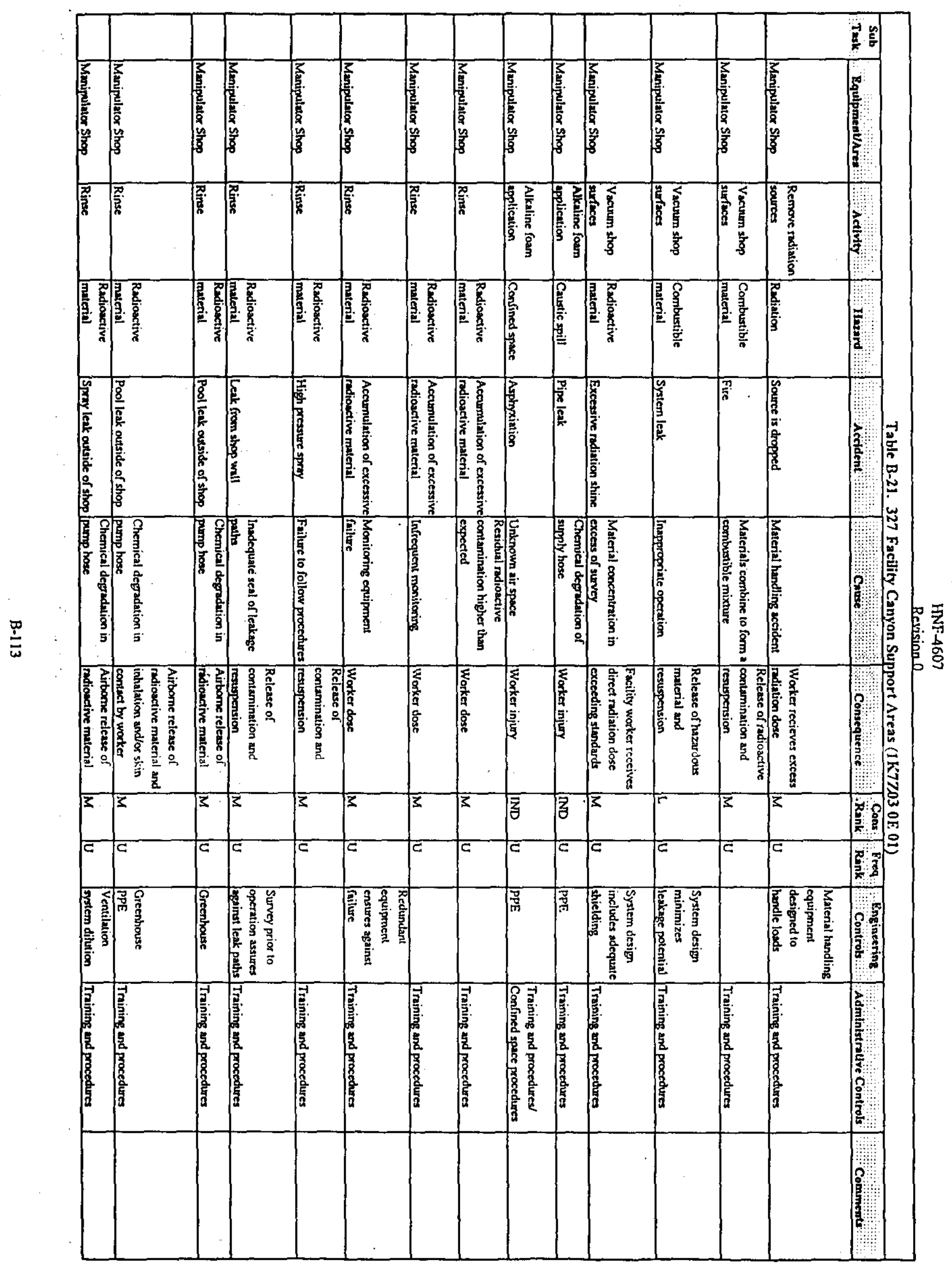




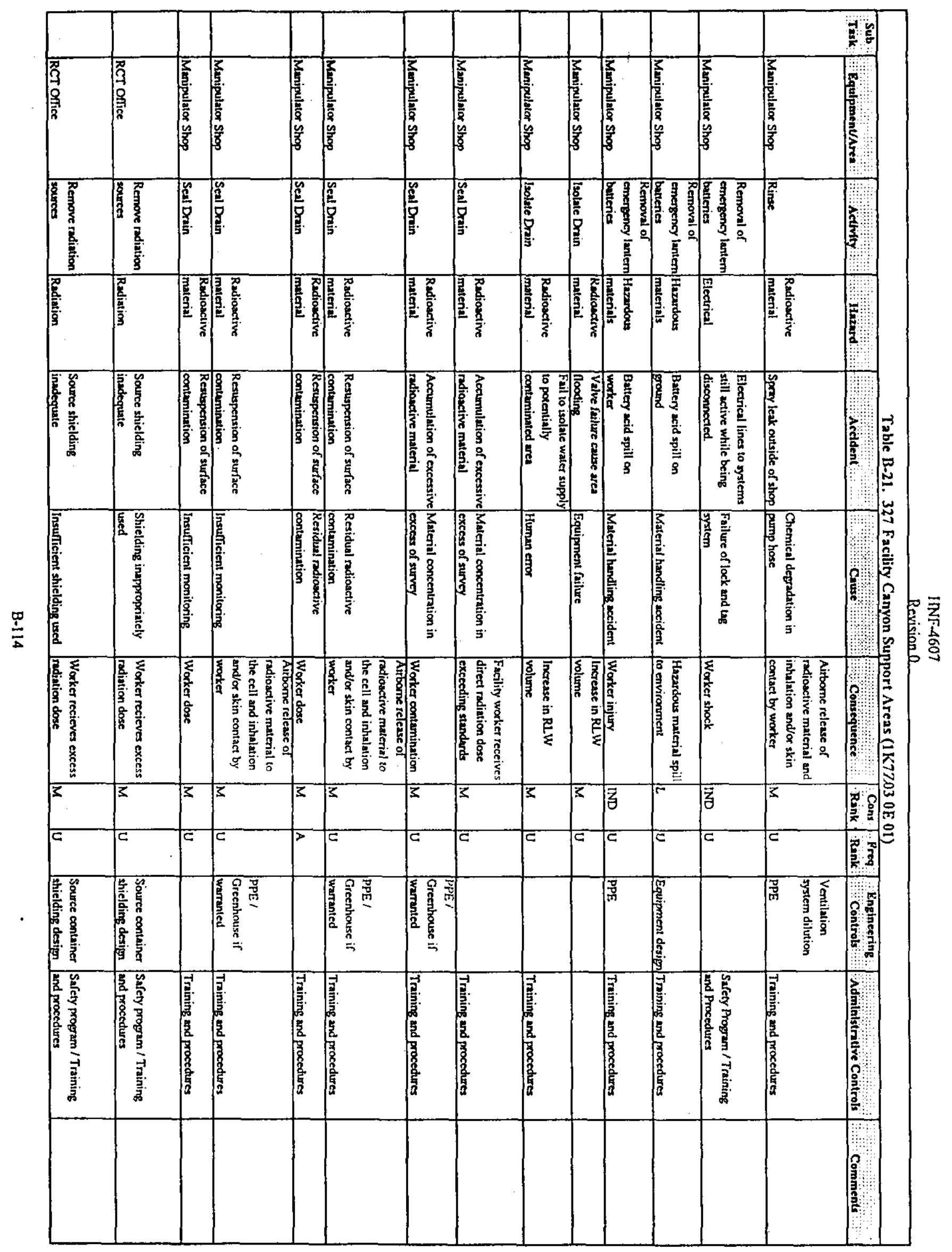




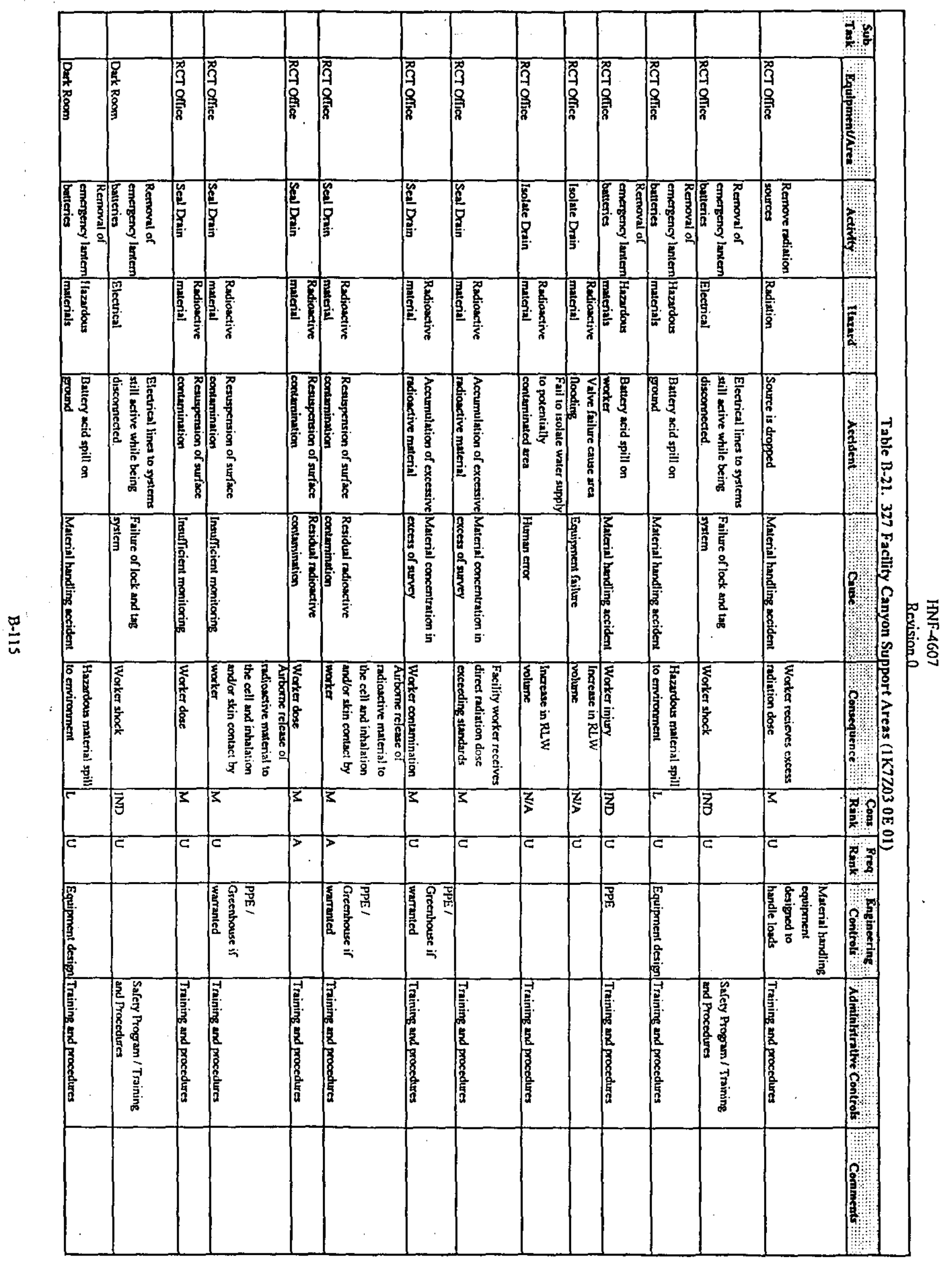




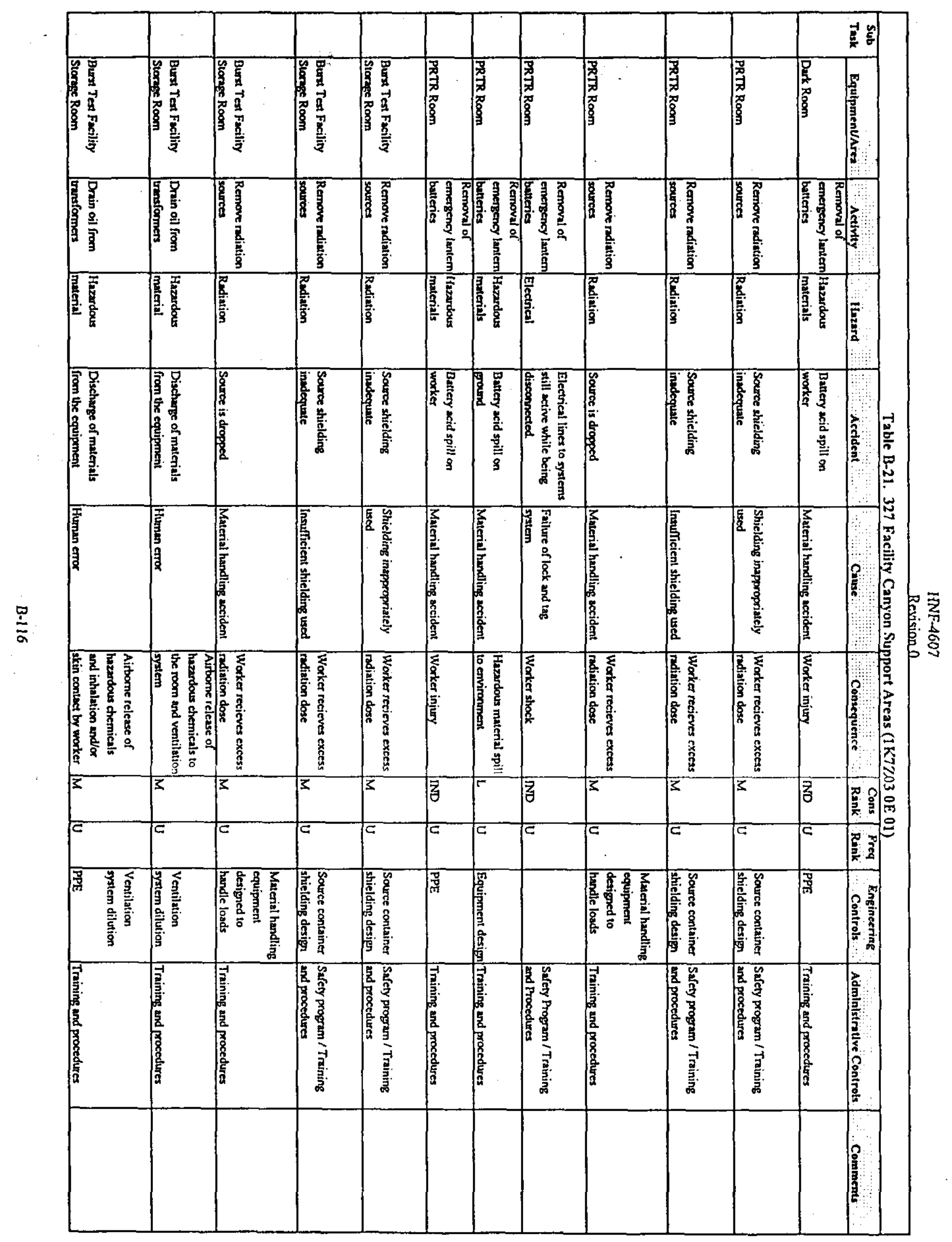




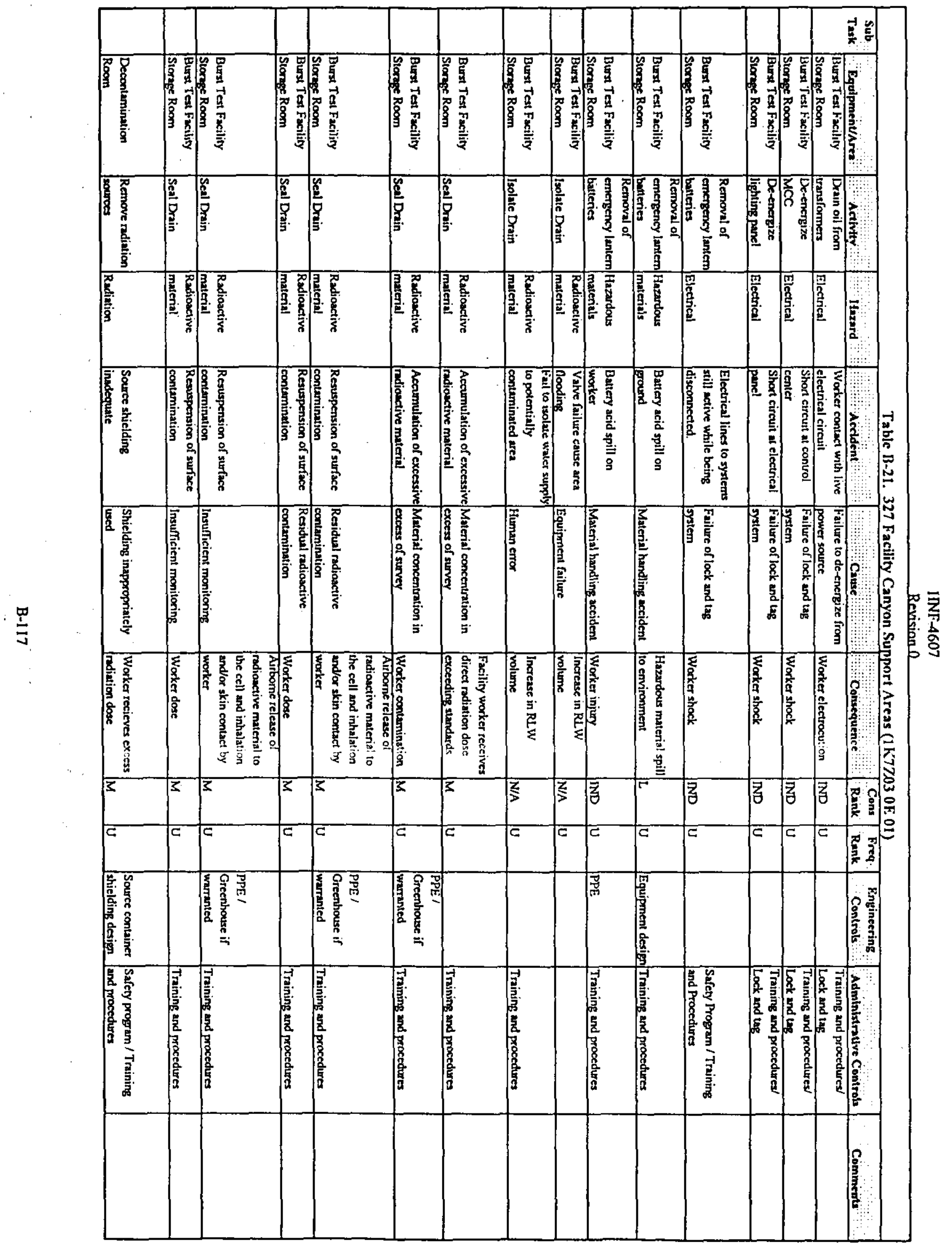




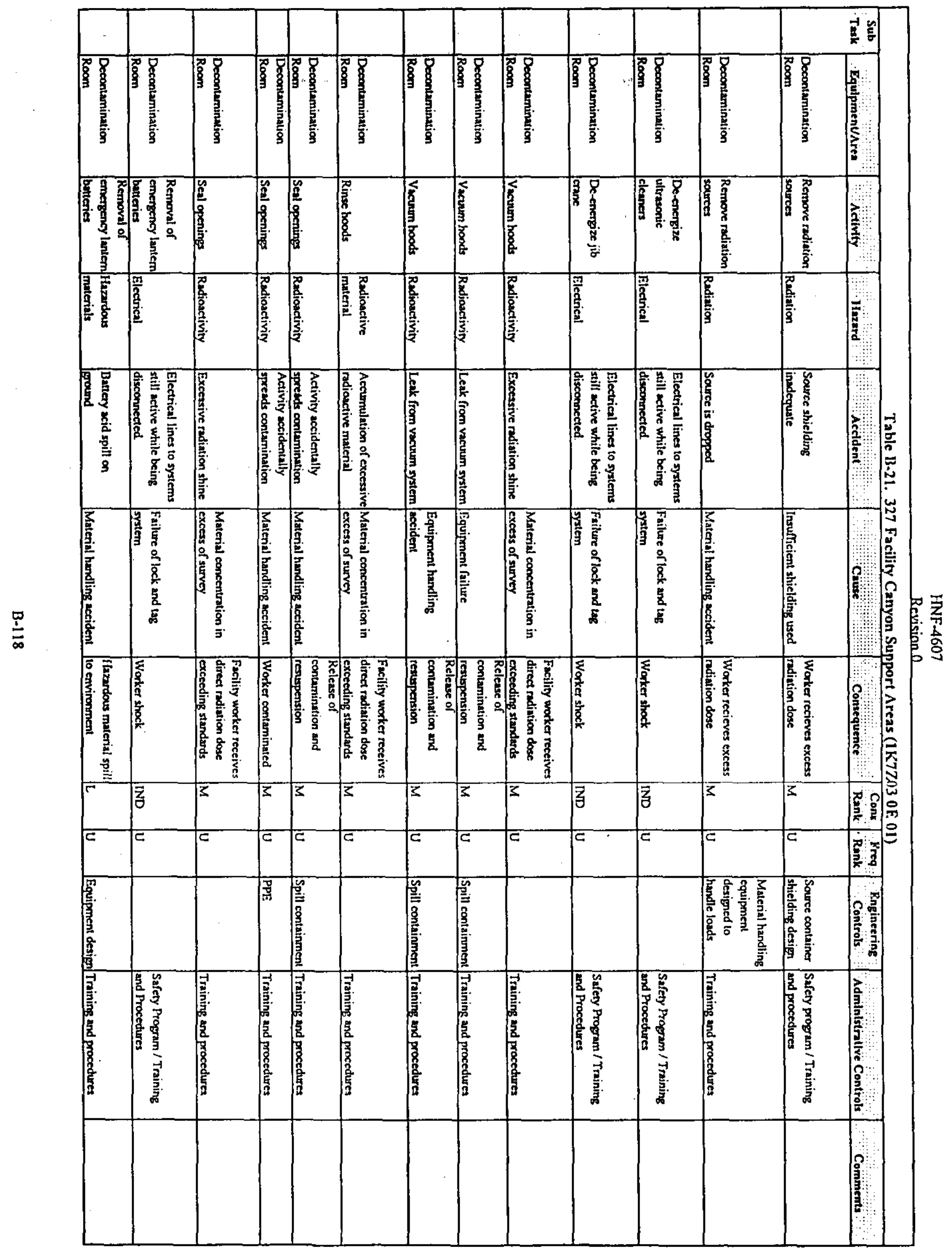




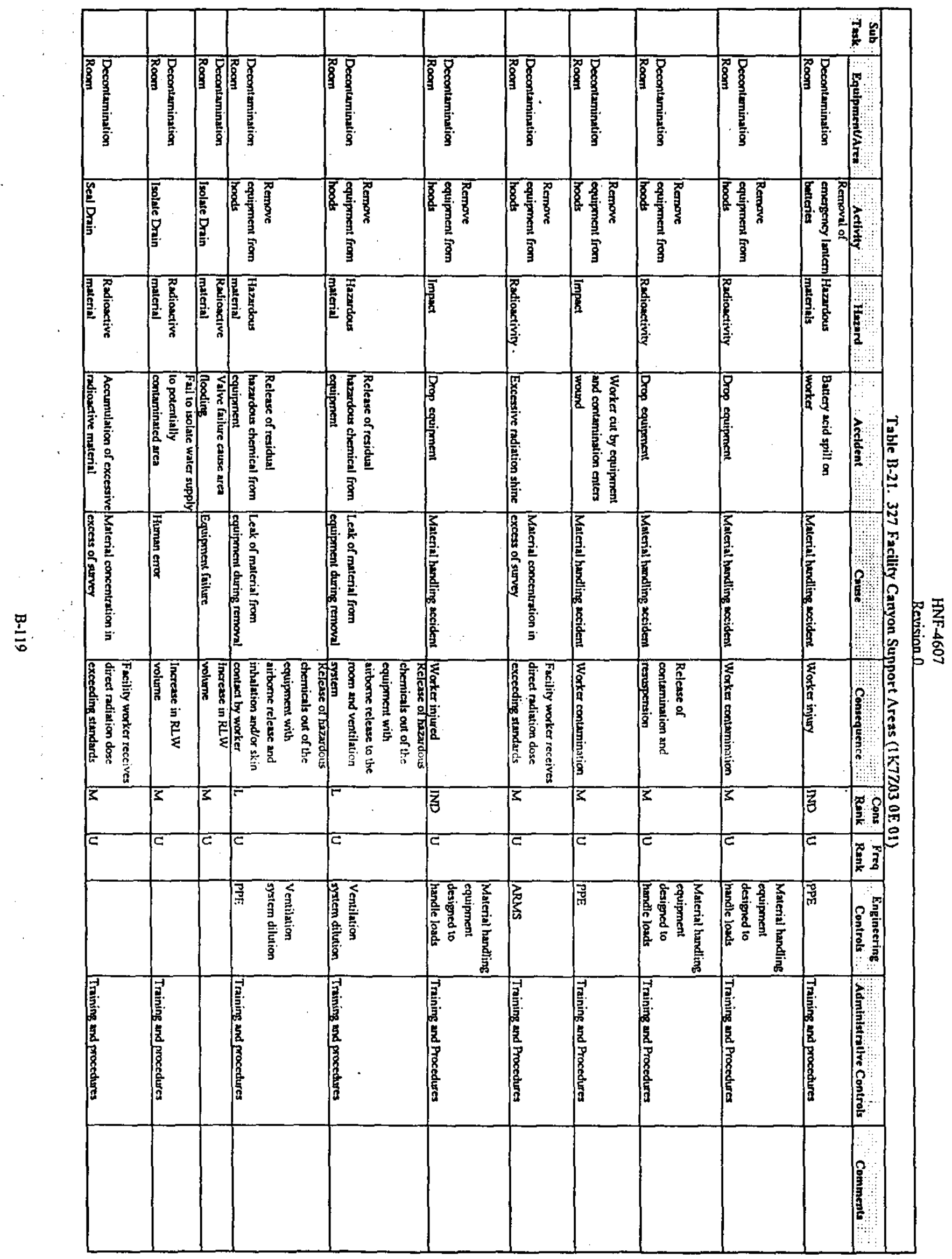




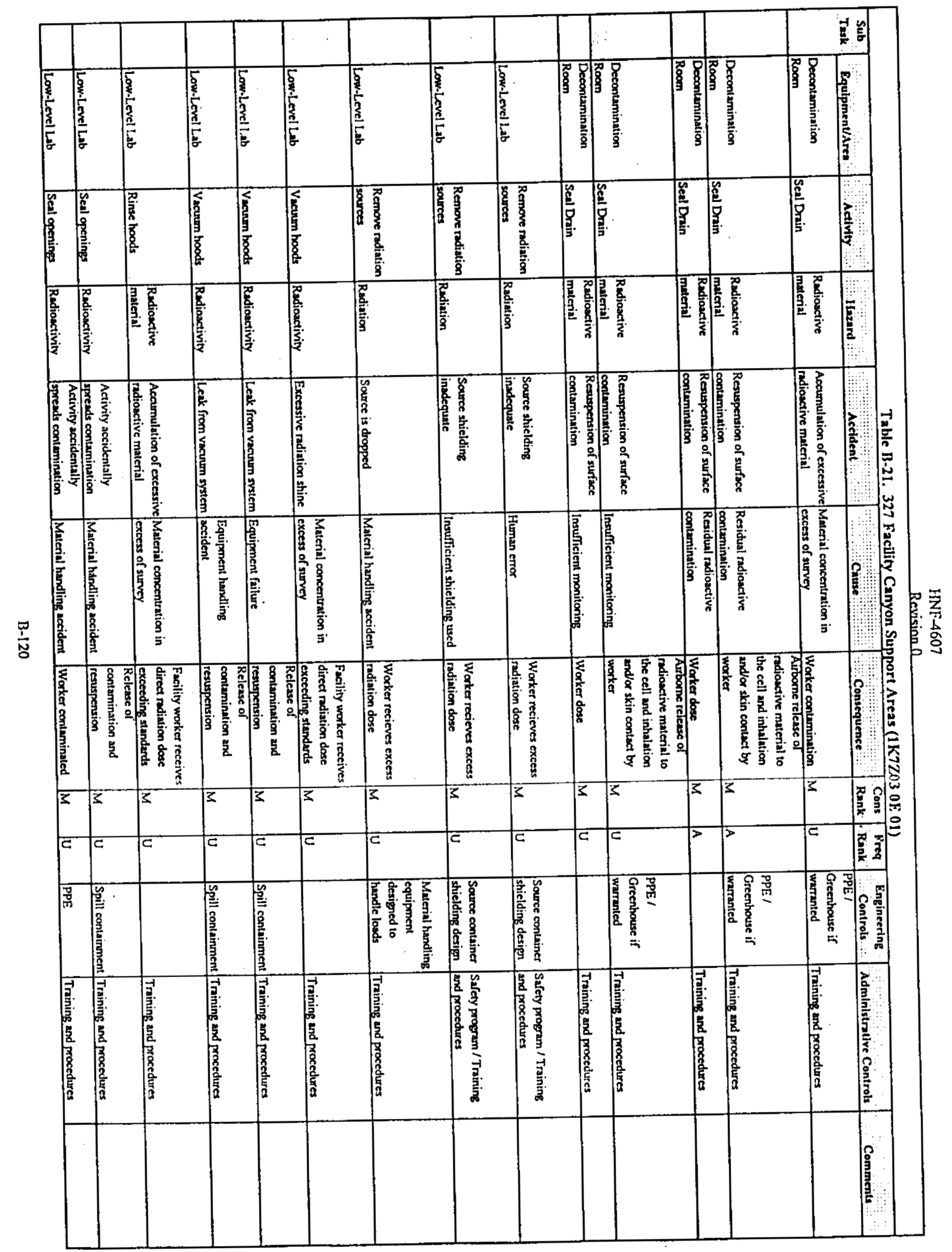




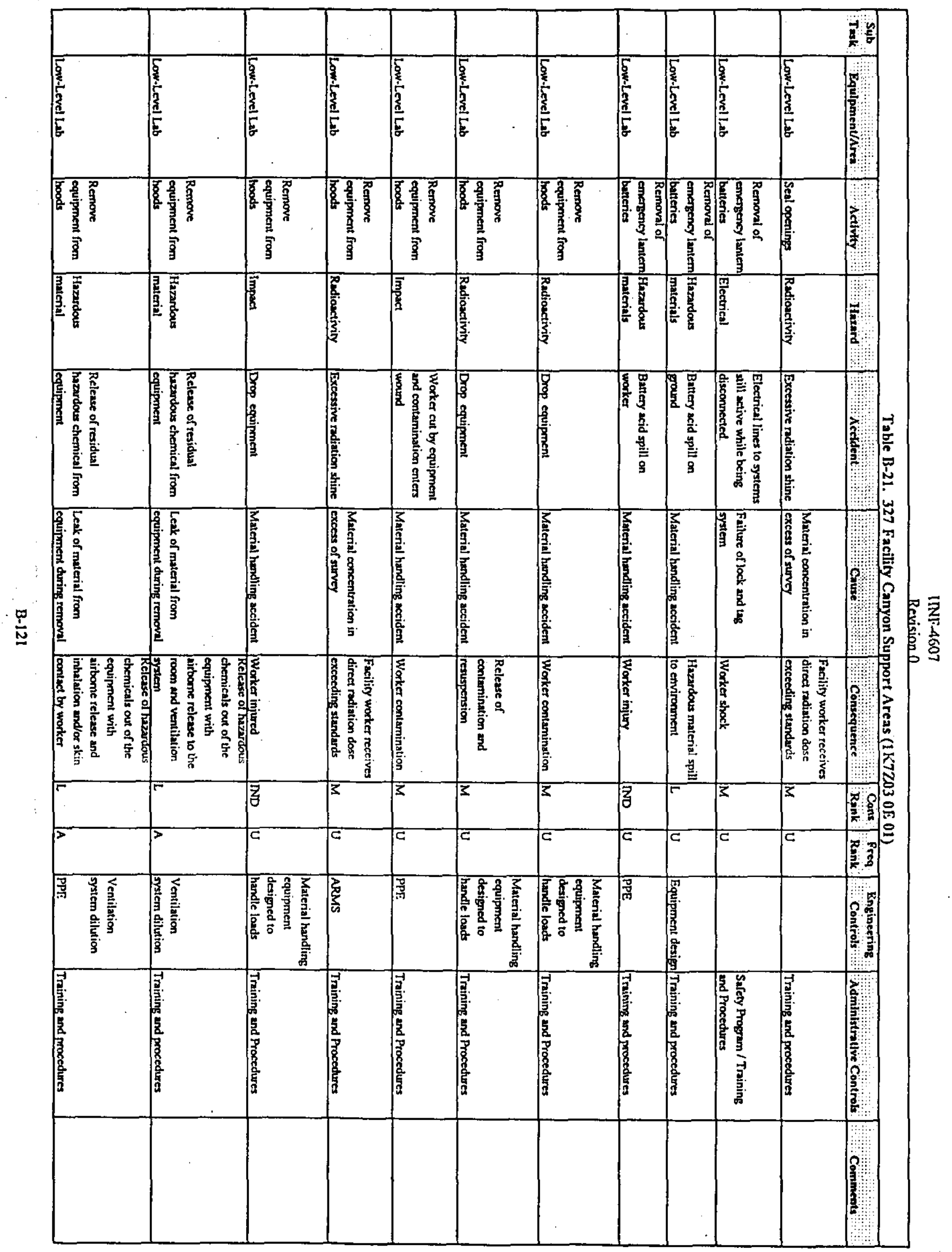




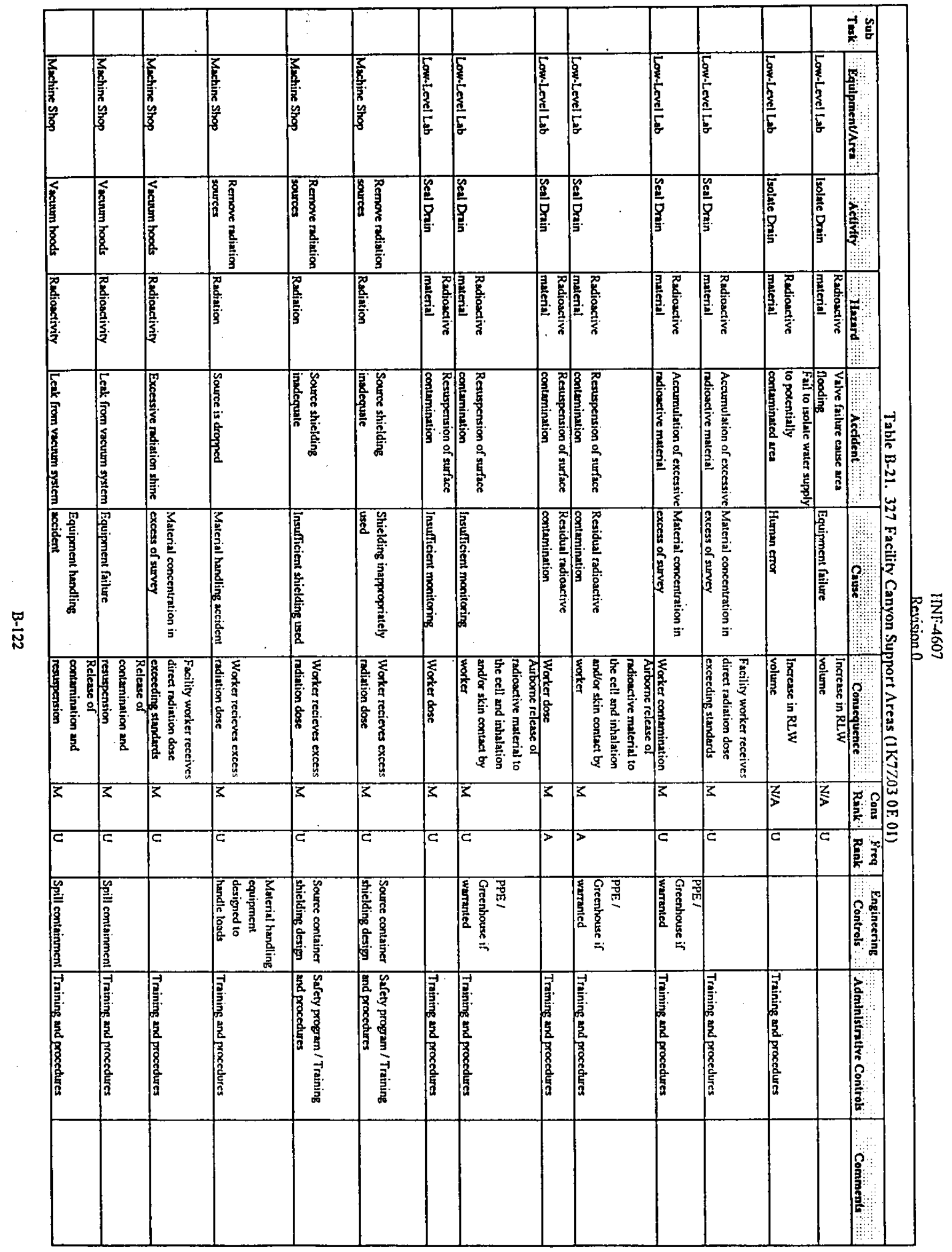




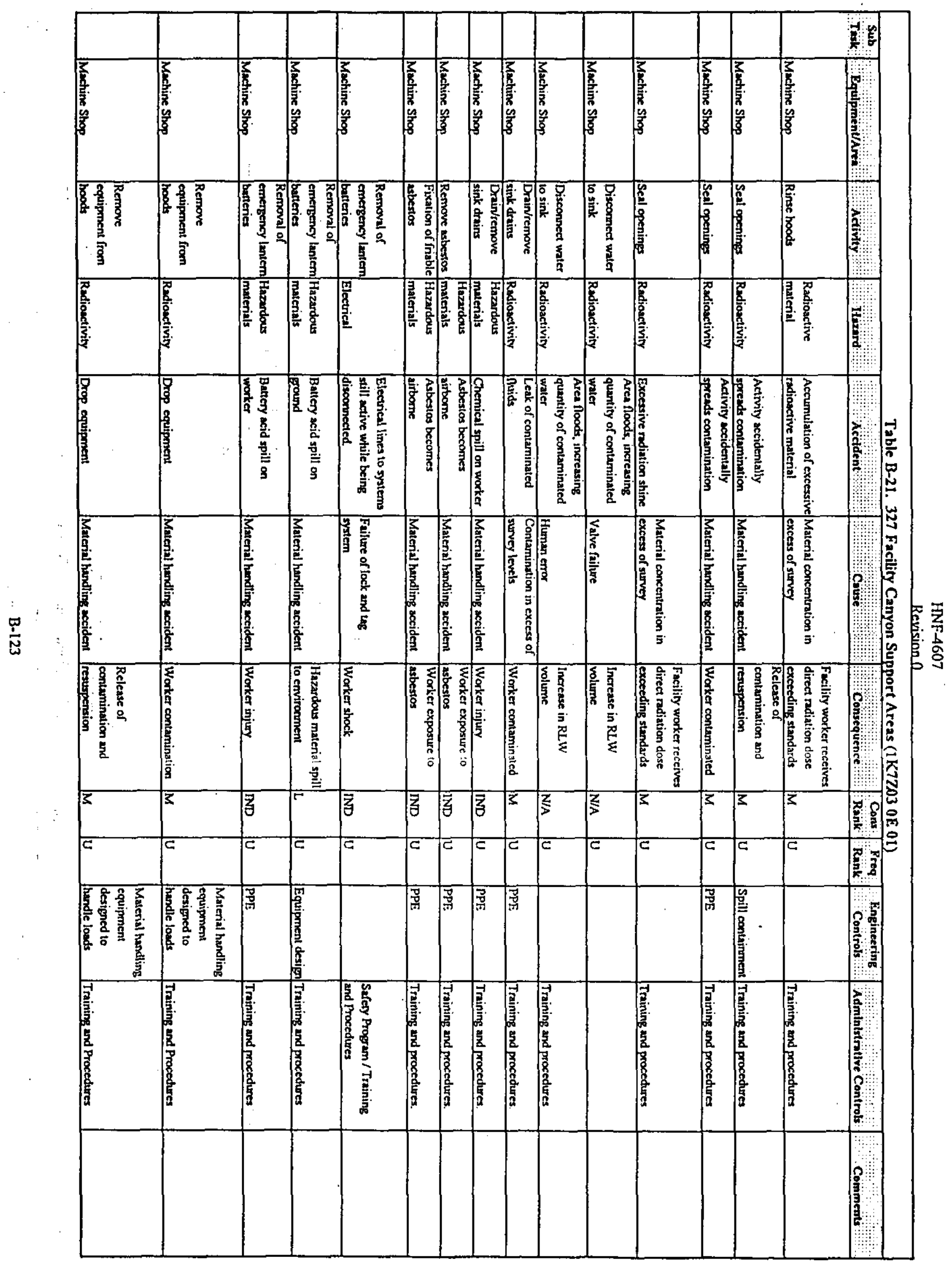




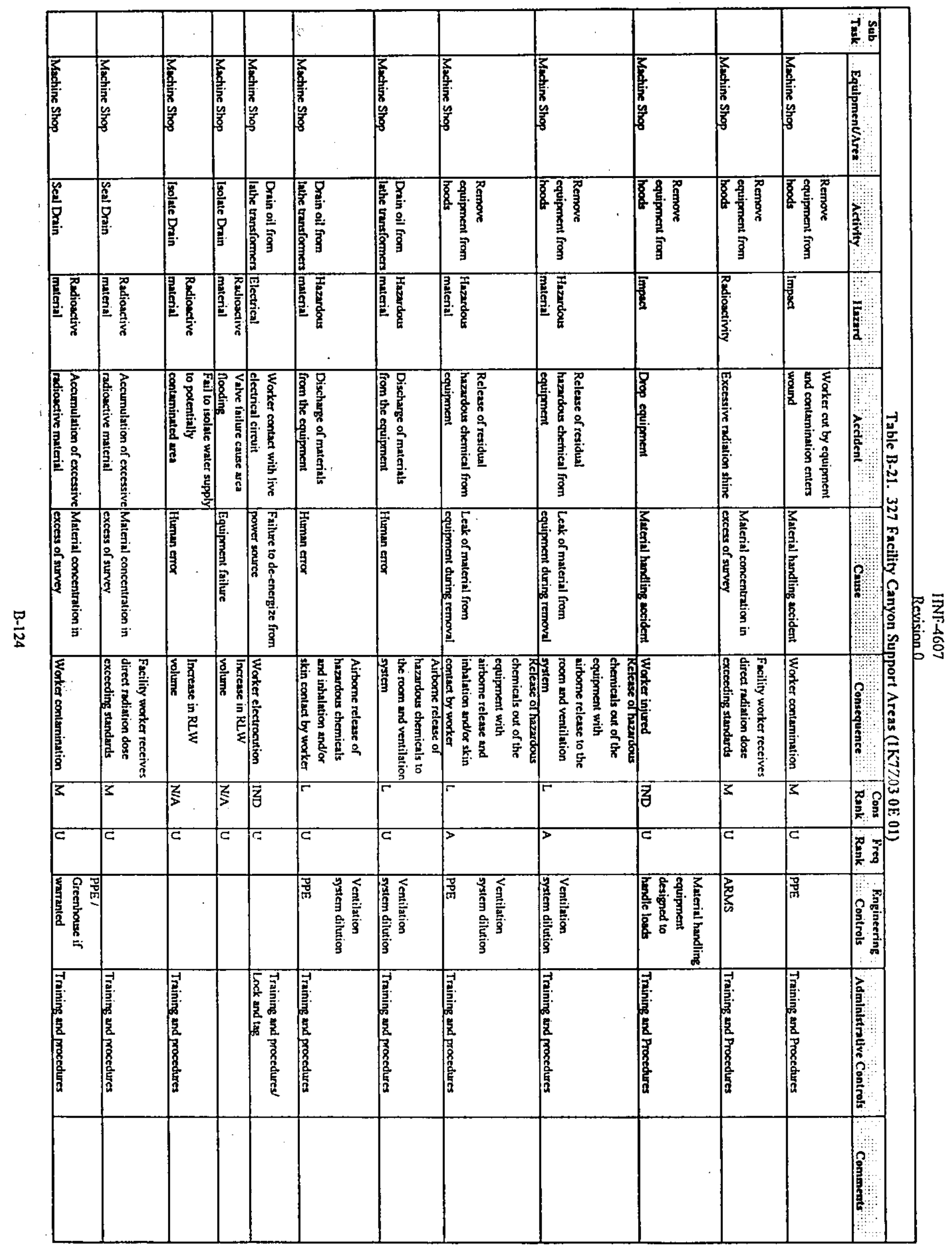




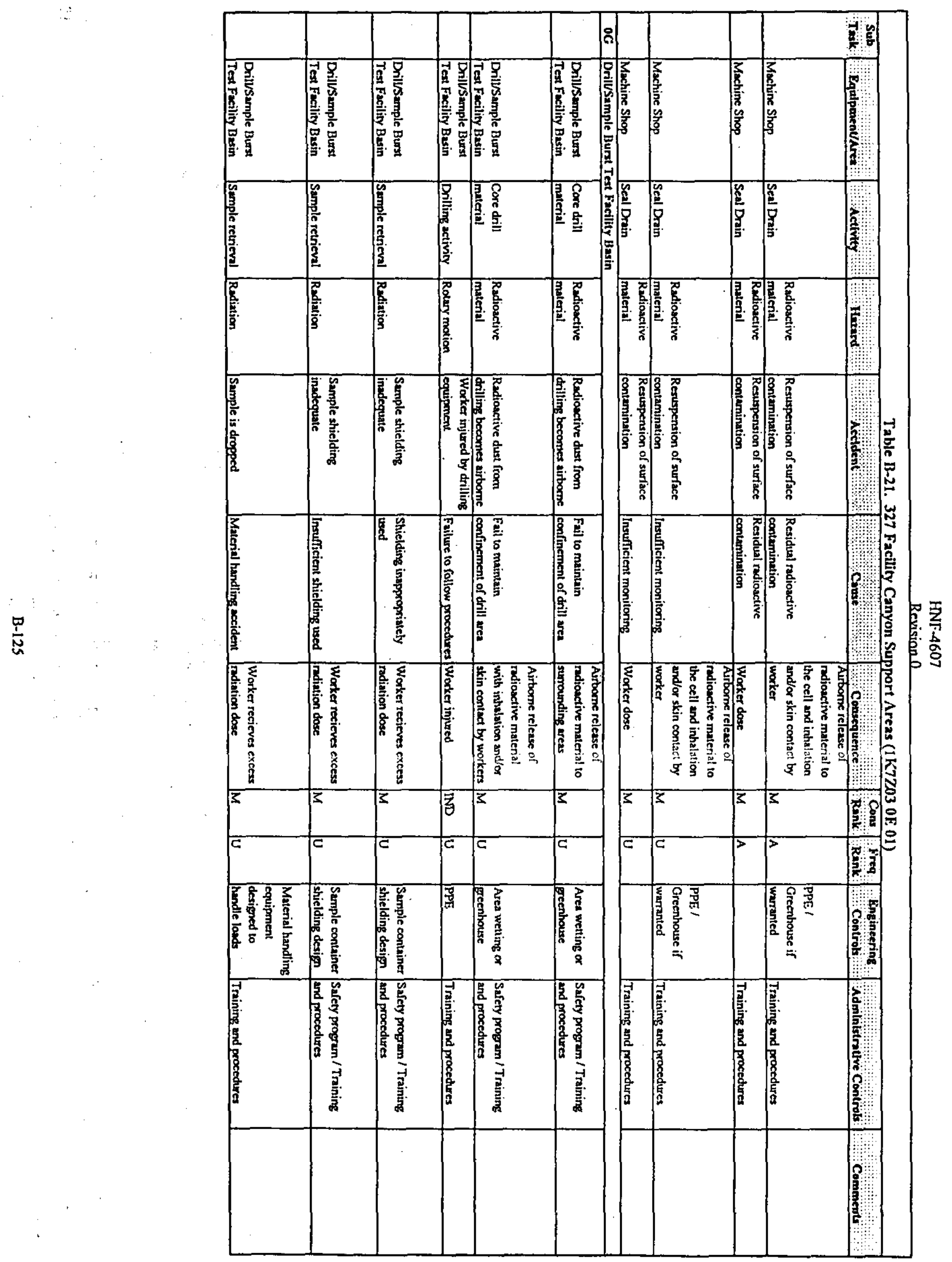




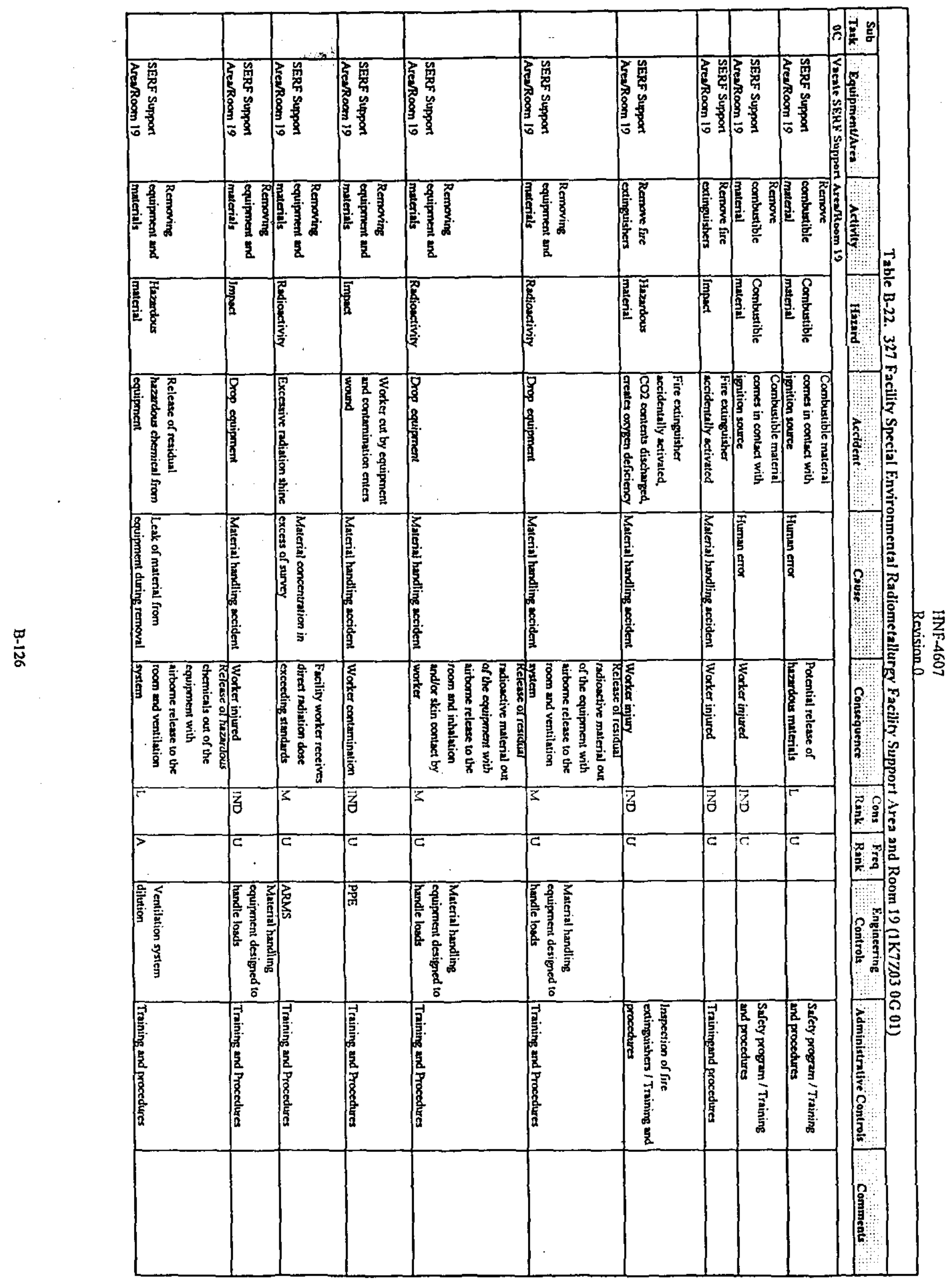




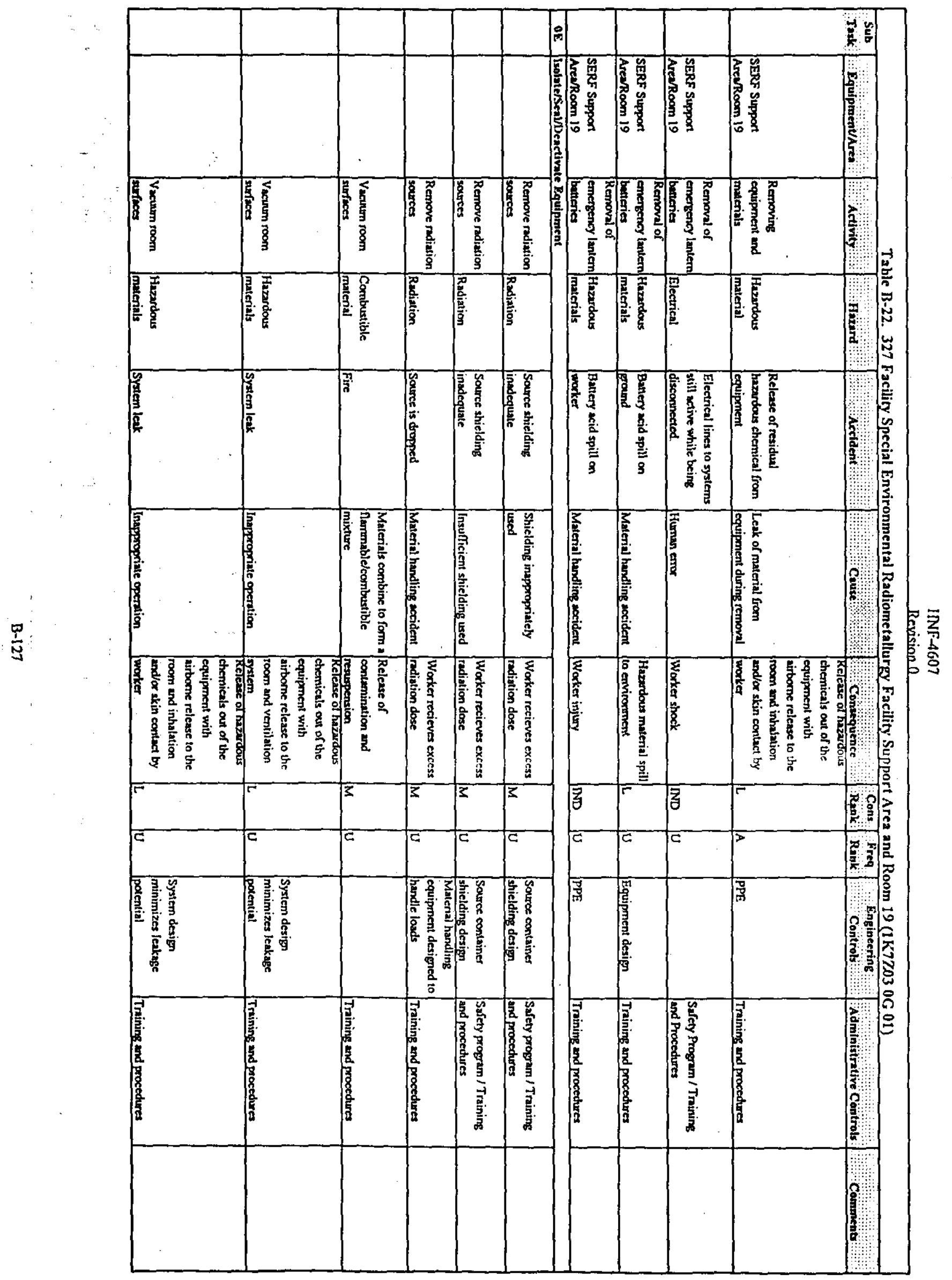




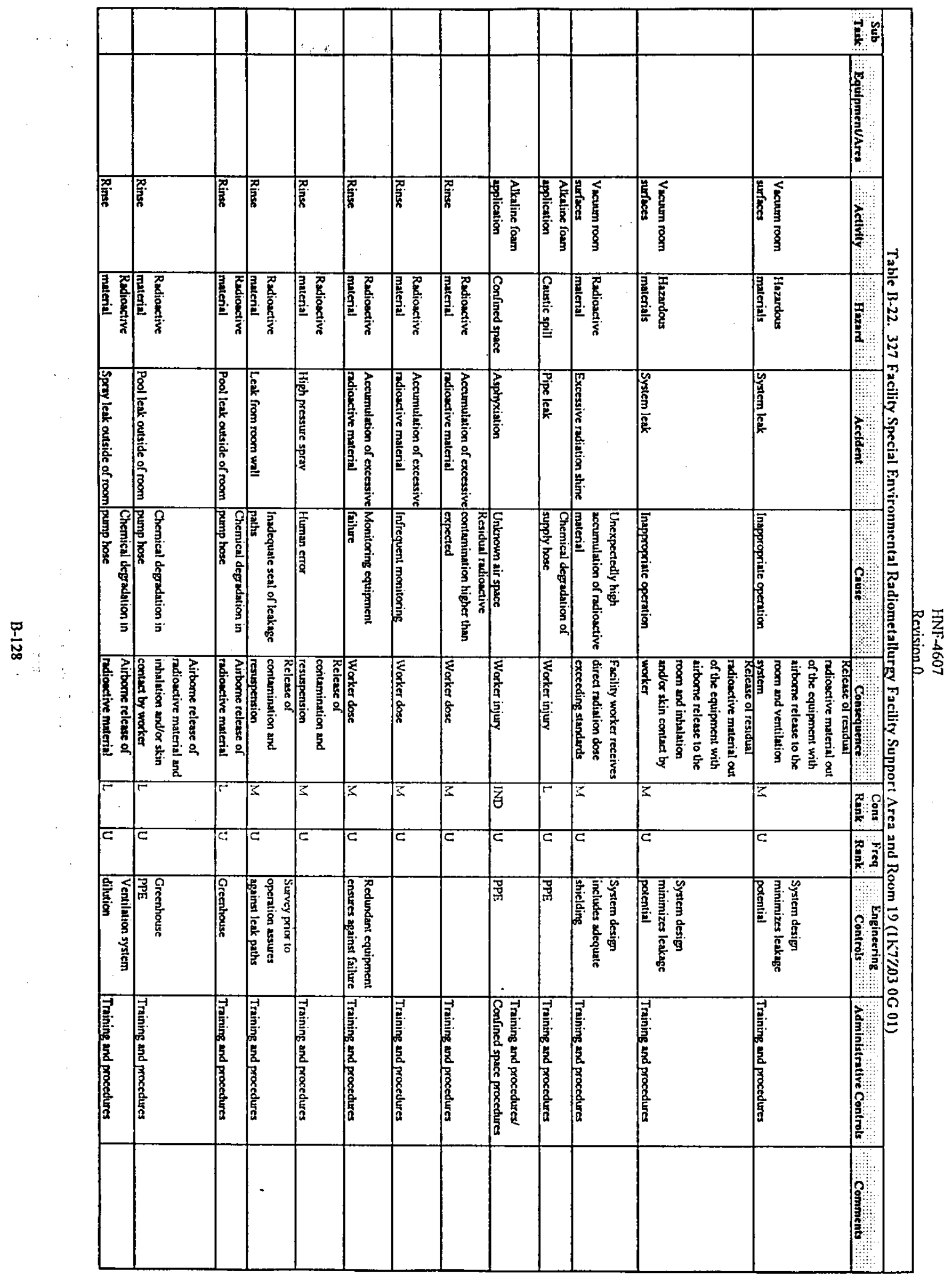




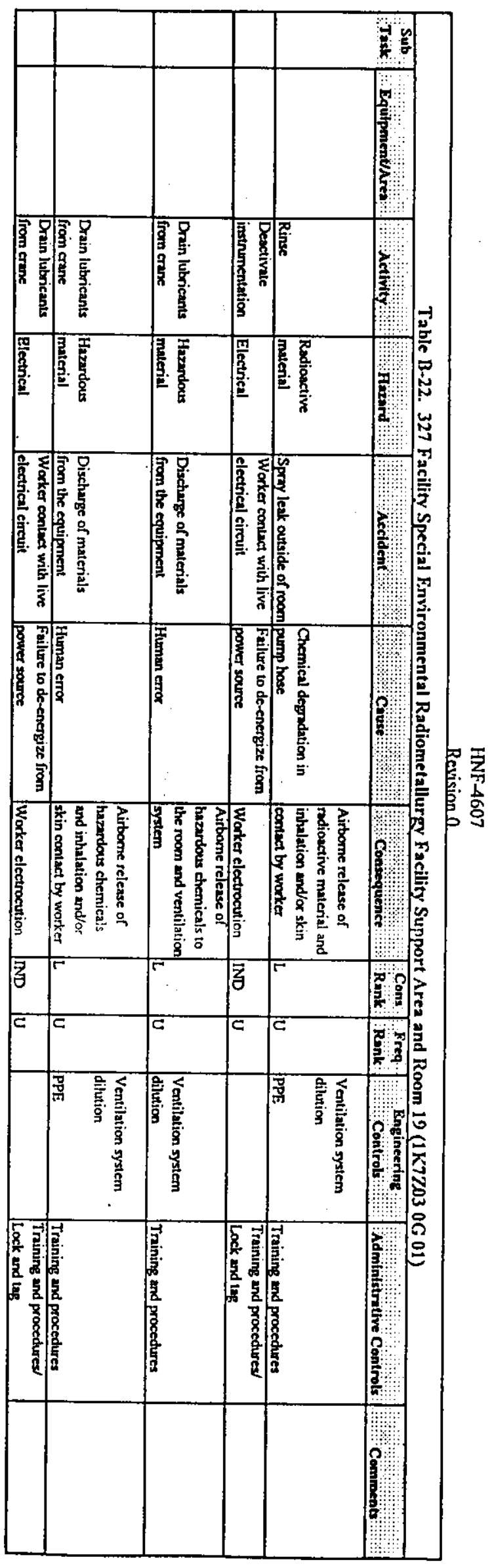




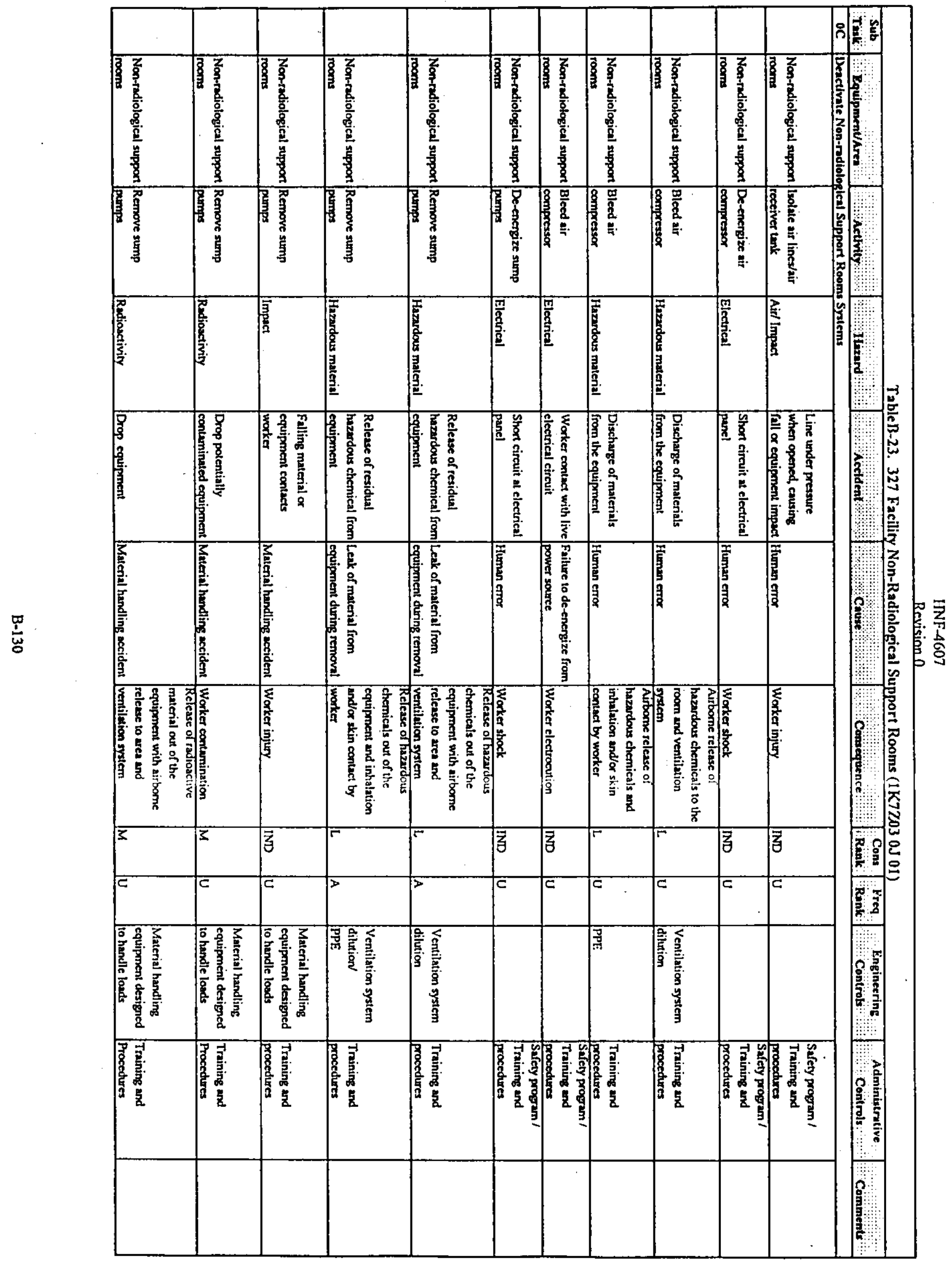




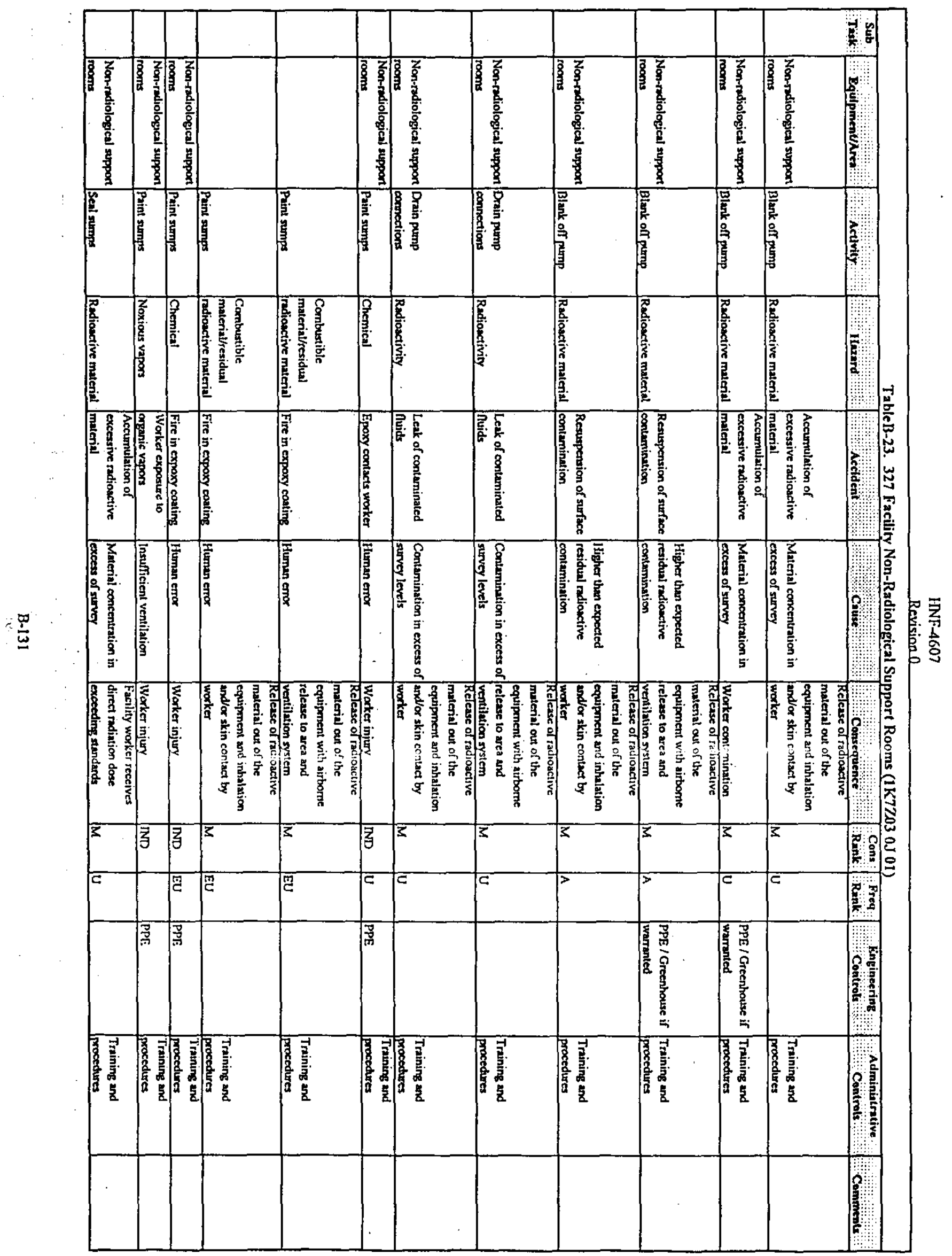




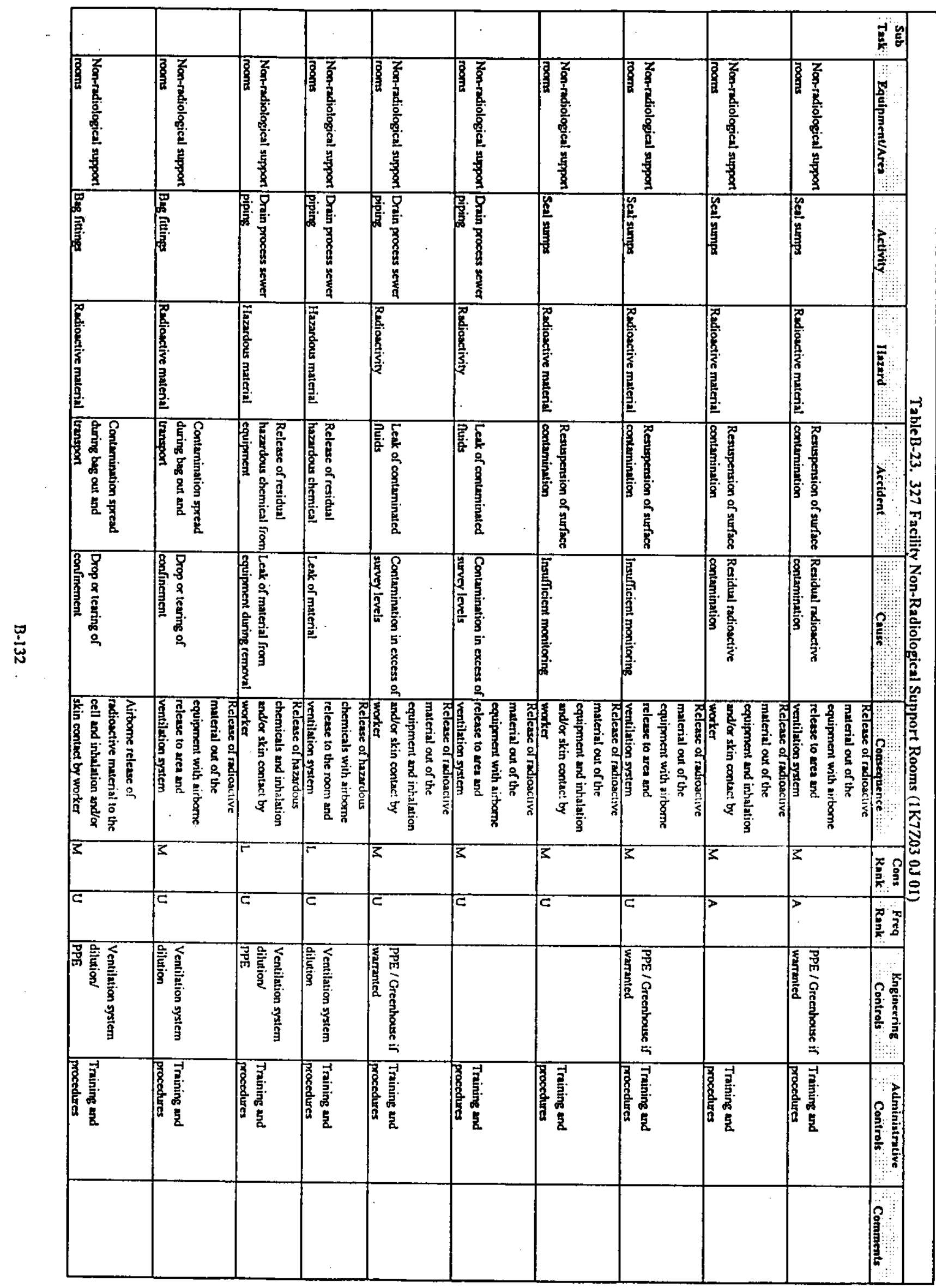




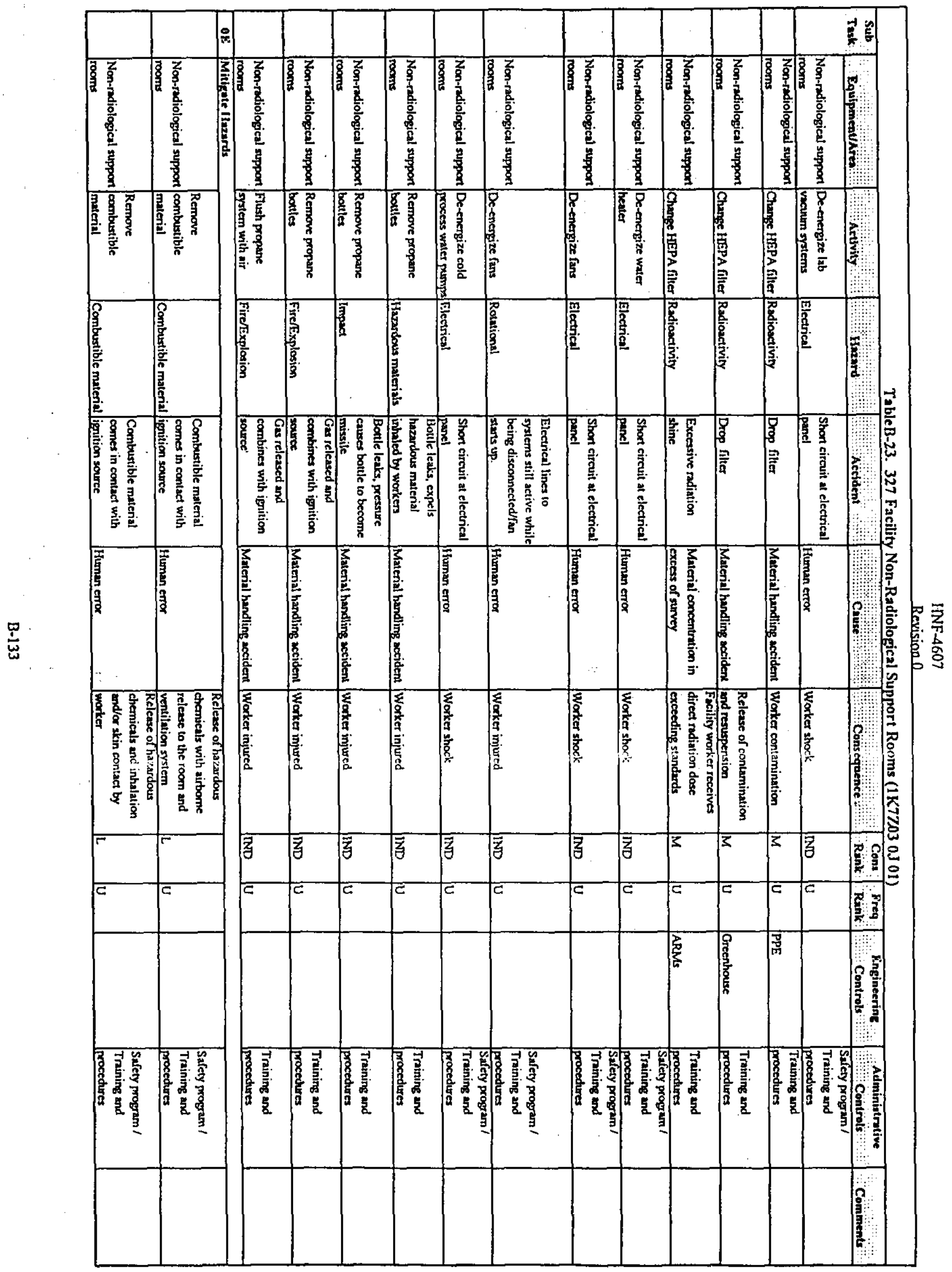




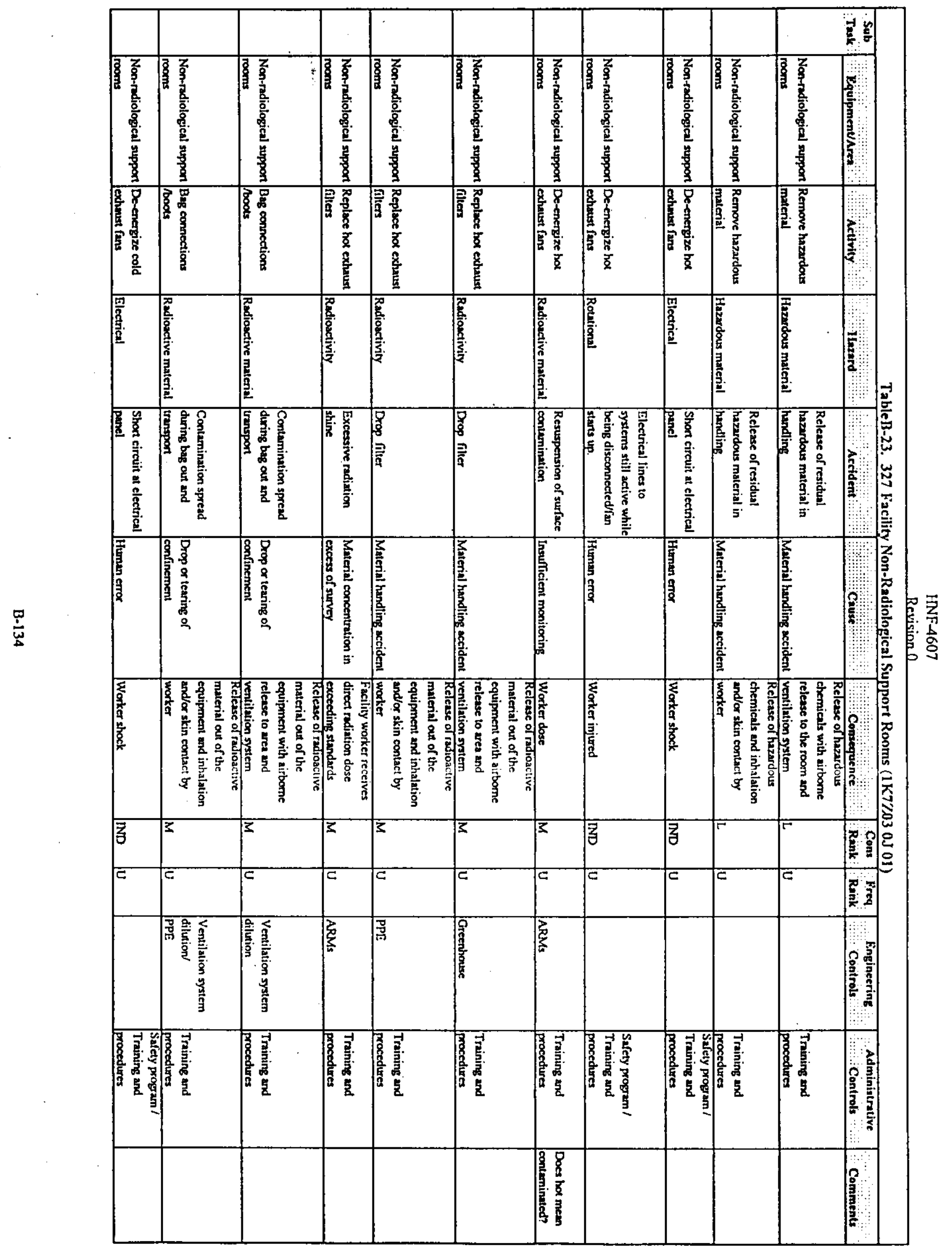




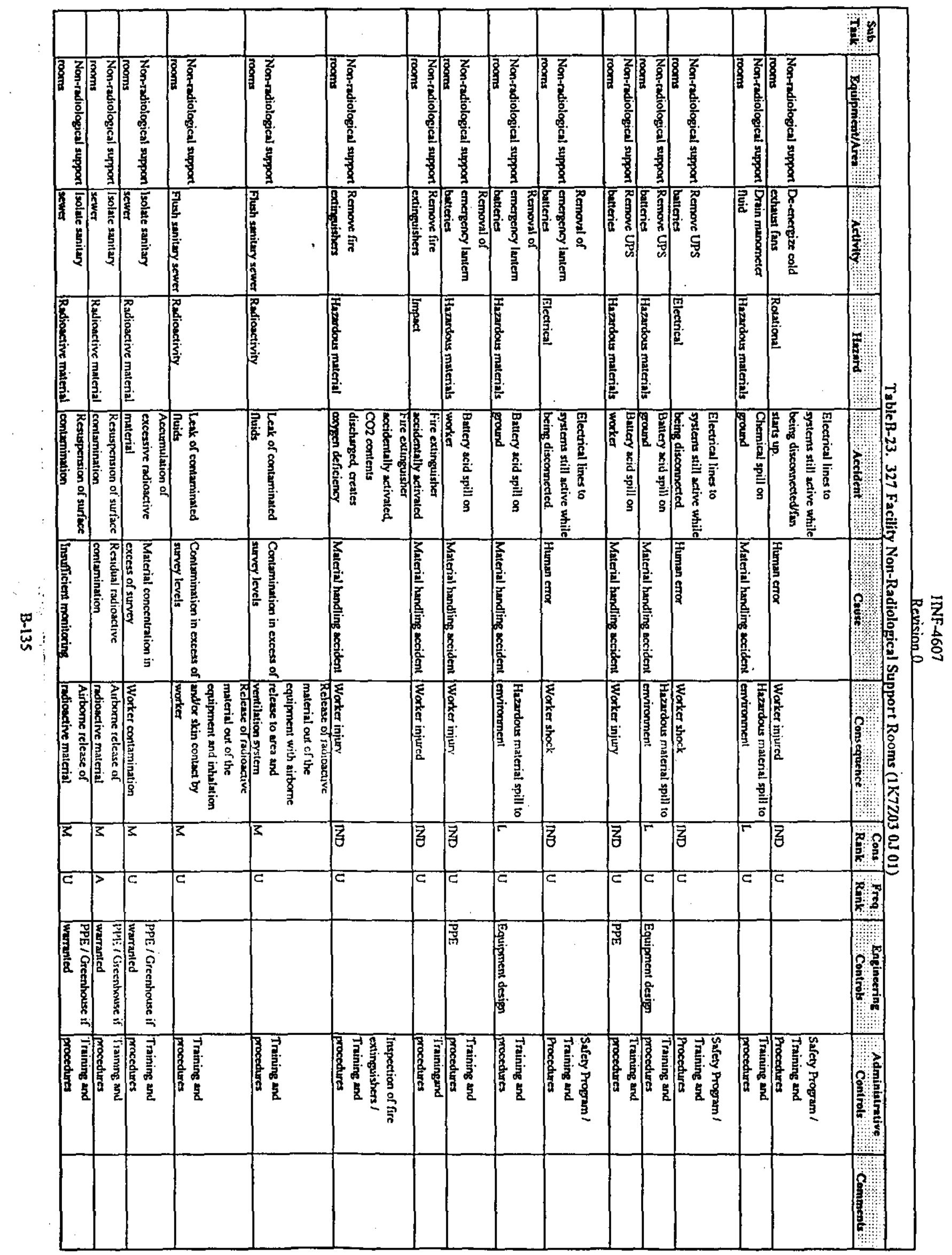




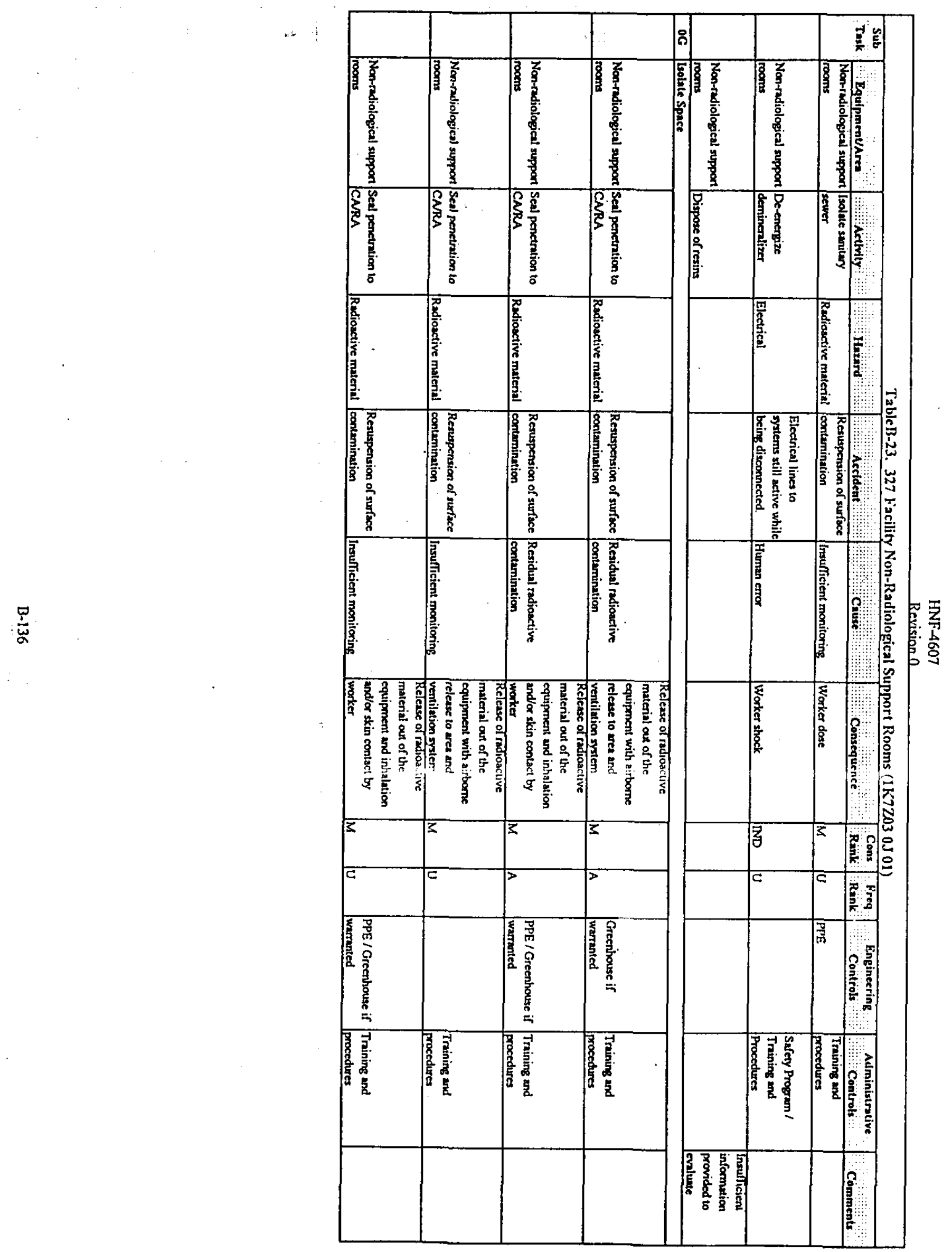




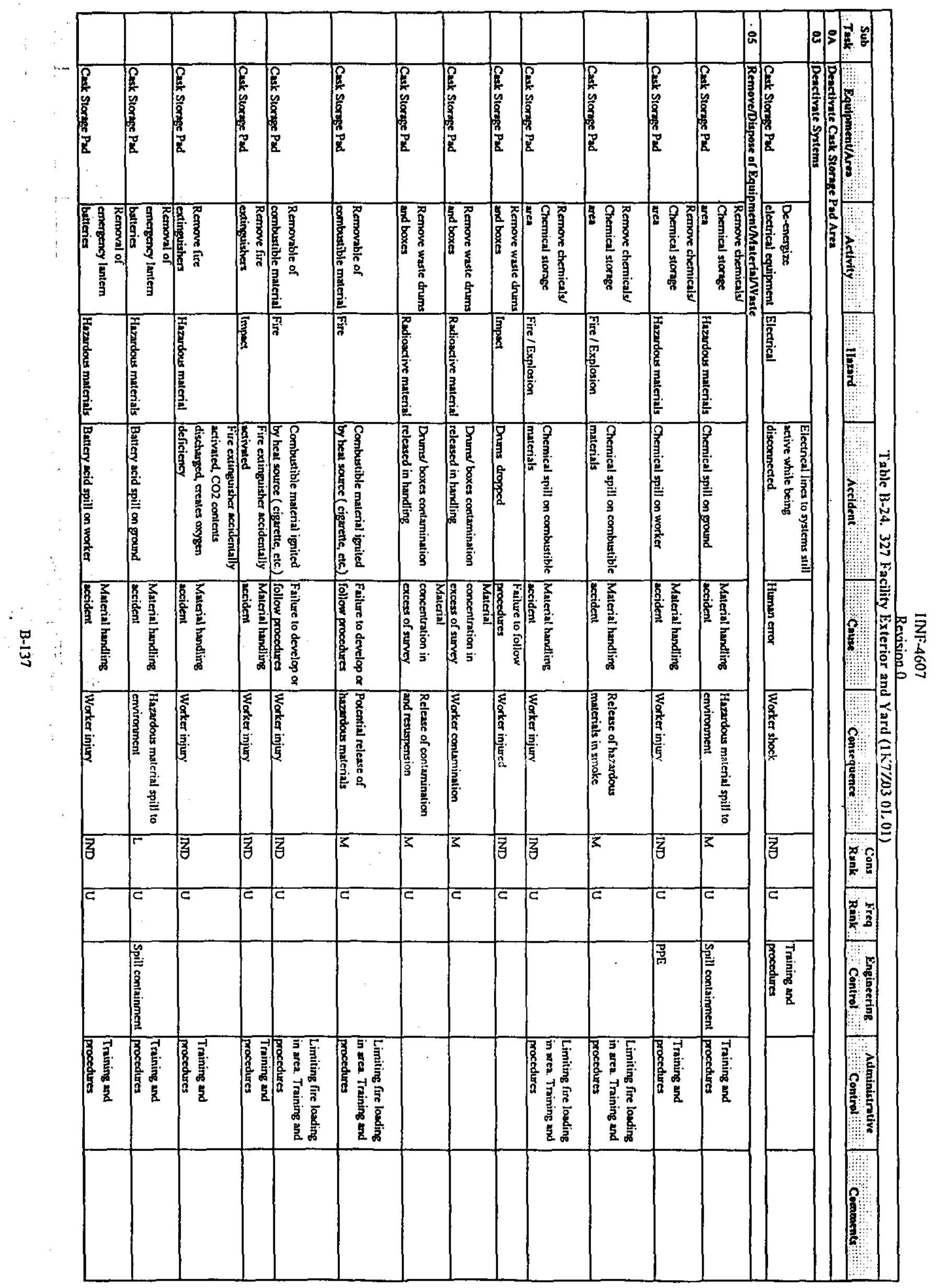




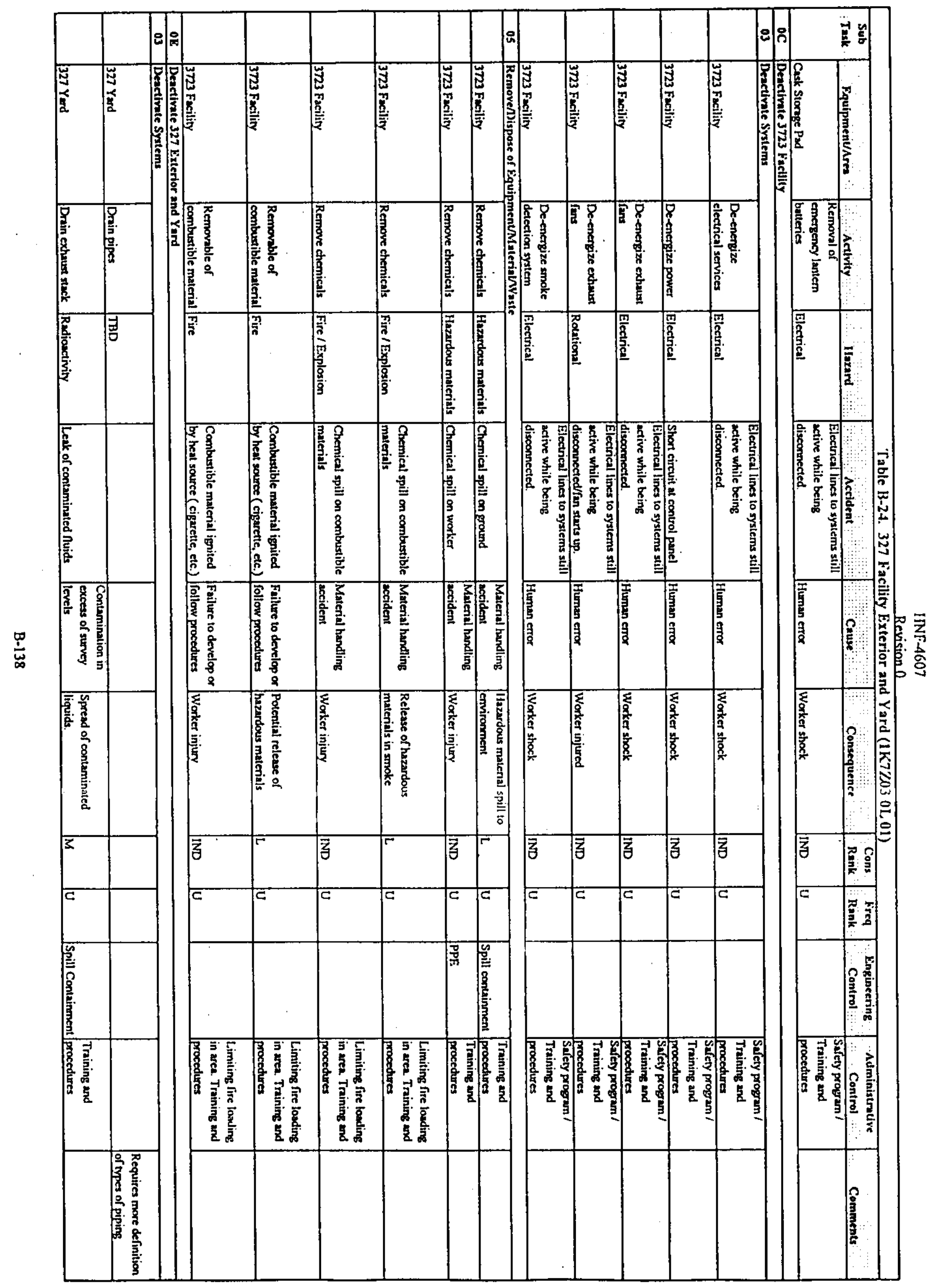




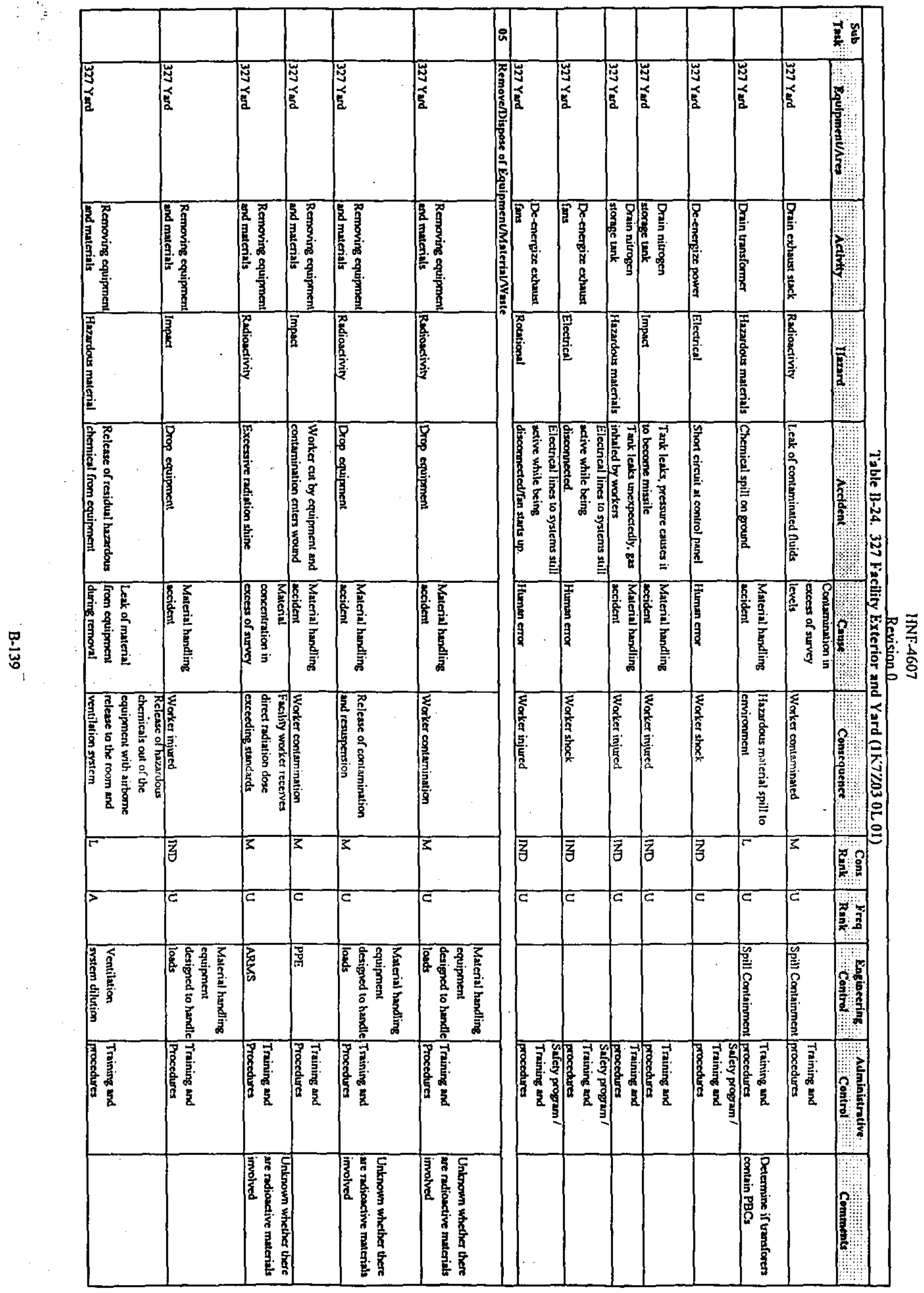




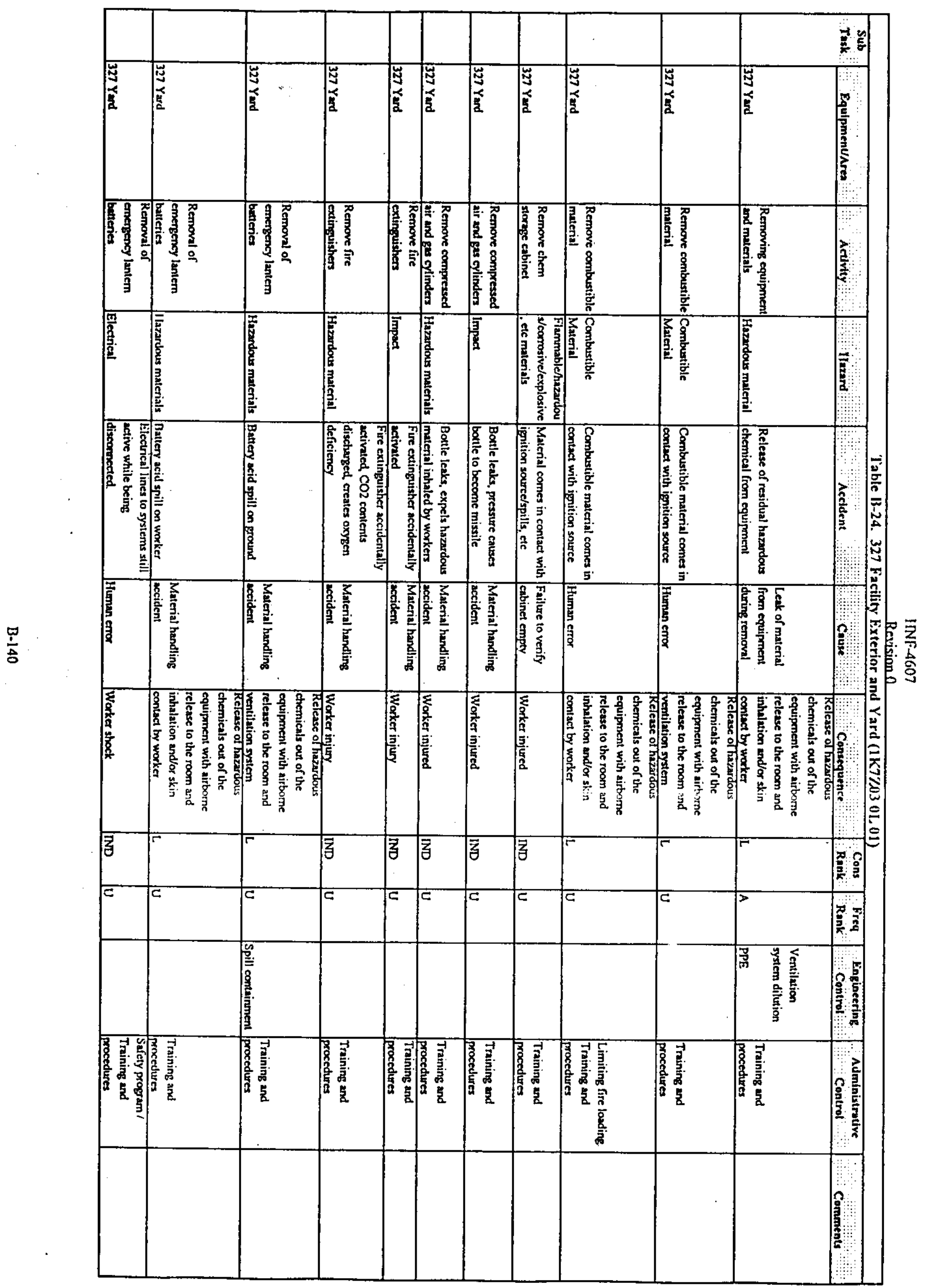




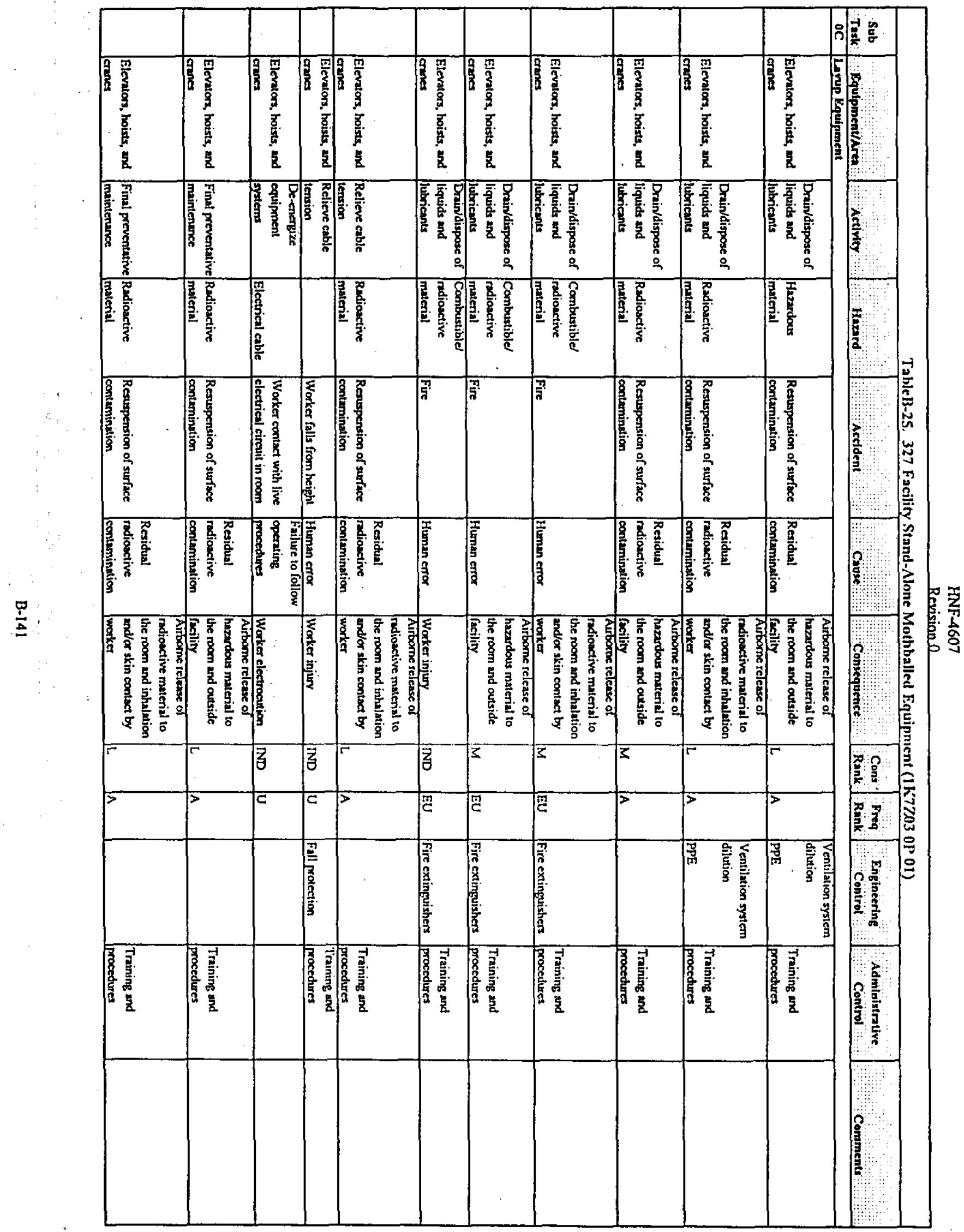




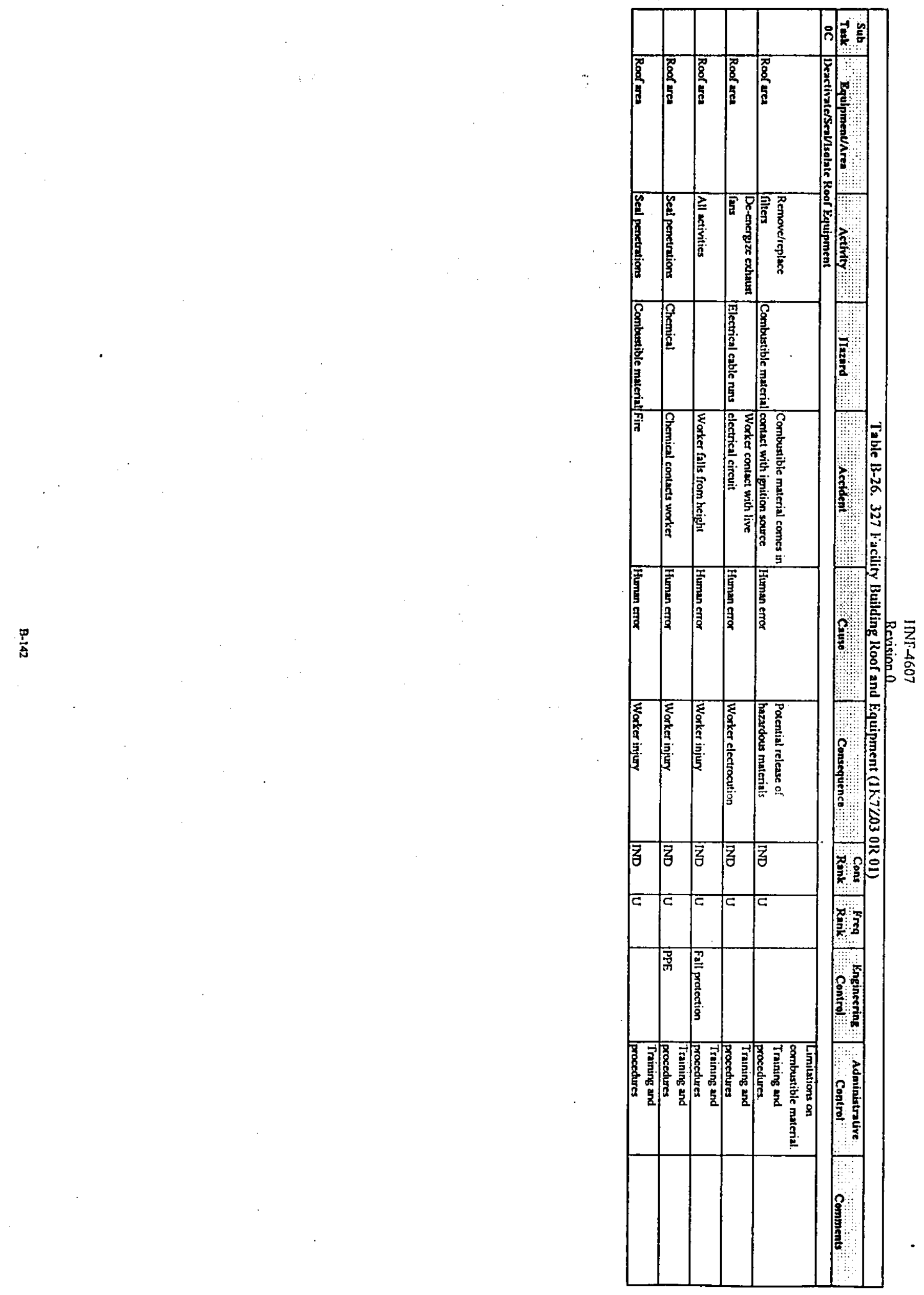




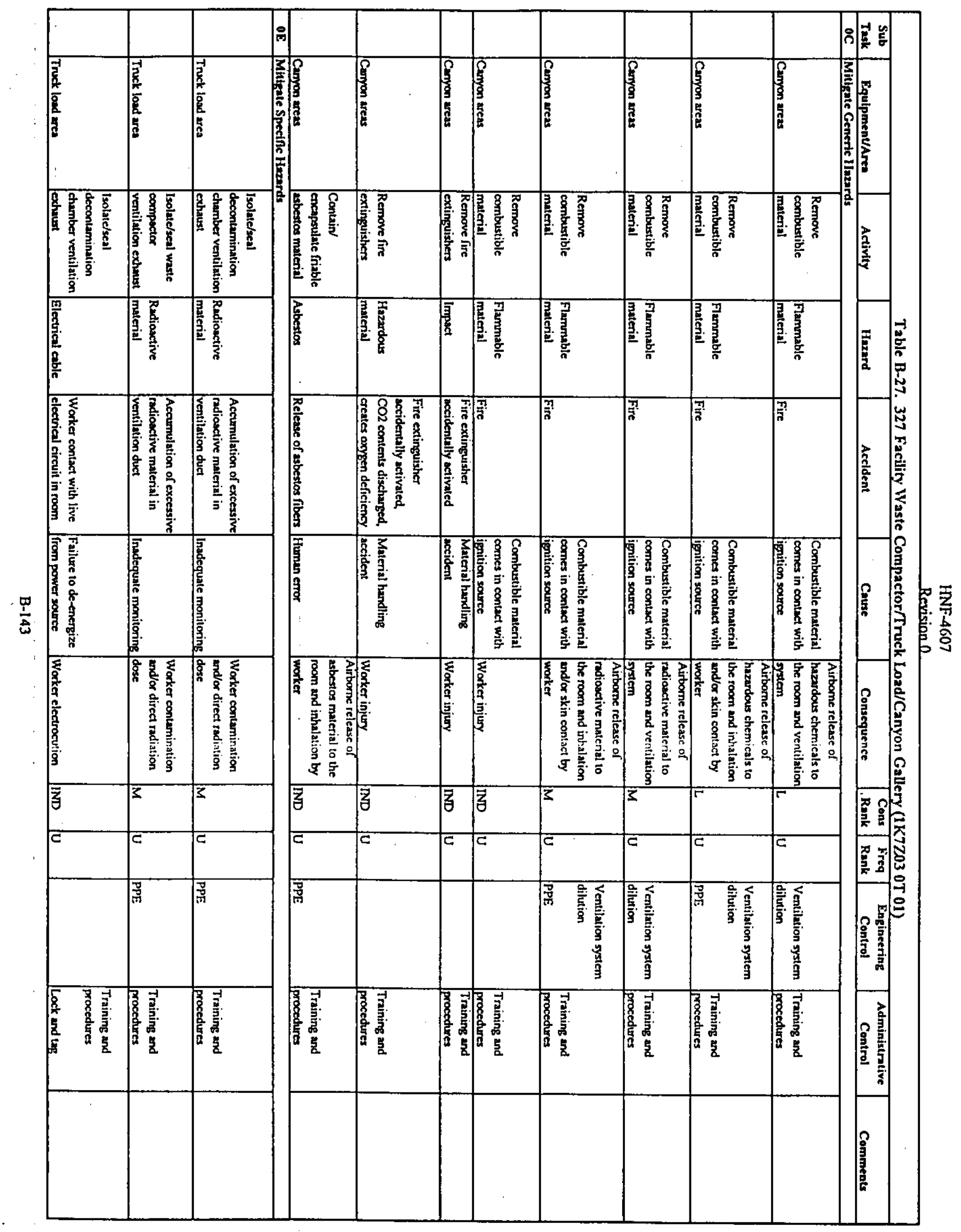




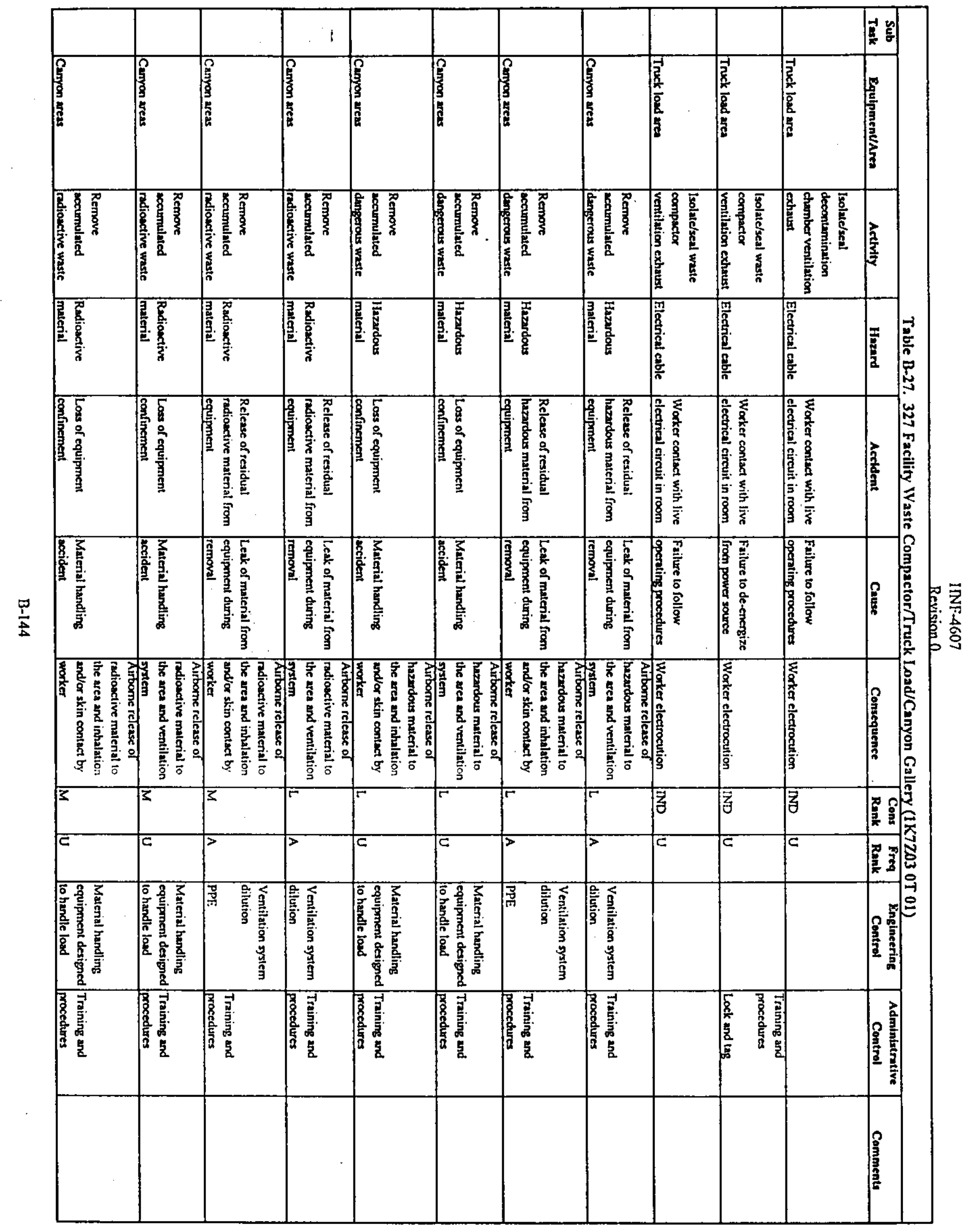




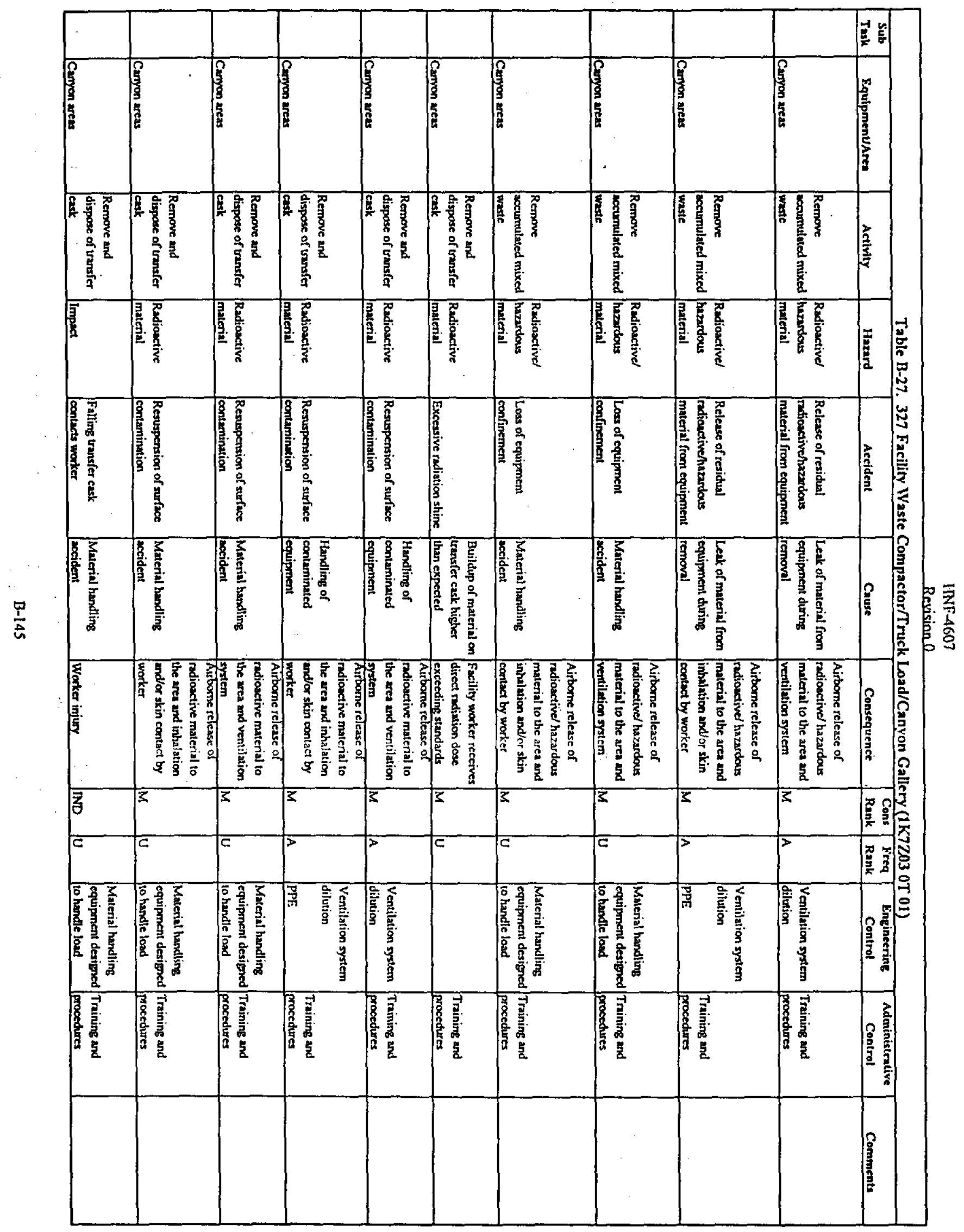




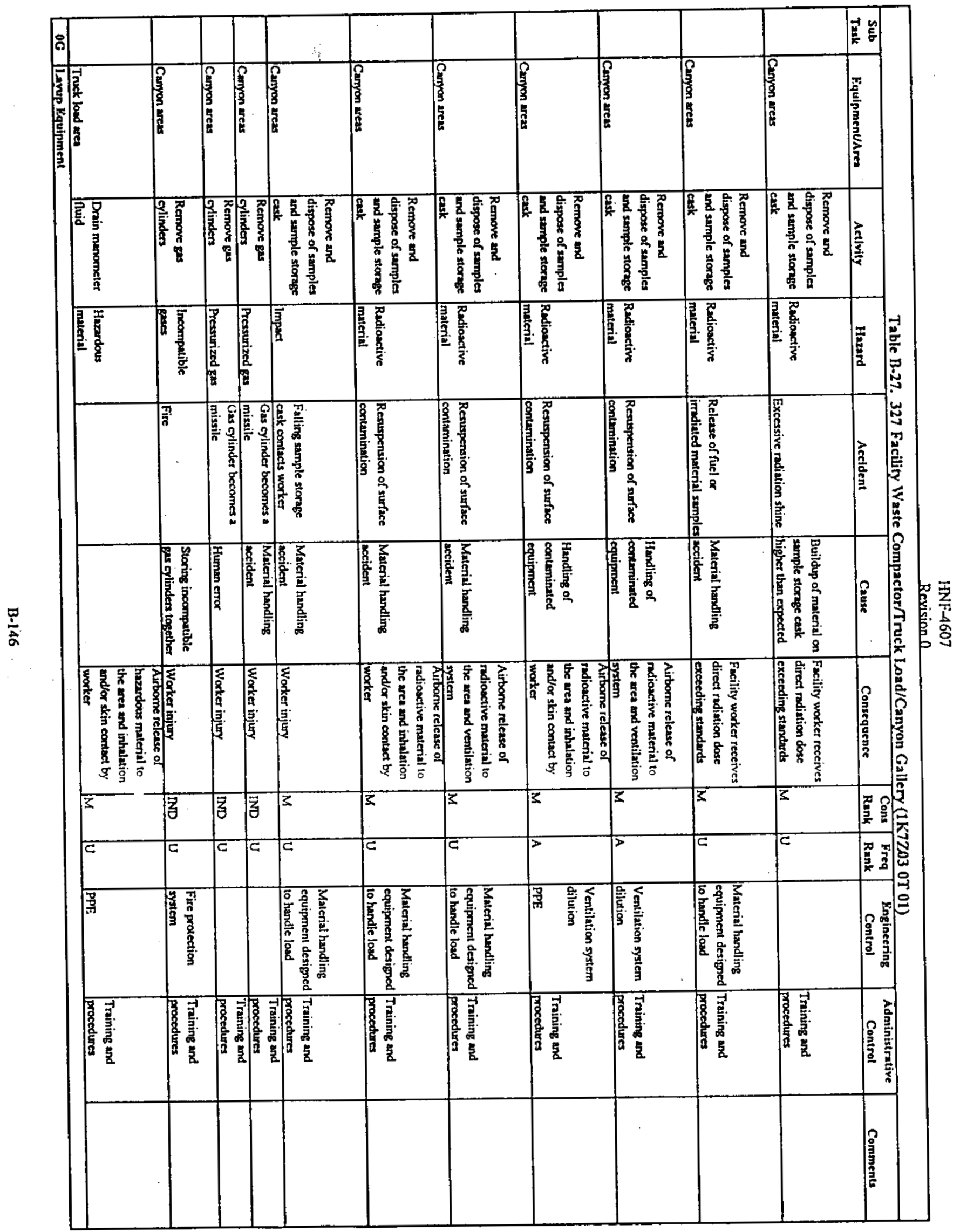




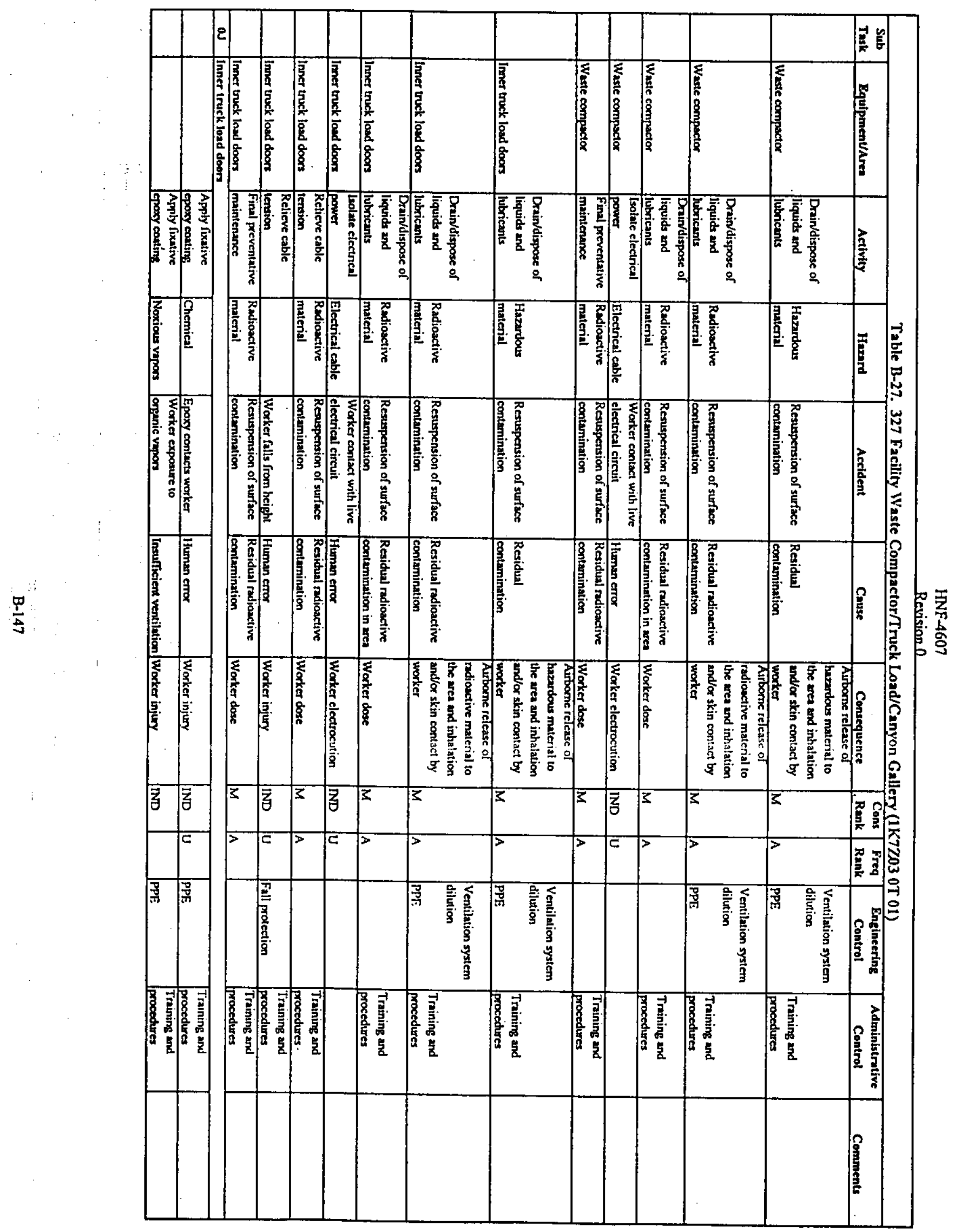




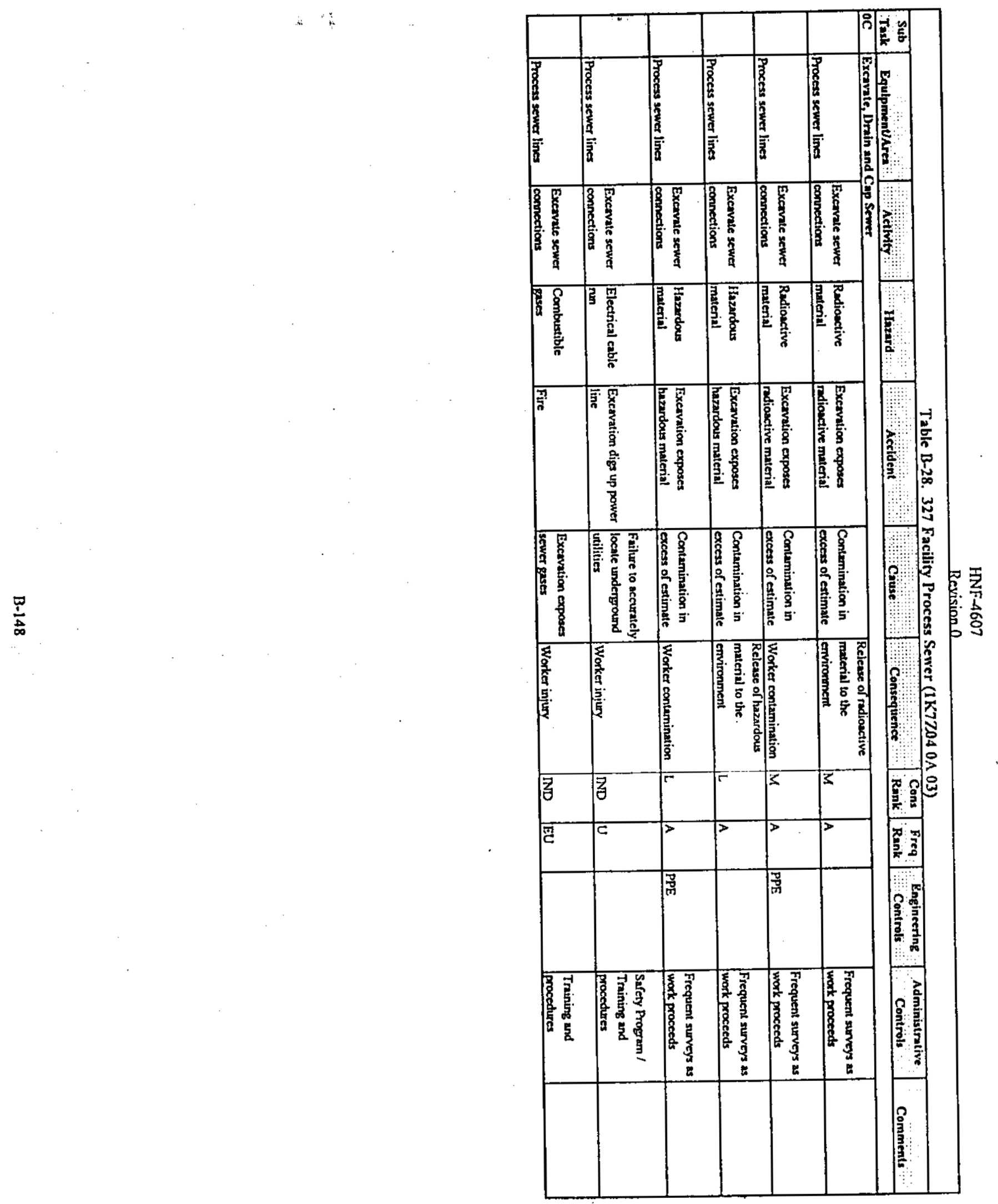




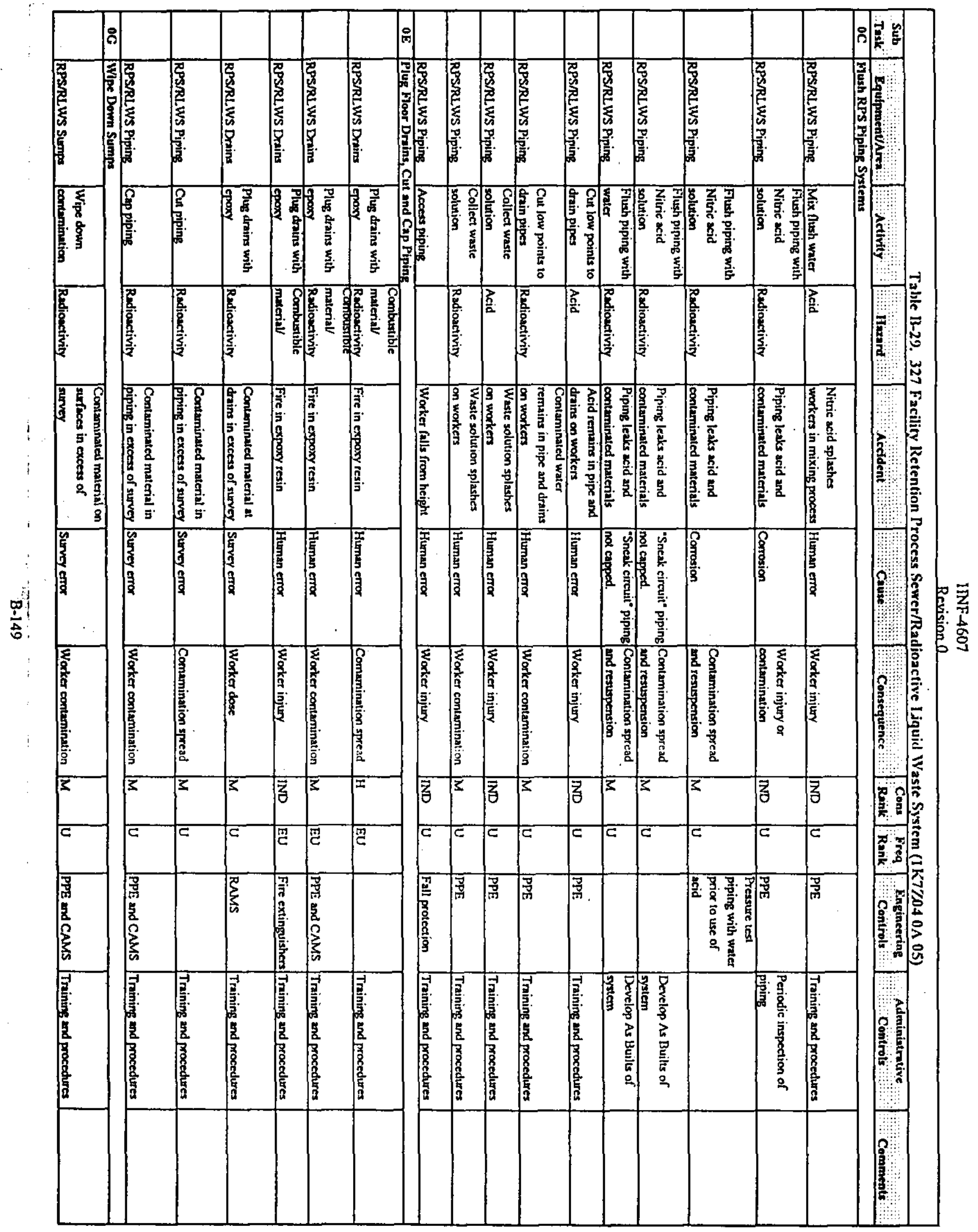




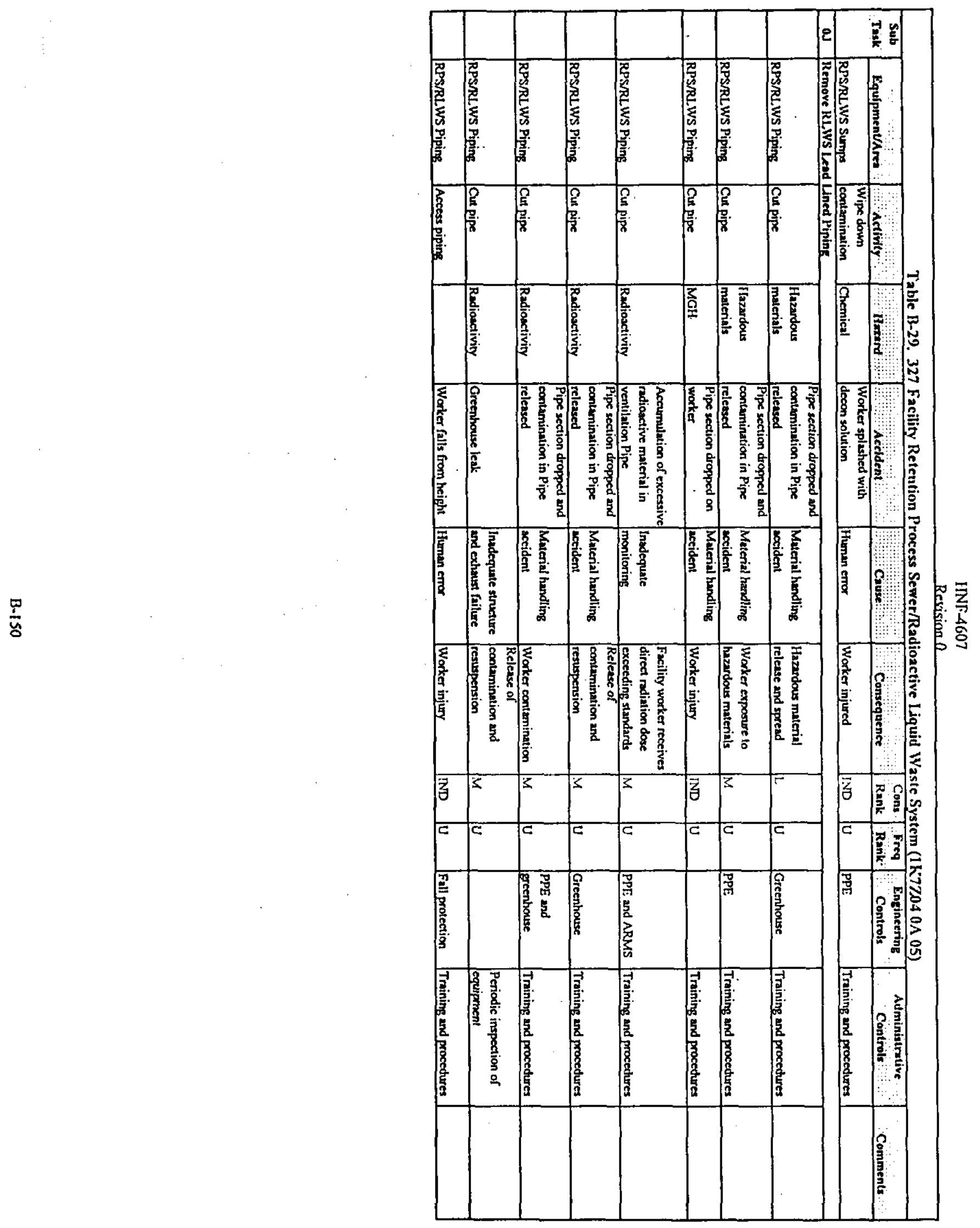




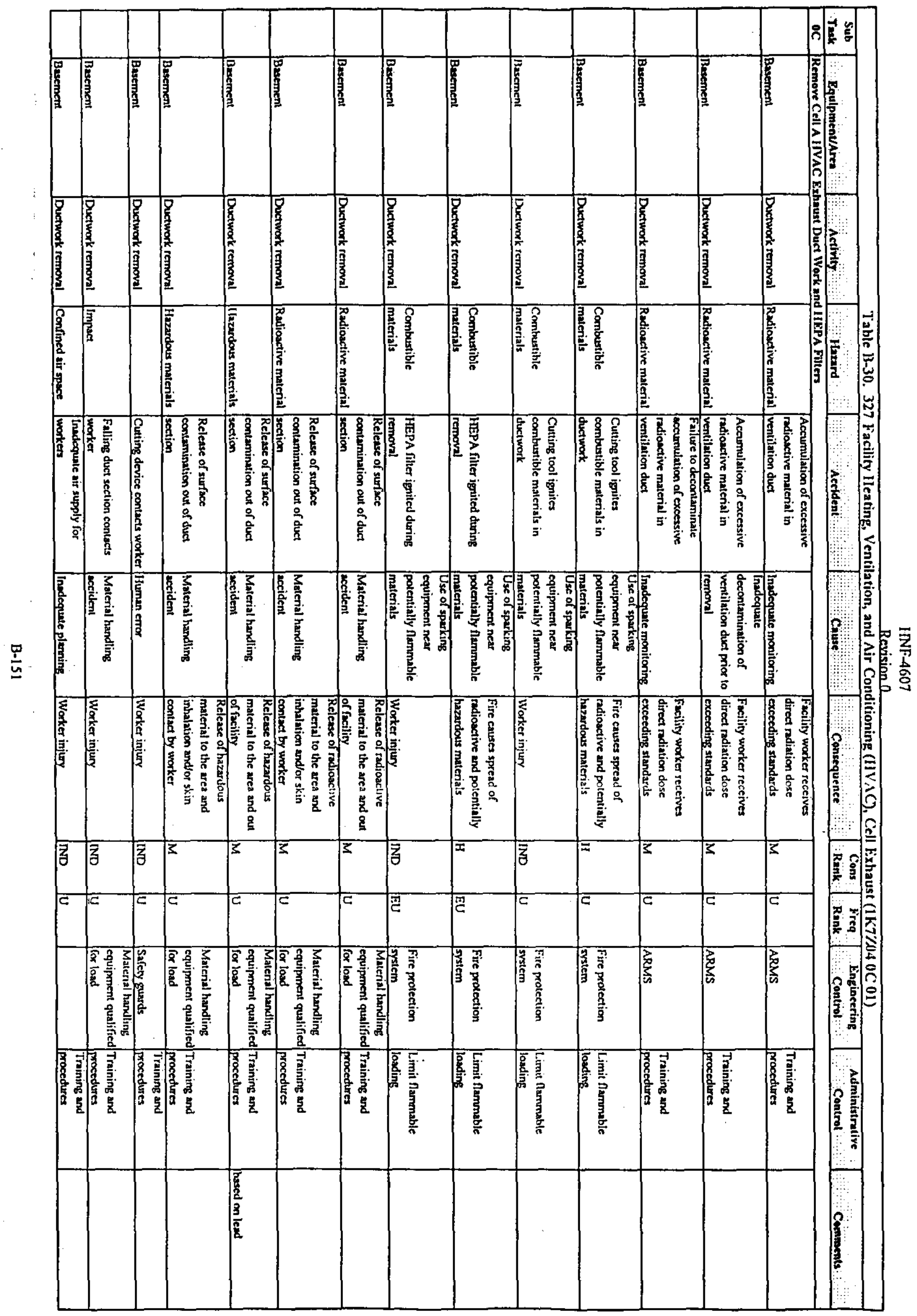




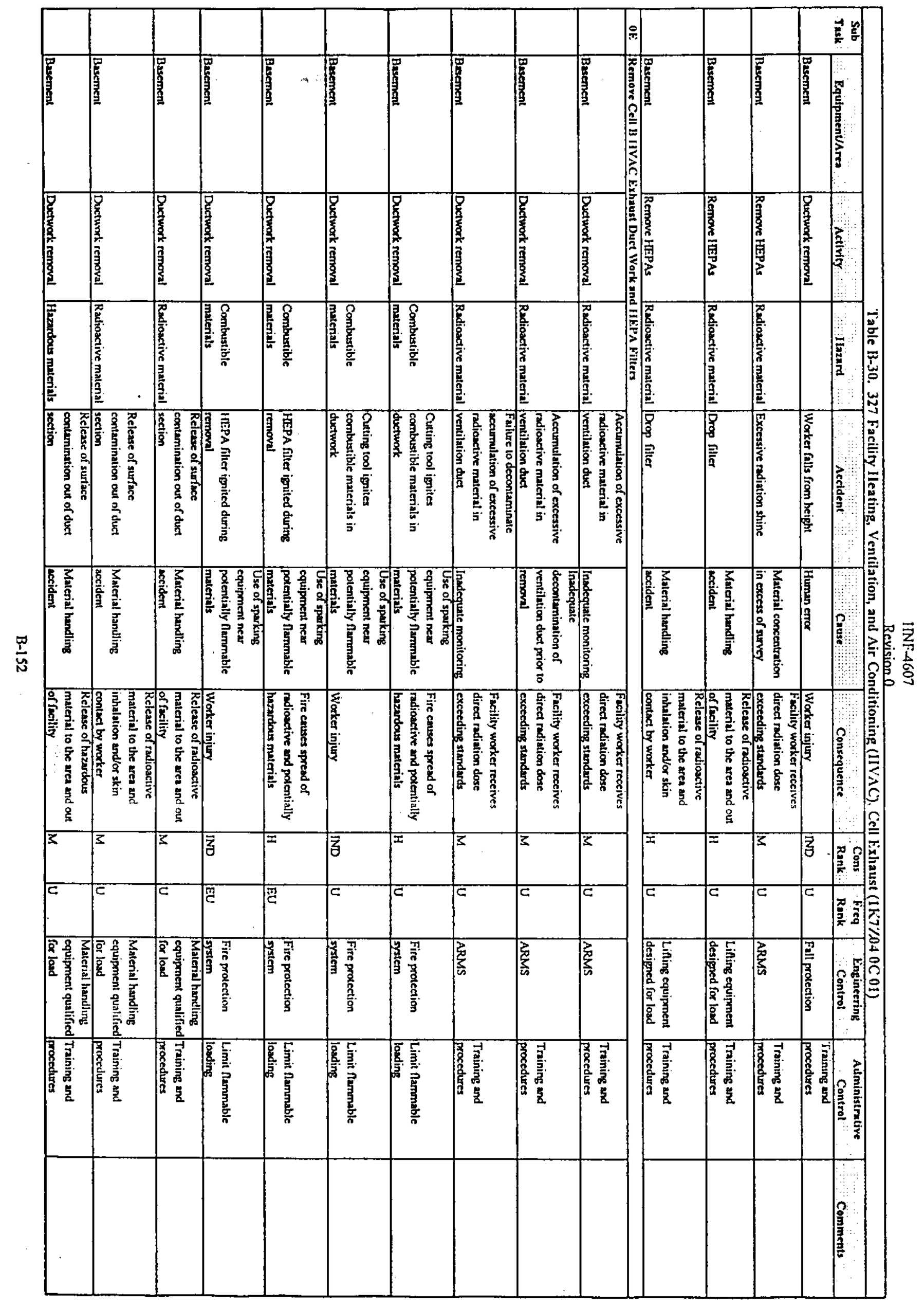




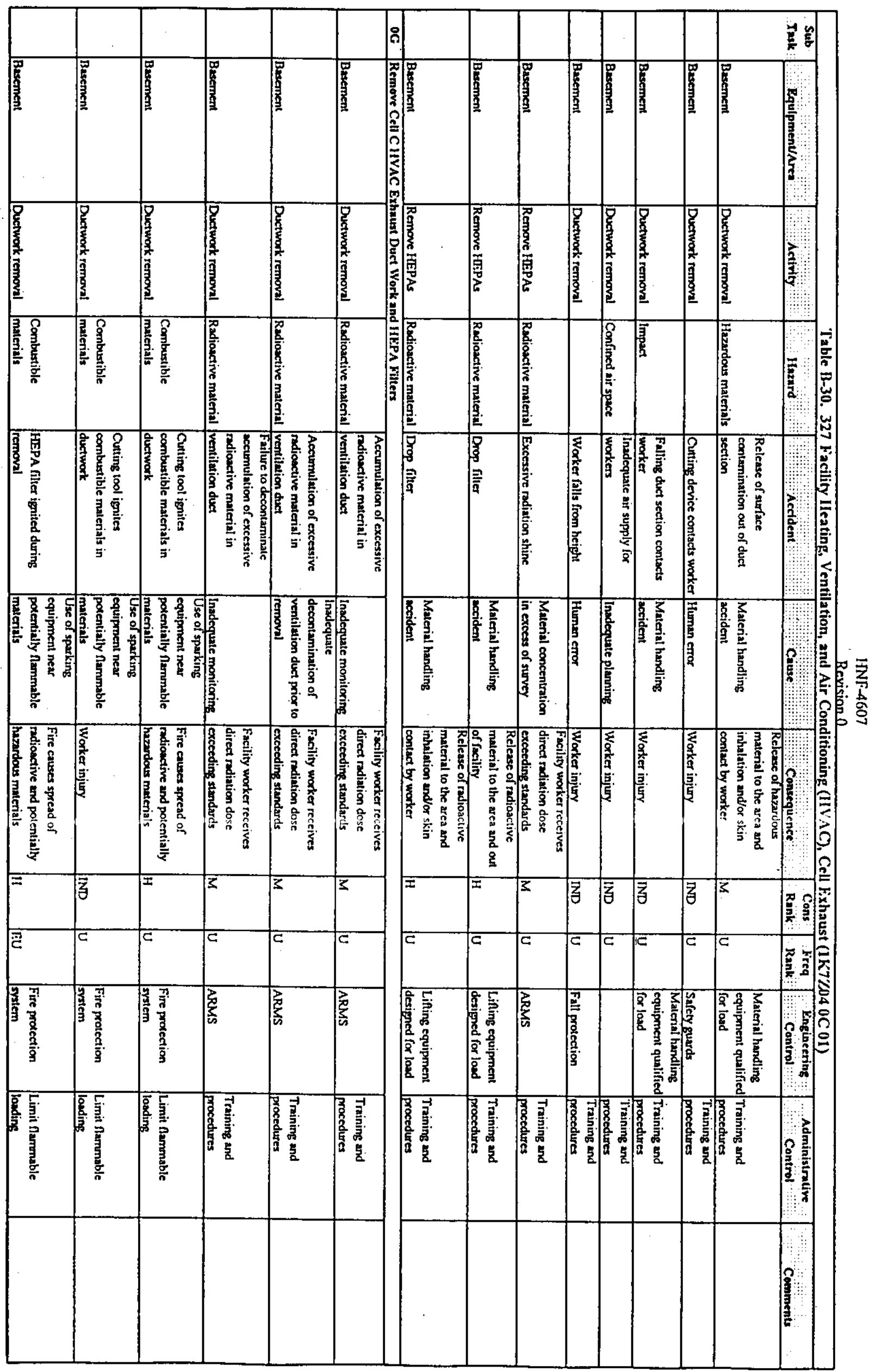




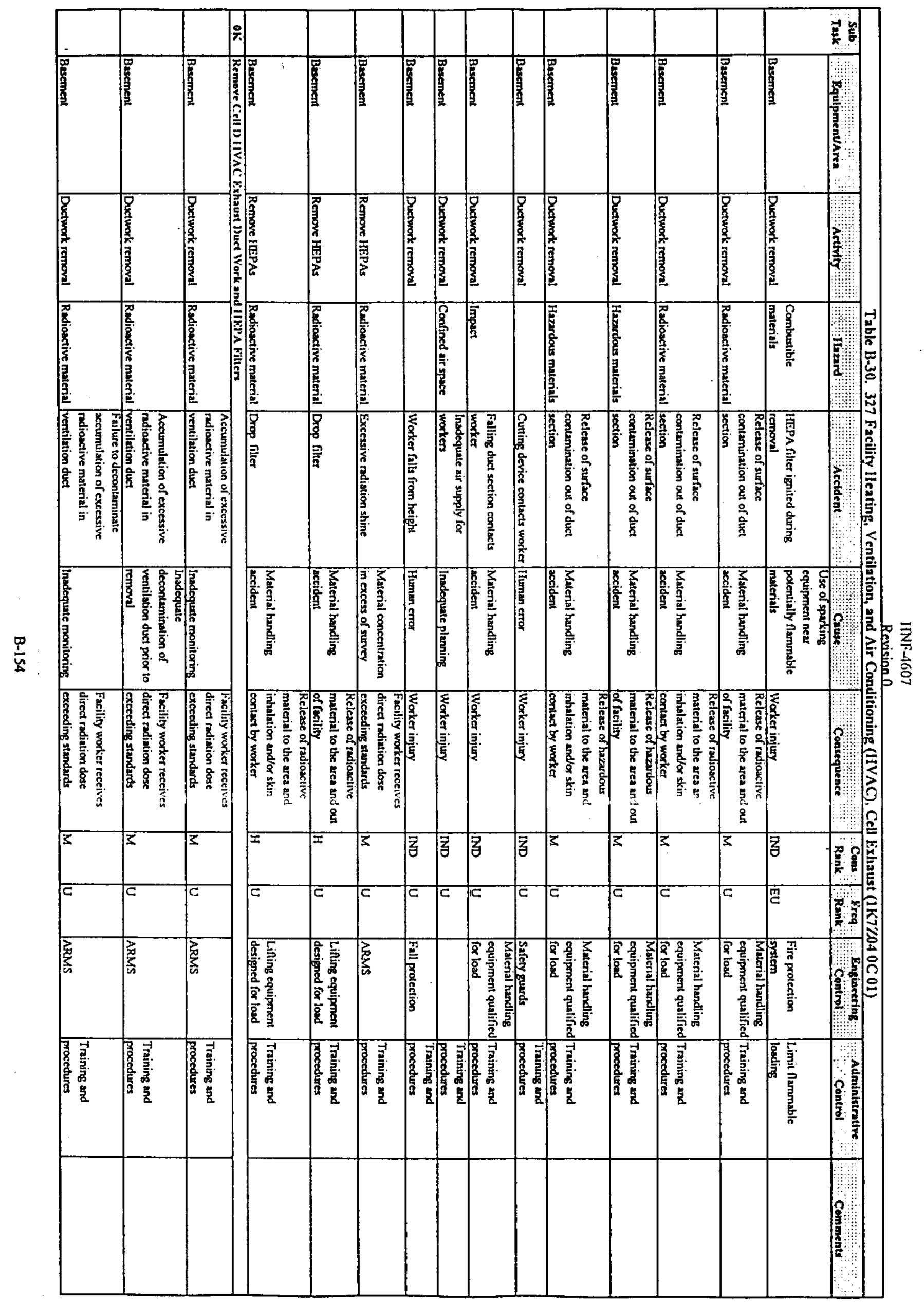




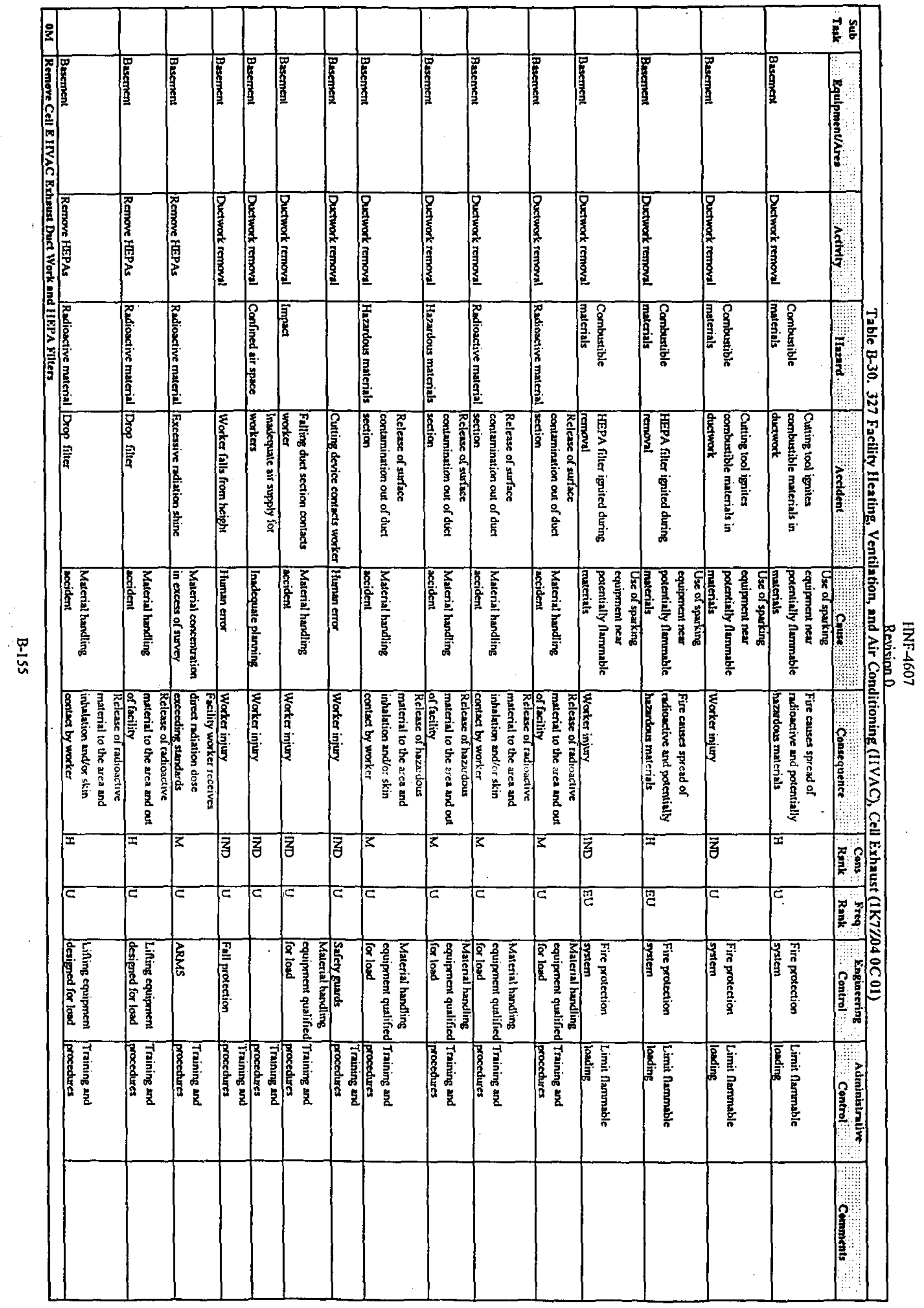




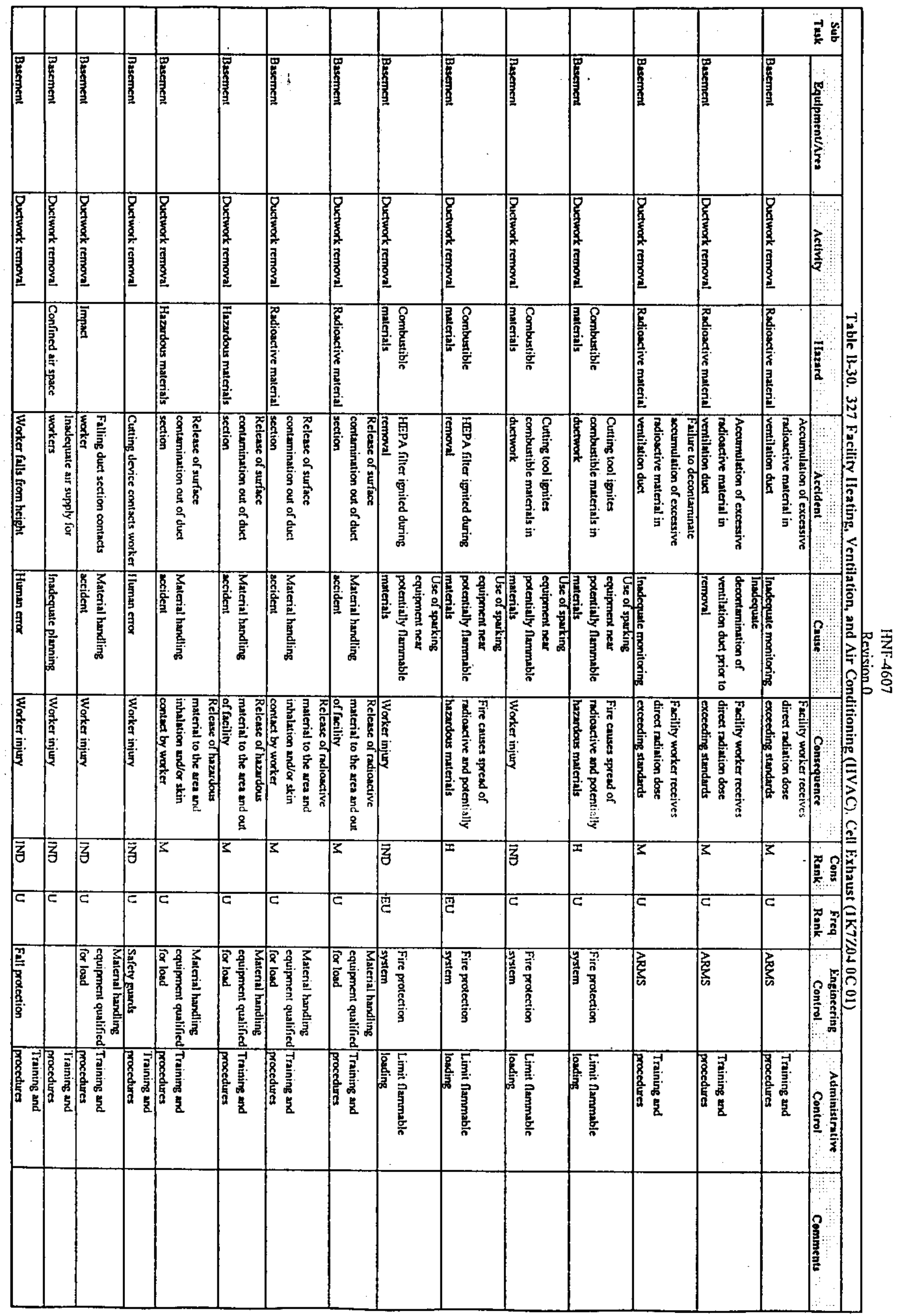




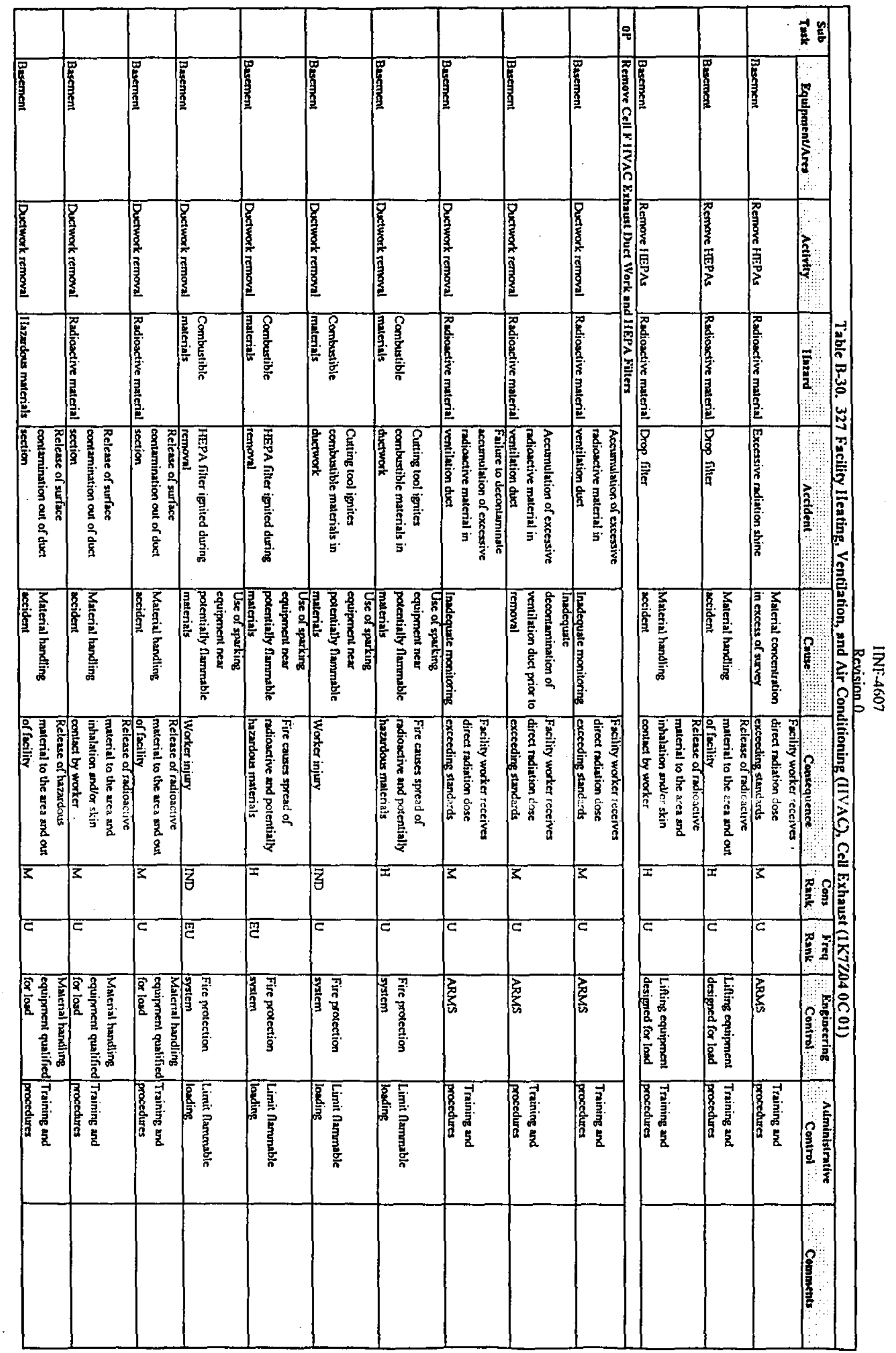




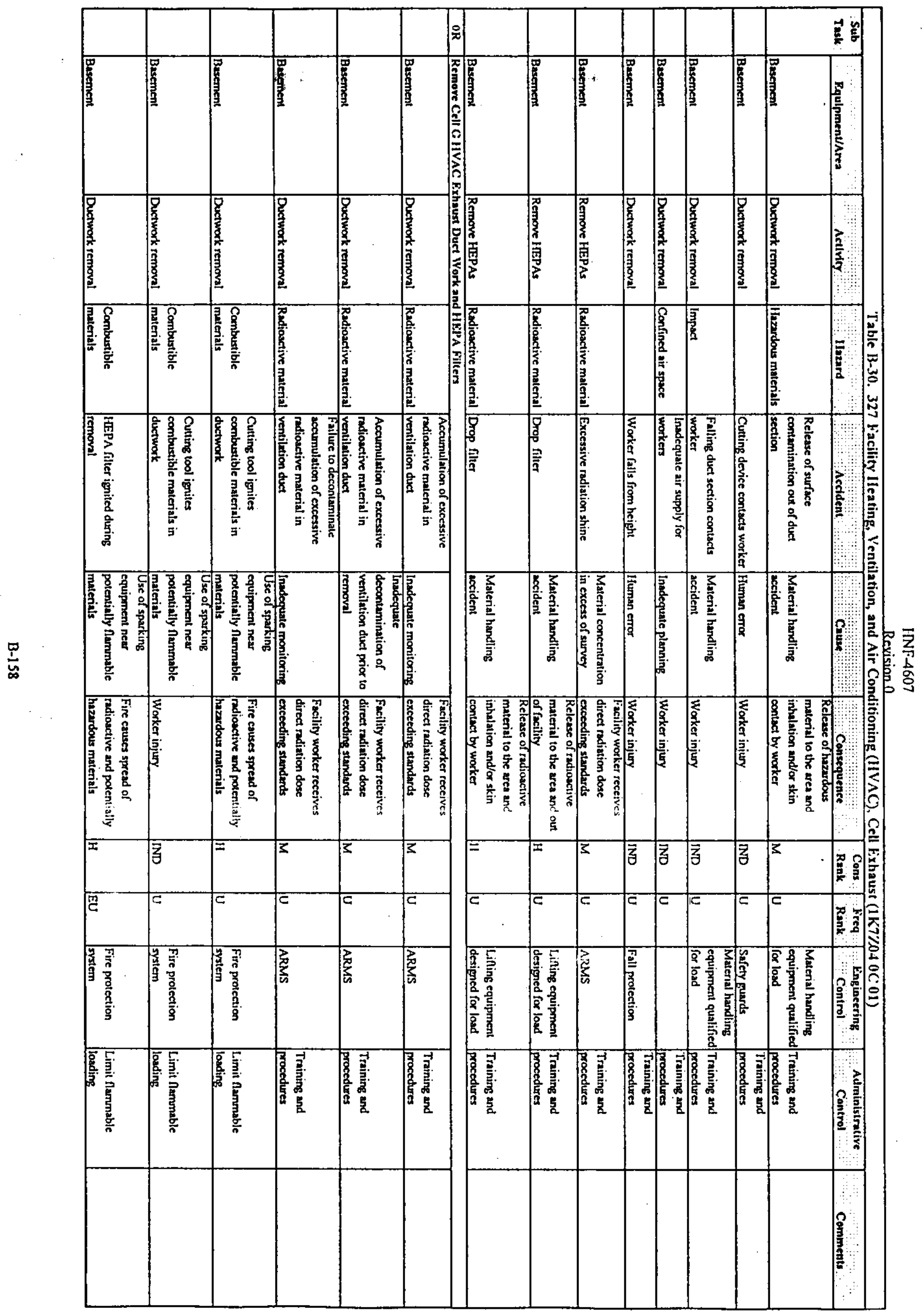




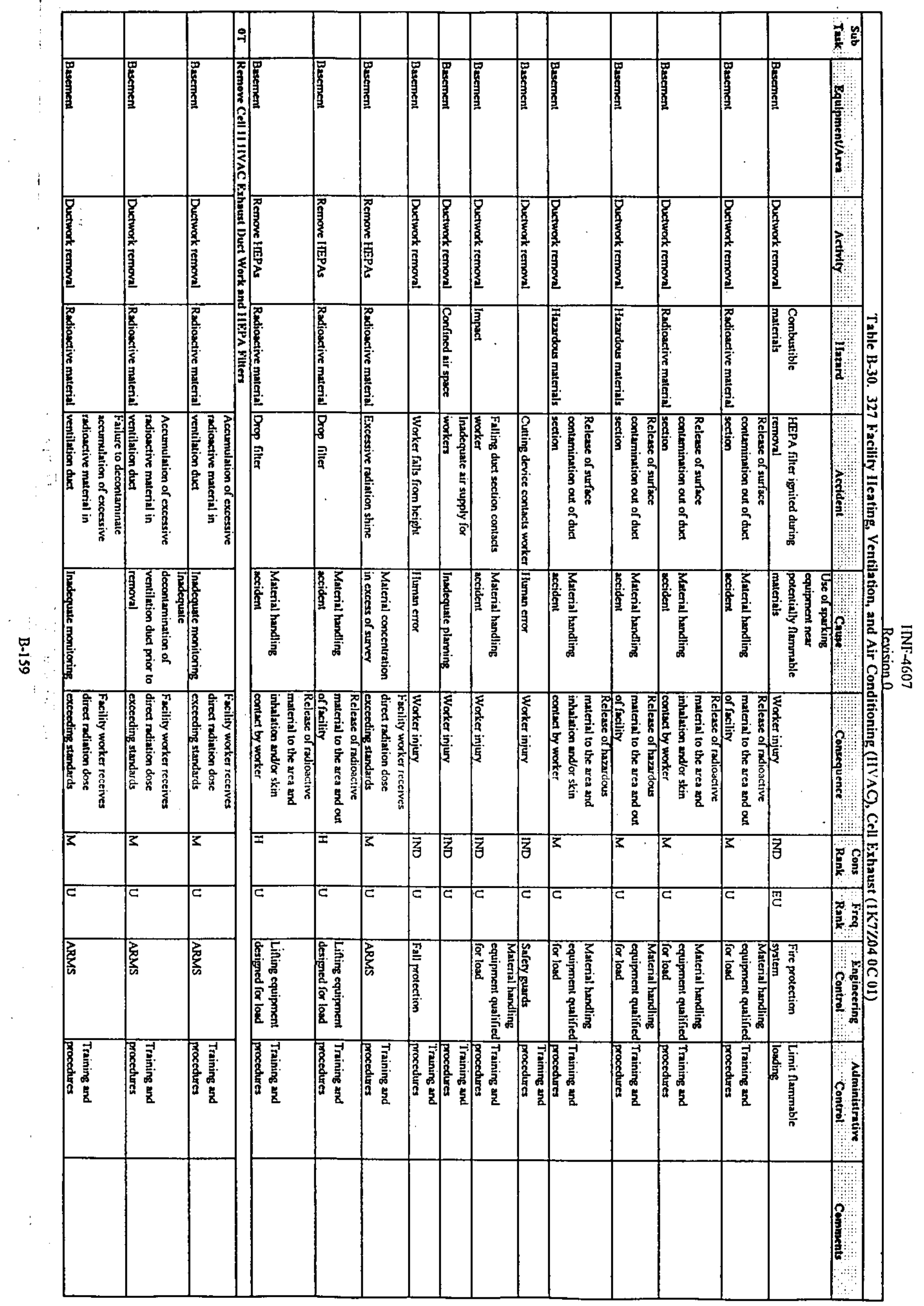




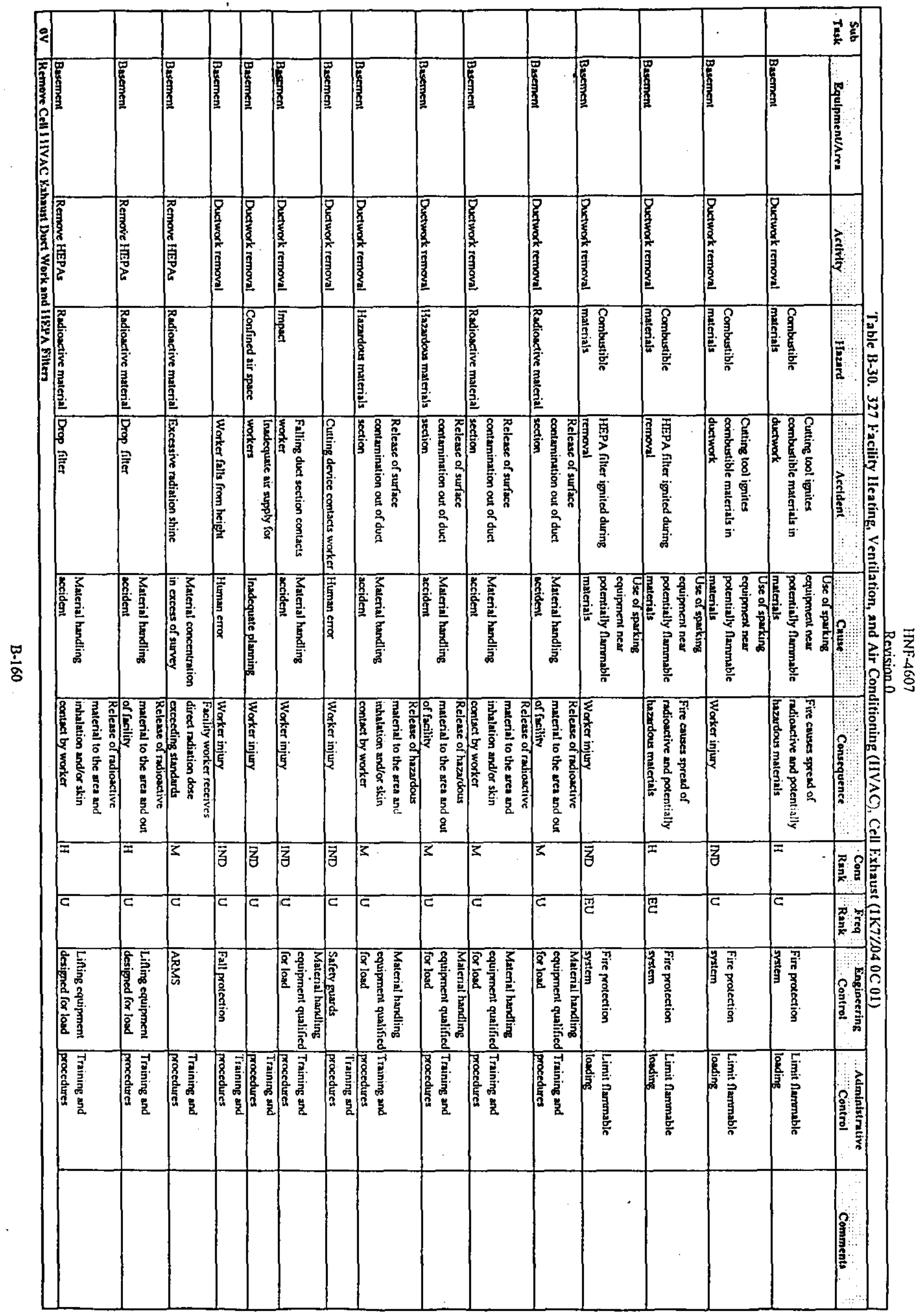




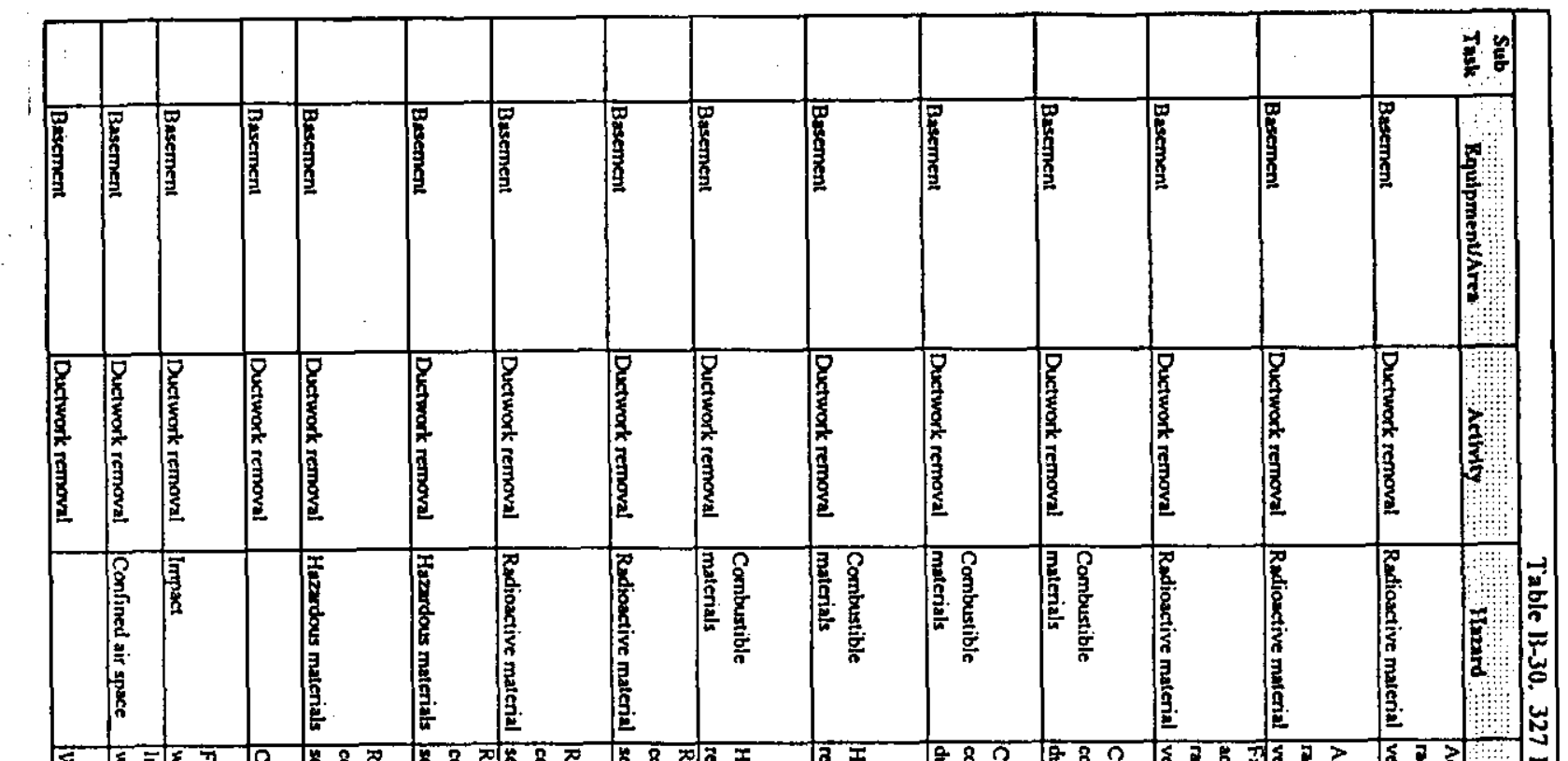

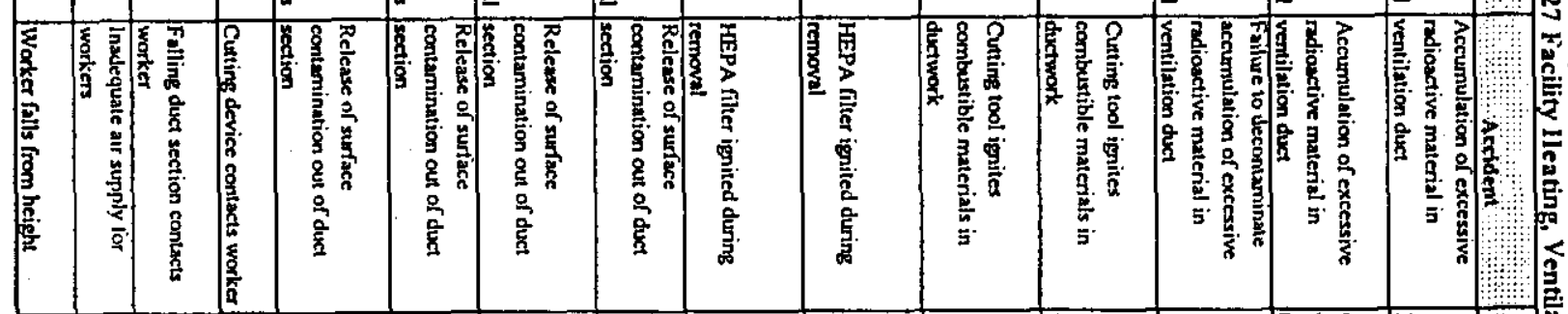

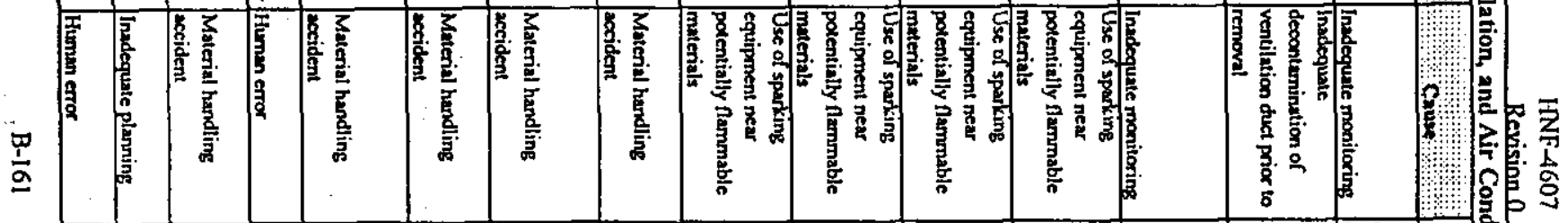

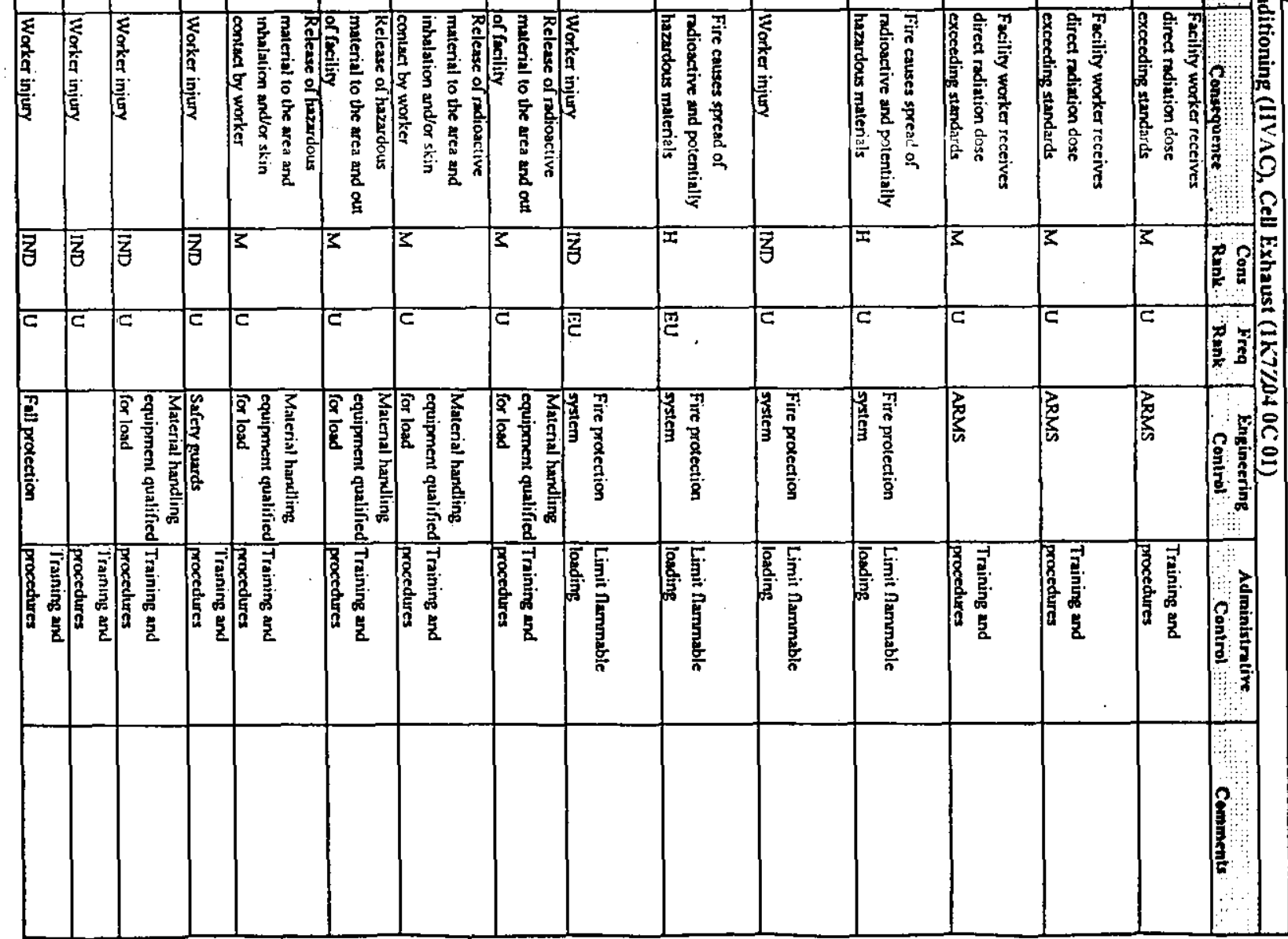




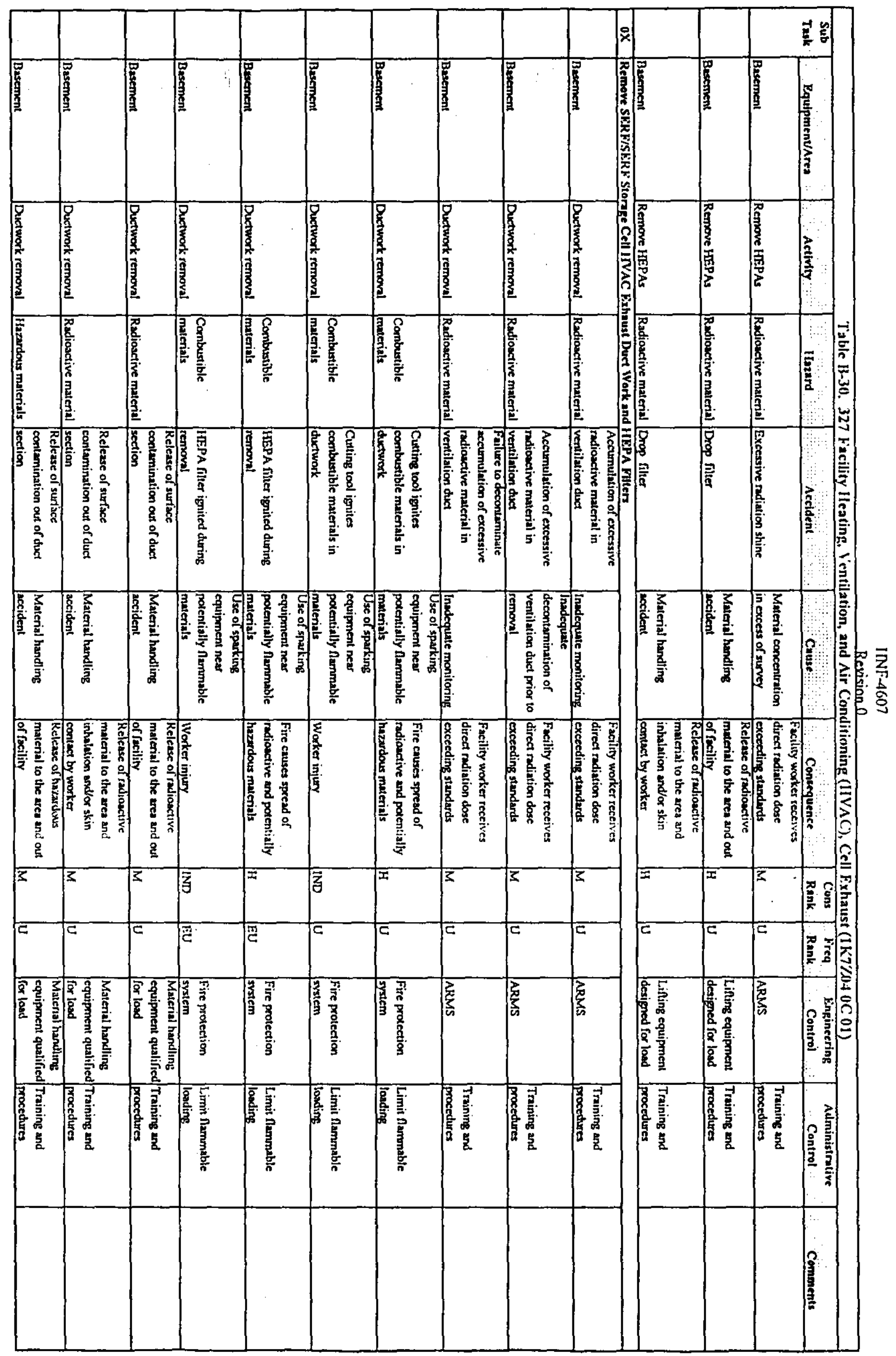




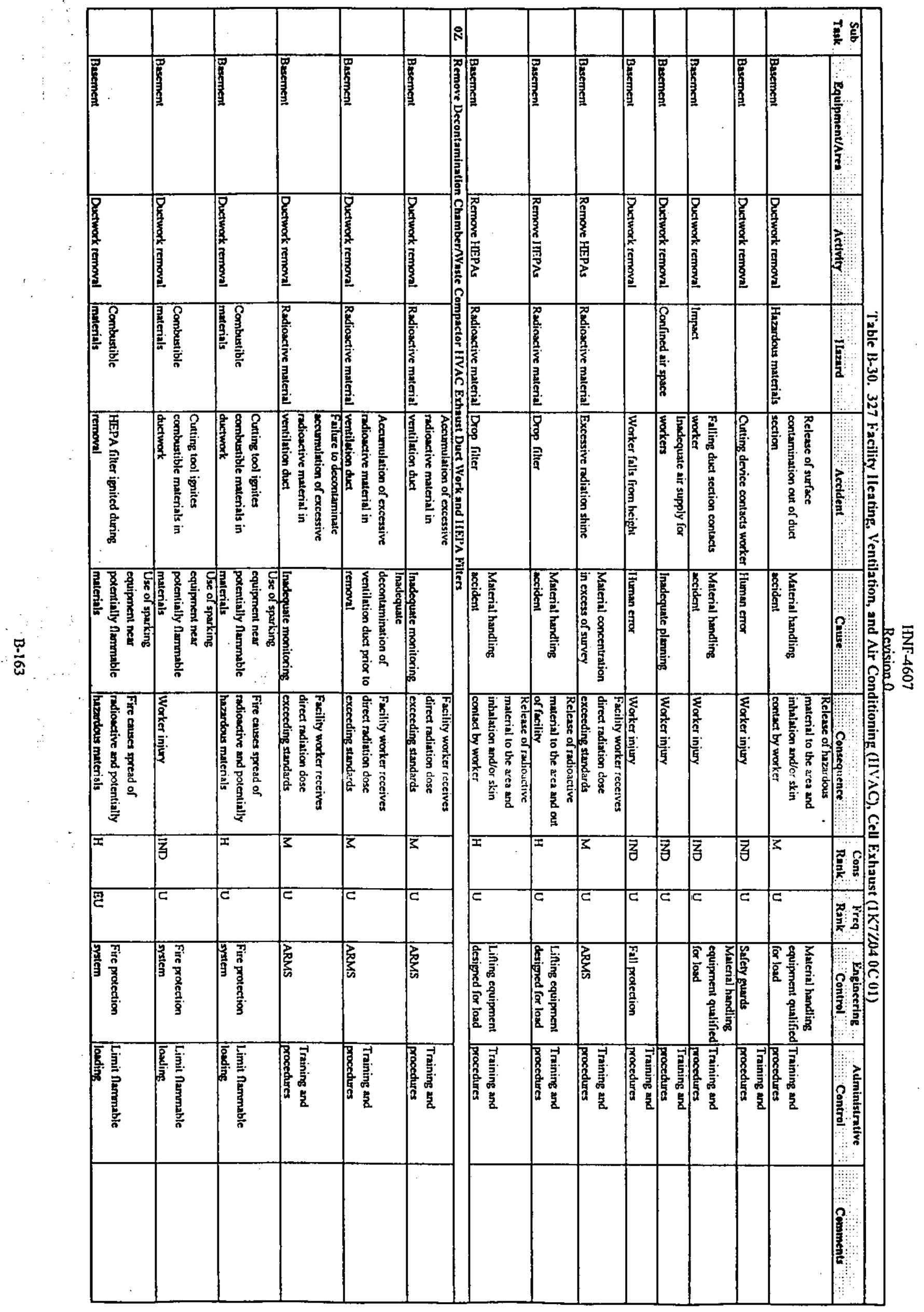




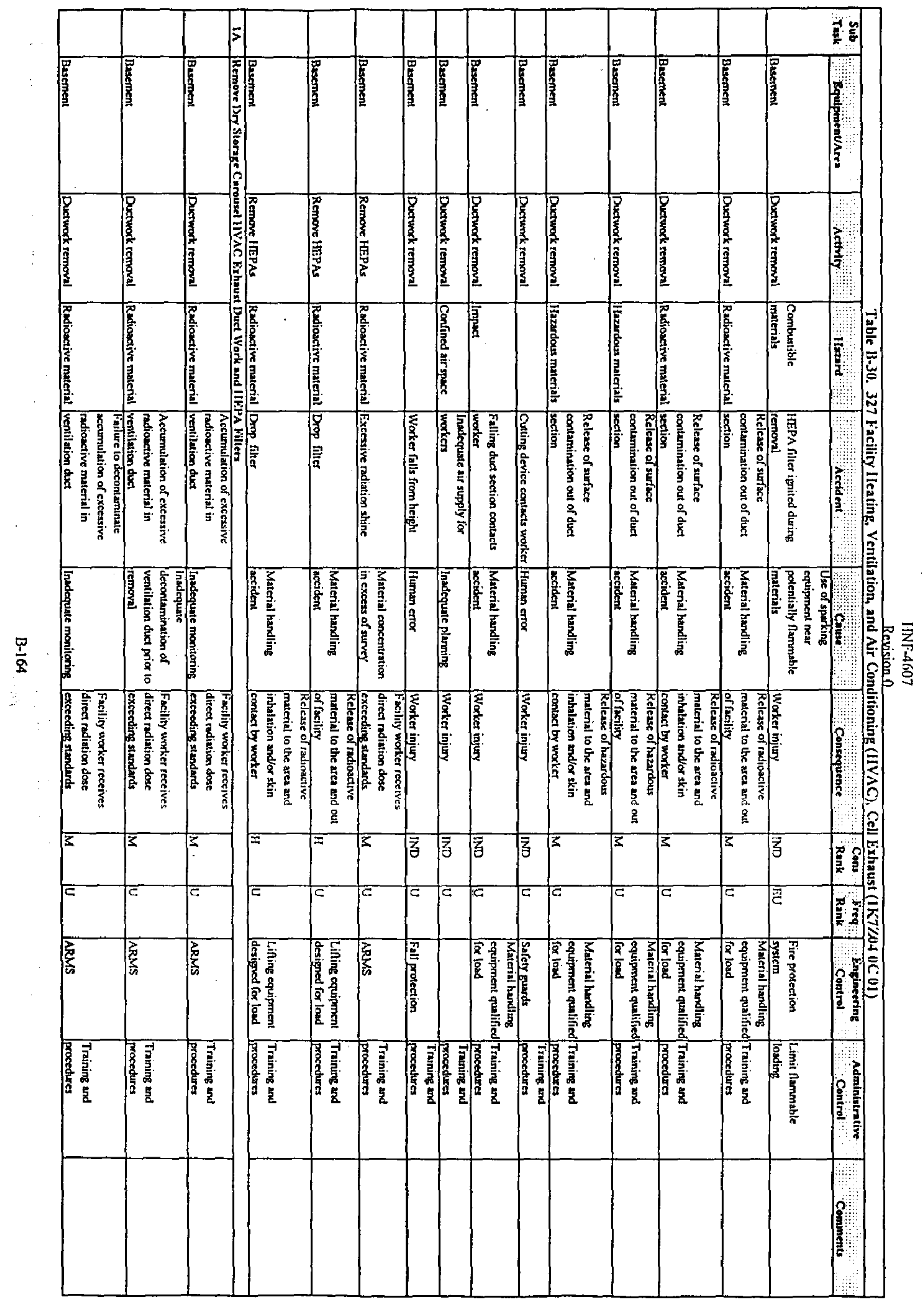




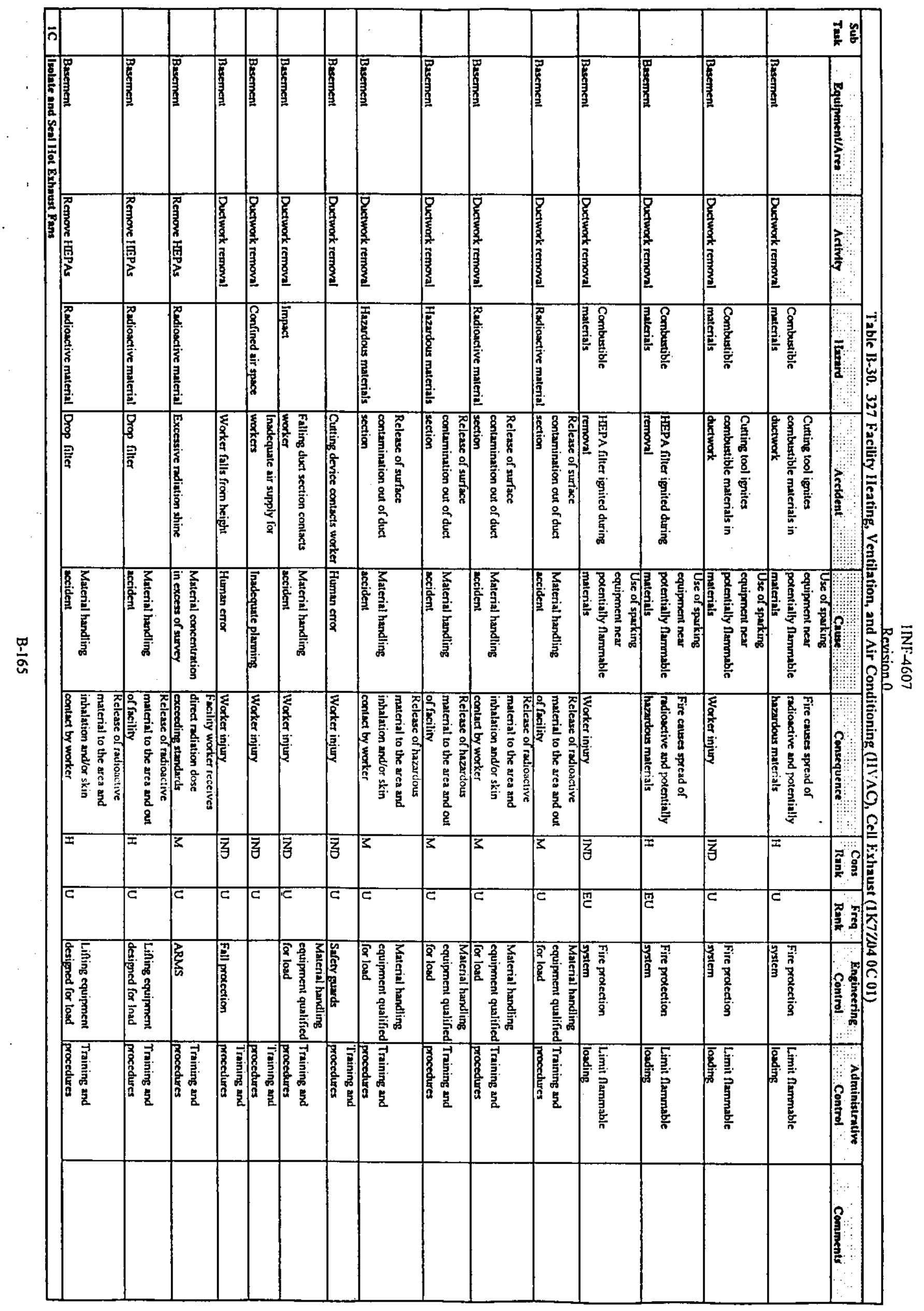




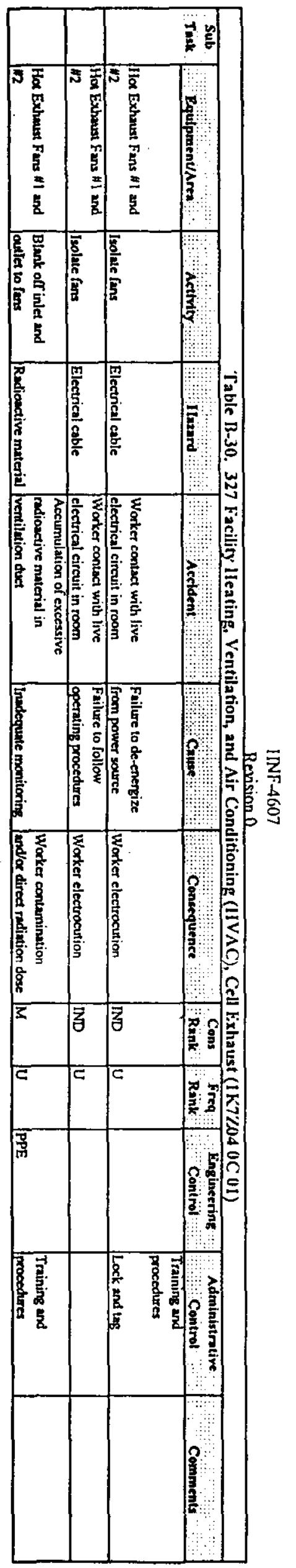




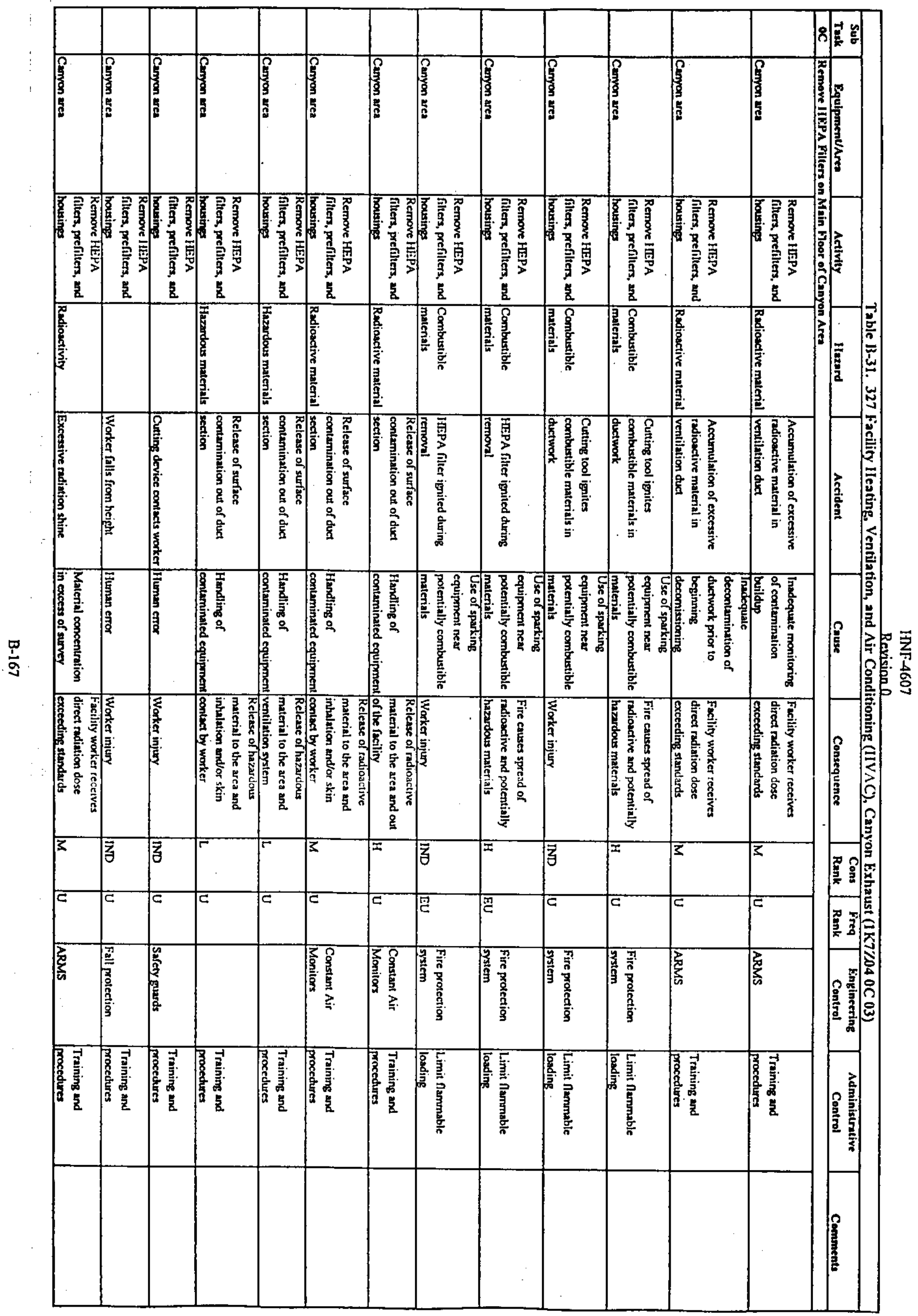




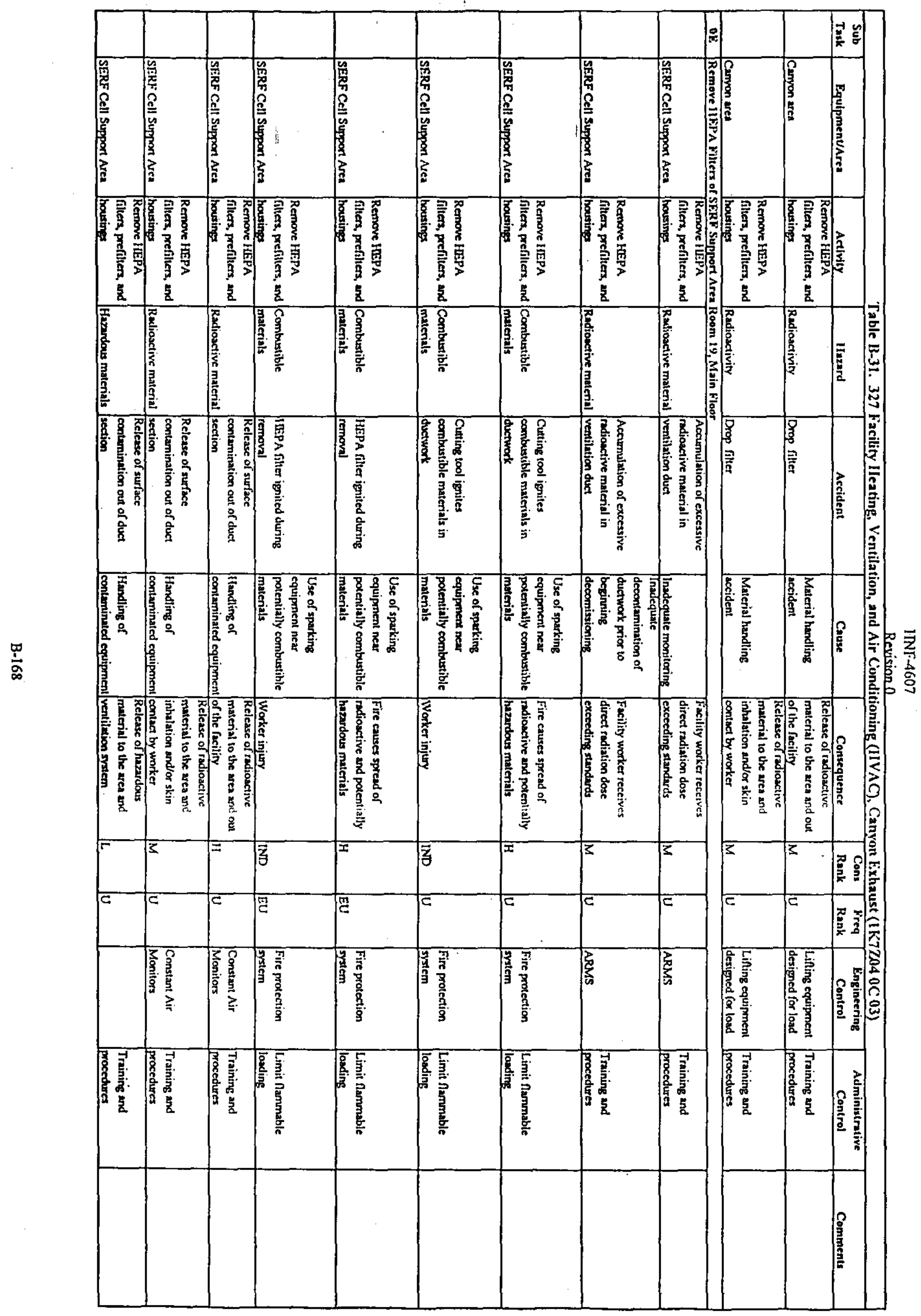




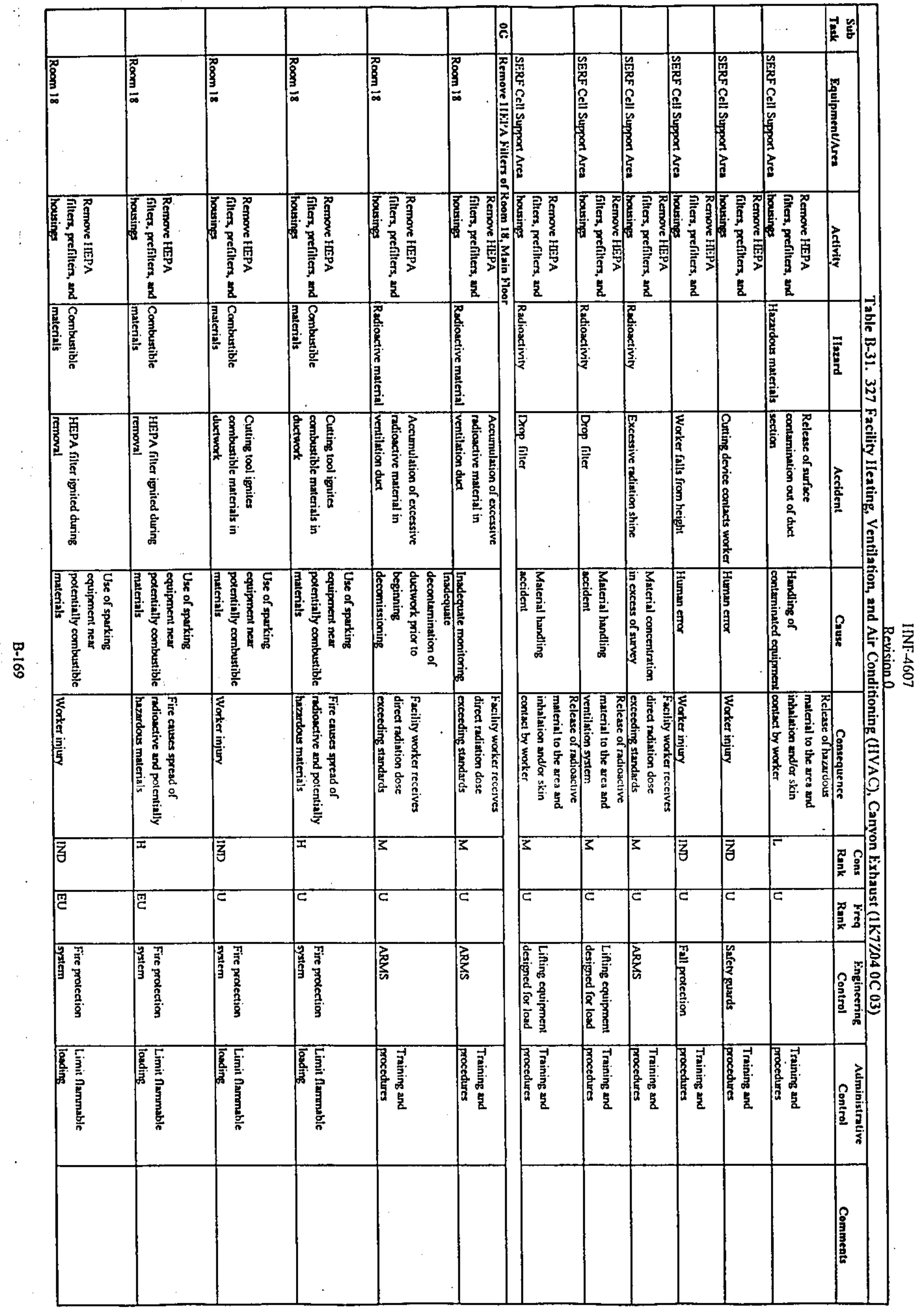




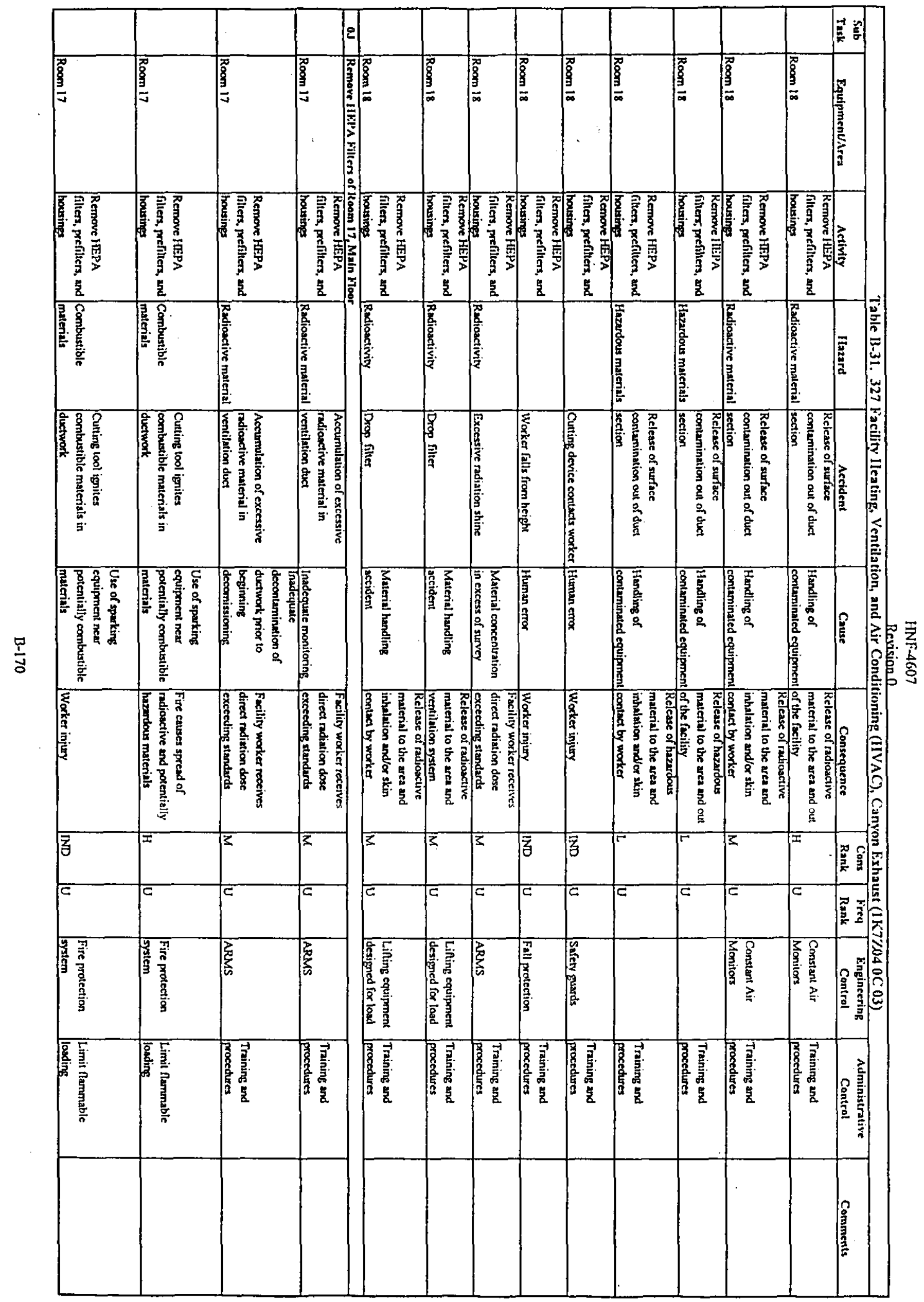




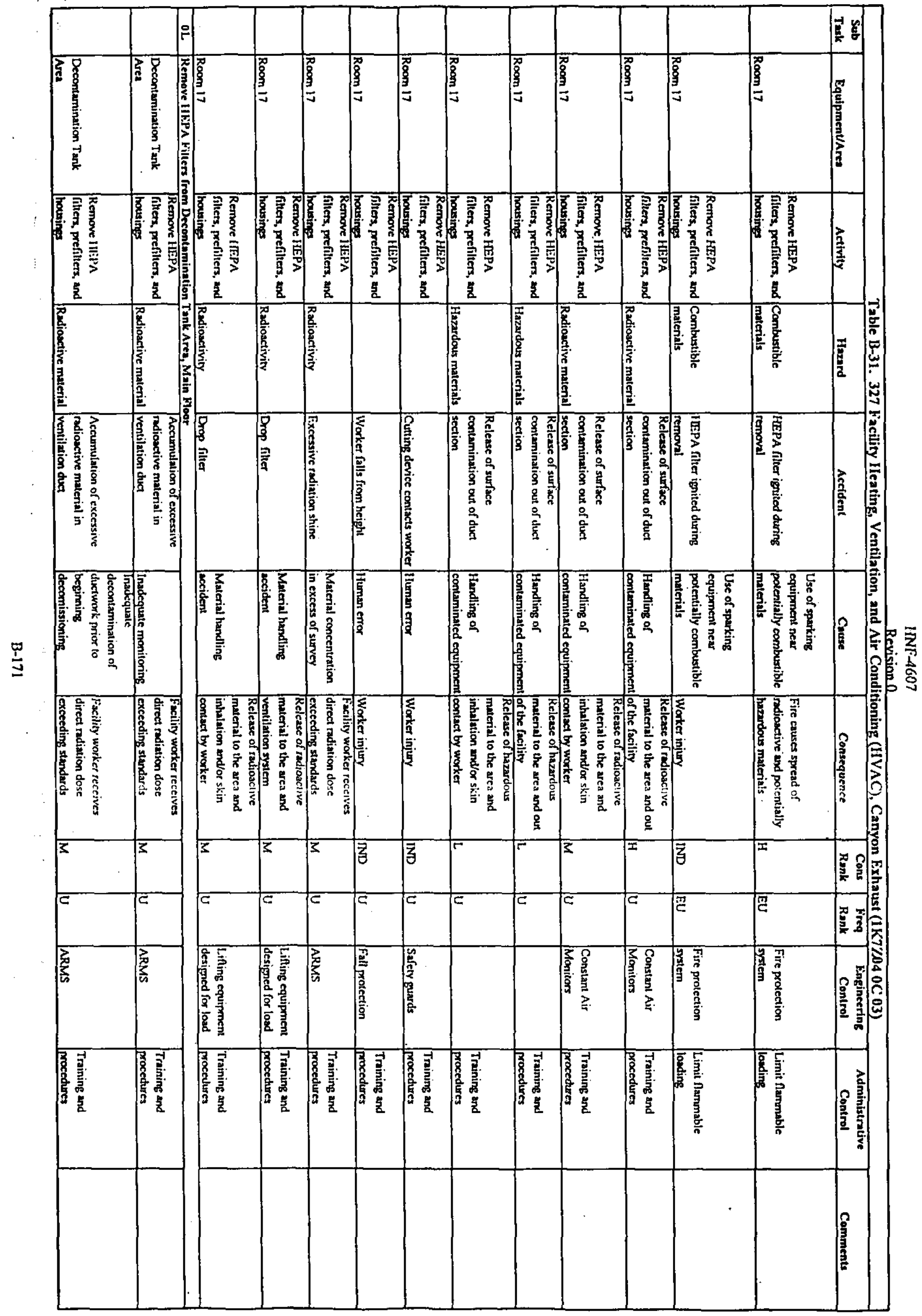




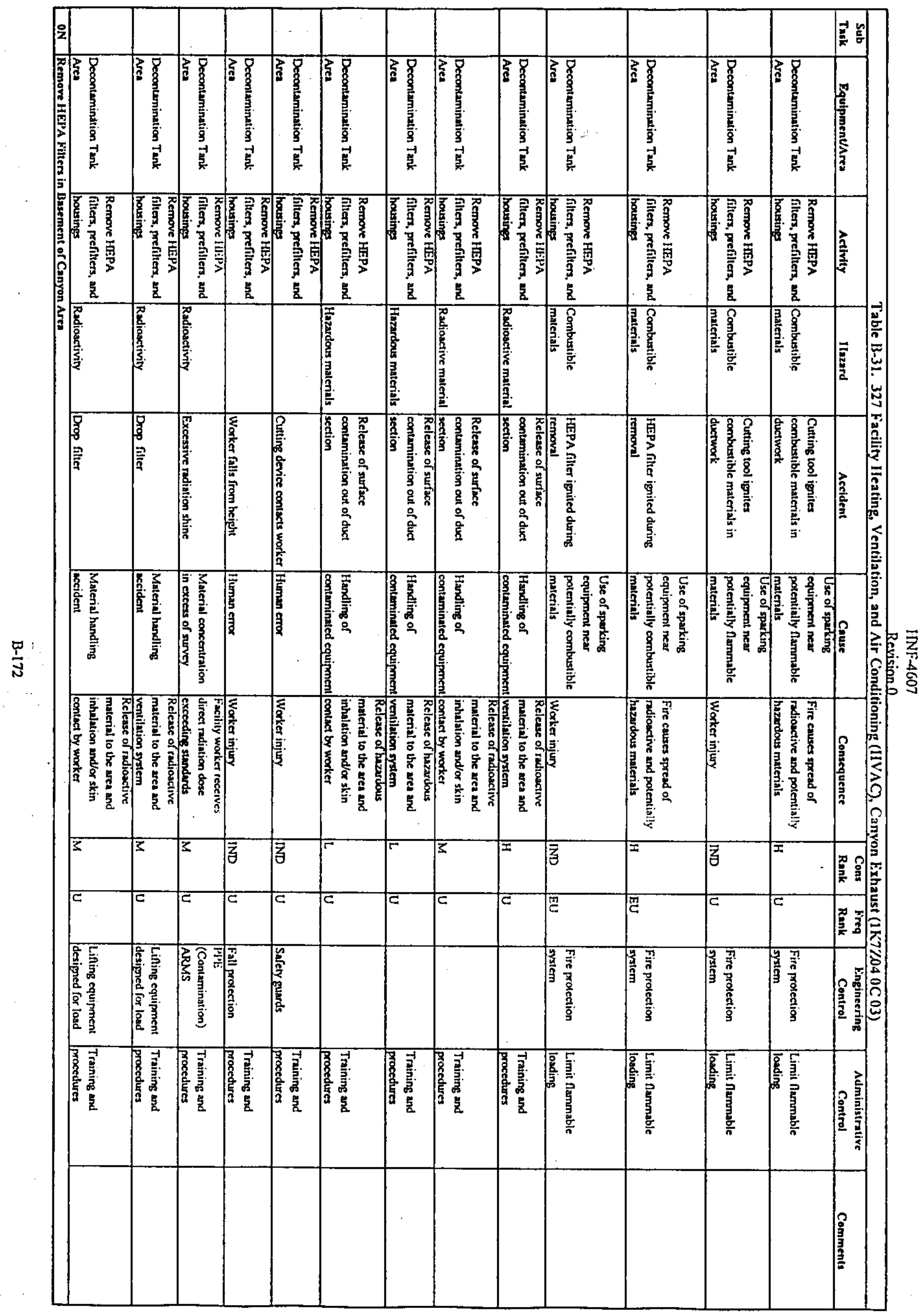




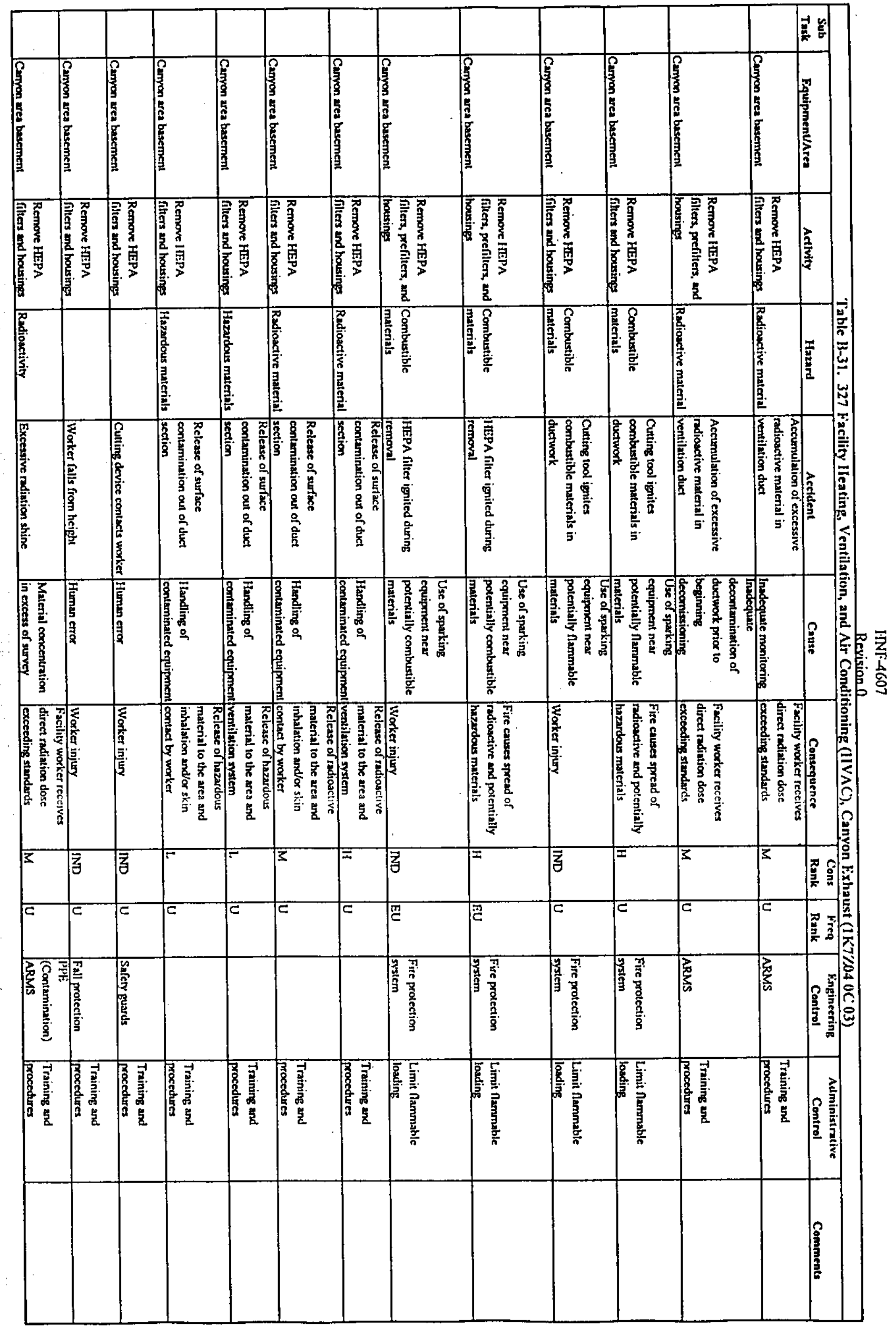




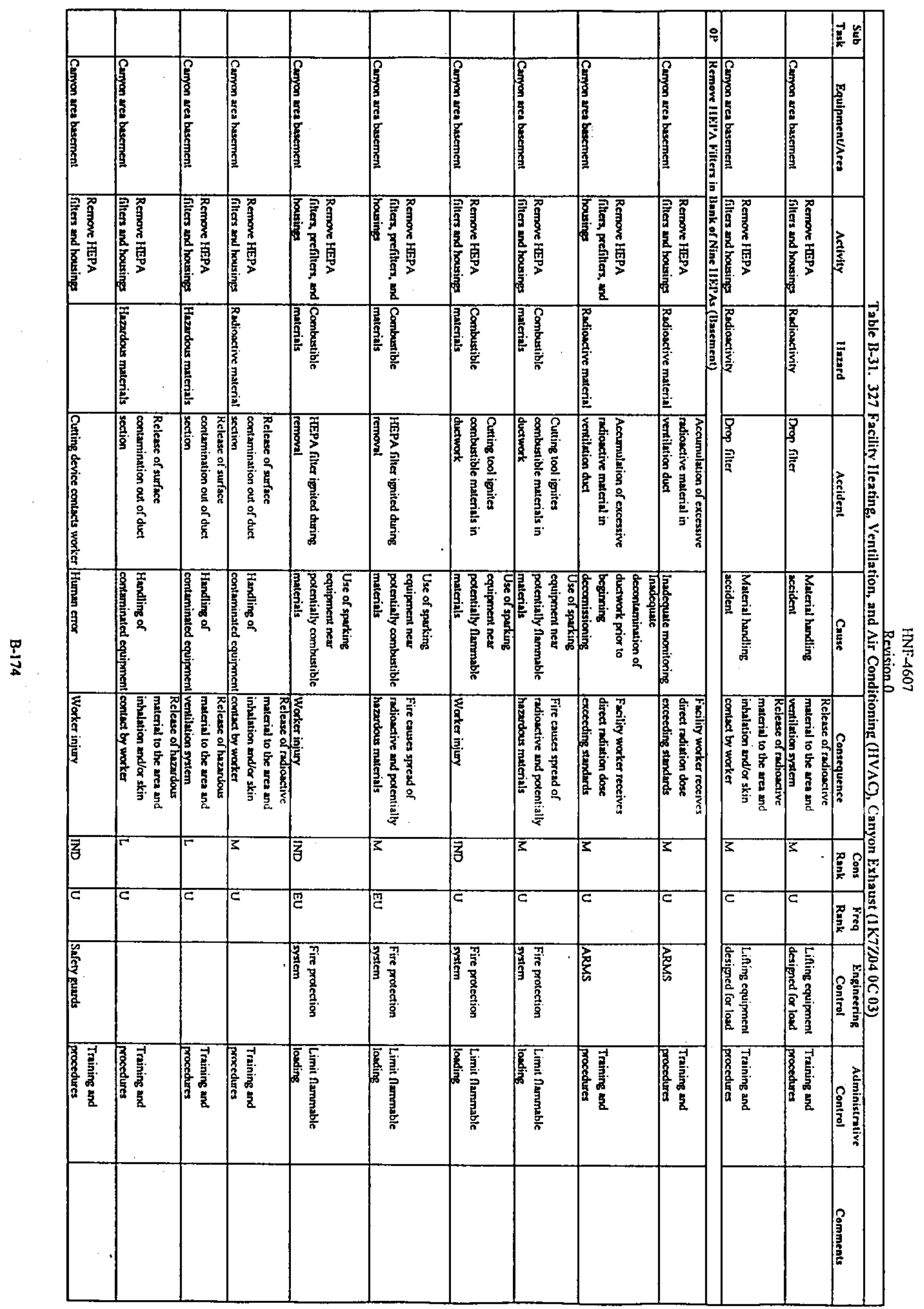




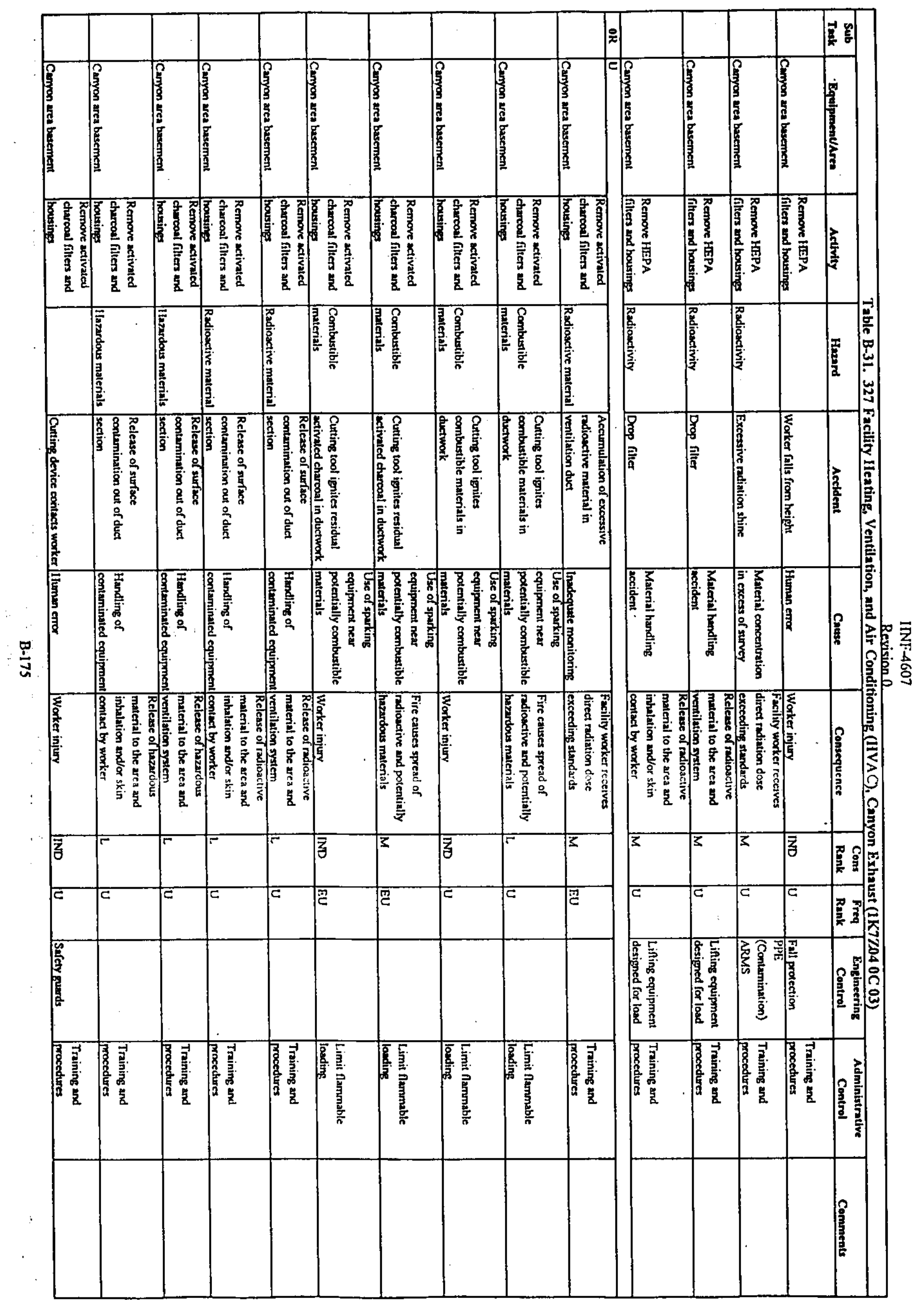




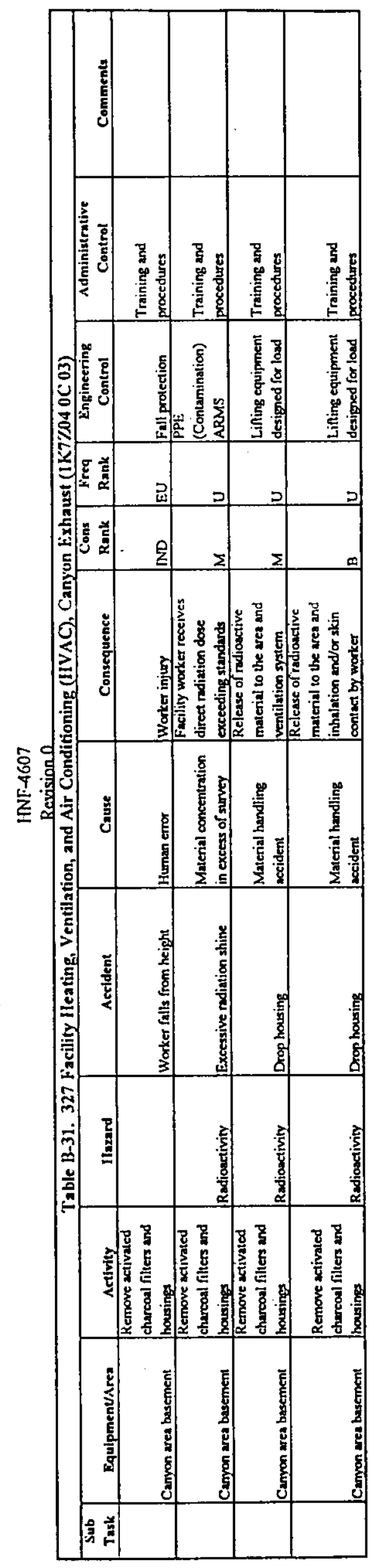

$\stackrel{\frac{2}{3}}{3}$ 